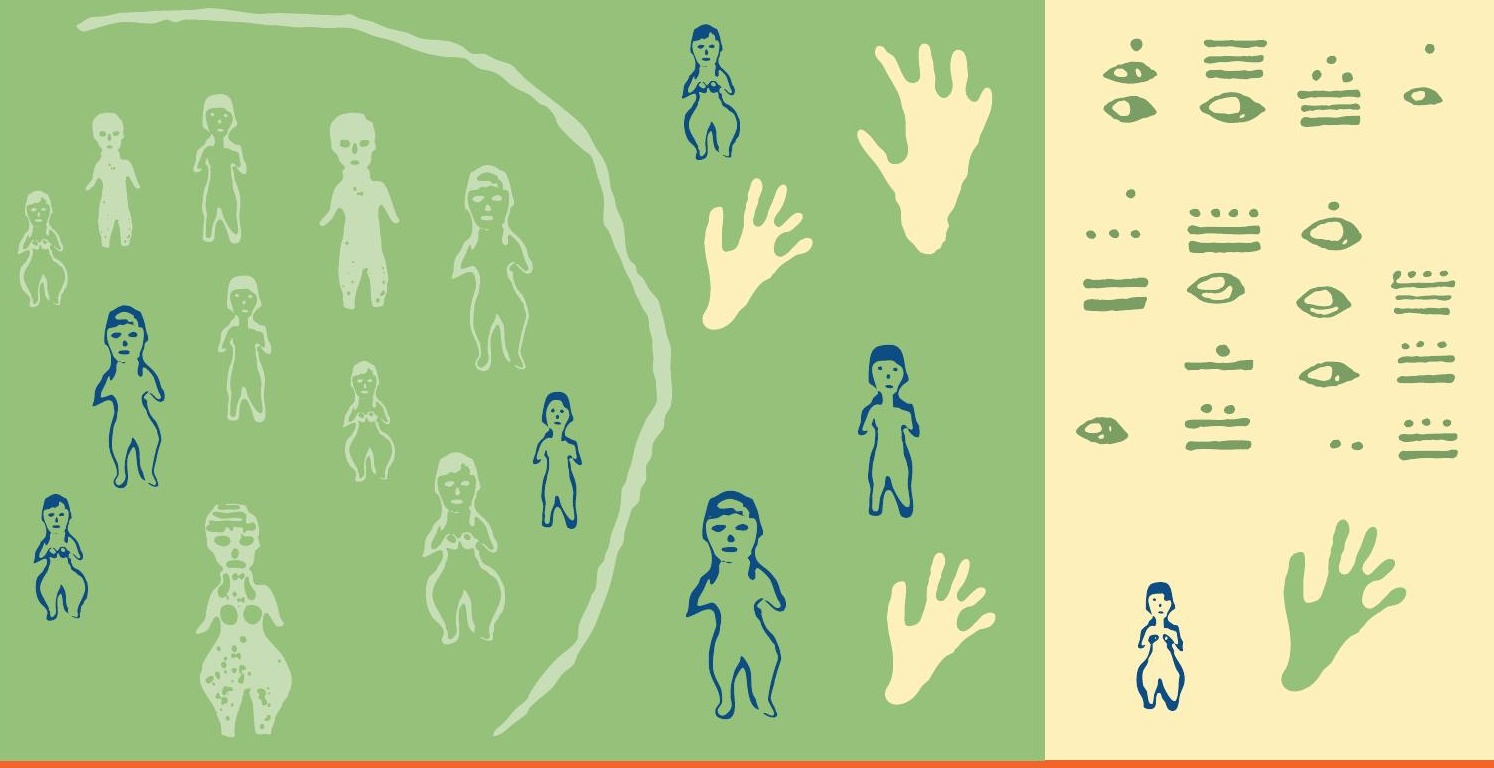

\title{
Ageing, Human Rights and Public Policies
}

Sandra Huenchuan

Editor

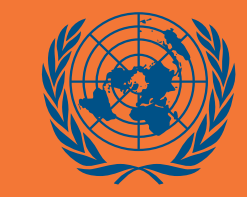

UNITED NATIONS

E C L \& C 


\section{Ageing, Human Rights and Public Policies}

Sandra Huenchuan

Editor

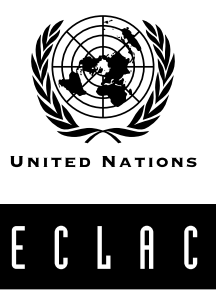

Economic Commission for Latin America and the Caribbean (ECLAC)

Santiago de Chile, April 2010 


\title{
Libros de la CEPAL
}

\author{
100 \\ Alicia Bárcena \\ Executive Secretary \\ Antonio Prado \\ Deputy Executive Secretary \\ Dirk Jaspers_Faijer \\ Director, Latin American and Caribbean Demographic Centre \\ (CELADE) - Population Division of ECLAC \\ Susana Malchik \\ Officer-in-Charge \\ Documents and Publications Division
}

This document was prepared under the supervision of Dirk Jaspers_Faijer, Director of the Latin American and Caribbean Demographic Centre (CELADE) - Population Division of ECLAC, and the coordination of Sandra Huenchuan. Susana Schkolnik and Miguel Villa also collaborated in its preparation. Inputs were provided by Daniela González, María Chiara Di Cesare, Jorge Rodríguez, Fabiana del Popolo, Mauricio Holz, Guiomar Bay, Paulo Saad, Alejandro Morlachetti, Tim Miller, Jonathan Linares, Laura García and Ernesto Espinoza of CELADE-Population Division of ECLAC.

Contributors to the report included Ernesto Espíndola and Fabiola Fernández of the Social Development Division of ECLAC; Karoline Schmid of ECLAC subregional headquarters for the Caribbean; Fabio Bertranou of the International Labour Organization (ILO); Enrique Vega, Javier Vásquez and John Silvi of the Pan American Health Organization (PAHO); and José Miguel Guzmán of the United Nations Population Fund (UNFPA).

The focal points on ageing of the countries of the region contributed through their responses to the survey on programmes for older persons in Latin America and the Caribbean, as did the Country Offices of the United Nations Population Fund (UNFPA) and the Representative Offices of the Pan American Health Organization (PAHO).

This book adapts and updates the document entitled "Report on the Regional Strategy for the Implementation in Latin America and the Caribbean of the Madrid International Plan of Action on Ageing", which was prepared with financial support from the United Nations Population Fund (UNFPA) and presented at the second Regional Intergovernmental Conference on Ageing in Latin America and the Caribbean, held in Brasilia in December 2007. The coordinators are particularly grateful for the comments and suggestions made by Irma Arriagada, reviewer for the ECLAC Publications Committee.

\author{
United Nations Publication \\ ISBN: 978-92-1-121699-8 \\ LC/G.2389-P \\ Sales No. E.09.II.G.139 \\ Copyright (c) United Nations, April 2010. All rights reserved \\ Impreso en Naciones Unidas, Santiago, Chile
}

Applications for the right to reproduce this work are welcomed and should be sent to the Secretary of the Publications Board, United Nations Headquarters, New York, N.Y. 10017, United States. Member States and the governmental institutions may reproduce this work without prior authorization, but are requested to mention the source and inform the United Nations of such reproduction. 


\section{Contents}

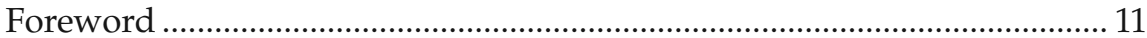

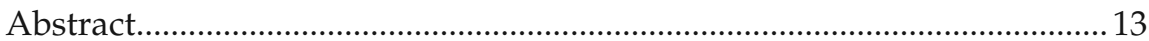

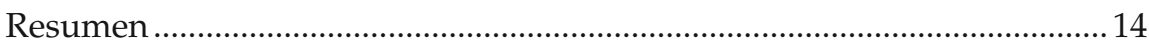

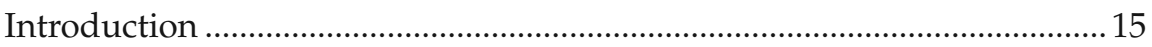

Chapter I

Ageing in the context of a rights-based approach to development.............19

A. The rights-based approach, development and the challenge of a society for all ages...................................................19

B. The consensus on rights, social protection and modalities for inclusion of older persons .....................................21

C. Constitutional protection of rights in old age in Latin America and the Caribbean ..................................................... 26

D. Special laws for protection of the rights of older persons: advances and challenges.

Chapter II

Uneven population ageing in the region 37

A. Demographic transition and the ageing process in Latin America and the Caribbean

B. Population ageing: a gradual and inexorable process 
C. The older population and internal differentiation 57

D. Dependency ratio and demographic bonus in Latin America and the Caribbean: an opportunity and challenge

Chapter III

Income protection and ageing in Latin America and the Caribbean...........73

A. Income and poverty in old age: regional trends......................... 75

B. Income protection and pension systems...................................... 81

C. Employment in old age: trends and forms of economic participation.

D. Non-contributory pensions and protection against the risk of loss of income in old age

E. Progress in implementing the Regional Strategy on Ageing in Latin America and the Caribbean: social security, employment and new business creation.

\section{Chapter IV}

Health protection and ageing in Latin America and the Caribbean.

A. Epidemiological transition, ageing and the health of the population

B. Epidemiological profile, health needs and ageing ................... 117

C. Burden of disease: the impact of mortality and disability in old age.

D. Health spending, ageing and the effect of non-demographic factors .

E. Health insurance coverage in old age and inequalities in access to health care

F. Explicit guarantees and options for closing health equity gaps in old age

G. Progress of the Regional Strategy for the Implementation in Latin America and the Caribbean of the Madrid International Plan of Action on Ageing: health services, professional training and long-term care

\section{Chapter V}

Enabling environments and ageing in Latin America and the Caribbean

A. Living arrangements and ageing .............................................. 145

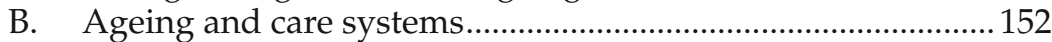

C. Housing, local environments and ageing .................................. 162

D. Progress in implementing the Regional Strategy on Ageing in Latin America and the Caribbean: enabling social and physical environments 
Chapter VI

Implementing the Regional Strategy on Ageing in Latin America and the Caribbean: challenges and perspectives

A. The main challenges ................................................................. 183

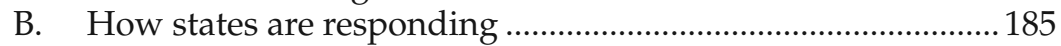

C. Ageing and a society for all ...................................................186

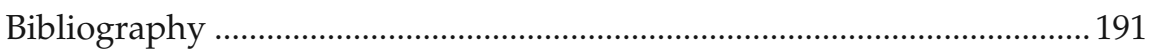

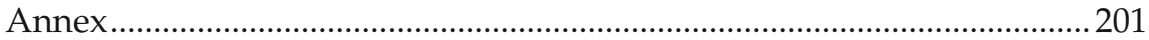

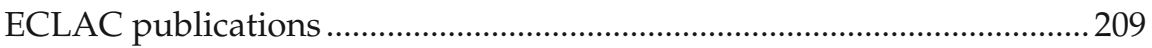

\section{Tables}

I.1 Committee on Economic, Social and Cultural Rights: contents of general comment No 6 .

I.2 Selected Latin American and Caribbean countries: civil and political rights guaranteed under special laws for the protection of older persons..

I.3 Selected Latin American and Caribbean countries: economic, social and cultural rights guaranteed under special laws for the protection of older persons.....

II.1 Latin America and the Caribbean (selected countries): differences in survival years at age 60 for men and women, 1950-2050.

III.1 Characteristics of national social security systems in English-speaking Caribbean countries

III.2 Principal areas of intervention of Latin American and Caribbean economic security programmes targeted at older persons

IV.1 Latin America and the Caribbean: burden of disease indicators by age group, gender, cause and income bracket, 2002

IV.2 Argentina, Colombia, Ecuador and Uruguay: estimated mortality rates for men and women aged 65 and above, 1995 and 2005

IV.3 Latin America and the Caribbean: distribution and level of health spending, 2002 and 2004.

IV.4 Latin America and the Caribbean: packages of explicit universal guarantees and diseases included with a higher incidence among older persons

IV.5 Main areas of intervention of health programmes targeting older persons in Latin America and the Caribbean.

V.1 Proportion of older persons having difficulty and receiving help with activities of daily living 
V.2 Latin America and the Caribbean (selected countries): housing deficiency index for households containing older persons ............. 166

V.3 Main areas of intervention of physical and social environment programmes designed for older people in Latin America and the Caribbean

A.1 Latin America and the Caribbean: total, proportion and growth rate of the population aged 60 and over, 1950-2050

A.2 Latin America and the Caribbean: ranking of countries and territories by stages of ageing, 2000

A.3 European Community (selected countries): population aged 65 and over, national total and three major cities, 1999-2003.....

A.4 Latin America and the Caribbean (selected countries): population aged 60 and over, national total, major cities, other urban and rural, 2000 round of censuses. 206

A.5 Latin America and the Caribbean: indices of total dependency and dependency in old age, by five-year periods, 1950-2050. 207

\section{Figures}

I.1 Dimensions of the new rights-based social protection covenant ....22

II.1 Latin America and the Caribbean: the status of countries in terms of demographic transition, 2005-2010.

II.2 Latin America and the Caribbean (selected countries): demographic transition patterns, 1950-2005.

II.3 Latin America and the Caribbean (selected countries): life expectancy at birth, both sexes, 1950-2005

II.4 Latin America and the Caribbean (selected countries): global fertility rates, 1950-2005

II.5 Latin America and the Caribbean: average age and sex structures of the population, by stage of demographic transition of the region's countries, 1950-2000

II.6 Latin America and the Caribbean: average age and sex structures of the population, by stage of demographic transition of the region's countries, 2000-2050

II.7 Latin America and the Caribbean: population aged 60 and over, 1950-2050

II.8 Latin America and the Caribbean: position of countries according to stage of population ageing process, 2007

II.9 Latin America and the Caribbean: percentage of people aged 60 and over and growth rate of that population, by countries' stage in ageing process, $1950-2050$

II.10 Latin America and the Caribbean and Europe: percentage and growth rate of the population aged 60 and over, 1950-2050. 
II.11 Latin America and the Caribbean: percentage and growth rate of the population aged 60 and over and those aged 75 and over, and distribution of the older population by major age groups, 1950-2050

II.12 Latin America and the Caribbean (selected countries): percentage of population aged 75 and over as a proportion of total older persons, by stage of ageing, censuses of 1990 and 2000.

II.13 Latin America and the Caribbean (selected countries): femininity index of the population aged 60 and over, nationwide, urban and rural totals, 2000 round of censuses .

II.14 European Union: percentage of population aged 65 and over, nationwide total and three types of city by size

II.15 Latin America and the Caribbean: percentage of population aged 60 and over, by area of residence and sex.

II.16 Latin America and the Caribbean: percentage of the total population aged 60 and above living in urban areas, by sex, 1970, 2005 and 2050

II.17 Latin America: total dependency ratio for children under 15 and adults aged 60 and over, 1950-2100

II.18 Latin America and the Caribbean: absolute estimated and projected population growth by decade and age groups, selected periods

III.1 Latin America and the Caribbean (selected countries): sources of income for older persons living in urban areas, around 1997, 2002 and 2005.

III.2 Latin America and the Caribbean (selected countries): incidence of poverty according to type of household (urban areas), around 1997, 2002 and 2005.

III.3 Latin America and the Caribbean (selected countries): incidence of poverty according to type of household (rural areas), around 1997, 2002 and 2005.

III.4 Latin America (selected countries): contribution coverage for each household income quintile, around 2003.

III.5 Latin America (selected countries): informal employment and pension coverage, around 2005

III.6 Latin America (selected countries): receipt of retirement or other pension income

III.7 Latin America (selected countries): receipt of retirement or other pension income in urban areas, according to gender, around 1997, 2002 and 2005.

III.8 Latin America (selected countries): proportion receiving retirement or other pension income, according to area of residence, around 1997, 2002 and 2005.

III.9 Latin America: life expectancy and gross number of working years by gender, 1990-2030 
III.10 Latin America (selected countries): economic participation rate and pension coverage among people aged 60 or over, around 2005

III.11 Latin America (selected countries): economic participation rate of older persons and per capita GDP in 2005

III.12 Latin America (selected countries): participation rate of people aged 60 or over in 1995 and 2005, showing the change between 1995 and 2005 .

III.13 Latin America (selected countries): proportion of older persons in informal employment, around 1990, 2000 and 2003

III.14 Latin America (selected countries): proportion of older persons in formal employment, 1990, 2000 and 2003.

III.15 Latin America: growth rates for the economically active participation by gender, 1990-2030

III.16 Latin America: effect of non-contributory pensions on poverty

III.17 Latin America: cost of targeted and universal pensions ................... 101

IV.1 Latin America and the Caribbean: percentage of deaths in the population 65 and older, 1950-2050.

IV.2 Latin America and the Caribbean: percentage of deaths due to chronic and degenerative causes and average age of population

IV.3 Latin America and the Caribbean: life expectancy at birth, by sex

IV.4 Latin America and the Caribbean: burden of disease indicator, 2002.

IV.5 Argentina, Chile and Uruguay: nationwide prevalence of disability, population aged 65 and over, by sex

IV.6 Latin America and the Caribbean: health spending as a percentage of public and family expenditure, 2004

IV.7 Latin America and the Caribbean: access to health care by older persons, by socio-economic status, 2006

IV.8 El Salvador, Honduras and Uruguay: access to health care among older persons, by socio-economic status, 2006

V.1 Latin America (selected countries): relationship between the percentage of older persons and the percentage of households containing older persons, 1990 and 2000 censuses

V.2 Latin America and the Caribbean: households containing older persons, 1990 and 2000.

V.3 Latin America (selected countries): persons aged 60 and over living alone, 1980, 1990 and 2000.

V.4 Latin America (selected countries): persons aged 60 and over living alone, urban and rural areas, 2000 
V.5 Latin America (15 countries): multigenerational households and the contribution of older persons to household income, around 2005

V.6 Latin America: number of persons aged over 75 and children under 5, 1950-2050

V.7 Latin America and the Caribbean: institutions concerned with older persons' welfare

V.8 Latin America and the Caribbean (selected countries): older persons living in their own homes, 2000 censuses

V.9 Latin America and the Caribbean (selected countries): older persons living in their own homes, urban and rural areas, 2000 censuses.

V.10 Latin America and the Caribbean (selected countries): older persons living in households with no drinking water supply inside the home, 2000 censuses

V.11 Latin America and the Caribbean (selected countries): older persons living in households with no sanitation, 2000 censuses

V.12 Latin America and the Caribbean (selected countries): hazards affecting older persons in the home.

\section{Boxes}

I.1 Obligations assumed by states with respect to human rights...........20

I.2 Special laws protecting the rights of older persons: the objectives of legal coverage. 29

I.3 Budget and guarantee of rights in old age............................................34

II.1 Population ageing and indigenous populations ...................................66

III.1 Ageing and intergenerational transfers...............................................79

III.2 Retirement and pension systems: reforms and implications ............ 82

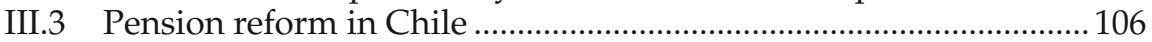

IV.1 Latin America and the Caribbean: self-perception of

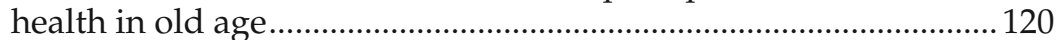

IV.2 Institutionalization, long-term care and human rights.................... 125

IV.3 Systems integrated from the start: health in the Caribbean ............ 132

IV.4 The integrated health-care programme for older persons in Cuba

V.1 Perceptions of ill-treatment and violence against older persons in Latin America and the Caribbean

V.2 The quality of local environments in old age: perceptions of local infrastructure and equipment in Chile.

V.3 Integrated centres for the care of older persons in Brazil and the prevention of violence against them 



\section{Foreword}

A paradigm shift has occurred since the early 1990s in the analysis of ageing and the situation of older persons, both of which have increasingly been viewed from a human rights perspective. This approach, which the United Nations fully supports, essentially affirms the ethical and legal imperative of considering older persons as the bearers of rights rather than as a vulnerable group requiring protection.

Using these new criteria, and in the current context of demographic change characterized by significant population ageing, efforts are being focused on ensuring the integrity and dignity of older persons, broadening the real protection of their human rights in conditions of equality and nondiscrimination, increasing their autonomy and strengthening the ethical principle of solidarity.

This new book by ECLAC looks at ageing from different perspectives -including development - and thus offers an invaluable theoretical and conceptual contribution to the analysis of ageing within the framework of rights-based social protection. It also contains a comparative study of progress towards guaranteeing and protecting the rights of older persons. This includes the passage of legislation designed exclusively to protect the rights of older persons, regulate basic aspects of human coexistence - such as the right to association, non-discrimination and personal safety- and make such rights as education, work, social security, housing and family protection entitlements under the law.

From the perspective of population studies, this book offers a general overview of the ageing phenomenon, showing that a shift in the 
age distribution of the population has occurred in all countries. There are considerable differences, however, from one country to another in the magnitude of the process, depending on the stage of the demographic transition that countries have reached. In 2007, 9.1\% of the region's population was aged 60 or over and, although in the mid-twentieth century ageing was a phenomenon associated mainly with developed countries, it is projected that the older population in Latin America and the Caribbean will surge in the future, with little time to adapt to the consequences of this change in a context of lagging socio-economic development.

This book also looks at social protection systems, particularly in terms of income security, health and social services for older persons and, in so doing, provides a detailed analysis of the impact of ageing on each of these areas based on data from various sources. It offers an evaluation of each country's progress towards the application of the Regional Strategy for the Implementation in Latin America and the Caribbean of the Madrid International Plan of Action on Ageing, approved in 2003, based on the results of a survey on programmes for older persons in Latin America conducted by the Latin American and Caribbean Demographic Centre (CELADE) - Population Division of ECLAC in 2007, which were evaluated from a human rights perspective.

Lastly, the book considers the challenges the region faces in building a society for all ages, a concept which originated in the Programme of Action of the World Summit for Social Development held in Copenhagen in 1995. In that framework, it examines some of the priority measures aimed at improving conditions for older persons, taking into consideration the generations to come.

We trust the book will represent a fresh contribution by CELADE to the debate on a topic which will be increasingly prominent on development agendas and in public policies. It is also very timely, coming a decade after the International Year of Older Persons in 1999, which sought to raise awareness on the challenges posed by ageing in society. This objective remains as important as ever for the Latin America and Caribbean countries and is directly related to honouring regional and global commitments undertaken in this area.

\author{
Alicia Bárcena \\ Executive Secretary \\ Economic Commission for Latin America \\ and the Caribbean (ECLAC)
}




\section{Abstract}

Two aspects of the gradual but inexorable ageing of the population in Latin America and the Caribbean are of particular concern. One is that the population is ageing faster in the region than it did historically in the developed countries. The other is the regional context of unrelenting inequality, weak institutional development, the poor coverage and quality of social protection systems and the high demands placed on the family to provide security and protection.

This new book from the Economic Commission for Latin America and the Caribbean (ECLAC) examines the ageing phenomenon from the demographic perspective, the guaranteeing of human rights in old-age and the public policies that the countries of the region are deploying in fulfilment of agreements arising from the first and second meetings of the Regional Intergovernmental Conference on Ageing in Latin America and the Caribbean (2003 and 2007).

The book sets out the framework of rights-based social protection policies and how they apply to the particular situation of the elderly population and looks at the status of older persons in terms of income security, access to health and inclusive environments. It also examines the impacts of population ageing on social protection systems - pensions, health and social services- and gives a general overview of the state of play of older persons' rights in national legislations and public policies implemented in the region. The book concludes with a summary of the main challenges that population ageing poses to the building of democratic and inclusive societies and emphasizes the need to move forward in adapting policy responses to the demographic panorama of the coming decades. 


\section{Resumen}

El paulatino pero inexorable envejecimiento de la población de América Latina y el Caribe presenta dos características que preocupan: un ritmo más rápido que el registrado históricamente en los países desarrollados y un contexto caracterizado por una persistente desigualdad, un débil desarrollo institucional, sistemas de protección social de baja cobertura y calidad y una institución familiar muy exigida en materia de seguridad y protección.

En este nuevo libro de la Comisión Económica para América Latina y el Caribe (CEPAL) se analiza el fenómeno del envejecimiento desde la perspectiva demográfica, la garantía de derechos humanos en la vejez y las opciones de políticas públicas que los países de la región están poniendo en práctica en virtud de los acuerdos derivados de la primera y segunda Conferencia regional intergubernamental sobre envejecimiento en América Latina y el Caribe (2003 y 2007).

En el libro se presenta el marco de políticas de protección social basadas en derechos y su aplicación a la situación específica de la población de edad avanzada y se analiza la situación de las personas de edad en términos de seguridad de ingresos, acceso a la salud y entornos inclusivos. Asimismo, se ofrece una perspectiva de los impactos del envejecimiento demográfico en los sistemas de protección social - pensiones, salud y servicios sociales - y se brinda un panorama general de la posición que han alcanzado los derechos de las personas de edad en las legislaciones nacionales y las políticas públicas que se implementan en la región. La publicación concluye con una síntesis de los principales retos que el envejecimiento de la población plantea para la construcción de sociedades democráticas e inclusivas y resalta la necesidad de avanzar progresivamente en la adecuación de las respuestas públicas al escenario demográfico de las próximas décadas. 


\section{Introduction}

The purpose of this book is to present and analyse the available information on the process of population ageing, the status of the older adult population and the advances made by countries in applying the Regional Strategy for Implementation in Latin America and the Caribbean of the Madrid International Plan of Action on Ageing.

The Regional Strategy contains targets, goals and recommendations for action for the benefit of older persons in three priority areas: older persons and development, advancing health and well-being in old age, and enabling environments. The Strategy was adopted at the First Regional Conference on Ageing in November 2003 and ratified by ECLAC in resolution 604(XXX) of 2004. The Strategy was first reviewed and evaluated in 2007 at the Second Regional Intergovernmental Conference on Ageing in Latin America and the Caribbean, where participating countries adopted the Brasilia Declaration, the importance of which was ratified in resolution 644(XXXII) at the thirtysecond session of ECLAC, held in Santo Domingo in June 2008.

The Latin American and Caribbean region is witnessing a slow but inexorable ageing of its population. This is an across-the-board phenomenon, since all of its societies are ageing, albeit at different rates from country to country. Predictably, a demographic transformation of this sort will have far-reaching repercussions on society and in specific public-policy spheres, such as social cohesion, human rights and the role of the State.

Two features of this phenomenon are arousing great concern: first, population ageing in the region has been occurring more rapidly than it did in what are today's developed countries; second, it is taking place within a context of high poverty levels, persistent inequality, weak institutionbuilding, low coverage and quality of social protection systems, and an overburdened family structure. Indeed, in addition to taking charge of the needs of elderly members, the family is filling the vacuum left by the scant presence of other institutions in the areas of protection and cohesion. 
In their efforts to address the challenges of ageing, countries are taking steps to create and develop laws, policies and programmes designed to improve the living conditions of the older population. Since 2003, new public policy niches have taken shape and further interventions have been made in this area, although differences in situation and achievements still persist across countries and subregions due, in some cases, to a lack of homogeneity within societies and to the characteristics of their development processes. Thus, while countries with an older population usually have more extensive coverage, in nations still in the midst of the transition, the challenges posed by the older adult population exist alongside with problems associated with the poverty and exclusion of other social groups.

Governments have become more conscious of the importance of the rights of older persons and, for some years now, have been acting on this concern by creating legal frameworks for protection. However, there is a wide gap between the de jure and de facto situations, since there are still insufficiencies in the real exercise of these rights and, today, a significant proportion of the older adult population still lacks access to social security, health care or basic services. In most cases, this vulnerability is not age-related, but instead stems from the generally precarious nature of the protection mechanisms provided by the State. In other cases, it is attributable to blatant inequality in income or scant regard in public policy for the requirements of this social group due to the deep-rooted notion that problems of ageing are a matter for the private sphere rather than an issue calling for collective solidarity.

In Latin America and the Caribbean, the poorest and least institutionally developed countries are those where the population ageing process is the least advanced. The change in the age structure may bring tangible benefits for these countries by creating opportunities through an increasingly favourable ratio between the population of dependent ages and the working-age population. The challenges for these countries are, first, to develop a long-range vision which will direct attention towards the current agenda on population ageing, without neglecting the urgent need to solve short-term problems and, second, to build up human capital and job-related skills and expand the capacity of production sectors in order to ensure their effective performance and thus make certain that these opportunities are not allowed to slip by.

In countries where population ageing is imminent (which means that the time for action is limited), authorities cannot simply replicate the solutions applied in developed countries because the economic, institutional and historical realities are different. Thus, they face the challenge of developing alternatives of their own to address this phenomenon, without losing sight of basic issues relating to different generations' harmonious coexistence and intergenerational solidarity. 
Population ageing must not be regarded as a matter that concerns only the current generation of older persons. As discussed in this document, the steps taken to address this issue in all areas of the public agenda and in all relevant laws and policies, as well as the corresponding budget allocations, will have an impact throughout society. The essential point, from this perspective, is to determine what steps need to be taken in order to build more cohesive, democratic and inclusive societies.

In this, as in any other sphere of public policy, the way forward depends on the mechanisms adopted and the scope for social cohesion within society, on how the reciprocal relationship between current generations is strengthened and on how this is accomplished without jeopardizing the future of coming generations. Authorities must take stock of the existing situation, deal with persistent lags and gradually move forward, expanding social protection to encompass the entire population.

ECLAC has attributed particular importance to this issue and has drawn attention to the need to expand coverage and increase the quality of social protection systems to cover risks arising from illness, old age, disability and death, among other situations of vulnerability. Entitlement to social rights embodies a genuine belonging to society, since it implies that all citizens are included in development and can enjoy the well-being that such growth provides (ECLAC, 2007a). In old age, in particular, this curbs the inequalities that accumulate over a lifetime and, at the same time, reduces the probability that disadvantages will be transmitted from one generation to the next.

Chapter I of this document, "Ageing in the context of a rights-based approach to development", presents the social protection policy approach proposed by ECLAC at its thirty-first session and discusses how it applies to the specific situation of the elderly population. An assessment is made of the progress achieved in terms of the constitutionalization and protection of the rights of older persons in the region through the passage of special laws. Obstacles to progress in protecting and enforcing the rights of older persons are also identified.

Chapter II, entitled "Uneven population ageing in the region", provides an overview of the demographic transition and ageing in the region, identifies the determinants of this process and considers some of the differences to be observed within the older adult population.

Chapter III, "Income protection and ageing in Latin America and the Caribbean" analyses sources of economic security, including participation in economic activities by older persons, and looks at how social security systems perform in providing long-term old-age support. It concludes with a section on advances in the implementation of the Regional Strategy in the areas of social security, employment, and enterprise.

Chapter IV, entitled "Health protection and ageing in Latin America and the Caribbean", addresses the relationship between demographic 
and epidemiological transition as well as its effects in terms of health requirements and coverage of the health system. It concludes with a section that describes achievements in the implementation of the Regional Strategy in the areas of health benefits, staff training and long-term care.

The fifth chapter, "Enabling environments and ageing in Latin America and the Caribbean", looks at social environments, specifically residential arrangements and care systems, and physical environments, in particular housing, access to basic services and public areas. The concluding section reviews advances in implementing the Regional Strategy as it applies to the issues of mistreatment, participation, support networks, education, housing, transport and accessibility.

The sixth and final chapter, "Implementing the Regional Strategy on Ageing in Latin America and the Caribbean: challenges and perspectives", looks at the principal achievements attained in the region as well as the main challenges that must be addressed in the future, with emphasis on the diverse range of situations and the need to broaden the scope of work in this area in order to bring government responses into line with demographic changes within the framework of a society for all. 
Chapter I

\section{Ageing in the context of a rights-based approach to development}

\section{A. The rights-based approach, development and the challenge of a society for all ages}

At its thirty-first session (March 2006), ECLAC proposed that "a rights-based approach should be used in framing public policy. The civil, political, economic, social and cultural rights enshrined in binding national and international agreements should form the normative framework for development" (ECLAC, 2006). This perspective alters the rationale on which laws, policies and programmes are based, since the starting point is the existence not simply of persons with needs who require assistance, but of subjects with rights, and these rights impose obligations on the State and the rest of society (Abramovich and Courtis, 2006; OHCHR, 2004; ECLAC, 2006). The individual is therefore the central subject of development, and the guarantees enshrined in the universal system of human rights protection constitute the conceptual framework accepted by the international community and capable of providing a coherent set of principles and rules for guidance (Abramovich, 2004; ECLAC, 2006). This approach is also useful for defining the obligations that States must assume with regard to the economic, social, cultural, civil and political rights to be enforced as part of their long-term strategy (see box I.1). 
Box I.1

OBLIGATIONS ASSUMED BY STATES WITH RESPECT TO HUMAN RIGHTS

Obligation to respect rights: States parties must refrain from interfering in the enjoyment of the economic, social and cultural rights enshrined in human rights instruments.

Obligation to provide protection: States parties must prevent third parties from infringing economic, social and cultural rights; for example, they must promote environmental protection by companies or punish any discrimination practised in private institutions.

Obligation to promote rights: States parties must take affirmative action to ensure that the exercise of rights is not illusory. This obligation implies organizing the entire government apparatus to ensure that it is capable of ensuring by law the free and full exercise of human rights (InterAmerican Court of Human Rights, Velásquez Rodríguez case, 29/7/1988).

Source: Sandra Huenchuan and Alejandro Morlachetti "Derechos sociales y envejecimiento: modalidades y perspectivas de respeto y garantía en América Latina", Notas de población, No. 85 (LC/G.2346-P) Santiago, Chile, 2007.

As a normative and programmatic framework for development, the human-rights-based approach has come to promience relatively recently in Latin America and the Caribbean (ECLAC, 2006), which accounts for the increase now being seen in legislative inititaives specifying particular rights and social and institutional efforts to formulate public policies from this persective (Guendel, 2000). All the States in the region have ratified at least three of the seven main human rights treaties that were in force in 2006, thereby assuming binding obligations under international law.

The integration of the human rights perspective into development facilitates special provision for the specific situations of vulnerable, marginal, underprivileged or socially excluded individuals and groups (OHCHR, 2004; ECLAC, 2006). This goes some way towards transcending the rationale of the conceptual and normative models that have traditionally framed public policies and development institutions, which arise from standardized conceptions of humanity in which certain atributes - male sex, adult age and a particular ethnic origin - are taken as the foundations for identity, the constitution of the individual subject and citizenship. Such frameworks fail to take fully into account the specificities of women, indigenous peoples, persons with disabilities or older persons.

The rights-based approach to development, conversely, recognizes human rights as an entitlement of all social groups, thus helping to ensure that those who were excluded in the past may henceforth be 
treated on an equal basis and with respect for human dignity. This should enhance social integration and contribute to the construction of "a society for all" (United Nations, 1995b).

The process of population ageing opens up new possibilities for this approach and, as a corollary, for the construction of citizenship for the twenty-first century. First, it helps to reconcile the needs and interests of all groups in society in order to advance towards full social integration, in which every individual, each with rights and responsibilities and regardless of age, has an active role to play (United Nations, 1995b). Second, it represents the emergence or consolidation of a new social actor who claims special treatment on the basis of age. And third, it creates new demands to expand, specify and deepen human rights.

Both perspectives - the new possibilities for the humanrights-based approach and the construction of twenty-first-century citizenship - are clearly legitimate, the first because explicit de facto and de jure inequalities have meant that older persons, like other social groups, have enjoyed only limited exercise of their rights to equality and freedom and the second because public policies have often failed to take their needs into account (United Nations, 1995a).

From this viewpoint, one of the central challenges of rights-based development is to contribute to the construction of a society that includes everyone, men and women alike, and in which people, irrespective of their age or other social differences, have the same opportunities to command full respect for, and exercise of, their fundamental human rights and freedoms.

\section{B. The consensus on rights, social protection and modalities for inclusion of older persons}

In 2006, ECLAC underscored the need to reach a new political consensus regarding the society that all stakeholders wish to build in order to reconcile well-known economic constraints and institutional weaknesses with the demands of rights-bearing social groups.

This proposal was welcomed by the member countries of the Commission in resolution 626 (XXXI) of 2006, which recognizes that "a different approach to social protection in Latin America and the Caribbean should be adopted in response to changes under way at the global level that affect our societies, and that improving social protection leverages positive synergies among social equity, participatory democracy and economic growth". 
In the interests of balancing a human rights agenda with the demands countries face today, ECLAC has proposed a new social protection covenant with three dimensions (normative, procedural and content-related) aimed at enabling all social groups to exercise citizens' rights. Specific attention must be given to demands of particular sectors - hitherto invisible from the point of view of the development agendaso that this new covenant can fully integrate them. In the case of older persons, the strategy involves developing and applying specific concepts and contents in all three dimensions (see figure I.1).

Figure I.1

DIMENSIONS OF THE NEW RIGHTS-BASED SOCIAL PROTECTION COVENANT

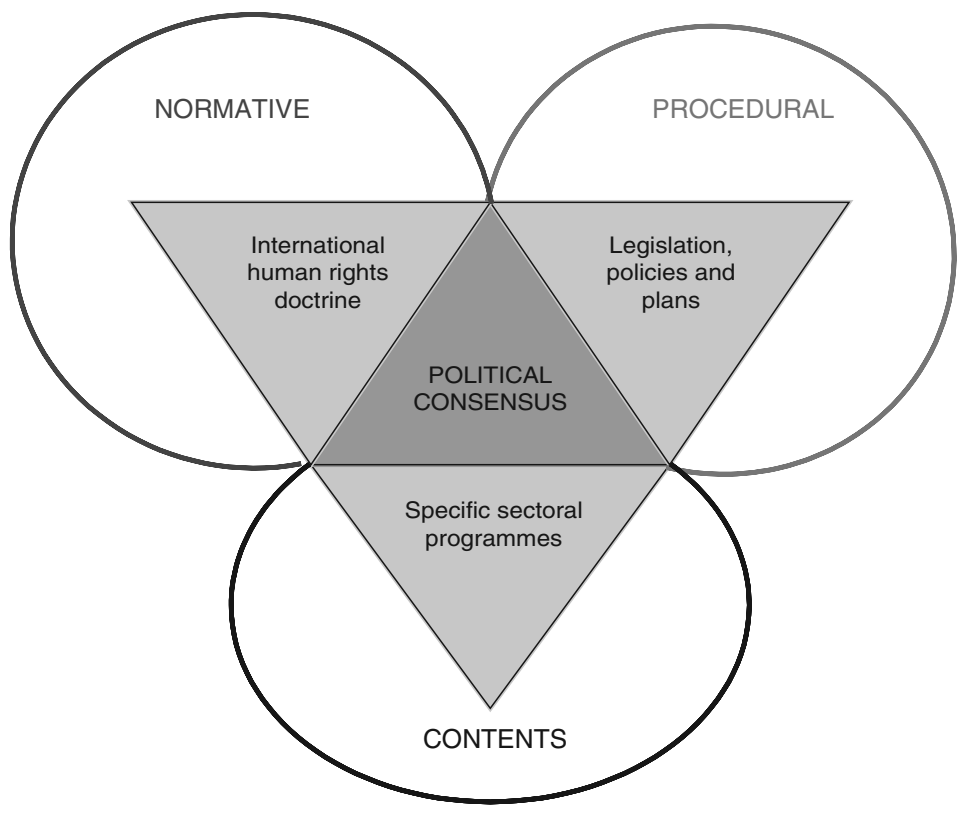

Source: Latin American and Caribbean Demographic Centre CELADE - Population Division of ECLAC, on the basis of Economic Commission for Latin America and the Caribbean (ECLAC), Shaping the Future of Social Protection: Access, Financing and Solidarity (LC/G.2294(SES.31/3)/I), Santiago, Chile, March 2006. 


\section{Normative dimension}

Public measures and the institutions responsible for the care of older persons must be explicitly built upon international human rights standards. Older persons are protected by binding human rights instruments including the Universal Declaration of Human Rights; the International Covenant on Civil and Political Rights; the International Covenant on Economic, Social and Cultural Rights; the American Declaration of the Rights and Duties of Man; the American Convention on Human Rights and the Additional Protocol in the Area of Economic, Social and Cultural Rights (also known as the San Salvador Protocol).

Article 17 of the San Salvador Protocol provides specifically for the protection of older persons. The States parties pledge to progressively supply suitable facilities, nourishment and specialized medical care for older persons who lack them; set up work programmes specially designed to give older persons the opportunity to engage in a productive activity; and foster the establishment of social organizations that can improve their quality of life. To date, the Protocol has been ratified by 14 countries in the region (Argentina, Brazil, Colombia, Costa Rica, Ecuador, El Salvador, Guatemala, Mexico, Panama, Paraguay, Peru, the Plurinational State of Bolivia, Suriname and Uruguay).

There is, however, no binding instrument embodying the rights of older persons such as exist for other social groups including women, children and persons with disabilities. Case law and the doctrine of the treaty committees therefore play an important role in promoting understanding of the rights of older persons.

Through the vehicle of their general comments and recommendations made to States, the committees have in fact produced a more precise definition of the main obligations arising out of human rights covenants and the contents of the rights safeguarded therein. This was the case of General Comment No. 6 issued by the Committee on Economic, Social and Cultural Rights in 1995, which addressed the economic, social and cultural rights of older persons (see table I.1). This document offers States parties guidance on how to interpret their obligations vis-à-vis the older persons in applying the various provisions of the Covenant (United Nations, 1999). 
Table I.1

COMMITTEE ON ECONOMIC, SOCIAL AND CULTURAL RIGHTS: CONTENTS OF GENERAL COMMENT No 6

\author{
Article of the International \\ Covenant on Economic, Social \\ and Cultural Rights
}

\author{
Equal rights for men and women \\ (article 3)
}

Right to work (articles 6, 7 and 8)

Right to social security (article 9)

Right to protection for the family (article 10)

Right to an adequate standard of living (article 11)

Right to the highest attainable standard of physical and mental health (article 12)

Right to education and culture (article 13)
Interpretation of the Committee on Economic, Social and Cultural Rights

States parties should pay particular attention to older women and should institute non-contributory old-age benefits or other assistance for all persons, regardless of their sex, who find themselves without resources on attaining an age specified in national legislation.

States parties must adopt measures to prevent discrimination on grounds of age at the workplace, ensuring that older workers enjoy safe working conditions until their retirement; it is desirable that States also promote employment of older workers in places where they can make the best use of their experience and knowhow, and set up retirement preparation programmes.

States parties must establish general regimes of compulsory old-age insurance, establish a flexible retirement age, provide non-contributory old-age benefits and other assistance for all older persons who, when reaching the age prescribed in national legislation, have not completed a qualifying period of contribution and are not entitled to an old-age pension or other social security benefit or assistance and have no other source of income.

Governments and non-governmental organizations must establish social services to support the family when there are older people in the home, and must also implement special measures for low-income families who wish to keep older persons relatives at home.

The basic needs of older persons in terms of food, income, care, self-sufficiency and others should be met. In addition, policies should be designed to enable older persons to continue to live in their homes by improving and adapting their accommodation.

Maintaining health into old age implies investment in health during the entire life span.

This right must be approached from two different and complementary viewpoints: (i) the right of older persons to benefit from educational programmes, and (ii) making the know-how and experience of older persons available to younger generations.

Source: Sandra Huenchuan and Alejandro Morlachetti, "Derechos sociales y envejecimiento: modalidades y perspectivas de respeto y garantía en América Latina”, Notas de población, No. 85 (LC/G.2346-P) Santiago, Chile, 2007, on the basis of United Nations, "The economic, social and cultural rights of older persons", General Comment, No. 6 (E/C.12/1995/16/Rev.1), Geneva, Committee on Economic, Social and Cultural Rights, 1995. 


\section{Procedural dimension}

Legislation and policies on ageing must promote and protect fundamental rights and freedoms during old age. To make this a reality, political authorities must supply the necessary instruments and the resources to implement them, for example, by enshrining these rights in the constitution, enacting special laws for the protection of such rights or guaranteeing the rights of older persons in policies or plans of action. They must also assign a budget to fund the regulatory and policy provisions the country has pledged to fulfil.

Three fundamental criteria must be met in order to translate this instrumental dimension into practice: non-discrimination, progressiveness and participation. As defined in different international human rights instruments, discrimination against older persons means any differentiation, exclusion or restriction based on age which has the intention or effect of preventing or nullifying the recognition, enjoyment or exercise of their fundamental human rights and freedoms (Vásquez, 2004).

The Committee on Economic Social and Cultural Rights has identified older persons as one of the groups vulnerable to rights discrimination and therefore has recommended that States: (i) review their legislation and eliminate any de jure or de facto discrimination; (ii) approve rules that protect older persons from discrimination, and (iii) establish affirmative action measures whenever they bring opportunities for older persons in line with those provided to other social groups in the enjoyment of given rights (Abramovich and Courtis, 2006).

While the criterion of progressiveness recognizes that not all rights can be fully enforced in a short space of time, this does not mean that the State can postpone fulfilling this commitment indefinitely or until the achievement of a given level of economic development. Progressiveness also carries an obligation to produce results, meaning that the State should demonstrate quantitative and qualitative advances towards achieving the full realization of rights. It also precludes the adoption of regressive measures, based on the principle of non-retrogression applicable to human rights (Huenchuan and Morlachetti, 2007).

In short, States should plan the necessary measures to enforce the rights of older persons, since progressive realization requires targets, indicators and benchmarks with respect to the realization of such rights (OHCHR, 2004). The opinions of older persons should be taken into consideration when determining these benchmarks, and older persons should be encouraged to participate in the process and form part of accountability bodies. Thus, information on rights and freedoms must be provided and disseminated so that the older persons and the organizations 
that represent them are aware of them and can make full use of them (Vásquez, 2004). This calls for specific mechanisms to enable older persons to exercise their right to participation and to ensure that they can access the information they need to increase their influence.

\section{Content-related dimension}

The content-related dimension refers to implemenation of and responsbility for the measures deployed through sectoral programmes or specific schemes for older persons (health and housing, among others). In particular, the orientation, benefits or services provided under these programmes or schemes should further progress towards full enjoyment of rights for older persons. At the least, such programmes must be universal and offer mechanisms for making benefits and services enforceable (ECLAC, 2006).

This dimension includes the responsibility and enforceability issues associated with a rights-based approach, whereby States must create and develop mechanisms to fulfil their obligations. These mechanisms range from legal and quasi-legal provisions to administrative and policy instruments (OHCHR, 2004). For example, there are institutions such as the ombudsman (as in the case of Guatemala) at the domestic level, and those within the Inter-American system (Inter-American Commission on Human Rights and the Inter-American Court of Human Rights) at the international level. These instruments must be accessible and comprehensible to older persons so they can make use of them should the need arise.

International human rights standards are an essential tool for promoting and protecting the rights of older persons in a positive and comprehensive way. In order to move forward towards a social protection covenant that fully encompasses this social group, it is crucial to recognize that older persons have general and specific rights within the framework of the principles of universality and solidarity.

\section{Constitutional protection of rights in old age in Latin America and the Caribbean}

The international agreements and regulations on human rights serve as the regulatory frame of reference for a rights-based approach; nevertheless, the constitution of each country is the instrument which establishes the status of those treaties within its domestic legal system (ECLAC, 2006). Ever since the first steps towards establishing democracy in the region, the tendency 
has been to incorporate these international instruments into domestic law. ${ }^{1}$ As a rule, constitutional texts either interpret or explicitly incorporate the rights recognized in international treaties.

While all the rights and guarantees recognized in constitutional texts are, of course, applicable to older persons, in some cases the rights of this social group are specifically recognized; this is extremely important, since the Constitution - as a legal set of regulations - is the paramount expression of the country's entire legal, social, economic, political, civil and cultural system. The national constitution, therefore, takes precedence over provincial constitutions, laws in general, decrees, regulations and administrative orders. In federative countries, however (Argentina, Brazil and Mexico), the states or provinces reserve certain powers under the constitution which they do not delegate to national government; thus, the adoption of a law on the rights of older persons would require the support of each of the provinces or states to ensure nationwide enforceability.

Strictly speaking, constitutional rights, public organization and budgetary decisions should all be correlated in a logical manner. While administrative structures and budgetary legislation are means by which rights are enforced, the protection of constitutional rights is an end in itself. Many of the constitutions in the region have provisions that give priority to observance of the rights of older persons, protect older persons against violence or condemn age-based discrimination.

The constitutional charters of the Bolivarian Republic of Venezuela, Brazil, Colombia, Costa Rica, the Dominican Republic, Honduras, Nicaragua, Panama and Paraguay state expressly that older persons have the right to special protection from the State. Some charters guarantee comprehensive protection for older persons, recognizing some economic and social rights, ranging from health care, food, decent living conditions and housing to the more general concept of the welfare State (the Bolivarian Republic of Venezuela, Brazil, Guatemala, Ecuador and Panama). In all of these cases, it is the duty of the State to promote and implement policies or programmes to ensure that rights can be effectively exercised. In other countries, the State must adopt legislative measures for the protection of older persons; in Argentina, for example, there is an obligation to enact

\footnotetext{
Some constitutions specifically list the main human rights treaties (Argentina, the Bolivarian Republic of Venezuela and Nicaragua), which explicitly gives them constitutional status and hence greater enforceability in domestic law. Others treat human rights treaties as a guide for the interpretation of established rights (Colombia). Some constitutions state that international treaties take precedence over domestic law, which, in principle, could be interpreted as meaning that they come under the constitution, but above domestic legislation (Brazil, Costa Rica, Honduras and Guatemala). The Chilean and Ecuadorian constitutions treat international treaties more broadly, promoting and conferring respect for human rights.
} 
legislation and promote affirmative action to guarantee true equality of opportunities and treatment for older persons, as well as the full enjoyment and exercise of rights recognized in international treaties.

A number of specific social rights are also protected, such as the right to social security, which figures in all the constitutions examined, although the scope of provisions varies from country to country. The Brazilian Constitution explicitly guarantees a minimum income for older persons in need, irrespective of their contribution to social security. The Colombian Constitution affirms that the State shall guarantee a food subsidy for indigent older persons and the Cuban Constitution provides explicitly for social assistance to the elderly who lack resources and protection.

Under the Brazilian and Ecuadorian constitutions, older persons are identified as a vulnerable group and are granted priority care, with the additional stipulation that such assistance is mandatory in cases of domestic violence. The constitutional charters of Brazil, Ecuador and Mexico condemn age-based discrimination in general, while those of the Bolivarian Republic of Venezuela, Panama and Paraguay forbid age-based discrimination in the labour market. Lastly, the constitutions of Colombia and Brazil expressly stipulate older persons' right to participation and integration into the community.

Explicit constitutional recognition of the rights of older persons imposes on the authorities the obligation of enforcing them. Although specific legislation would be desirable, the inclusion of these rights in the text of the constitution nevertheless gives them legal standing and makes them directly applicable and binding on all public authorities, which may not infringe them by action or omission.

In short, the enshrinement of the rights of older persons in the constitution means that the legal system, public policies, institutions and official government acts should be adapted accordingly.

\section{Special laws for protection of the rights of older persons: advances and challenges}

States must promote the full enjoyment of the rights of older persons, establishing the legal, political, economic, social and cultural conditions that will allow the integral development of the human individual. In this regard, a country must not only refrain from interfering in the exercise of individual rights, but must also take positive action by adopting administrative and legislative measures to ensure that these rights are in fact enforced. 
Legislatively speaking, countries often recognize some rights of older persons by including them in general laws (as in the case of Nicaragua, where this age group is considered to be vulnerable and is treated as a priority group under Health Act 423) or by enacting laws that protect these rights fully. This section deals with the second type - "special laws" - adopted within the statutory framework of ageingrelated measures in countries that have one.

\section{The objectives and contents of legal coverage in special laws}

Several countries in the region have special legislation enacted to promote and guarantee the human rights of older persons (see box I.2). This means that the standards recognized in human rights treaties and constitutional provisions are included, or at least interpreted, in the text of the law.

Box 1.2

SPECIAL LAWS PROTECTING THE RIGHTS OF OLDER PERSONS: THE OBJECTIVES OF LEGAL COVERAGE

In Brazil, law 10,741 (2003) establishes that older persons enjoy all the rights borne by all people and that families, communities and governments have an obligation to ensure the effective use of these rights.

In Costa Rica, law 7,935 (1999) establishes that public and private institutions that administer social programmes for older persons must provide information and advice on the guarantees enshrined in the law as well as the rights legally afforded to older persons.

In Ecuador, law 127 establishes the Office of the General Prosecutor for the Elderly, an institution that protects the economic and social rights and legal claims of older persons with a view to enforcing the rights enshrined in the law.

In El Salvador, the Comprehensive Care for Older Adults Act (2002) establishes that older persons must be informed of their rights and of the laws that guarantee them and that they shall enjoy the rights afforded to them by the constitution, the international treaties ratified by El Salvador and other laws that guarantee their protection.

In Guatemala, the Protection of the Elderly Act (1996) is aimed at protecting the interests of older persons and ensuring that the State guarantees and promotes their right to an adequate standard of living. 
Box 1.3 (concluded)

In Mexico, the Rights of Older Persons Act (2002) is intended to guarantee that older persons can exercise their rights and enforces them through national public policies on observance of the rights of older adults.

In Peru, the Older Adults Act (2006) establishes that older persons have a right to State protection in the exercise and defence of their rights and offers a legal framework which guarantees legal mechanisms to enforce observance of the rights recognized in the constitution and in the international treaties in force.

In Puerto Rico, law 121 (1986), known as the "Bill of Rights for Older Persons and Public Policy", recognizes the State's responsibility - to the extent that means and resources allow - to provide the conditions for older persons to enjoy a full life and exercise their natural, human and legal rights.

In the Dominican Republic, law 352-98 (1998) guarantees the rights of the older persons and provides for measures through which the State, communities and families support all governmental and non-governmental organizations in promoting their rights.

In the Bolivarian Republic of Venezuela, the Social Services Act (2005) guarantees protected persons their human rights without discrimination under the terms and conditions set forth in the constitution and in the laws of the Republic, as well as the treaties, pacts and conventions the country has signed and ratified.

In Uruguay, law 17,796 (2004) concerns comprehensive protection for older persons and establishes countrywide rights to active integration into the family and community; treatment with dignity and without discrimination; comprehensive and coordinated health and medical assistance; access to education, adequate housing, food and shelter; and access to leisure activities, transport and communications, among others.

Source: Sandra Huenchuan and Alejandro Morlachetti, "Derechos sociales y envejecimiento: modalidades y perspectivas de respeto y garantía en América Latina", Notas de población, No. 85 (LC/G.2346-P) Santiago, Chile, 2007.

Some civil and political rights are protected under existing legislation (see table I.2). In all cases, these rights are specified in order to give tangible form to the provisions of the constitution or treaties. With respect to economic, social and cultural rights, the different laws provide for the right to work, social security, education, health care, housing and social welfare, among others (see table I.3). 
Table I.2

SELECTED LATIN AMERICAN AND CARIBBEAN COUNTRIES: CIVIL AND POLITICAL RIGHTS GUARANTEED UNDER SPECIAL LAWS FOR THE PROTECTION OF OLDER PERSONS

\begin{tabular}{|c|c|c|c|c|c|}
\hline $\begin{array}{l}\text { Countries/ } \\
\text { Civil and political rights }\end{array}$ & $\begin{array}{l}\text { Right to } \\
\text { life }\end{array}$ & $\begin{array}{l}\text { Personal } \\
\text { freedom } \\
\text { and } \\
\text { security }\end{array}$ & $\begin{array}{c}\text { Freedom } \\
\text { of thought, } \\
\text { conscience or } \\
\text { religion }\end{array}$ & Association & $\begin{array}{c}\text { Non- } \\
\text { discrimination }\end{array}$ \\
\hline Brazil & • & $\cdot$ & $\cdot$ & • & • \\
\hline Costa Rica & - & - & - & $\bullet$ & - \\
\hline \multicolumn{6}{|l|}{ Ecuador } \\
\hline El Salvador & & & & - & - \\
\hline \multicolumn{6}{|l|}{ Guatemala } \\
\hline Mexico & • & - & & $\bullet$ & - \\
\hline Paraguay & & & & & - \\
\hline Peru & • & & & & \\
\hline Puerto Rico & & • & & & \\
\hline Dominican Republic & & & & • & \\
\hline Uruguay & & • & & & \\
\hline $\begin{array}{l}\text { Venezuela (Bolivarian } \\
\text { Republic of) }\end{array}$ & & & & - & \\
\hline
\end{tabular}

Source: Latin American and Caribbean Demographic Centre (CELADE) - Population Division of ECLAC, on the basis of special laws in force in the countries included in the table.

Table I.3

SELECTED LATIN AMERICAN AND CARIBBEAN COUNTRIES: ECONOMIC, SOCIAL AND CULTURAL RIGHTS GUARANTEED UNDER SPECIAL LAWS FOR THE PROTECTION OF OLDER PERSONS

Countries/

Economic, social and cultural rights

$\begin{array}{ccc}\begin{array}{c}\text { Education } \\ \text { and culture Work }\end{array} & \begin{array}{c}\text { Physical } \\ \text { Social } \\ \text { security }\end{array} & \begin{array}{c}\text { and } \\ \text { mental } \\ \text { health }\end{array}\end{array}$
Adequate
Housing standard of Family rights for

Equal living protection men and women

\begin{tabular}{|c|c|c|c|c|c|c|c|c|}
\hline Brazil & - & - & - & - & - & - & - & \\
\hline Costa Rica & - & - & - & - & - & - & - & \\
\hline Ecuador & - & & - & - & - & - & & \\
\hline EI Salvador & - & - & - & - & - & & - & \\
\hline Guatemala & - & - & - & - & - & - & - & - \\
\hline Mexico & - & - & - & - & - & - & - & \\
\hline Paraguay & & - & & - & & & & \\
\hline Peru & - & - & & - & & - & - & \\
\hline Puerto Rico & & - & & - & - & & - & \\
\hline $\begin{array}{l}\text { Dominican } \\
\text { Republic }\end{array}$ & - & • & - & • & • & & • & \\
\hline Uruguay & - & & - & - & - & & - & \\
\hline $\begin{array}{l}\text { Venezuela } \\
\text { (Bolivarian } \\
\text { Republic of) }\end{array}$ & & - & - & - & - & & - & \\
\hline
\end{tabular}

Source: Latin American and Caribbean Demographic Centre (CELADE) - Population Division of ECLAC, on the basis of special laws of the countries included in the table. 


\section{Institutions created under special laws}

In several countries, the law provides for the establishment of special councils to govern public-policy formulation and implementation: Costa Rica (National Council for Older Persons), El Salvador (National Council for Comprehensive Care for Programmes for Older Persons), Guatemala (National Council for the Protection of Senior Citizens and its advisory body, the National Committee for Protection of the Aged), Mexico (Citizens' Council for Older Persons) and the Dominican Republic (National Council for the Elderly). All of these institutions consist of or have a board of directors comprising officials from the different ministries or State departments, as well as from academic organizations and civil society organizations that work with older persons.

In Brazil, law 8,842 (4 January 1994) provides for the creation of a national council and similar institutions at the state and municipal levels. Decree 5,109 (2004) regulates and sets out the composition, structure, scope and functioning of the national council, conferring on it the role of defining the regulations and priorities for national policy and overseeing their fulfilment. This council is bipartite in composition, with representatives of both the State and civil society organizations. The latter enjoy much broader prerogatives than in other countries within the council, including the opportunity of directing it for a certain period.

Some countries, for example, Chile, ${ }^{2}$ the Bolivarian Republic of Venezuela and Mexico have enacted legislation setting up special institutions to address the needs of older persons. In the Bolivarian Republic of Venezuela, a governing body established under the Social Services Act - the National Social Services Institute (INASS) - is responsible for executing policies and plans, exercising the functions of control, follow-up and evaluation, and taking the necessary measures to ensure that the rights of older persons are respected. Here, as in Brazil, state and municipal agencies known as Social Services Centres have been created under the legislation and are operated by states and municipalities under the coordination of INASS.

In Mexico, National Institute for Older Persons (INAPAM) was set up under the special law. As the governing body for national policy, it coordinates, promotes, supports, fosters, monitors and assesses public measures, strategies and programmes, in accordance with the principles, objectives and provisions contained in the law.

2 In Chile, law 19,828 provides for the creation of the National Service for Older Adults and regulates all aspects of its work. 
Lastly, the third institutional modality is an arrangement whereby a ministry acts as governing body. In Ecuador, the Ministry of Labour and Social Welfare is legally responsible for the protection of older persons. The Bureau for the Elderly, which comes under this ministry, was created to protect the economic and social rights of older persons and process legal claims on their behalf. In Paraguay, the Ministry of Public Health and Social Welfare is the State agency responsible for implementation of the law through the Social Welfare Institute, whose sphere of duty was recently established by decree 10,068 (2007).

Most special laws confer responsibilities for health, work, education and transport issues, among others, upon different ministries or State departments. Mexican legislation lists the obligations of each of the departments indicating their areas of competence and the older persons to whom their sectoral policies should apply.

\section{Guarantees established under special legislation}

The crucial question is whether the legislation guarantees the exercise of the rights it proclaims, that is, whether it institutes tutelage mechanisms or techniques whereby those rights may be claimed (Abramovich and Courtis, 2006). This may be accomplished by setting up administrative or constitutional control or monitoring mechanisms, such as human rights ombudsmen, access to justice or budget allocation mechanisms to ensure the fulfilment of rights (see box I.3).

Brazil has the greatest number of mechanisms for safeguarding the rights of older persons. The Statute on Older Persons establishes that the Office of the Attorney General or the Judicial Authority has the power to order protection measures in cases where the rights of older persons are infringed by deed or omission by the State or the family. In addition, the Councils and the Office of the Attorney General are empowered to oversee the policies and actions of government and non-governmental bodies and to set fines for non-compliance. The Office of the Attorney General may initiate legal action to protect individual and collective rights for older persons.

The Venezuelan Social Services Act states that the Office of the Attorney General must have specialized investigating magistrates who can initiate proceedings to establish the penal, civil or administrative liability of persons who commit offences against individuals or of institutions which, by deed or omission, infringe or jeopardize individual, collective or diffuse rights of the persons protected under the Act. 
Box 1.3

\section{BUDGET AND GUARANTEE OF RIGHTS IN OLD AGE}

Public funding is crucial for advancing towards enforcing the rights of older persons; the rights contemplated in the national legislation and the services or benefits that they imply cannot be provided without the requisite budget appropriations. The rights of older persons should be incorporated into the public budget in order to finance social protection within the framework of the new covenant proposed by ECLAC. In addition, mechanisms need to be studied to prevent any deterioration in the services or benefits required for the effective exercise of older persons' rights, in the framework of solidarity and universality. Most of the special laws enacted to protect older persons in the region, however, fail to mention the budget allocations necessary to guarantee the rights they establish. At most, a few contain the standard reference to the effect that the State will determine funding in the yearly budget law, or empower institutions to manage or use resources, for example, from donations or the proceeds of fines or lotteries.

In El Salvador, the governing body is authorized to approach public and private organizations at the national and international levels for funding. The law also states that the governing body or council members must include in their budgets the appropriations required to comply with its provisions. Dominican regulations stipulate an annual allocation equivalent to no less than $0.5 \%$ of the budget of the Secretariat of State for Public Health and Social Welfare for enforcement of these rights. In provinces where there are homes and day centres for older persons duly registered and recognized by the council, under the law at least $10 \%$ of the local council's health budget must be distributed equitably among those centres; and local councils must coordinate with the national council to this end. Lastly, the National Fund for the Elderly established under Ecuadorian law (article 16) is entitled to $10 \%$ of the budget of the Ministry of Health and the Environment of Ecuador, of which amount 10\% is earmarked for the National Institute for Gerontological Research.

Costa Rica operates a different financing mechanism. Law 7.972 on taxation of liquors, beer and cigarettes provides for an operation and maintenance allocation to the National Council for Older Persons (CONAPAM), with a view to improving the quality of care in publicly or privately run homes, shelters and day centres; financing programmes for care, rehabilitation or treatment of older persons who are indigent or in need; and financing organization, promotion, education and training programmes to develop the skills of older persons, improve their quality of life and enable them to remain in the family and the community.

Source: Latin American and Caribbean Demographic Centre (CELADE) - Population Division of ECLAC.

Concerning the competence of the judicial power or office of the ombudsman to deal with infringements of these rights, law 7.935 of Costa Rica establishes criminal, civil or administrative sanctions for physical or psychological aggression, sexual harassment or other offences, and disqualifies the perpetrator from performing duties in centres that care for older persons. It also provides for different sanctions -implemented by a 
civil magistrate - in case of abandonment, ill-treatment or neglect on the part of the family or private or public institutions.

In the Bolivarian Republic of Venezuela, the Office of the Ombudsman has specialized officials empowered to take legal action to defend and protect the rights of older persons and to inspect public or private care institutions and report to the competent authorities any violations of the rights and interests of persons protected by the law, in order to determine civil, criminal or administrative liability with a view to disciplinary action.

In Guatemala, an Office of the Ombudsman for Older Persons was set up by the Human Rights Procurator under Agreement with the General Secretariat No. 15/98. This Office has been active in the defence of the rights of older persons, as well as in promoting those rights by organizing educational and awareness-building activities in the community (CELADE, 2006a).

Lastly, in Mexico, any deed, act or omission that may or does impair or infringe legally established rights and guarantees may be reported to the National Human Rights Commission where the complaint is against a federal authority, or to a State Human Rights Commission where it concerns state or municipal authorities.

In sum, a key step has been taken towards the formation of a new covenant for social protection by countries which have enshrined the rights of older persons in the constitution or have adopted special laws to protect them. First, the domestic legal framework has been adapted to include rights for older persons. Second, the obligations that the State and the rest of society must assume in order to move towards the effective exercise of the rights of older persons have been identified. Thus, these countries have set a minimum standard on which the State is committed to work. As will be seen later, however, enormous challenges surround this minimum standard since, in practice, most of the countries have yet to adapt public policies to the new demographic reality. This is compounded by lags in social protection for other sectors of the population and the inequities that derive from the development model of the region's countries. In the scenario of the new and greater challenges posed by population ageing, older persons' rights cannot be truly protected until the entitlements established under the law have proper coverage and actually protect the people to whom they accrue. 

Chapter II

\section{Uneven population ageing in the region}

\section{A. Demographic transition and the ageing process in Latin America and the Caribbean}

Demographic transition is a model used to describe the basic characteristics of countries' population changes, and it consists of several stages. In the first stage, birth and mortality rates are high, which produces low population growth. In the second (truly transitional) stage, a reduction in mortality and a continuing high birth rate lead to an increase in population growth rates. In the third phase, known as advanced transition, mortality rates have fallen and birth rates decline too, which results in increasingly lower rates of population growth. In the post-transition phase, birth rates drop below the level of mortality rates, thus resulting in extremely low or even negative natural population growth (Chackiel, 2004; Schkolnik, 2007; Villa and González, 2004).

The initial stage of the demographic transition process is characterized by a change from high to low mortality rates and, subsequently, a steady decline in fertility, until both variables reach low levels (Chackiel, 2004; Schkolnik, 2007; Villa, 2005). This model was originally formulated to interpret the sociodemographic transformation that took place in European countries from the mid-eighteenth to the 
mid-twentieth centuries (Villa and González, 2004), but it offers a good fit, albeit with certain differences, with the process Latin America and the Caribbean has undergone in more recent times. In Europe, the transition lasted over a century, but the process has taken no more than 50 years in this region.

The region's countries are moving towards more advanced stages of the demographic transition, with this process now being consolidated by birth and mortality rates that are much lower than those seen in previous decades: the average birth rate is no higher than 19.9 per 1,000 and the mortality rate no more than 6.0 per 1,000. Even so, differences remain among and within countries, as is apparent in figure II.1, which shows each country's position on the Cartesian graph according to its birth and mortality rates for the period 2005-2010. The countries in the first quadrant are at the earliest stage of transition, as they still have higher birth and mortality rates than the regional average. In Haiti and the Plurinational State of Bolivia for example, mortality rates are high, which contributes to slower population growth (around 2.2\%).

Figure II.1

LATIN AMERICA AND THE CARIBBEAN: THE STATUS OF COUNTRIES IN TERMS OF DEMOGRAPHIC TRANSITION, 2005-2010

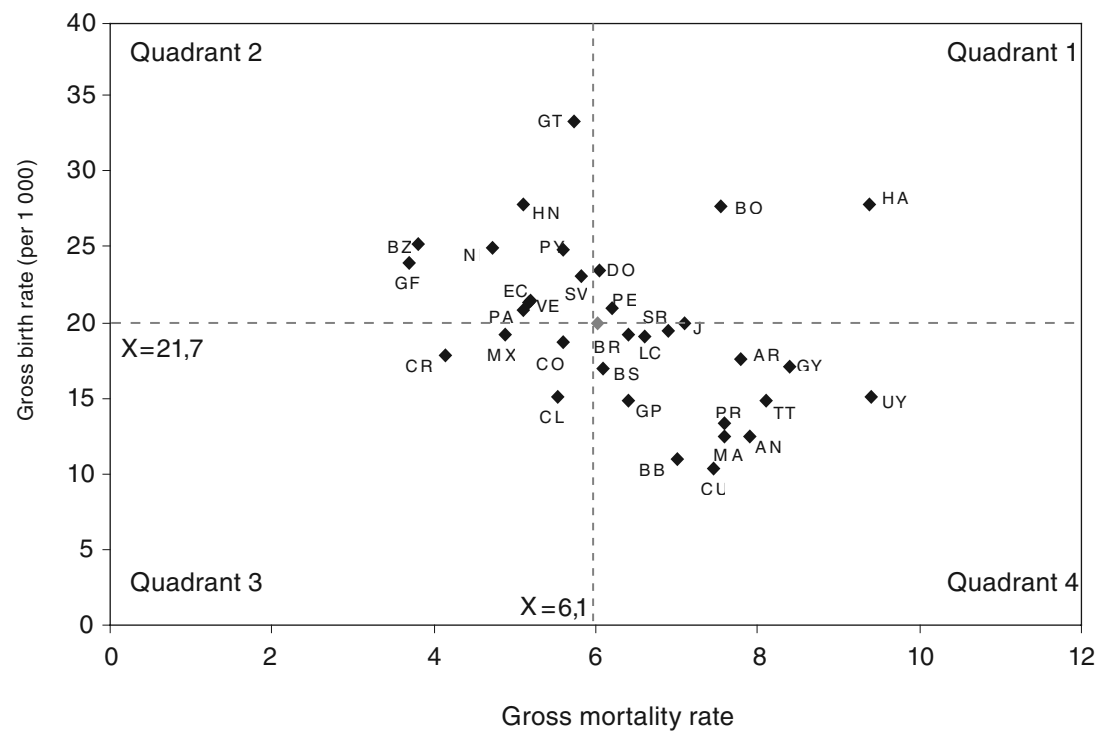

Source: Latin American and Caribbean Demographic Centre (CELADE) - Population Division of ECLAC, population estimates and projections [online] www.eclac.cl/celade/proyecciones/basedatos_BD.htm. 
Located in the fourth quadrant are those countries that have reached a very advanced stage of transition or even the post-transition, with low birth rates and the rising mortality rates typical of an older population. Cuba and other Caribbean countries show signs of being post-transitional, while Argentina and, to a lesser extent, Uruguay show signs of a more prolonged transition. The growth rates in these countries range from $-0.01 \%$ (Cuba) to $1 \%$ (Argentina).

The current position of the region's countries in terms of the demographic transition process is the result of their various experiences over the last 50 years, with multiple factors coming into play along that road. To demonstrate these trajectories, 11 countries at various stages of the process were selected, with the regional average used as a reference point (see figure II.2). There are distinctly heterogeneous patterns in the demographic development of the countries, some of whose vital rates were already well below the regional average in 1950-1955. In the 1950s, Uruguay, a demographic transition forerunner, had a mortality rate that the regional average did not equal until 25 years later, and a birth rate that the region caught up with only in 2000. However, the decline in Uruguay's vital rates slowed during the following decades, mainly as a result of gradual upward shift in the age structure. Cuba has also showed much lower vital rates than the regional average, although with very different patterns to those of Uruguay. Following the moderate vital rates registered in Cuba in the early 1950s, the mortality rate dropped sharply between 1950 and 1980, while the birth rate began to drop suddenly in the 1970s. This pattern of change - particularly rapid in recent decades- has slowed the rate of population growth, resulting in rapid ageing of the population and propelling the country into a very advanced stage of demographic transition.

Chile and Costa Rica display fairly similar trends, although in 1950 Costa Rica's gross birth and mortality rates were higher than those in Chile and the regional average. Both countries' vital rates declined considerably during the first period (1950-1980) and remained below the regional average between 1980 and 2005. The pace of change was faster than in Argentina and Uruguay, whose natural growth rates were very close to $1 \%$.

Mexico and the Bolivarian Republic of Venezuela are in intermediate positions, with trajectories similar to the regionwide pattern. The demographic transition process began later in Guatemala and Nicaragua, whose vital rates took until 1975-1980 to catch up with the regional average from the beginning of the period. The gap slowly closed and, during the second period (1980-2005), mortality rates dropped to moderate levels and birth rates began to decline. 
Figure II.2

LATIN AMERICA AND THE CARIBBEAN (SELECTED COUNTRIES):
DEMOGRAPHIC TRANSITION PATTERNS, 1950-2005

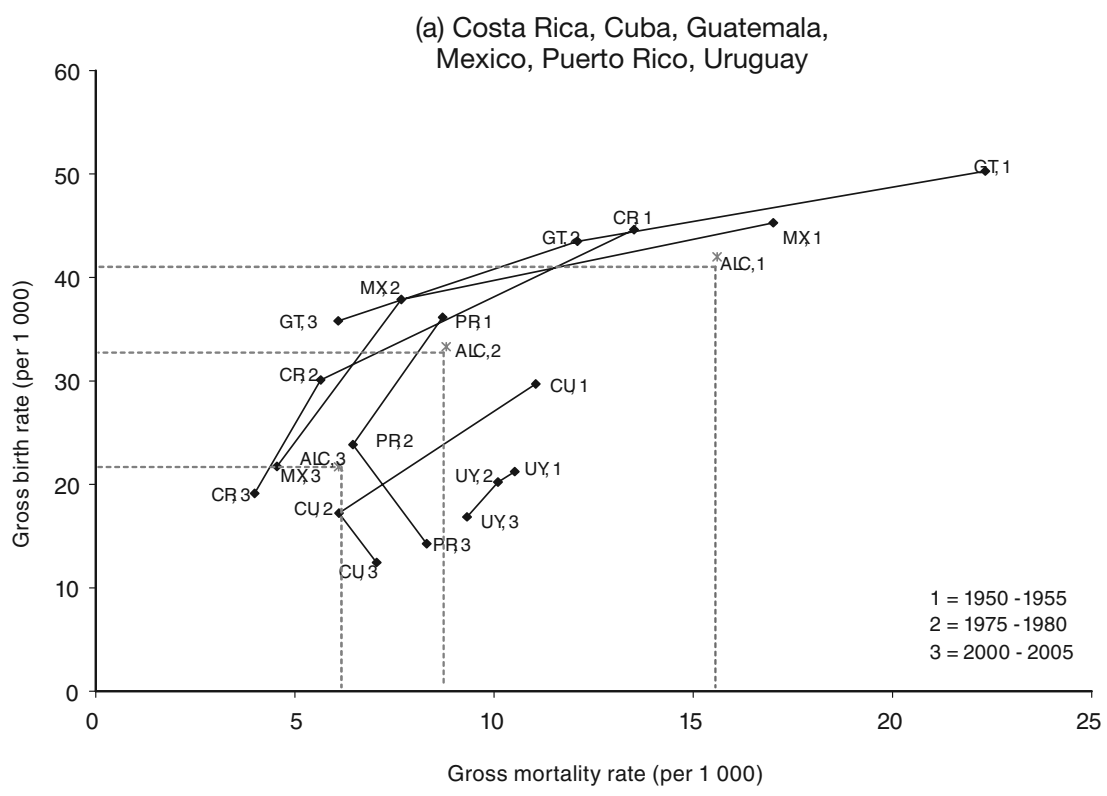

(b) Bolivarian Republic of Venezuela, Chile, Dominican Republic, Jamaica, Nicaragua

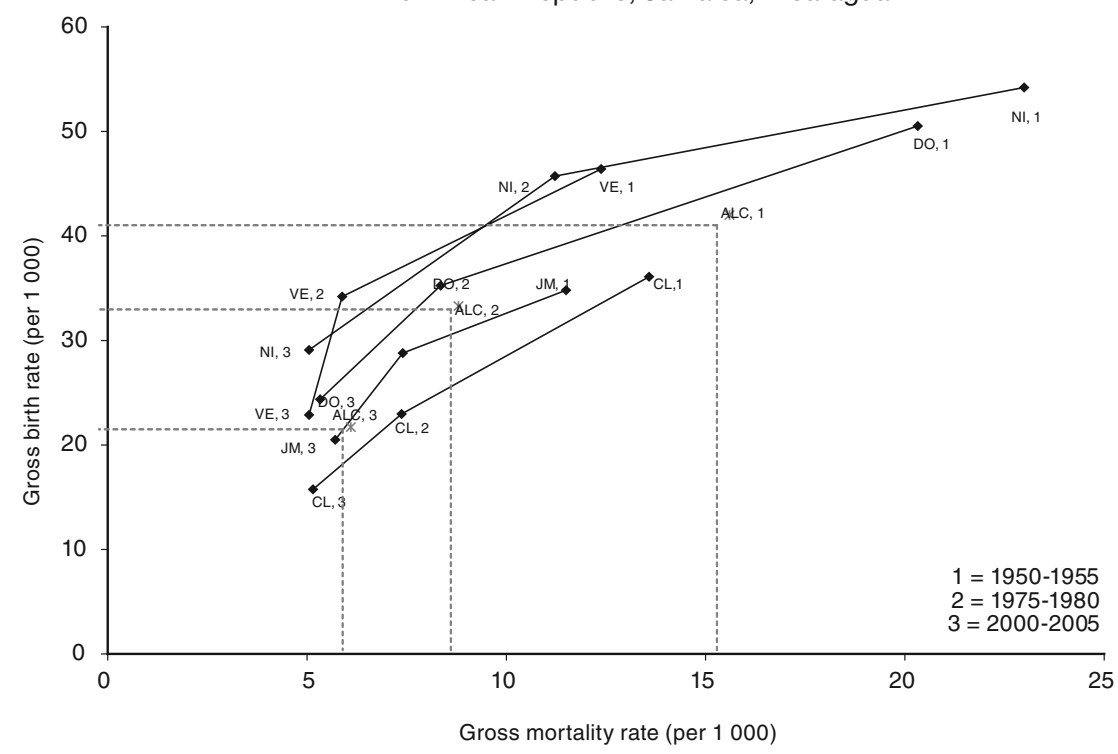

Source: Latin American and Caribbean Demographic Centre (CELADE) - Population Division of ECLAC, population estimates and projections [online] www.eclac.cl/celade/proyecciones/basedatos_BD.htm. 


\section{Fertility and mortality: a widespread and steady decline}

Irrespective of their scale and the length of time they have taken, changes in fertility and mortality in the region have resulted in profound demographic changes, most notably a reduction in population growth and a gradual upward shift in age structures (ECLAC, 2004).

Falling mortality rates are a factor in population ageing, but their impact varies depending on a country's stage of transition. A decline in mortality, particularly in young age groups, is what initiates the demographic transition process and results in longer life expectancy for the region's population.

Over the past 50 years, regional mortality has dropped by 10 percentage points to give a gross mortality rate of 6.1 deaths for every 1,000 inhabitants between 2000 and 2005. Haiti has the highest gross mortality rate $(9.8$ per 1,000$)$ and French Guiana has the lowest $(3.7$ per $1,000)$. Declining mortality has raised the life expectancy at birth of the Latin American population to 71.5 years in 2000-2005. The increase in life expectancy at birth has occurred across the board in the region: the figure is almost 80 years for both sexes in four countries (Chile, Costa Rica, Guadeloupe and Martinique). Having said that, there remain differences among countries (see figure II.3). ${ }^{1}$ In the five-year period 1950-1955, the largest difference in life expectancy at birth was between Uruguay (66.3 years) and Haiti (37.6 years). For the period 2000-2005, the greatest difference was between Martinique (79.1 years) and Haiti (59.2 years).

Female mortality is lower than male mortality throughout the region, which means that women have a longer life expectancy than men. This is due, among other things, to the reduction in pregnancy- and childbirth-related deaths, which are usually controlled more successfully than the causes that prevail among men, such as cardiovascular disease, external causes, violence and certain kinds of malignant tumours (ECLAC, 2004; CELADE, 2006a).

Chesnais (1990) identified three distinct phases in the mortality reduction process. The first is characterized by a decline in overall mortality and an increase in life expectancy at birth, due mainly to lower infant mortality and a resulting rise in the number of survivors at the base of the age pyramid. Although population growth is observed in all age groups, it is proportionally greater at younger ages as reduced risk of death in infancy and childhood initially promotes a rejuvenation of the population.

Life expectancy at birth is the most efficient indicator of a population's level of mortality, as it is free from the distortive effect of differences between age structures, while remaining sensitive to levels of infant and child mortality. 
Figure II. 3

LATIN AMERICA AND THE CARIBBEAN (SELECTED COUNTRIES):

LIFE EXPECTANCY AT BIRTH, BOTH SEXES, 1950-2005

(Percentages)

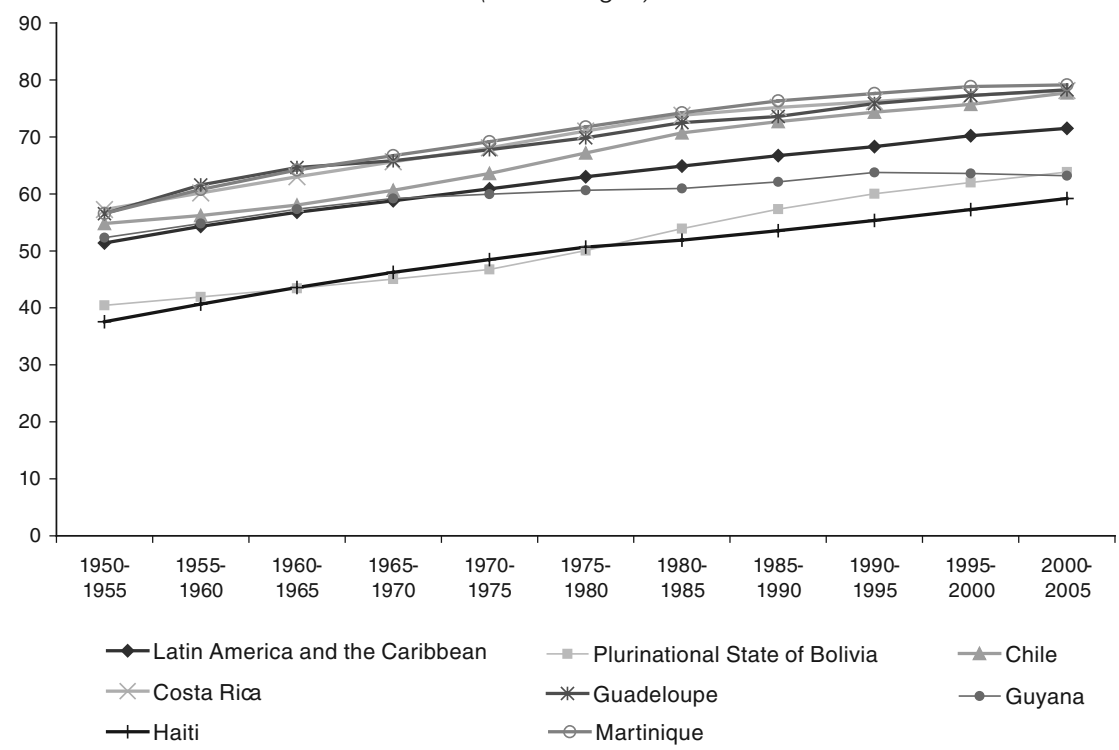

Source: Latin American and Caribbean Demographic Centre (CELADE) - Population Division of ECLAC, population estimates and projections [online] www.eclac.cl/celade/proyecciones/basedatos_BD.htm.

In Latin America and the Caribbean, the average infant mortality rate has fallen from 126 deaths of infants aged under one year per 1,000 live births between 1950 and 1955, to 26 deaths per 1,000 in 2000-2005. However, progress has been uneven despite the improvements recorded in many countries: 10 countries (Belize, Dominican Republic, Guatemala, Haiti, Guyana, Honduras, Nicaragua, Paraguay, Peru and the Plurinational State of Bolivia) still have child mortality rates above the regional average, whereas four countries and territories (Chile, Cuba, Guadeloupe and Martinique) have fewer than 10 deaths per 1,000 live births. Persistently high infant mortality rates constitute empirical evidence of the risks inherent in the transitional lag that exists both among and within countries (ECLAC, 2005).

The second stage of the process identified by Chesnais is a more evenly spread reduction in mortality across all age groups. The population structure shifts to accommodate a higher proportion of young people and adults as a result of the large cohorts born in the past with higher survival rates. This is the case of countries at an advanced state of demographic transition (see figure II.1), which have mortality rates of less than 10 per 1,000 for 2000-2005 and much reduced infant mortality rates. 
The third and final stage begins when high mortality among the young comes right down and mortality caused by degenerative diseases affecting mainly those aged over 50 declines (thereby increasing the probability of survival among older adults and intensifying population ageing). During this stage, a longer average lifespan is reflected in a much higher proportion of the very elderly, who tend to have a greater need for medical, institutional and family support. Practically none of the region's countries are at this stage, although mortality is rising as a result of population ageing in some places such as Bahamas, Cuba, Guyana, Puerto Rico and Trinidad and Tobago, which all registered slight increases in their gross mortality rates in the period 2000-2005, with an even higher rate predicted by 2025 (see table II.1). By 2050, several of the region's countries are expected to have higher mortality rates than they do now, mainly as a result of population ageing. This situation occurs because older adults make up a higher proportion of the total population. In other words, there are relatively more people in age groups at greater risk of death.

One of the most significant demographic transitions undergone by the region has been the heavy and sustained decline in fertility (Rodríguez, 2003). This profound shift in reproductive behaviour goes hand-in-hand with sociodemographic and cultural changes (Villa and Rivadeneira, 2000) and is taking place to a greater or lesser extent in all the countries, although individual experiences have been far from uniform (Schkolnik and Chackiel, 2003). As fertility falls, so the population gradually ages (Chackiel, 2003). As low fertility becomes an established pattern, differences in the age structure become greater, in what is a key feature of the process of population ageing.

When the global fertility rate goes into steady decline, the base of the age pyramid narrows. This change in the pyramid shape occurs during demographic transition, which results in ageing of the pyramid from the base. The link between low fertility and ageing is that the relative weight of other age groups increases in direct proportion with the decrease in that of the group aged 0 to 4 years. The proportion of older people grows and the lowest level of the age pyramid shrinks. With a steady decline in fertility over time, ageing originates in the middle of the pyramid, as there are proportionally more people of intermediate age than young age (which makes the pyramid more of a rectangle). Subsequently, the combination of low fertility and falling mortality among older people results in a wide tip and a narrow base (Villa and Rivadeneira, 2000). Falling fertility clearly has a stronger impact than changes in the mortality rate, which does not have such a direct impact until the most advanced stages of ageing (Chesnais, 1990). 
Table II.1

LATIN AMERICA AND THE CARIBBEAN (SELECTED COUNTRIES): DIFFERENCES IN SURVIVAL YEARS AT AGE 60 FOR MEN AND WOMEN, 1950-2050

\begin{tabular}{lccccc}
\hline Country & $1950-$ & $1975-$ & $2000-$ & $2025-$ & $2045-$ \\
\hline Argentina & 1955 & 1980 & 2005 & 2030 & 2050 \\
Bolivia (Plurinational State of) & 2.9 & 4.1 & 5.0 & 5.4 & 5.5 \\
Brazil & 1.1 & 1.2 & 1.9 & 2.8 & 3.6 \\
Chile & 0.6 & 0.8 & 3.0 & 3.7 & 4.3 \\
Colombia & 2.3 & 3.0 & 3.7 & 4.3 & 4.7 \\
Costa Rica & 1.1 & 1.6 & 2.2 & 3.1 & 3.4 \\
Cuba & 1.0 & 2.3 & 2.7 & 3.4 & 3.8 \\
Dominican Republic & 0.7 & 2.0 & 2.3 & 3.1 & 3.4 \\
Ecuador & 1.1 & 1.8 & 2.4 & 3.3 & 3.7 \\
El Salvador & 1.3 & 1.3 & 2.1 & 3.1 & 3.7 \\
Guatemala & 1.1 & 2.9 & 3.1 & 3.9 & 4.4 \\
Haiti & 0.4 & 1.0 & 0.0 & 2.8 & 3.8 \\
Honduras & 0.3 & 0.6 & 1.1 & 2.3 & 3.2 \\
Mexico & 0.9 & 1.6 & 2.6 & 3.2 & 3.7 \\
Nicaragua & 1.0 & 1.9 & 1.8 & 2.8 & 3.2 \\
Panama & 1.4 & 2.2 & 1.7 & 3.3 & 3.7 \\
Paraguay & 1.1 & 1.9 & 2.0 & 3.2 & 3.9 \\
Peru & 1.9 & 1.9 & 1.9 & 2.7 & 3.0 \\
Uruguay & 0.9 & 1.7 & 2.6 & 3.2 & 3.8 \\
Venezuela (Bolivarian Republic of) & 1.2 & 2.6 & 2.1 & 3.2 & 3.9 \\
\hline
\end{tabular}

Source: Latin American and Caribbean Demographic Centre (CELADE) - Population Division of ECLAC, estimates and projections.

Fertility has fallen in all the region's countries owing to a combination of factors. During the last four decades of the twentieth century, the reproductive behaviour of couples in Latin America and the Caribbean changed from a widespread pattern of large families to a new model of low fertility, with approximately two children per woman. Changes in economic and social structures led to a series of cultural transformations that contributed to the adoption of reproductive behaviour patterns in keeping with the ideal of a smaller family. This was in turn facilitated by the availability of contraception (ECLAC/ CELADE, 2008).

Notwithstanding, the region's countries differ markedly in the timing of the fall in fertility and the speed of the process. The global fertility rate (the average number of children that would be born per woman during her fertile years in the absence of mortality risks if her childbearing was consistent with age-specific fertility rates for a given period) ranges from below the replacement level (2.1 children per 
woman) in Barbados, Cuba, Puerto Rico and Trinidad and Tobago, to over four children per woman in Guatemala and Haiti (ECLAC, 2004; Villa and González, 2004; Chackiel, 2004).

Fertility began to decline first in Argentina and Uruguay. The early onset of fertility decline was due mainly to these two countries' considerable economic and social development in the first half of the twentieth century and the sociocultural influence of European immigration, and the total fertility rate in these countries had already dropped to around three children per woman by 1950. Thereafter, between 1950 and 2005, Argentina and Uruguay displayed the region's smallest decrease in fertility (less than $25 \%$ ). The drop in total fertility began later in the region's other countries. In all these countries the global fertility rate, which was over four children per women in 1950 (and over seven children in some cases), has dropped by over 30\% in the past 50 years and by as much as $70 \%$ in some countries. Particularly striking is the case of Cuba, whose fertility rate soared in the early 1960s before plummeting to below the replacement level in 1980. In the five-year period 2000-2005, the average number of children per woman in Cuba was just 1.6. Guatemala, Haiti, Paraguay and the Plurinational State of Bolivia (the countries with the highest fertility levels today) also stand out, as their fertility levels have dropped from high or very high levels in 1950 to below $45 \%$ of those initial figures in the last 50 years (see figure II.4).

Some uncertainty surrounds the likely traits of fertility in the next 50 years in the region, which has given rise to various inquiries and hypotheses (Villa, 2005; Chackiel and Schkolnik, 2004; CELADE, 2004). Certainly, in all of the region's countries the rate of reproduction may continue to drop and a number of factors could hasten the decline and push the rate below replacement level, but it is unclear how long this will take and how far the fertility rate will fall. Several studies (ECLAC/CELADE, 2008; Villa, 2004; Chackiel and Schkolnik, 2004; CELADE, 2004; Schkolnik, 2004) suggest possible fertility trends in Latin American and Caribbean countries. One possibility is that the region will follow the Cuban fertility trend and reach a level similar to that of Southern European countries. Another is that fertility in the region will behave similarly to that in Argentina and Uruguay, where the global fertility rate has slowed gradually but has not fallen below replacement level. 
Figure II.4

LATIN AMERICA AND THE CARIBBEAN (SELECTED COUNTRIES):

GLOBAL FERTILITY RATES, 1950-2005

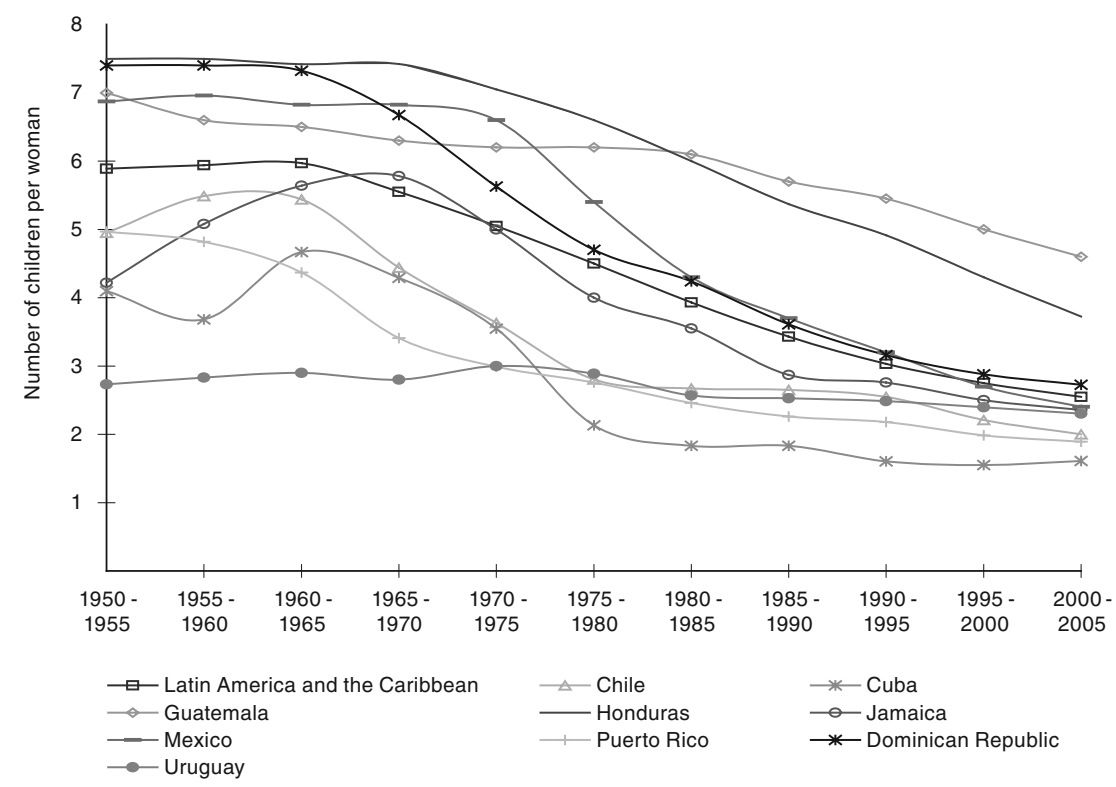

Source: Latin American and Caribbean Demographic Centre (CELADE) - Population Division of ECLAC, population estimates and projections [online] www.eclac.cl/celade/proyecciones/basedatos_BD.htm.

\section{Changes in the age structure of the population}

The components of demographic change (fertility and mortality) impact both the growth of the population and its age structure. As the demographic transition progresses and mortality and especially fertility decline, the population gradually ages (Chackiel, 2004; Villa and González 2004; ECLAC, 2004). This is defined as a progressive increase in the proportion of people aged 60 and above within the total population. This process gradually alters the profile of the age structure, whose conventional outline (a pyramid with a wide base and narrow tip) first morphs into a more rectangular shape and subsequently inverts its initial form, with the top wider than the base (Chesnais, 1990).

Changes observed in age structures over the last 50 years confirm the effects of fertility and mortality patterns (see figure II.5). In countries at a more advanced stage of demographic transition 
(quadrants 3 and 4 of figure II.1), the pyramid structure changed earlier than in those countries at an earlier stage in the process, where it did not begin to do so until the year 2000. Accordingly, the overall population became slightly younger in most countries in the period 1950-1975, as falling infant mortality rates increased the proportion of children aged under age 15 to $41 \%$ of the region's population in 1975 (Villa and Rivadeneira, 2000).

At the same time, the proportion of people aged 60 and over edged up slightly to $6.5 \%$, and the working-age population (15 to 59 years) decreased in relative terms. Of course, the nature of the structural changes varied according to the respective countries' stage of transition: in those at the most advanced stage, those aged 60 and over already represented $7.4 \%$ of the population in the 1950 s, while the average was $5.1 \%$ in countries at a less advanced stage. Twenty-five years later, this age group represented $11.2 \%$ of the population in quadrant 4 countries, while the proportion of children under age 15 remained constant. At the other extreme, in the countries furthest behind in the transition (quadrant 1), children under age 15 still represented $40 \%$ of the population and the proportion of older adults had hardly risen at all.

In 2000, the typical pyramid shape began to alter: owing to the steady fall in fertility rates, the proportion of children under age 15 fell in all countries, to reach a regional average of $31 \%$. This proportion was above $40 \%$ only in the most lagging countries, but had dropped to no more than $27 \%$ in the most transitionally advanced. Ageing was therefore being driven by the pyramid base, since the decrease in the number of children aged 0 to 14 proportionally raised the weight of the higher age groups. The central and upper bars became wider and the number of children under age 5 continued to fall (see figure II.5). Accordingly, the proportion of older adults increased in almost all the countries. In 2000, those aged 60 and over represented $8.3 \%$ of the regional population, rising to $14 \%$ in the most transitionally advanced countries and falling to $6.1 \%$ in the least transitionally advanced. The population aged 15 to 59 rose to $60 \%$ in 2000 , as a result of falling fertility and the inertial growth produced by patterns in previous decades.

According to a recent review of population projections conducted by the Latin American and Caribbean Demographic Centre (CELADE) Population Division of ECLAC, changes in the pyramid structure will be even more drastic in 2025, when children under 15 will represent only $23 \%$ of the population in Latin America and the Caribbean and 
Figure II.5

LATIN AMERICA AND THE CARIBBEAN: AVERAGE AGE AND SEX STRUCTURES OF THE POPULATION, BY STAGE OF DEMOGRAPHIC TRANSITION OF THE REGION'S COUNTRIES, 1950-2000

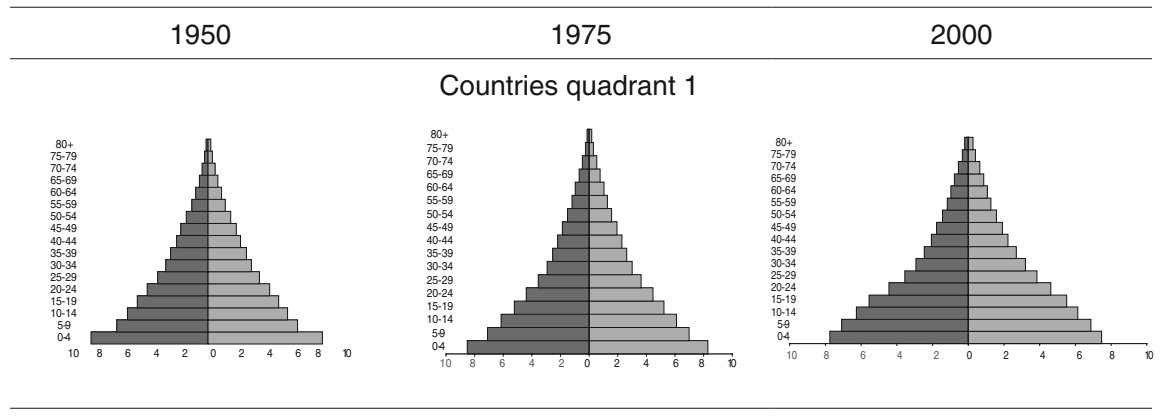

Countries quadrant 2
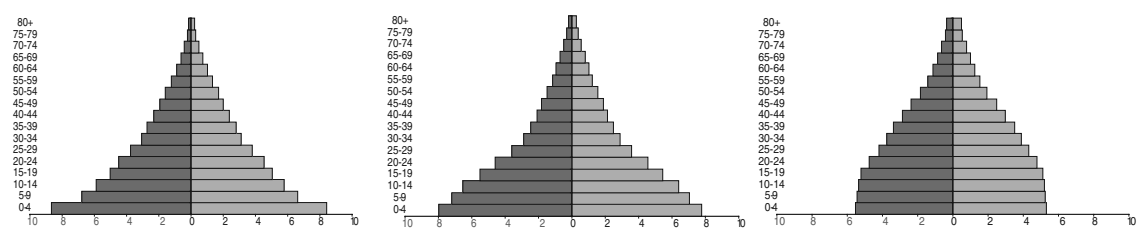

Countries quadrant 3
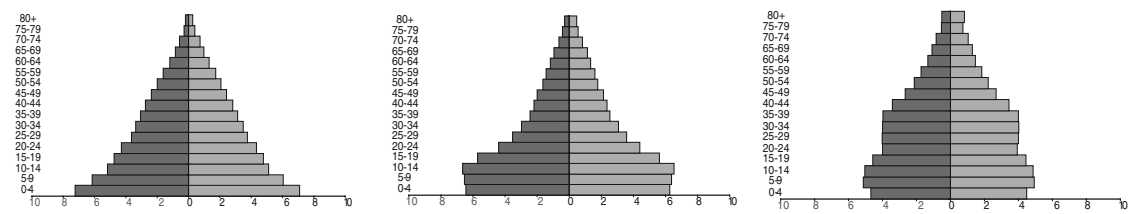

Countries quadrant 4
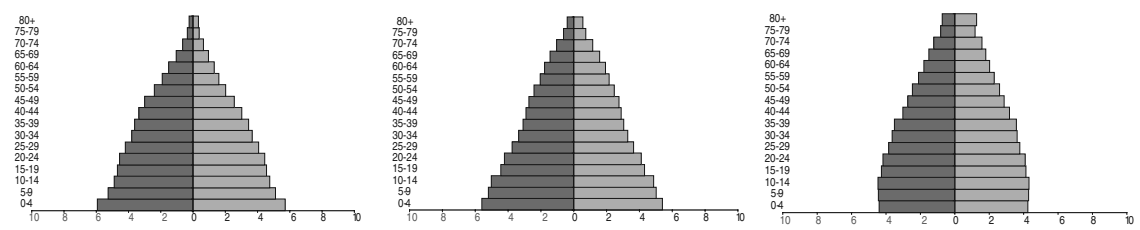

Men

Women

Source: Latin American and Caribbean Demographic Centre (CELADE) - Population Division of ECLAC, population estimates and projections [online] www.eclac.cl/celade/proyecciones/basedatos_BD.htm. 
older adults will make up almost 15\%. Also, the larger cohorts born in previous decades will be progressing through adulthood and broadening the central bands of the pyramid as part of an "era of retraction" (resulting from the past "era of expansion") that will continue for decades to come. The new age profile is forming a pyramid with a narrower base and wider central sections, corresponding to an older population structure (see figure II.6). Around 19\% of the population in the most transitionally advanced countries will be aged 60 or over, while the percentage of children under age 15 will drop to $20 \%$. The least transitionally advanced countries will have a smaller proportion of older adults (8\%), which will slowly increase in line with the decrease in the population aged 0 to 14 years $(31.7 \%)$.

By 2050, the classic pyramid structure will be completely replaced by a rectangular shape where each age group represents practically the same proportion of the population. Children under the age of 15 will represent $18 \%$ of the total regional population, and older adults will represent $24.3 \%$. Countries that were already displaying population ageing in 2000 will have the highest proportion of older people $(27 \%)$, while the least advanced countries in the transition will have considerably increased their proportion of people aged 60 and above to $14.7 \%$ of the total (see figure II.6).

\section{B. Population ageing: a gradual and inexorable process}

As a result of demographic transition, the population of Latin America and Caribbean is gradually but inexorably ageing. The next few decades will see steady increases in both the proportion and the absolute number of people aged 60 and over (see table A.1 of the annex). In absolute terms, the number of people aged 60 and over (currently 41 million) will grow by 57 million between 2000 and 2025, and by 86 million between 2025 and 2050. This population group is growing at a faster pace than other younger groups (average annual growth rate of $3.5 \%$ ). The rate of change within this age group will be between three and five times higher than among the total population in the periods 2000-2025 and 2025-2050. As a result, the proportion of people aged 60 and over in the total population will quadruple between 2000 and 2050, such that one in every four people in Latin America and the Caribbean will be an older adult in the year 2050 (see figure II.7). 
Figure II.6

LATIN AMERICA AND THE CARIBBEAN: AVERAGE AGE AND SEX STRUCTURES OF THE POPULATION, BY STAGE OF DEMOGRAPHIC TRANSITION OF THE REGION'S COUNTRIES, 2000-2050

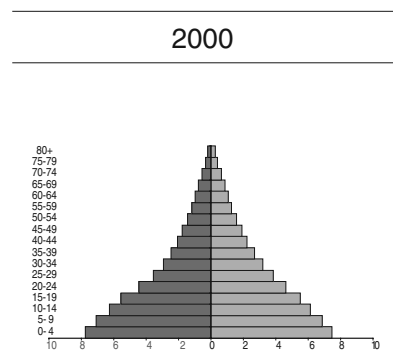

2025
2050

\section{Countries quadrant 1}
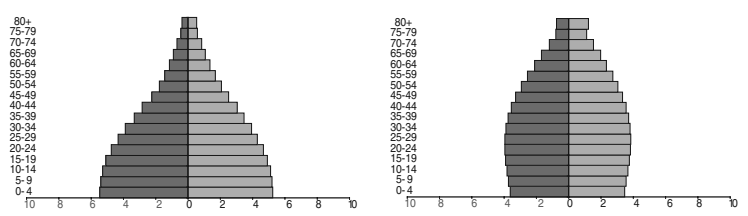

\section{Countries quadrant 2}
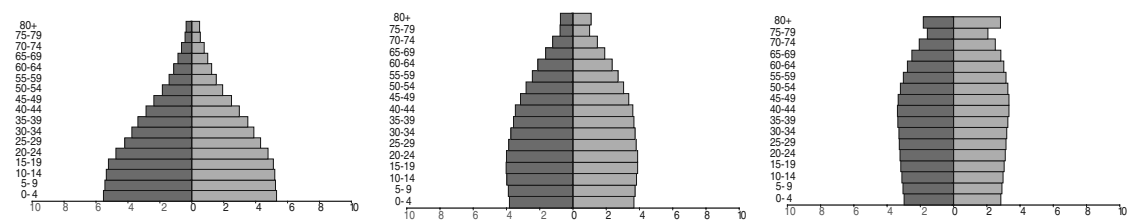

Countries quadrant 3
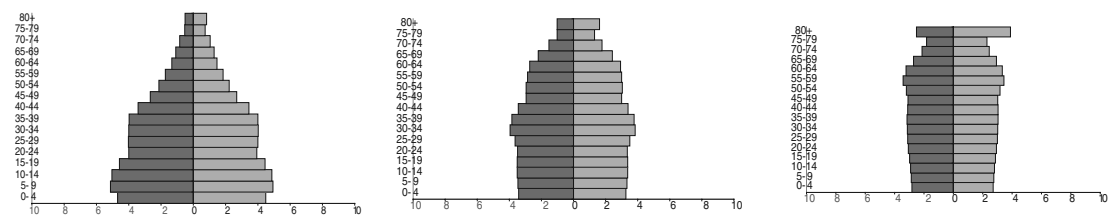

Countries quadrant 4
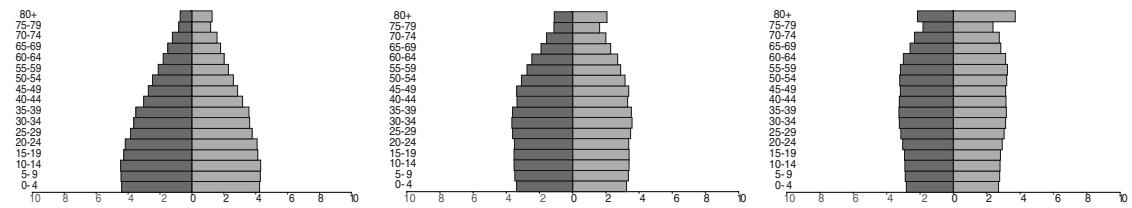

Men

$\square$ Women

Source: Latin American and Caribbean Demographic Centre (CELADE) - Population Division of ECLAC, population estimates and projections [online] www.eclac.cl/celade/proyecciones/basedatos_BD.htm. 
Figure II.7

LATIN AMERICA AND THE CARIBBEAN: POPULATION AGED 60

AND OVER, 1950-2050

(Thousands and percentages)

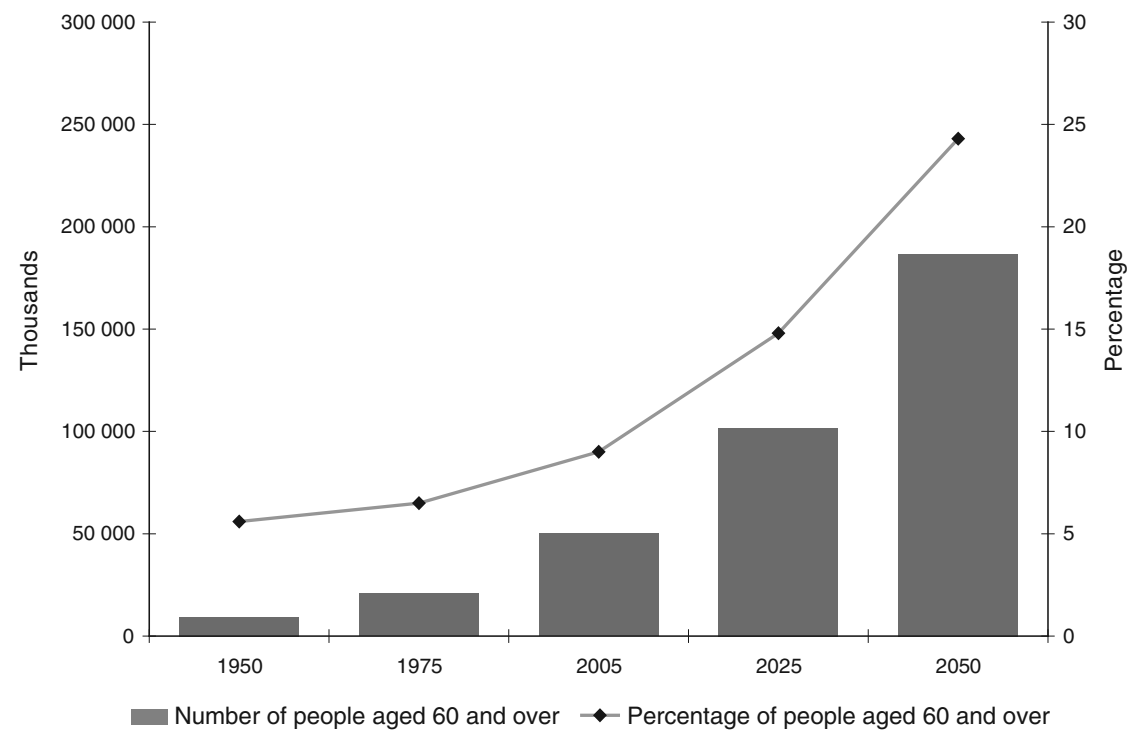

Source: Latin American and Caribbean Demographic Centre (CELADE) - Population Division of ECLAC, population estimates and projections [online] www.eclac.cl/celade/proyecciones/basedatos_BD.htm.

\section{National differences in the proportion of older adults and the growth rate of the older population}

The fact that countries are at various stages of demographic transition means that the ageing process is different in each one. In order to classify the region's countries according to their stage in the process of population ageing, the global fertility rate was combined with the ageing index (ratio between the number of people aged 60 and over and the number of children under the age of 15) for each country in the year 2007 (see figure II.8). As explained in the first section, the total fertility rate is used because it is key to the ageing process: declining fertility in the short-term produces ageing at the base of the pyramid as the proportion of children as a percentage of the total population falls. The ageing index is an indicator of the population structure by age: an increase in this indicator can mean that people are either living longer or having more children. 
Figure II.8

LATIN AMERICA AND THE CARIBBEAN: POSITION OF COUNTRIES ACCORDING TO STAGE OF POPULATION AGEING PROCESS, 2007

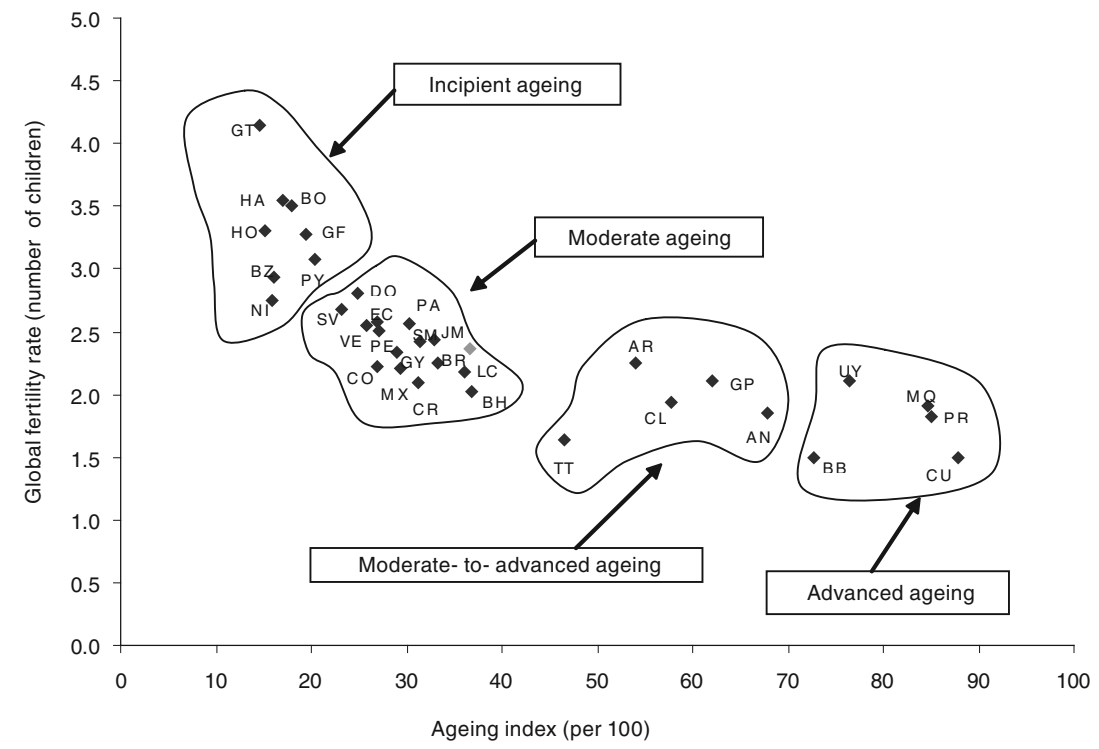

Source: Latin American and Caribbean Demographic Centre (CELADE) - Population Division of ECLAC, population estimates and projections [online] www.eclac.cl/celade/proyecciones/basedatos_BD.htm.

Figure II.8 shows that there are four distinct groups of countries. The first group has relatively high levels of fertility (over 2.8 children per woman) and an ageing index lower than 20 older adults for every 100 children under the age of 15 . These countries are at the incipient stage of the demographic transition process (eight countries). The second group consists of 15 countries with lower fertility rates (between 2.8 and 2 children per woman) and an ageing index that ranges between 23.2\% and $36.9 \%$, which means they are at the moderate stage of ageing. The five countries in the third group are at a moderate-to-advanced stage of ageing, as their fertility rates vary between 2.3 and 1.6 children per woman and their ageing indices range from 67.8 to 46.5 older adults per 100 children under the age of 15 (five countries). The fourth and final group of countries has lower levels of fertility (below the replacement rate, except for Uruguay) and ageing indices over $72.7 \%$ (five countries) (see figure II.8 and table A.2 of the annex).

The groups of countries shown in figure II.8 are directly linked to their stage in the process of demographic transition (see figure II.1). In other words, the ageing process intensifies as countries progress through 
demographic transition. Having said that, the process has not been uniformly intense throughout the region, as some countries have quickly exceeded levels of $10 \%$ of the population aged 60 and over, while other countries have taken longer to surpass that percentage (see figure II.9).

Figure II.9
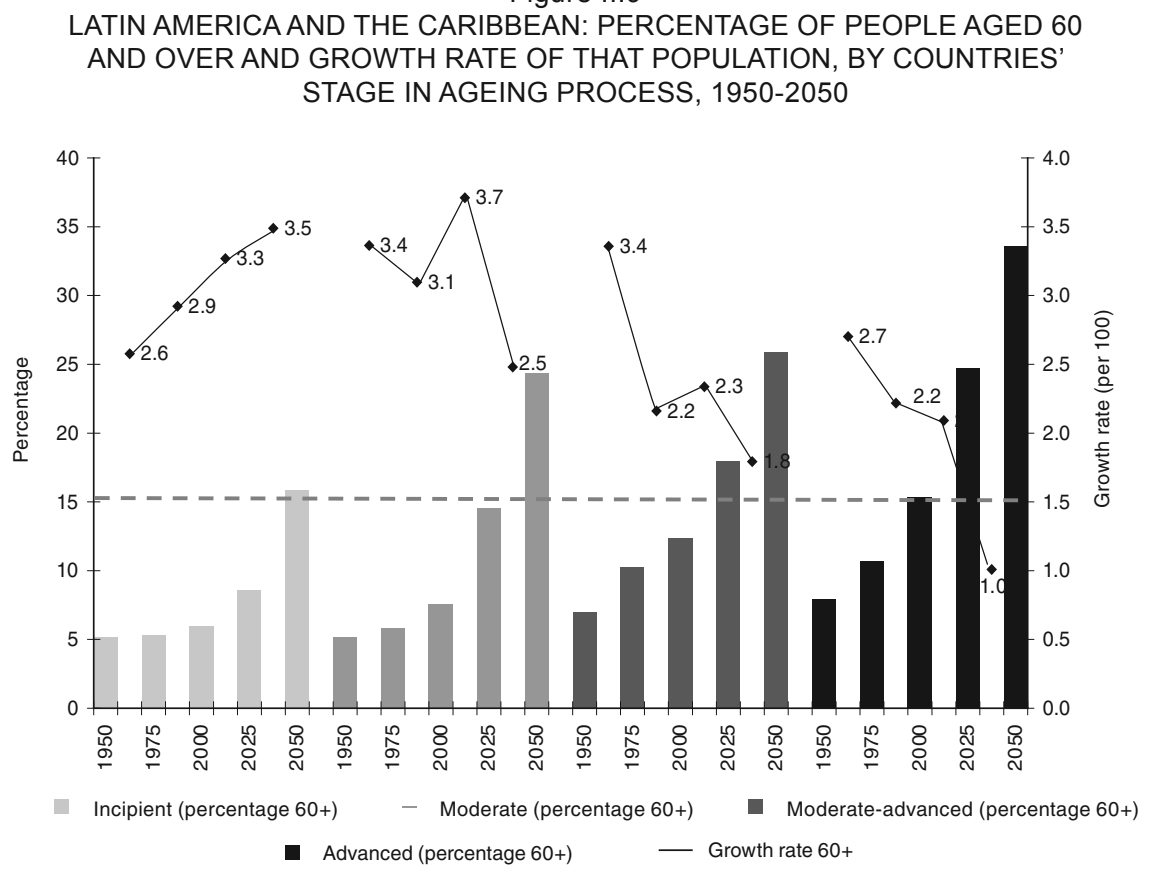

Source: Latin American and Caribbean Demographic Centre (CELADE) - Population Division of ECLAC, population estimates and projections [online] www.eclac.cl/celade/proyecciones/basedatos_BD.htm.

In 2000, older adults represented an average of $6 \%$ of the population in countries with incipient ageing, and $7.6 \%$ in countries with moderate ageing. The proportion of older people had already exceeded $10 \%$ in the other two categories: countries with moderate ageing posted $12.4 \%$ and in those at the most advanced stage of the process, people aged 60 and above accounted for 15\% of the population. Between 1950 and 1975, countries where fertility and mortality had already begun to fall at the beginning of that period saw the population of those aged 60 and above grow at an average annual rate of $2.7 \%$. As a result, in 1975 one in 10 people was aged 60 or over. In 2000, this age group made up $15 \%$ of the population, although the growth rate had slowed to $2.2 \%$ by that time (see figure II.9). 
During the first 25 years of the period 1950-2000, although countries with moderate-to-advanced ageing recorded a similar percentage of older adults $(10.3 \%$ in 1975$)$, the average annual growth rate of 3,4\% was higher than in countries with advanced ageing, as they started off with a lower proportion of older persons in 1950 (7\%). Between 1975 and 2000, the older population in moderate-to-advanced countries grew at the same speed as in countries with advanced ageing (2.2\%). Despite this, the percentage of older adults only rose to $12.4 \%$.

Countries with incipient and moderate ageing entered the period 1950-2000 with the same proportion of older adults (5.1\%). However, this percentage did not increase at the same rate (see figure II.9), mainly because fertility declined more sharply in countries with moderate ageing, which resulted in an average growth rate of $3.4 \%$ for older adults, who came to represent $5.8 \%$ of the population in 1975 .

In countries where fertility was slower to fall, on the other hand, the percentage of older adults only rose by $0.2 \%$, with an average annual growth rate of $2.6 \%$. In some countries, the population aged 60 and over even fell as a result of the rejuvenation caused by declining mortality (especially among infants) and persistently high fertility. In the period 1975-2000, the number of older adults increased at the same rate in countries with incipient and moderate ageing. However, the proportion of older adults in the two categories of country is not the same as in 1950, as older adults represent $6 \%$ of the population in countries with incipient ageing, and $7.6 \%$ of the population in countries with moderate ageing (see figure II.9).

According to population estimates and projections, the number of older adults will continue to rise in the region, despite the persistence of differences among countries. In countries with advanced ageing, older adults will represent $25 \%$ of the total population in 2025. In 2050, 34 in every 100 people will be aged 60 or over. The growth rate will nonetheless be much slower, as the older population will increase at an average annual rate of $2.1 \%$ in the period $2000-2025$, with the growth rate falling to as low as $1 \%$ over the following 25 years (2025-2050).

In countries with moderate-to-advanced ageing, the number of older adults will continue to grow by $2.3 \%$ between 2000 and 2025, which means that this age group will represent $18 \%$ of the total population by the end of the period. Although this growth rate will drop to $1.8 \%$ over the 25 years following 2025, those aged 60 and over will nonetheless represent $26 \%$ of the total population by 2050. In countries with moderate ageing, on the other hand, the growth rate of the population aged 60 and over will continue to rise and will even exceed the percentages recorded by more advanced countries at some stage in the process. The older population in these countries is therefore expected to increase by $3.7 \%$ between 2000 and 2025, and by a 
slightly lower $2.5 \%$ in the period 2025-2050. In countries with incipient ageing, growth rates of the older population will always rise, reaching 3.5\% between 2025 and 2050, although older adults will still only represent $15 \%$ of the population by 2050 (see figure II.9).

\section{The peculiarities of population ageing in the region}

One of the most striking differences between the ageing process in Latin America and the Caribbean as opposed to that experienced in Europe is that the former has moved along much more quickly and has therefore been played out over a shorter period of time. This indicates that the demographic transition process started much earlier in European countries, and that the shift from high to low levels of fertility and mortality was much slower than in Latin America and the Caribbean. In other words, the population aged more gradually.

In the mid-twentieth century, around $12.3 \%$ of Europe's population was aged 60 or over, while older adults represented $5.5 \%$ of the total population in Latin America and the Caribbean. A quarter of a century later, older adults represented over 15\% of the total population in Europe, thanks to an average annual growth rate of $2.2 \%$ in the period 1950-1975. In Latin America and the Caribbean, between 1950 and 1975 fertility was already falling and the base of the age pyramid was gradually narrowing as a result. During this time, the proportion of older adults grew by an average annual rate of $3.3 \%$. In 2000, the percentage of older adults in Europe was 2.5 times higher than in Latin America and the Caribbean, although the proportion has grown at a faster rate in the latter than in the former $(2.9 \%$ compared with $1.1 \%$ in the period 1975-2000). Although the proportion of older adults in Europe will be twice that of Latin America and the Caribbean in 2025, this region's older population will post the highest growth rate in its history (3.4\%) for the period 2000-2025 (see figure II.10).

There is one feature of ageing in Latin America and the Caribbean that goes beyond the realm of demographics. Many authors agree that demographic transition in Europe was associated with a structural socioeconomic shift that resulted in long-term increases in the standard of living and economic activity. As a result, the two processes interacted in a positive way by reinforcing each other. ${ }^{2}$ The structures and institutions of European countries had sufficient time to adapt to the emerging demographic scenarios and to produce the resources needed to tackle the new challenges involved (Villa and Rodríguez, 2002). In Latin America and the Caribbean, on the other hand, the pace of demographic transition and population

For further information on this issue, see Hill, Morelos and Wong (1999), Kirk (1996), Livi-Bacci (1994), Vallin (1994) and Rodríguez (2001). 
ageing has been faster, which means that there has been less time to make the necessary socio-economic and institutional adjustments to adapt to the emerging demographic situation. One manifestation of this asymmetry is the rapid demographic transition process compared with slower and more volatile economic and social development.

Figure II. 10

LATIN AMERICA AND THE CARIBBEAN AND EUROPE: PERCENTAGE AND GROWTH RATE OF THE POPULATION AGED 60 AND OVER,

1950-2050
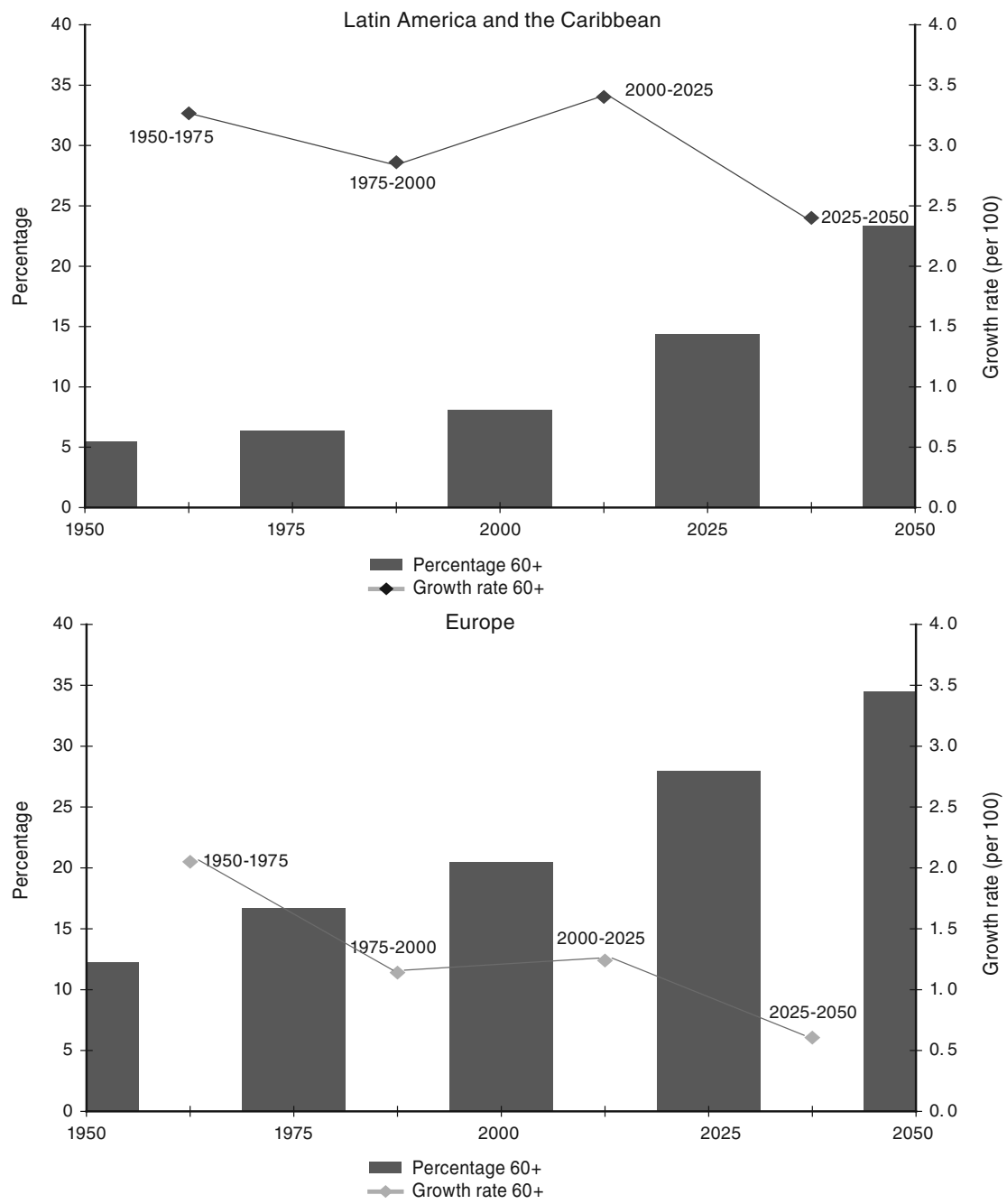

Source: Latin American and Caribbean Demographic Centre (CELADE) - Population Division of ECLAC, population estimates and projections [online] www.eclac.cl/celade/proyecciones/basedatos_BD.htm. 


\section{The older population and internal differentiation}

The population of those aged 60 and over is not a homogenous group, hence an analysis of some sociodemographic characteristics shows up some differences according to age (60-74 years or aged 75 and over), sex and place of residence, which are all factors that influence access to economic security, as well as health, environment and poverty.

\section{Ageing within the older population}

In addition to the projected increase in the older population as a whole in the region over the next few decades, the proportion of very old people within the older population is also set to rise. Over the next 50 years, older adults will age rapidly, as the age group that will expand most dramatically corresponds to those aged 75 and over (see figure II.11). The growth rate of the population aged 75 and over is expected to remain above that of the population aged 60 and over during the period 1950-2050 (see figure II.11). In 2025 , this age group is expected to have doubled to represent $4 \%$ of the population, before expanding to almost $9 \%$ of the total in 2050 .

Data from the two most recent census rounds in some of the region's countries do not show a clear trend in the pace of ageing among the older population. Even so, 10 of the 12 countries analysed have seen increases in the proportion of people aged 75 and over compared to those aged between 60 and 74 . In the 1990 round of censuses, Brazil was the country with the smallest proportion of people aged 75 and over among the older population $(22.3 \%)$, while Mexico had the highest percentage (33.9\%). In the first decade of the twenty-first century, Brazil continued to have the lowest proportion (24.6\%), with Ecuador now laying claim to the highest percentage (33.9\%) (see figure II.12). The lack of clarity in terms of ageing within the older population seems to be explained by the incorporation of larger cohorts than in the past during the period between the two census rounds (1990-2000). This affects the demographic dynamics within the older population and may even give rise to relative rejuvenation, as in the case of Mexico.

Ageing within the population aged 60 and over may increase the need for medical, institutional and family support. It is therefore necessary that policies targeting this age group take into account the change in the age structures within the older adult population. 
Figure II.11

LATIN AMERICA AND THE CARIBBEAN: PERCENTAGE AND GROWTH RATE OF THE POPULATION AGED 60 AND OVER AND THOSE AGED 75 AND OVER, AND DISTRIBUTION OF THE OLDER POPULATION BY MAJOR AGE GROUPS, 1950-2050
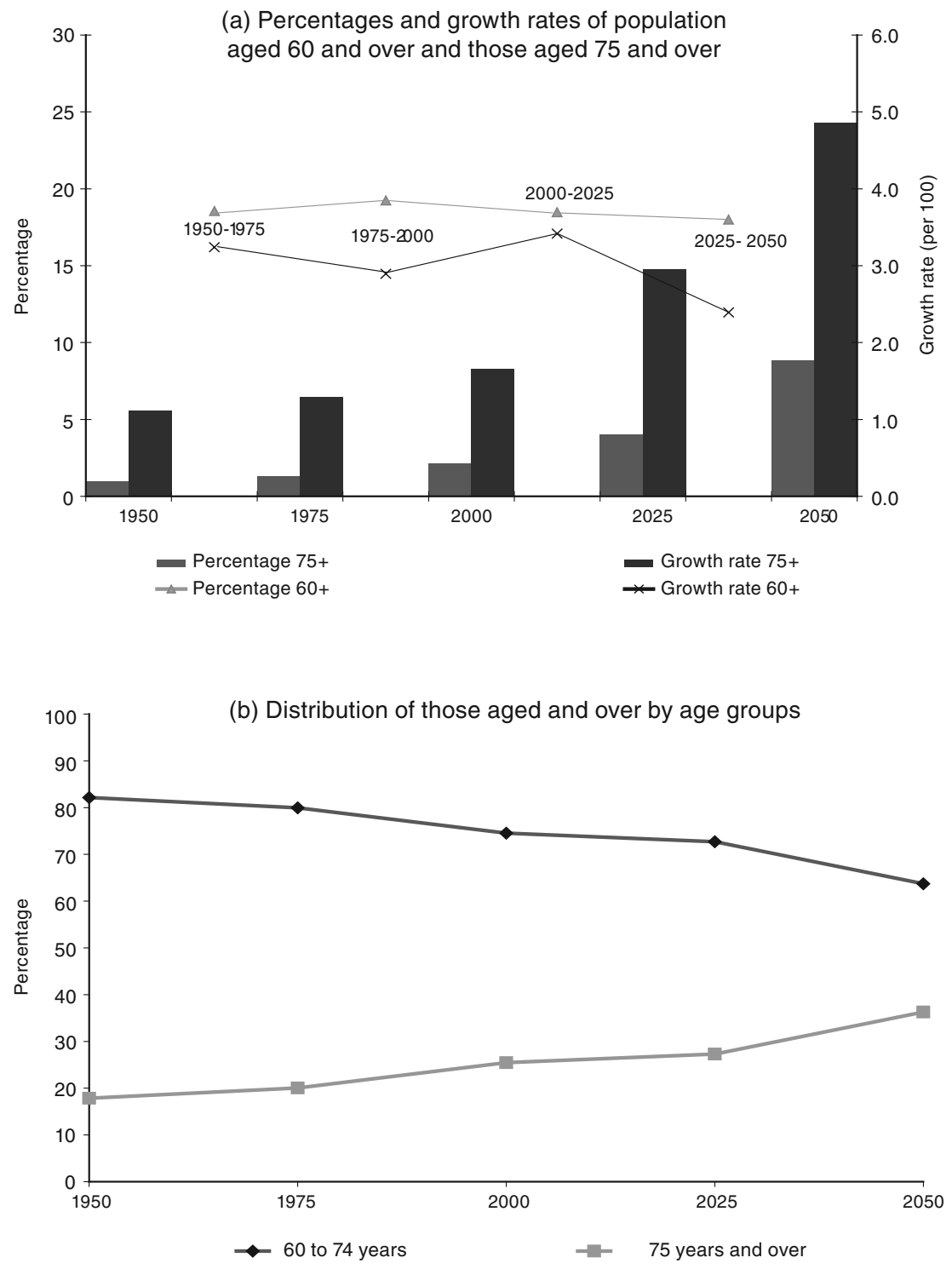

Source: Latin American and Caribbean Demographic Centre (CELADE) - Population Division of ECLAC, population estimates and projections [online] www.eclac.cl/celade/proyecciones/basedatos_BD.htm. 
Figure II.12

LATIN AMERICA AND THE CARIBBEAN (SELECTED COUNTRIES): PERCENTAGE OF POPULATION AGED 75 AND OVER AS A PROPORTION OF TOTAL OLDER

PERSONS, BY STAGE OF AGEING, CENSUSES OF 1990 AND 2000

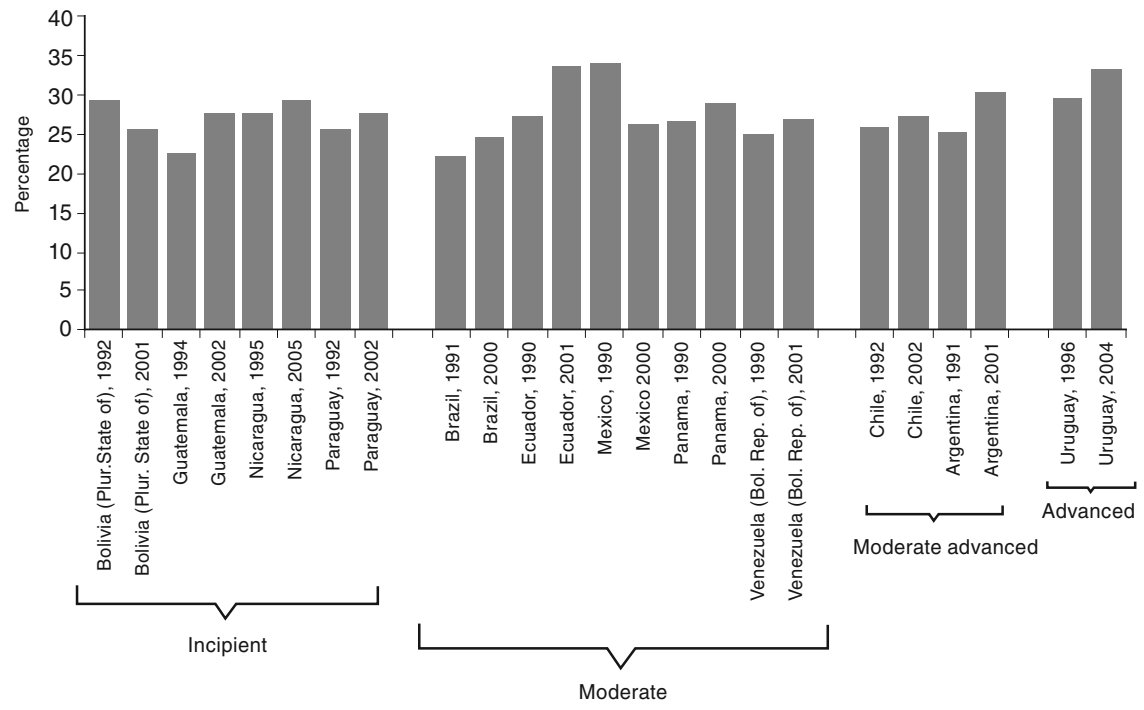

Source: Latin American and Caribbean Demographic Centre (CELADE) - Population Division of ECLAC, population estimates and projections [online] www.eclac.cl/celade/proyecciones/basedatos_BD.htm.

\section{Gender differences in the composition of the older population}

In Latin America, there are currently 121 women for every 100 men in the population aged 60 and over. Women tend to be even more predominant in countries with a greater life expectancy at the age of 60, combined with the fact that the gap between men and women gets wider as the population ages. According to the 2000 round of censuses, Uruguay, Argentina and Chile have the highest proportion of women in this age group (between 130 and 140 women for every 100 men). Panama and Guatemala, on the other hand, have the lowest proportion of women in this age group, although they still outnumber men (see figure II.13). There are also gender differences based on the area of residence of older adults: there are more women in urban areas and more men in rural areas (where there were fewer than 100 women for every 100 men in almost every country analysed) (see figure II.13). This may be due to the fact that cities have been more attractive to women for some time. The rural-to-urban migration of the past had a large female component, thereby increasing the proportion of women in cities. 
Figure II.13

LATIN AMERICA AND THE CARIBBEAN (SELECTED COUNTRIES): FEMININITY INDEX OF THE POPULATION AGED 60 AND OVER, NATIONWIDE, URBAN AND RURAL TOTALS, 2000 ROUND OF CENSUSES
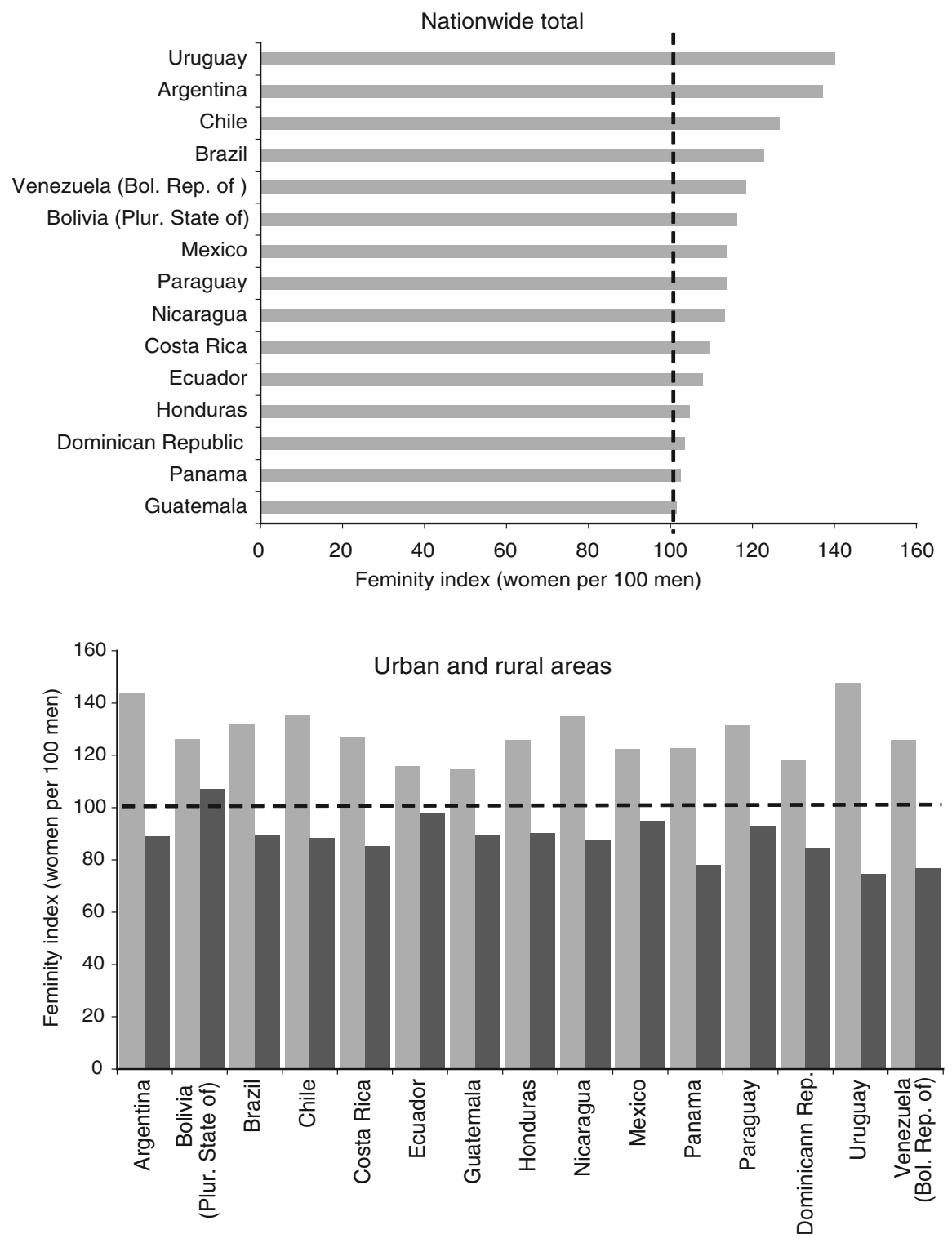

Urban

Rural

Source: Latin American and Caribbean Demographic Centre (CELADE) - Population Division of ECLAC, on the basis of census microdata from the relevant countries. 
The predominance of women is directly related to the fact that women tend to have greater life expectancy at the age of 60 . In the past, men and women would have a similar number of years remaining at the age of 60. However, the decline in mortality (particularly maternal mortality) and increase in life expectancy widened the gap between men and women. This difference is not the same in all the region's countries. According to estimates and projections for the period 2000-2005, Uruguay and Argentina have the widest gap (with women living on average five years longer than men from the age of 60 to reach 83 years). In Guatemala, on the other hand, there is no difference between men and women (with both sexes living for 19.8 years from the age of 60), while in Haiti older women only live an average of one year longer than men. Although this difference will continue over the next few decades, there is no single identifiable trend in the region, as some countries will see the gap widen even more while in others the discrepancy could become less apparent (see table II.1).

It is vital to explicitly consider the gender dimension in population ageing, as older women in developing countries are particularly affected by this process. Women's situation in old age is aggravated by a lifetime of inequality and social exclusion. Women's longer life expectancy implies that a high percentage will be living as widows, which is often associated with loneliness and abandonment. Older women tend to have fewer years of schooling, receive lower incomes than men during their working lives and reach old age economically and socially disadvantaged. Nonetheless, many older women continue to play an important role in the family (as heads of household or raising dependent minors) and, even when very old, are the only source of caregiving in the event of illness or disability in most countries.

\section{The urbanization of ageing and ageing in the countryside}

Population ageing manifests itself differently depending on the territory. Each country's ageing process is unique because of the stage reached in terms of demographic transition. These distinctions tend to be stylized, as the fact that the process occurred earlier in industrialized countries resulted in more advanced ageing. International migration patterns certainly influence the differences in ageing between countries, especially in terms of the process in industrialized countries being weakened by waves of young immigrants from developing countries. Nevertheless, the effect of international migration on ageing has been secondary in comparison with the effect of demographic transition, and the former may be a temporary effect as migrants will eventually age too. 
The differences in the ageing process are often expected to be as apparent within countries as among them, such that areas with more advanced socio-economic development and demographic transition should show higher levels of ageing. Given the well-known socio-economic and demographic differences between urban and rural areas, the former are expected to have a larger proportion of people aged 60 and over than the latter. However, this is not always the case, given the powerful effects of internal migration (especially from rural to urban areas).

In industrialized countries, internal migration tends to be extremely selective and different according to life cycle. Cities, which have become areas of net emigration due to outflows towards suburbs and the countryside, become home to young people seeking educational, employment and leisure opportunities, while the countryside attracts certain kinds of families and especially older people. The net result of these patterns is that ageing is more marked in rural areas. ${ }^{3}$ According to data from the Statistical Office of the European Communities (EUROSTAT), almost $15 \%$ of the population in the 25 European Union countries were aged 65 or over at the beginning of the twenty-first century. In cities in general, this percentage is around $14 \%$, with the proportion being nearer to $13 \%$ in cities with a population of 500,000 or more (see figure II.14). However, there are some European countries where the largest cities have the highest ageing indices (see figures for Spain and Italy in table A.3 of the annex). The predominant effect nonetheless remains that three of the main European countries (Germany, the United Kingdom and France) all feature the above-mentioned pattern of lower levels of ageing in cities (see table A.3 of the annex).

In Latin America and the Caribbean, the striking unevenness in the demographic transition between urban and rural areas has resulted in a more intense ageing process in the former. However, this phenomenon is less defined due to the effect of internal migration, in particular rural-tourban flows. Even though rural-to-urban migration is not the main form of migration in the region (as flows between cities also take place on a large scale), there is nonetheless more migration into than out of cities, which results in a net transfer of population from the countryside.

As this migrant population tends to be mainly women of working age, the result is premature ageing in rural areas (strictly speaking, there is a much higher dependency ratio than there would be in the absence of rural-to-urban migration) and a dramatic expansion of intermediate age groups and an overrepresentation of women in cities (CELADE, 2003). This does not mean that urban areas have a lower level of ageing than

3 Presentation by professor Paul Gans, at the International Seminar "Migration and Development: The Case of Latin America", Santiago, Chile, 7 and 8 August 2007. 
rural areas. Indeed, figure II.15 shows that urban ageing is similar to the nationwide total and is expected to remain at similar levels up to 2050. The much more advanced stage of demographic transition in urban areas should result in a higher proportion of older adults. However, this is not the case because of the inflows of young people into the city from the countryside.

Figure II.14

EUROPEAN UNION: PERCENTAGE OF POPULATION AGED 65 AND OVER, NATIONWIDE TOTAL AND THREE TYPES OF CITY BY SIZE

(Percentages)

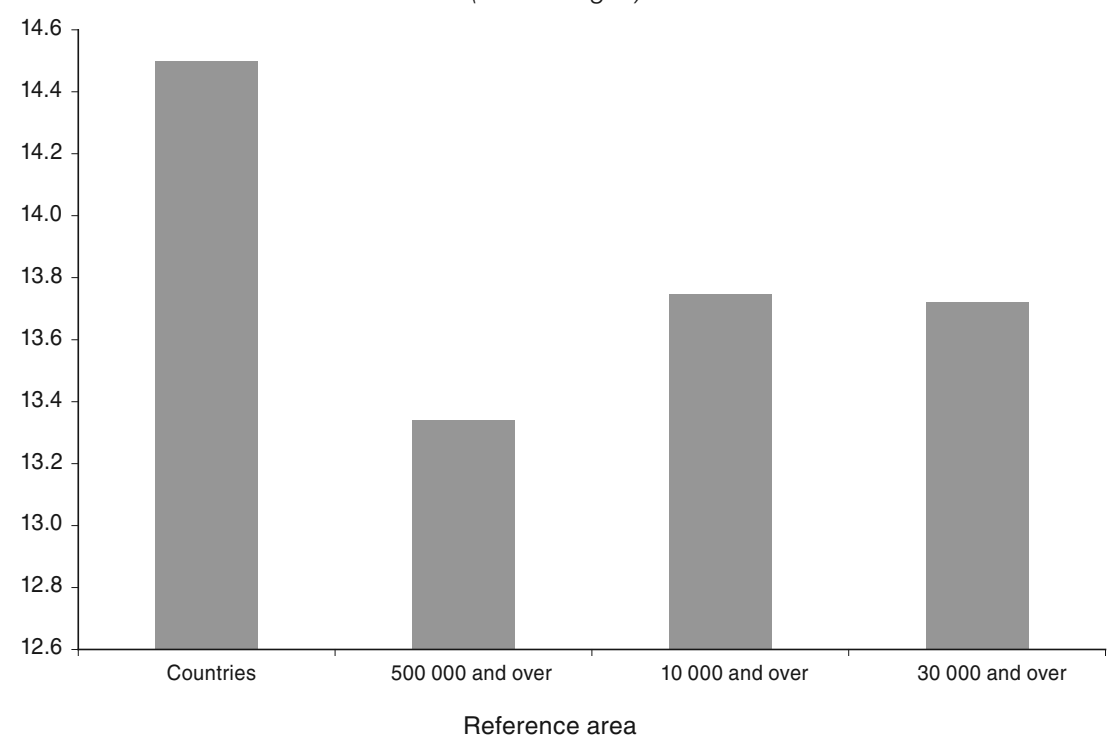

Source: Latin American and Caribbean Demographic Centre (CELADE) - Population Division of ECLAC, on the basis of information from the Statistical Office of the European Communities (EUROSTAT) [online] http://epp.eurostat.ec.europa.eu.

Because women have constituted a majority of the internal migrants in Latin America and the Caribbean (Rodríguez, 2004), there are major differences between urban and rural ageing in terms of men and women. While the ageing index has been systematically higher among men in rural areas (an estimated 23\% of the rural male population will be aged 60 or over by 2050 , compared with $21 \%$ in urban areas), the opposite is true for older women, who will represent $26 \%$ of the population in cities and $23 \%$ in rural areas by 2050 (see figure II.15). 
Figure II.15

LATIN AMERICA AND THE CARIBBEAN: PERCENTAGE OF POPULATION AGED 60 AND OVER, BY AREA OF RESIDENCE AND SEX

(Percentages)

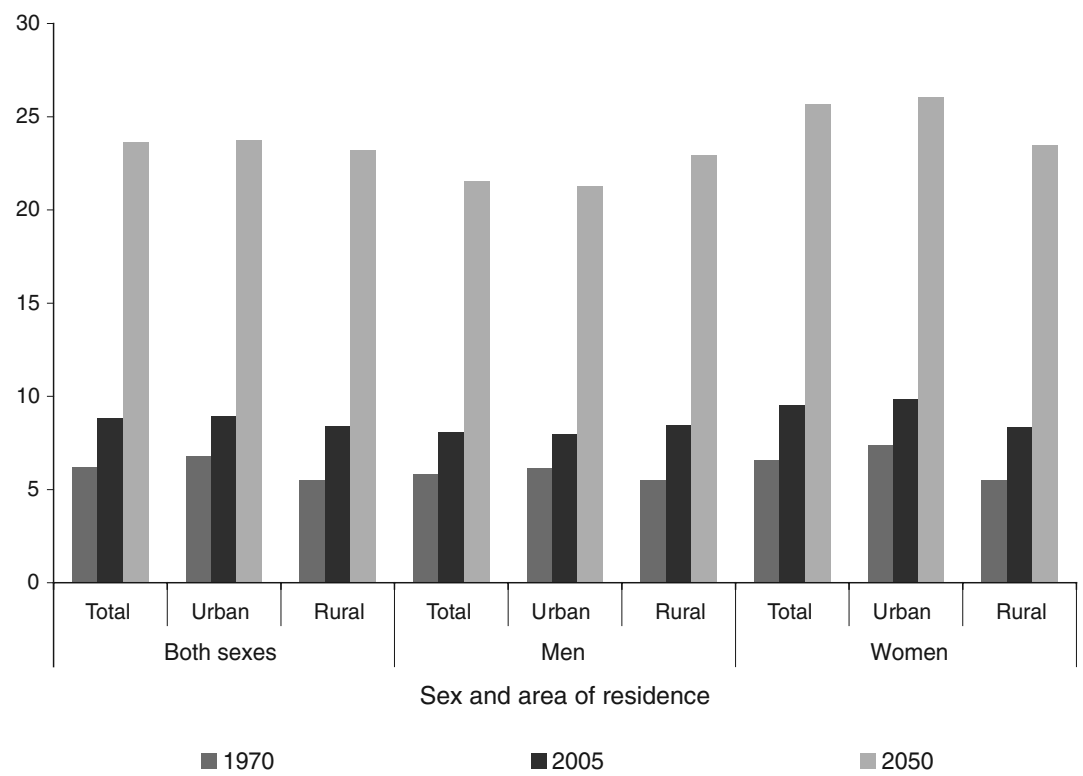

Source: Latin American and Caribbean Demographic Centre (CELADE) - Population Division of ECLAC, population estimates and projections [online] www.eclac.cl/celade/proyecciones/basedatos_BD.htm.

The premature ageing of the population in the Latin American countryside is the result of very different factors than those at work in the European Union. In European countries, rural ageing is a result of the migration of older people who prefer to live in the countryside (particularly middle- and high-income retired people seeking a better standard of living in rural settings that tend to be well served and connected). In Latin America, on the other hand, rural ageing is the result of strong push factors that drive young people out of the countryside (Guzmán and others, 2006 and 2007; CELADE, 2003). In other words, rural ageing in Latin America is the result of the countryside being abandoned rather than selected as a lifestyle choice.

Early ageing in the countryside does not alter the long-term trend of urbanization among all age groups. According to figure II.16, the percentage of older people in the region living in urban locations rose significantly between 1970 and 2005 from $60 \%$ to $80 \%$ (77\% among men and $81 \%$ among women), with the figure expected to reach $85 \%$ by 2050 ( $83 \%$ for men and $86 \%$ for women). 
Figure II.16

LATIN AMERICA AND THE CARIBBEAN: PERCENTAGE OF THE TOTAL POPULATION AGED 60 AND ABOVE LIVING IN URBAN AREAS, BY SEX, 1970, 2005 AND 2050

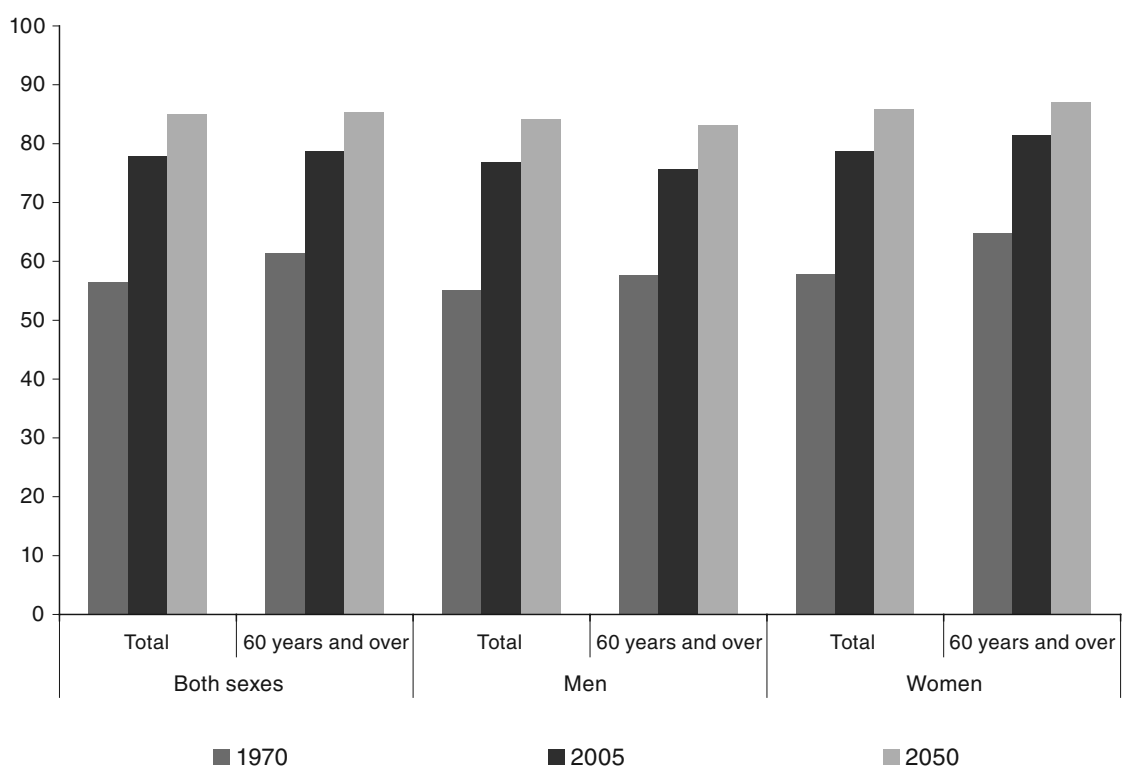

Source: Latin American and Caribbean Demographic Centre (CELADE) - Population Division of ECLAC, population estimates and projections [online] www.eclac.cl/celade/proyecciones/basedatos_BD.htm.

The region will therefore have two territorial features of ageing: a predominance of urban locations among older adults (which will influence their living conditions and requirements) and premature ageing in the countryside (which will impact on the development and needs of rural areas). The regional situation obviously differs from country to country, as some have an older rural than urban population (Chile, Ecuador, Mexico, Panama and the Plurinational State of Bolivia), while others have a similar level of ageing in urban and rural areas (Honduras, Paraguay and the Bolivarian Republic of Venezuela) and yet others have an older urban than rural population (Argentina, Brazil, Costa Rica and Guatemala) (see table A.4 of the annex). This lack of uniformity can also be observed in cities, some of which have levels of ageing higher than the nationwide average (Greater Buenos Aires, Rio de Janeiro, San José and Guatemala City), while other cities have below average levels of ageing (São Paulo, Quito and Panama City). 
Box II.1

POPULATION AGEING AND INDIGENOUS POPULATIONS

Except in the case of Chile, indigenous peoples have a young or very young demographic profile with high fertility and mortality levels (ECLAC, 2007b). This applies even in countries with more or less advanced levels of population ageing. Within the relative "youthfulness" of indigenous age structures, there are four types that range from the "youngest" to the "most mature" or "aged":

(i) Group 1. "Very young" structure with a "very wide" base: Panama, Paraguay, Guatemala and Honduras. These coexist with less youthful nonindigenous populations, with the non-indigenous population in Panama being distinctly "mature".

(ii) Group 2. "Young" structure with a "wide" base: Costa Rica, Ecuador, Mexico and the Plurinational State of Bolivia. All three countries have "mature" non-indigenous populations typical of an advanced stage of demographic transition except the Plurinational State of Bolivia, where the non-indigenous population remains young.

(iii) Group 3. "Mature" structure with a "stable" base: Brazil. The indigenous population combines with a non-indigenous population that is also "mature" but with a narrowing base.

(iv) Group 4. "Aged" structure with a "narrowing" base: Chile. The indigenous population structure is similar to that of the non-indigenous population, which results in an age pyramid that is somewhat rectangular.

Examining the age structures of indigenous populations in relation to data concerning specific peoples shows that there is a range of situations in each country. The figure below demonstrates that some peoples, such as the Ngöbe in Panama and the Q'eqchi in Guatemala, follow the general pattern of a younger structure. In these countries, there are also peoples with less youthful structures, such as the Kuna and the K'iche, whose fertility is reportedly lower.

The age structure of the indigenous peoples is reflected also in two other indicators: the ageing index and the potential dependency ratio.a While in Costa Rica, Guatemala, Honduras, Panama and Paraguay there are approximately 10 indigenous persons of 60 years of age or older per 100 young indigenous persons under the age of 15 , in the case of non-indigenous peoples, this index ranges from 14 to 30 older adults per 100 children and young people. In Ecuador, Mexico and the Plurinational State of Bolivia, the index for the indigenous population is approximately $20 \%$. Chile presents the maximum (37\%) and is the country with the highest percentage of older indigenous persons $(9.8 \%)$.

In terms of demographic interpretations and their policy implications, it is interesting to note that for indigenous peoples, old age does not have negative connotations but is associated rather with cultural continuity. A person's status and role in society may be enhanced with age, since it is considered that older persons are founts of wisdom and collective memory, which must be transmitted to the young people to ensure that the culture of the group or people is carried on (Huenchuan, 2006). Whether and to what extent these conceptions are maintained must be determined, however, by the territorial, cultural and demographic realities of each people. 
Box II.1 (continued)

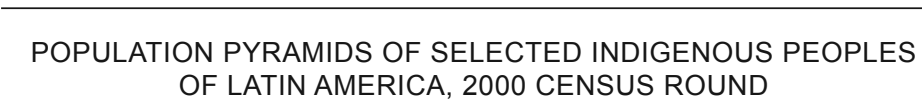

\section{Guatemala}

K'iche people

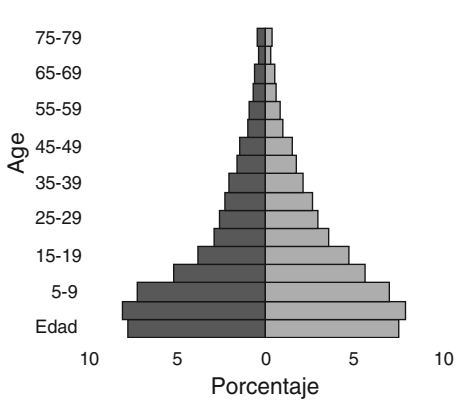

\section{Q'eqchi people}

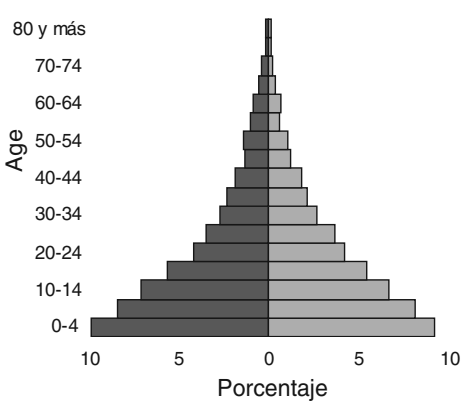

Panama
Ngöbe people

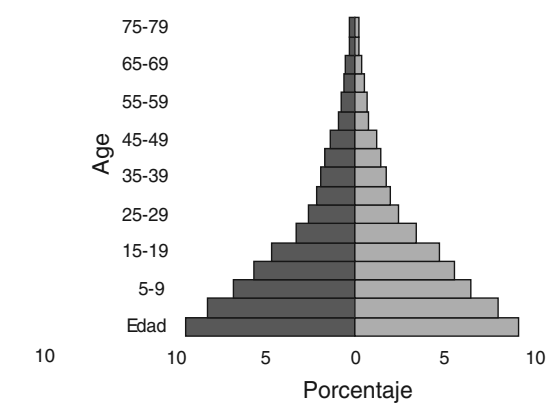

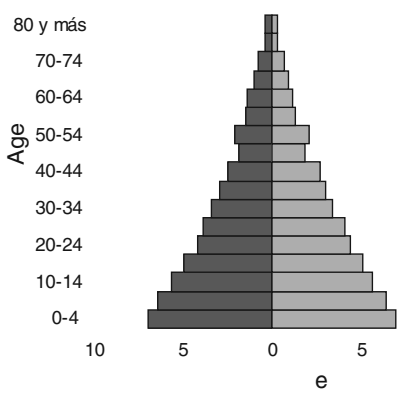

Source: Economic Commission for Latin America and the Caribbean (ECLAC), Social Panorama of Latin America 2006 (LC/G.2326-P), Santiago, Chile, 2007. United Nations publication, Sales No. E.06.II.G.133.

For example, a case study of the Zoque people in Chiapas (Mexico) shows how the force of modernity, combined with poverty and marginalization, has eroded the social status and respect shown towards the elderly, which results in a loss of traditional roles and the appreciation they once commanded and affects their living conditions (Reyes Gómez, 2002).

From the point of view of economics, any interpretations of the dependency ratio must be placed in their sociocultural and territorial context as, to a greater or lesser extent, indigenous peoples live in subsistence economies, in which each family member has a specific task to perform (Descola, 1986). 
In short, while the fast pace of ageing in the region is the most significant demographic phenomenon of the current century, for the indigenous population the challenges are still centred on the population of children and young people. This means that States must consider setting differential priorities in public policies, not only in terms of the allocation of resources to expand education and health-care coverage, but also, in terms of measures whose content, management and administration are relevant for the indigenous peoples themselves (ECLAC, 2007b).

Source: Latin American and Caribbean Demographic Centre (CELADE) - Population Division of ECLAC, on the basis of Social Panorama of Latin America 2006 (LC/G.2326-P), Santiago, Chile, 2007. United Nations publication, Sales No. E.06.II.G.133.

${ }^{a}$ Refers to the number of children aged 0 to 14 and the number of people aged 60 and over for every 100 adults aged 15 to 59 .

\section{Dependency ratio and demographic bonus in Latin America and the Caribbean: an opportunity and challenge}

The total dependency ratio is a synthetic index of the population's age structure (CELADE, 2006a), that facilitates an analysis of the effects of ageing on the generation structure, in the light of the ratio between those who are most likely to be dependent (older adults and children) and the working-age population (see table A.5 of the annex). However, any analysis and interpretation should be carefully carried out, as both young and aged populations present high demographic dependency indices. In the first instance, this index falls with declining fertility, which reduces the proportion of children before a steady rise in the older adult population (see figure II.17).

At different times, in accordance with each country's stage of demographic transition, the dependency ratio rises again (see table A.5 of the annex). To differentiate if the greater economic burden is represented by children or older adults, the children's dependency ratio (also called the youth ratio) can be differentiated from the old age ratio. The old age ratio is used to measure the older population's potential need for social support from the working-age population. As shown in figure II.17, an increase in the dependency ratio in the region is increasingly determined by the proportion of those aged 60 and over, which has greater repercussions in terms of economic costs than those involved in youth dependency. This is mainly due to health care and social security requirements. 
Figure II.17

LATIN AMERICA: TOTAL DEPENDENCY RATIO FOR CHILDREN UNDER 15 AND

ADULTS AGED 60 AND OVER, 1950-2100

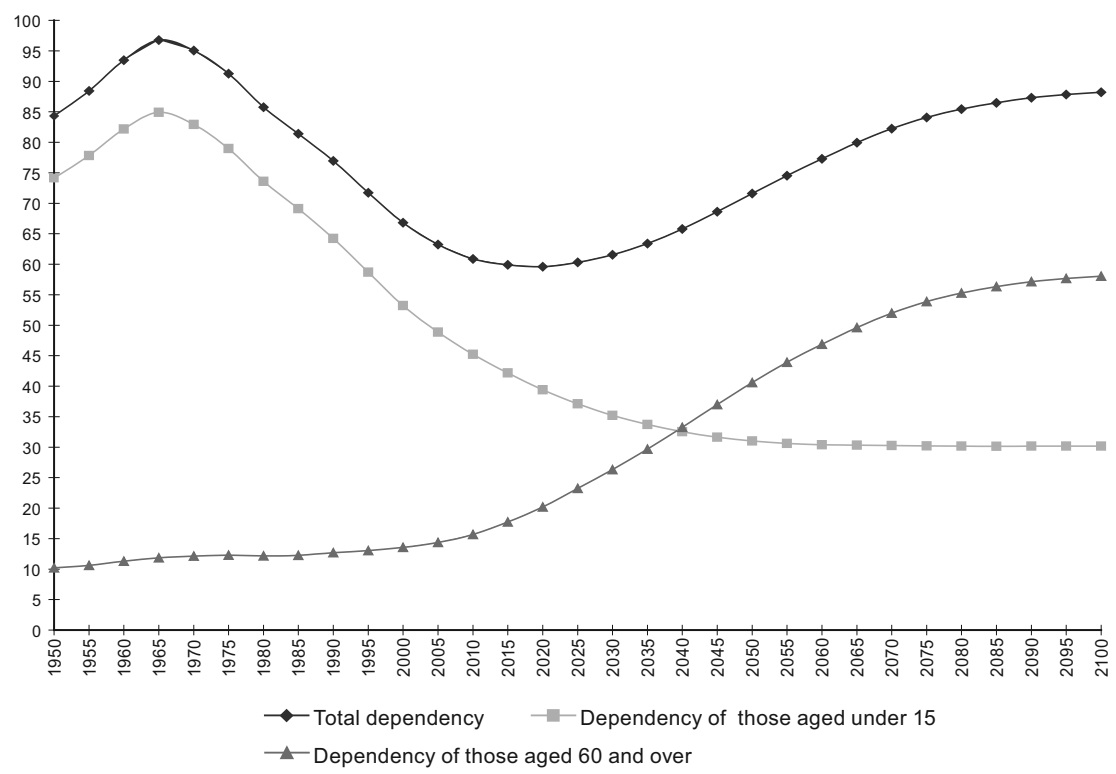

Source: Latin American and Caribbean Demographic Centre (CELADE) - Population Division of ECLAC, Demographic Observatory: Population Projection, No. 3 (LC/G.2348-P), Santiago, Chile, 2007. United Nations publication, Sales No. E/S.07.II.G.121; and population projections and estimates [online] www. eclac.cl/celade_proyecciones/basedatos_BD.htm.

Population projections for Latin America made by CELADE clearly show that as of 2025 the total dependency ratio will begin to increase and that the number of older adults will surpass the number of children under 15 in 2040 (see figure II.17). There are, however, differences among countries in the region, with respect to when these changes will occur, since different countries are at different stages of population transition. In the case of Cuba, which is at a very advanced stage of the transition of population ageing, the dependence ratio of older adults will begin to surpass children under 15 in 2010, 30 years before it occurs region-wide.

On the other hand, countries that are beginning the transition and are at an early or moderate stage of ageing (for example, El Salvador and Belize) will undergo these changes ten years later than the rest of the region (approximately in 2050). In other countries like Guatemala, Haiti and the Plurinational State of Bolivia (and to a lesser degree French Guiana, Honduras and Paraguay) the number of children will continue to 
be significantly higher than the number of older adults until after the first half of this century.

Thus, countries further along in the ageing process have different challenges than those at an earlier stage. The former must adapt to changes in the age structure of their populations now, while the latter must create the conditions necessary to address the rapid ageing of their populations in the future.

At the beginning of demographic transition, the high growth rate of children aged 0 to 14 years resulted in a high dependency ratio in the region, which placed demands on health systems, especial in terms of maternal and infant health care and education (see figure II.18). Progress in the demographic transition process combined with low fertility to reduce the total dependency ratio to below 60 people under the age of 15 and older people aged 60 and over for every 100 people aged 15 to 59 . The change has been particularly striking in countries at a more advanced stage of transition (Uruguay, Cuba, Argentina and Chile). Currently, higher absolute population growth can be seen in those aged 15 to 59, who constitute the demographic group in the most productive stage of their lives (see figure II.18). Given that total dependency ratios will tend to fall during a given time, most of the region's countries will be able to take advantage of the opportunities provided by this demographic bonus to extend their productive potential and prepare for the final stage of demographic transition characterized by a relative increase in the older adult population.

Reduced pressure from the demands of the child population (which initially occurs in the absence of a striking rise in the number of older people) forms the basis for the demographic bonus and offers the chance to carry out productive investments, increase social investment in combating poverty, improve the quality of education and promote health reforms. This would also help to anticipate the measures needed to tackle the increase in the older adult population, whose demands will be more costly. The demographic bonus is also referred to as a "window of opportunity" for capitalizing upon the initial effect of the drop in fertility, since this is when the age structure of the population offers the most advantageous conditions. This is because the dependency rate during this stage is low, as the proportion of children and adolescents has declined but the proportion of the population represented by older age groups has not yet risen significantly (ECLAC, 2004).

However, in order to benefit from this temporary demographic bonus or dividend, measures must be implemented to raise the skills of human resources by systematically improving the quality of education and employment training. There must also be an increase in the capacity of productive sectors to ensure that these resources are used effectively. 
Figure II.18

LATIN AMERICA AND THE CARIBBEAN: ABSOLUTE ESTIMATED AND PROJECTED POPULATION GROWTH BY DECADE AND AGE GROUPS, SELECTED PERIODS

(Thousands)

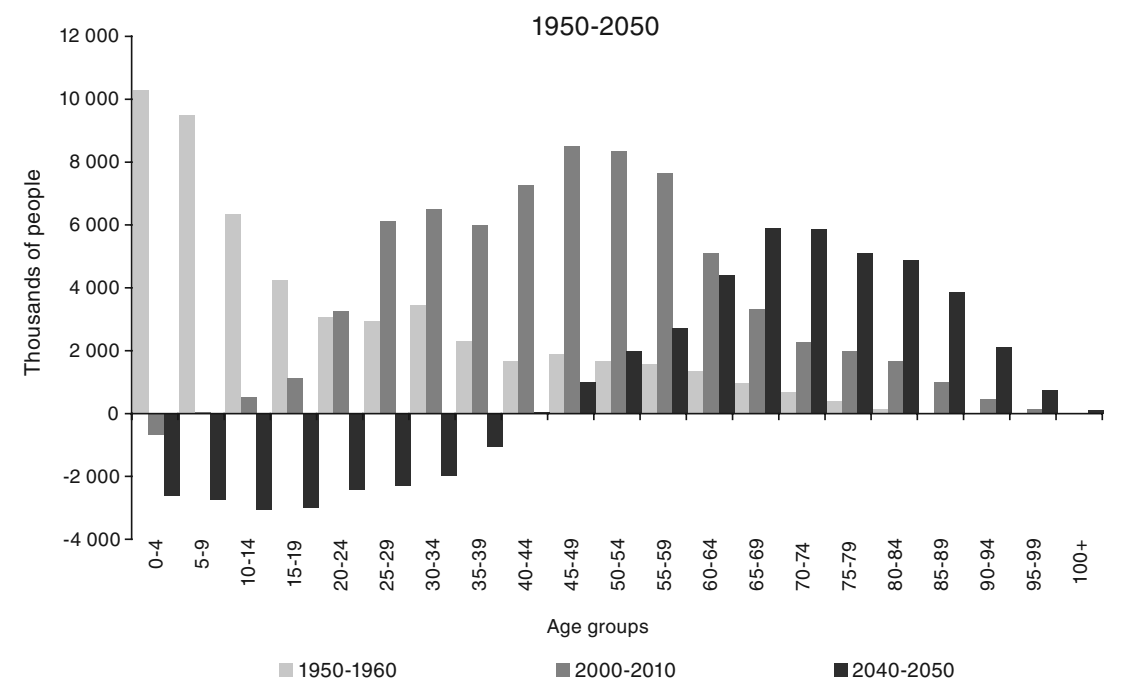

$2000-2010$

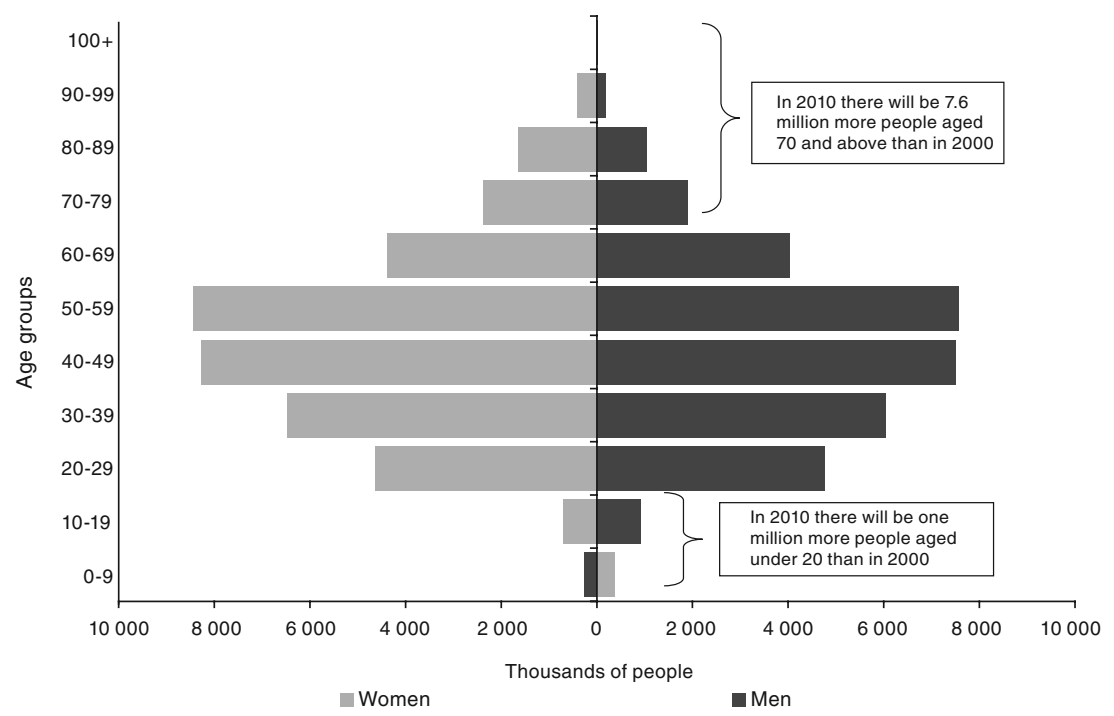

Source: Latin American and Caribbean Demographic Centre (CELADE) - Population Division of ECLAC, on the basis of United Nations, World Population Prospects: The 2006 Revision, New York, 2006. 
Not all of the benefits of this bonus are guaranteed, as they depend partly on the capacity of the region's economies to generate employment while the window exists. Otherwise, the bonus will simply represent an additional burden for the countries, in the form of strong pressure from the population seeking employment in a context of limited growth of work (Villa, 2003).

The demographic bonus ends as the dependency ratio rises, it is therefore limited in time. As fertility continues to fall and life expectancy rises, the proportion of older adults increases. This in turn pushes up the dependency ratio once again, which generates more demands in terms of health care and economic security. It is therefore vital to take advantage of the demographic bonus and prepare for the huge challenges of population ageing for the region's governments and for civil society, families and the older adults themselves (who have a major role to play in the process). Promoting solidarity pension financing; increasing health care services for older people with trained personnel, appropriate infrastructure and an emphasis on preventive care; and providing support mechanisms for families with elderly members - these are some of the areas that must be incorporated into the region's public policies (Jaspers, 2007). 


\section{Chapter III \\ Income protection and ageing in Latin America and the Caribbean}

The entitlement and guarantee of rights to lifelong income security are issues still pending on the social agendas of most Latin American and Caribbean countries and economic uncertainty continues to dominate the day-to-day lives of much of the region's population.

While social protection should play a key role in reversing this situation, the imbalances between social protection systems and the realities which they are meant to address have worsened in recent decades. As a result, protection is unequal and the risks of illness, unemployment, disability and old age lead to a reduction in or loss of economic income for satisfying basic needs, which any society should guarantee as a fundamental right.

The demographic, social and economic bases on which social protection systems were founded have changed. As a corollary, with the exception of a handful of countries, the main problem in the region is low benefit coverage. In the specific case of transfers from the social security system, more than half of the older adult population has no access to retirement or other pensions to mitigate the risks arising from loss of income in old age. This is because social security schemes have been heavily contributions-oriented, which excludes a large segment of the population, mostly women, peasants, informal workers and migrants. In general, these groups end up without sufficient guaranteed economic income in old age despite their lifelong social contribution to society, increasing their need to obtain income from employment. 
Even so, there is still less poverty in households with older members than in any other type of living arrangement because, despite the poor coverage of retirement and pension systems, they are still the most important policy instruments for alleviating poverty and vulnerability in old age. At the same time, they contribute to the welfare of other generations.

Ideally, social protection systems should ensure income security during old age for all, and they need to provide benefits that place recipients above the socially acceptable minimum living standards (United Nations, 2007b). However, the way in which social protection systems operate at present means that only people who began accumulating pension entitlements from an early stage in their career have a good chance of escaping poverty in old age (ILO, 2002b). These unprecedented demographic changes facing Latin American and Caribbean countries call for new thinking regarding the formulation and implementation of income protection policies. This new thinking requires that we view ageing as a lifelong and society-wide phenomenon.

ECLAC believes that in order to build a more solidarity-based system of social protection, means must be sought to strengthen the capacity of national economies for creating decent work for the entire economically-active population, and to turn labour markets into a gateway to social protection. In addition, ECLAC proposes that employment-based protection should be supplemented with non-contributory solidaritybased mechanisms (ECLAC, 2006). The challenge, therefore, is to develop a concept of social rights that not only includes but also transcends the labour market (Abramovich and Courtis, 2006).

This chapter examines the information available in the region on income generation in old age and analyses the influence of biographical, generational and protection-system factors. It also describes the measures which Latin American and Caribbean countries are taking to improve the economic conditions of older persons, in the light of the recommendations of the Regional Strategy on Ageing in Latin America and the Caribbean. One of the main conclusions of this review is that the economic status of older persons is gradually being included in government agendas. However, the challenge of raising social protection thresholds remains. A rights-based analysis reveals that the challenges are even more demanding because current actions should be guided by two basic human rights principles: universality and solidarity. 


\section{A. Income and poverty in old age: regional trends}

\section{Income composition and economic strategies in old age}

Economic participation, social security and family support are the main sources of income in old age (Guzmán, 2002a). The relative importance of each mechanism varies from one country to another depending on level of economic and institutional development, labour market characteristics and phase of demographic transition.

In developed countries with more evolved social security systems, a large proportion of older persons obtain their income solely from retirement or other pensions, and, as people get older, employment income becomes less important. In Latin America and the Caribbean, however, the economic strategies of today's older generation are different. In a context of low retirement or other pension coverage, labour-force participation of older persons increases and, when they receive no income of any kind, family support is vital (Huenchuan and Guzmán, 2007).

Figure III.1 shows the percentage of older persons living in urban areas and receiving income from two of the most important income sources in old age: retirement or other pensions and employment income. In a number of countries there was an increase in the percentage of older persons receiving income solely from retirement or other pensions in 2005 (Colombia, Ecuador, El Salvador, Honduras, Mexico, Panama and Paraguay). However, with the exception of two countries (El Salvador and Uruguay), the increase was less than five percentage points.

In the same year, there was a decline in the percentage of older persons receiving only employment income and in those receiving both types of income, although countries did not all follow the same pattern. For example, between 1997 and 2002, in the Bolivarian Republic of Venezuela there was a 20 percentage point increase in the number of older persons receiving a combination of retirement or other pension income and employment income. At the same time, the percentage of those receiving only social security income fell.

Furthermore, data from thirteen countries in the region shows that the percentage of older persons receiving no income at all fell slightly in the latest year for which figures are available, although it is still the largest of all the groups analysed. An average of $43 \%$ of older persons received no income of any kind in 1997, a figure which increased slightly in 2002, before falling to $39 \%$ in the latest year analysed. The averages mask differences, and a glance at countries with weak social security systems reveals that the percentage of older persons with no income at all ranged 
from $40 \%$ to $66 \%$ in 2005 . Not only does this population segment suffer acute economic vulnerability, it is also prey to the risks associated with poor health, disability and declining social support networks.

Figure III.1

LATIN AMERICA AND THE CARIBBEAN (SELECTED COUNTRIES): SOURCES OF INCOME FOR OLDER PERSONS LIVING IN URBAN AREAS,

AROUND 1997, 2002 AND 2005

(Percentages)

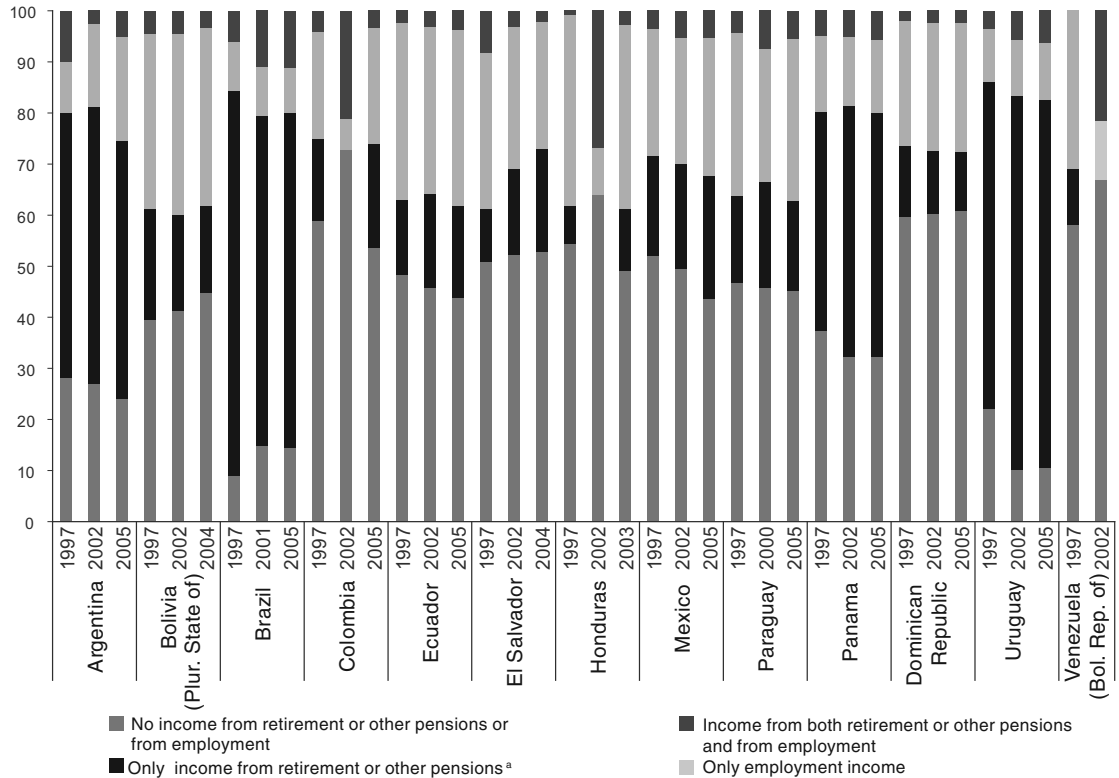

Source: Economic Commission for Latin America and the Caribbean (ECLAC), on the basis of data from household surveys conducted in the relevant countries.

a Income from retirement or other pensions corresponds to total income transfers to people in the variable "active population" category declaring themselves to be "persons receiving retirement or other pensions".

\section{Poverty in households with older members and protection against risks}

The latest poverty and indigence figures available show significant progress in terms of both poverty alleviation in households with older persons and protection against risks in old age. Having remained broadly unchanged between 1997 and 2002, the proportion of people living in poverty and indigence fell in 2005 in most countries in the region (ECLAC, 
2007b). Echoing this trend, the incidence of poverty in households with older members also declined.

In 2005, both urban and rural households with older members continued to be less poor than households without older members, although the gap between the two types of household varies widely from country to country. In Brazil and the Plurinational State of Bolivia, the incidence of poverty in urban households with no older members is more than 10 percentage points greater than in households with older members; these differences increase by more than 35 percentage points in rural areas of Brazil. By contrast, in Costa Rica, Dominican Republic, El Salvador and Honduras, poverty is greater in households with older members and, with the exception of a couple of countries, the differences between the two types of household are fairly small (see figures III.2 and III.3).
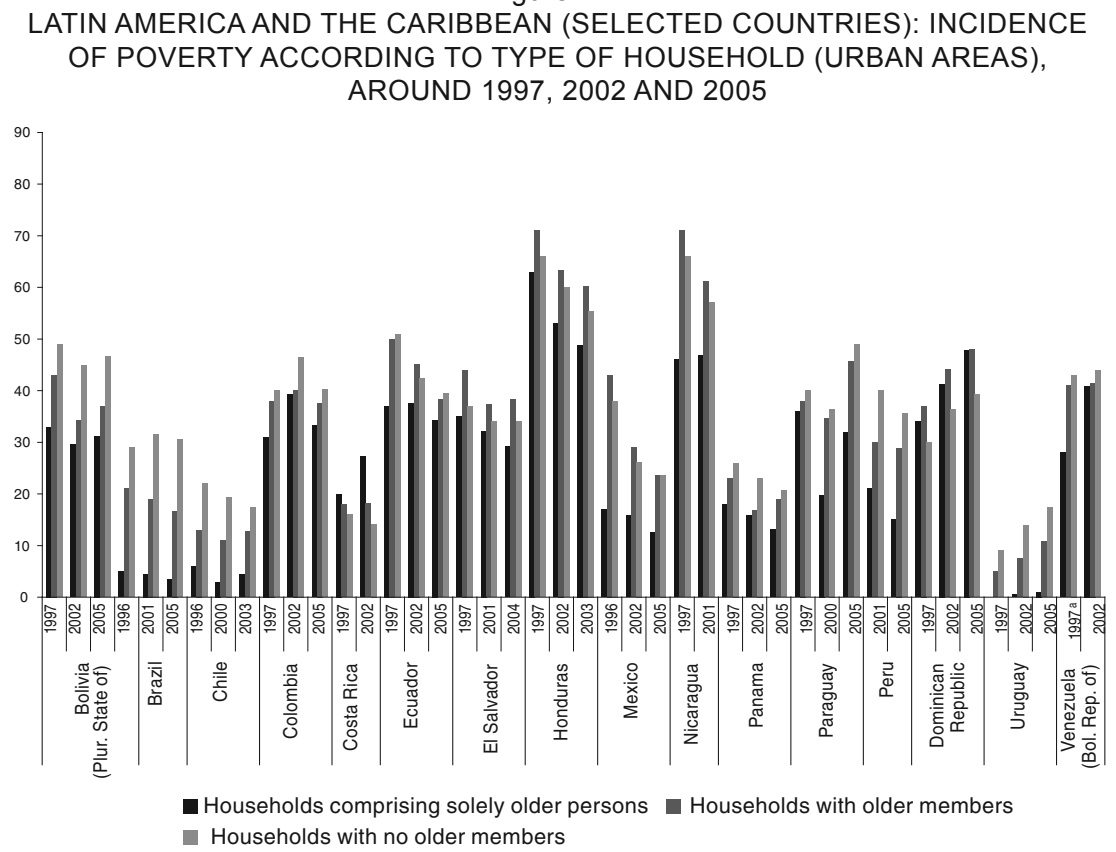

Source: Economic Commission for Latin America and the Caribbean (ECLAC), on the basis of data from household surveys conducted in the relevant countries.

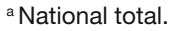


Figure III.3

LATIN AMERICA AND THE CARIBBEAN (SELECTED COUNTRIES): INCIDENCE OF POVERTY ACCORDING TO TYPE OF HOUSEHOLD (RURAL AREAS),

AROUND 1997, 2002 AND 2005

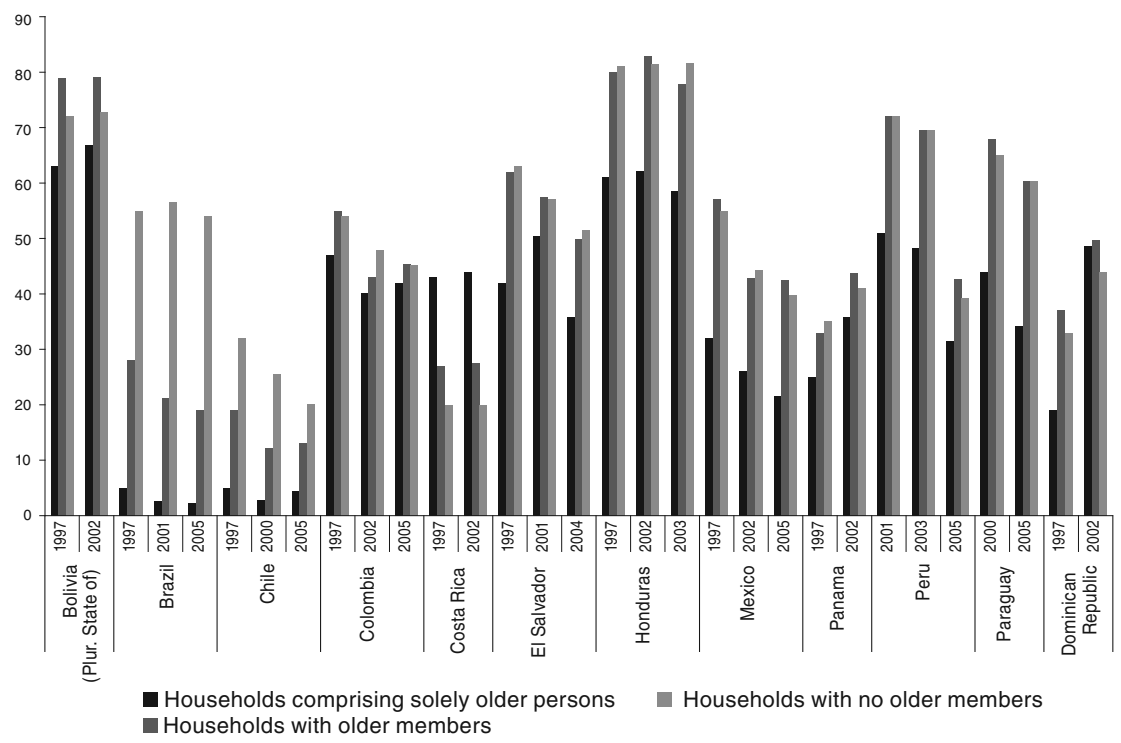

Source: Economic Commission for Latin America and the Caribbean (ECLAC), on the basis of data from household surveys conducted in the relevant countries.

In developed countries, there is a lower poverty incidence in households with older members and in households composed solely of older persons because pensions are the main source of livelihood and protection in old age (United Nations, 2007b). However, the pattern cannot easily be replicated in Latin America and the Caribbean for several reasons, including the low levels of social security coverage. For instance, in countries with high poverty levels such as Honduras, Nicaragua and Paraguay, older persons and their households replicate the national pattern and there is no marked distinction between households with older persons and those without.

By contrast, in countries like Chile, Brazil, Panama and Uruguay, where there is wider social security coverage and the household poverty rate is lower than the regional average, the differences between households with and without older members are more sharply defined (ECLAC, 2007b). Some studies show that in these countries, cash transfers to older persons, especially from social safety net protection programmes, are key to reducing the risk of poverty and mitigating the negative effects of 
vulnerability (Tabor, 2002) and benefitting other generations (Schwarz, 2002; Hoskins, 2002). ${ }^{1}$ This is because "when older persons live with younger family members, the former provide a considerable proportion of the household income, including what they receive from social security. Private and public transfers within families could thus be said to complement each other by contributing to intergenerational solidarity and social protection in the broad sense of the word" (Machinea, 2006).

Box III.1

\section{AGEING AND INTERGENERATIONAL TRANSFERS}

The demographic transition being experienced by Latin American countries is changing the age structure of the population, with possible consequences for long-term economic growth. One such consequence is a smaller proportion of children and young people in the population, leading to an increase in available income per capita which could be used, for example, for investing in human capital (first demographic dividend). A second consequence would be a larger proportion of older persons leading to increased capital in the economy if the rate of savings for old age increases based on longer life expectancies (second demographic dividend).

In either case, the effect will depend on the age structure of consumption and employment income. The difference between the two variables will determine which age groups are economically dependent and therefore must finance their consumption from sources other than the labour market. This will depend crucially on the will to maintain or increase the resources spent on education and the relative importance of income generated by capital markets in financing the consumption of older persons.

A study of three Latin American countries (Chile, 1997, Costa Rica, 2004 and Uruguay, 1994), conducted as part of the national transfer accounts project, estimated the age profiles for economic dependency (defined as the point at which a person's consumption exceeds his or her employment income), identifying three common phases: (i) dependency during youth; (ii)independence in mid-life and (iii) dependency in old age, when people no longer obtain sufficient labour income to finance their consumption (see figure 1).

Despite this common pattern, there are interesting differences among countries in terms of both the length of time people spend in each of these phases. In Chile in 1997, on average, people consumed less than they earned in the labour market, which meant they could transfer resources or accumulate capital for a period of 30 years and they spent around two thirds of their lifetime in a state of economic dependency. In Costa Rica, an average person's employment income exceeds his or her consumption for a period of 33 years, meaning that they must obtain income from non-labour sources for 57 years. In Uruguay, the average person spends 30 years in a state of economic independency and 60 years in a state of dependency.

(continued)

An exercise conducted in Brazil showed that, if transfers to older persons were discounted, poverty incidence would increase significantly, especially among the oldest old (Ricardo Paes de Barros, cited by Goldani, 2006). 
Box III. 1 (continued)

\section{Figure 1 \\ AGE PROFILE FOR NET \\ TRANSFERS (AVERAGE OF \\ SELECTED COUNTRIES)}

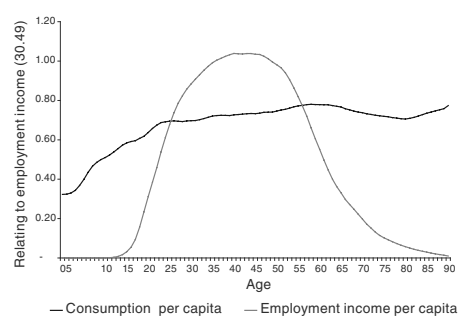

Figure 2

AGE PROFILE FOR CONSUMPTION AND EMPLOYMENT INCOME

(AVERAGE OF SELECTED COUNTRIES)

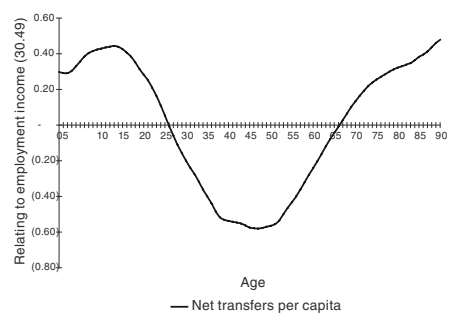

Source: Latin American and Caribbean Demographic Centre (CELADE) - División de Población de la CEPAL, on the basis of M. Holz 2005 ; L. Rosero 2005; M. Bucheli 2005. National Transfers Accounts Project. http: //www.ntaccounts.org.

While average periods of economic dependence and independence are important indicators as to the amount of resources that must be reassigned, the composition by income sources for the financing of consumption during these periods also determines an economy's position in terms of taking advantage of the two demographic dividends that occur during demographic transitions.

Income may be derived from four different sources during the period of dependency: public transfer systems, private transfer systems, labour markets and capital markets. Calculations in the three Latin American countries show vast differences in the composition of consumption financing in the two dependent groups. In Chile, for example, $74 \%$ of consumption by minors aged under 15 years is financed by the private transfer system, while $25 \%$ comes from the public system (see figure 2). In the case of Costa Rica the figures are $70 \%$ and $27 \%$, respectively.

For the population aged 65 and over, the composition of consumption financing is different. In Costa Rica, for example, 19\% of consumption is financed by income from the labour market, $63 \%$ by the public transfer system, $16 \%$ by capital markets and $2 \%$ by the private transfer system. In the case of Uruguay, the figures are $4.9 \%, 46.5 \%, 66 \%$ and $-18 \%$, respectively, while in Chile they are $27 \%, 33 \%, 39 \%$ and $1 \%$.

Given these figures, there are two scenarios for the possible effects of demographic transitions on long-term economic growth. As evidenced, consumption by children and young people is predominantly financed by private transfers that come mainly from within the household. This implies that a decrease in the proportion of children and young people in a population which occurs during the first phase of demographic transition would free up resources mainly in family budgets. Therefore, increases in spending per student will depend on how families choose to spend their extra resources. At the same time, the State could capture these resources by increasing taxes and investing in public education. Thus, the impact on investment in human capital will depend on the decisions that Governments make regarding their spending. Moreover, and given that resources from capital markets play 
Box III. 1 (concluded)

a significant role in financing the consumption of older persons in these three countries, longer life expectancy and a consequent lengthening of the second period of dependence would increase capital stock when the working population saves more to finance their old age.

Source: Latin American and Caribbean Demographic Centre (CELADE) - Population Division of ECLAC, on the basis of information from the ECLAC/CIID project "Population ageing, intergenerational transfers and social protection" and Jorge Bravo and Mauricio Holz, "Interage transfers in Chile 1997: economic significance", Santiago, Chile, Economic Commission for Latin America and the Caribbean (ECLAC), unpublished; Luis Rosero-Bixby and Arodys Robles, "Los dividendos demográficos en Costa Rica a partir del mapeo de la economía del ciclo vital del individuo", document presented at the second Congress of the Latin American Population Association (ALAP), Guadalajara, 3-5 September 2006; Marisa Bucheli, Rodrigo Ceni and Cecilia González, "Intergenerational transfers in Uruguay", Documento de trabajo, No. 5/7, Universidad de la República, July 2007.

\section{B. Income protection and pension systems}

Retirement and other pensions form part of the social security system and have probably been one of the most intensive and controversial areas of public policy reform in recent decades, with the result that pensions have a long history and are highly diverse in terms of organization, financing and performance (Mesa-Lago, 1978) (see box III.2).

Retirement and other pensions afford protection against the risk of loss of income in old age, guaranteeing older people's economic selfsufficiency. However, according to a World Bank study, "Latin America's more than decade-long experience with pension reform has delivered significant fiscal, social and financial benefits, but the failure to extend access to formal financial protection for old age to a broader segment of society has been a major disappointment" (Gill, Packard and Yermo, 2004).

In English-speaking Caribbean countries, defined-benefit pay-as-yougo pension systems have hardly been altered (see table III.1) and, given their relatively short history and low demographic dependency rate, they remain solvent. In fact, these countries have managed to accumulate reserve funds amounting on average to $19 \%$ of regional GDP. Nonetheless, the long-term financial sustainability of these regimes is threatened by projected changes in their demographic structures (less imminent but faster than in the rest of the region), high rates of unemployment, rising indices of informality and emigration from the region to the rest of the world (ECLAC, 2006). 
Box III.2

RETIREMENT AND PENSION SYSTEMS: REFORMS AND IMPLICATIONS

At least 10 Latin American countries have initiated structural reforms since 1981 , that is to say, reforms that not only change the pension financing regime by introducing advance funding (wholly or partially), but also include privately managed pension funds. In addition, these changes established or embedded reforms considered to be parametric, meaning that the reforms improved the financial viability of systems by changing the conditions for benefit entitlement (such as the retirement age) or the financial parameters (such as contribution rates). In other countries, the reforms were nonstructural, although they did introduce major changes that involved economic policy discussions and negotiations between key stakeholders that were as important as the structural reforms.

\section{TYPE OF RETIREMENT OR OTHER PENSION REFORM DEPENDING ON THE TYPE OF CONTRIBUTION SCHEME UNDER THE REFORMED SYSTEM}

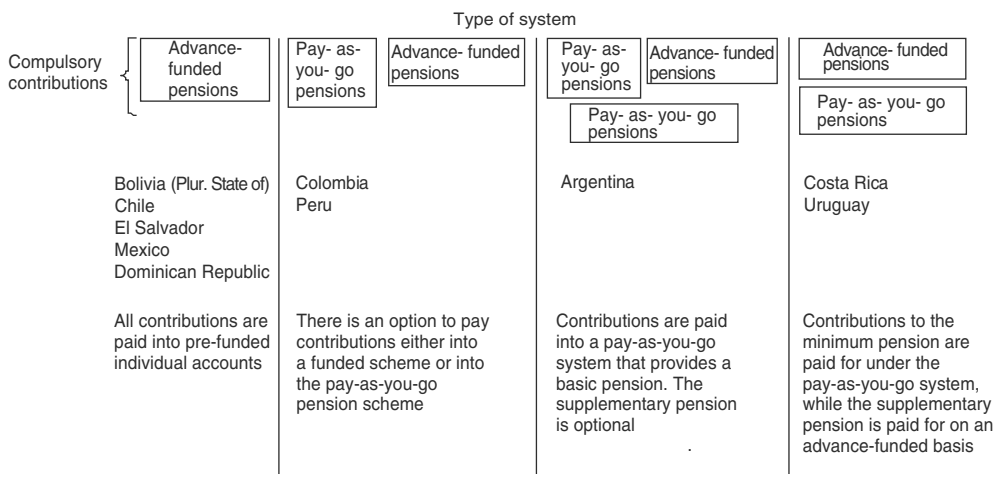

Source: Fabio Bertranou, Envejecimiento, empleo y protección social en América Latina, Santiago, Chile, International Labour Organization (ILO), 2006.

The countries with structural reforms are: Chile (1981), Peru (1992), Colombia (1993), Argentina (1994), Uruguay (1996), Mexico and El Salvador (1997), Plurinational State of Bolivia (1998), Costa Rica (2000) and the Dominican Republic (2003). Although Nicaragua (2000) and Ecuador (2001) introduced structural changes in legislation, the changes failed to be implemented for various legal and administrative reasons. Among the countries with non-structural changes, the highest-profile case, due to its regional representativeness, is Brazil, with its reform for private sector workers in 1999 and for public sector workers between 2003 and 2004. Other countries with non-structural changes include Panama, which incorporated the changes in 2005, although the new legislation was later amended. In addition, Colombia refined certain aspects of its reform in 2003 and Peru introduced additional changes in 2004. In recent years, therefore, the trend in countries other than the 10 that adopted structural reforms has been away from extending structural reforms and towards a continued process of parametric change, which has extended to countries that introduced the private component in the 1990s (Colombia and Peru). 
Box III. 2 (concluded)

In many respects the structural reforms have followed Chile's 1981 reform, with their common denominator being the model of changes in the 1990s promoted by the World Bank, with its multi-pillar system proposal (1994). Even so, characteristics have varied widely from one country in the region to another. From a structural standpoint, the reforms have pursued different paths and, according to Mesa-Lago's characterization in numerous studies (2004), three models could be said to have emerged: substitutive, parallel and mixed models. In the substitutive model, pre-funded individual accounts entirely replaced defined-benefit pay-as-you-go (PAYG) pension systems, meaning that workers entering the labour market pay all their contributions into the new advance funded scheme. In the parallel model, workers can choose between contributing to a funded scheme or to a publicly-managed defined-benefit pay-as-you-go pension scheme. Mixed schemes are a combination of the previous two models. The latter's financing and benefit parameters were also reformed.

One important aspect of all these reforms is that, while they have radically altered the financing and organizational aspects of pension systems, they reserve major responsibilities for public institutions, chiefly in the area of regulation, control and management, with the result that the reformed systems are mixed in character. What is more, in the case of Chile, which opted for the purest substitutive model, in addition to regulatory, control and management responsibilities, the State is also in charge of managing the old system during the transition phase and maintains a strong presence, particularly in the provision of non-contributory benefits and in guaranteeing basic or minimum benefits.

Source: Fabio Bertranou, Envejecimiento, empleo y protección social en América Latina, Santiago, Chile, International Labour Organization (ILO), 2006.

\section{Long-term pension coverage and the protection paradox}

The main problem with retirement and pension systems in most countries in Latin America and the Caribbean is low coverage (ECLAC, 2006). This stems from a variety of factors, including problems with access to the social security system during working life.

Figure III.4 shows the employment-based pension coverage for each household income quintile, together with each country's coverage inequality index. Coverage varies considerably across the region according to the realities of the social situation and labour in each country, which produce large differences in employment-based coverage between the populations in the first and fifth household income quintiles. This is more the case in countries where the gaps between socioeconomic levels are extremely wide. 
Table III.1

CHARACTERISTICS OF NATIONAL SOCIAL SECURITY SYSTEMS IN ENGLISH-SPEAKING CARIBBEAN COUNTRIES

\begin{tabular}{|c|c|c|c|c|c|c|c|c|c|c|c|c|c|c|c|c|}
\hline \multirow{2}{*}{ Country } & \multirow{2}{*}{$\begin{array}{l}\text { Maximum } \\
\text { contributable } \\
\text { earnings }^{\mathrm{a}}\end{array}$} & \multicolumn{2}{|c|}{$\begin{array}{c}\text { Pension to average } \\
\text { insurable wages } \\
\text { (percentages) }\end{array}$} & \multicolumn{3}{|c|}{$\begin{array}{l}\text { Replacement rates } \\
\text { (percentages) }\end{array}$} & \multirow{2}{*}{$\begin{array}{c}\text { Minimum } \\
\text { contribution } \\
\text { period (weeks) }\end{array}$} & \multicolumn{2}{|c|}{ Retirement age } & \multirow{2}{*}{$\begin{array}{l}\text { Administrative } \\
\text { expenses as } \\
\text { a percentage } \\
\text { of contribution } \\
\text { income (2003) }\end{array}$} & \multicolumn{3}{|c|}{$\begin{array}{l}\text { Life expectancy at birth } \\
\text { (years) }\end{array}$} & \multicolumn{2}{|c|}{$\begin{array}{l}\text { Rate of return } \\
\text { on reserves }\end{array}$} & \multirow{2}{*}{$\begin{array}{c}\text { Investment } \\
\text { as a } \\
\text { percentage } \\
\text { of reserves }\end{array}$} \\
\hline & & Average & Minimum & $\begin{array}{c}10 \\
\text { years }\end{array}$ & $\begin{array}{c}30 \\
\text { years }\end{array}$ & Maximum & & Normal & Early & & $2000-2005$ & $2025-2030$ & $2045-2050$ & $\begin{array}{c}10 \\
\text { years }\end{array}$ & $\begin{array}{c}5 \\
\text { years }\end{array}$ & \\
\hline Anguilla & 2.02 & 30.6 & 26.3 & 30 & 50 & 60 & 250 & 65 & $\ldots$ & 22.8 & $\ldots$ & $\ldots$ & $\ldots$ & 2.5 & 1.5 & 91.8 \\
\hline $\begin{array}{l}\text { Antigua and } \\
\text { Barbuda }\end{array}$ & 1.88 & 22.2 & 6.3 & 25 & 45 & 50 & 350 & 60 & $\ldots$ & 17.7 & $\ldots$ & $\ldots$ & $\cdots$ & 0.8 & 1.5 & 44.4 \\
\hline Bahamas & 1.36 & 25.4 & 16 & 30 & 55 & 60 & 150 & 65 & 60 & 19.9 & 69.4 & 75.7 & 77.3 & 4.8 & 4 & 92.4 \\
\hline Barbados & 2.09 & 49 & 30.6 & 40 & 60 & 60 & 500 & 65 & 63 & 6.1 & 77.2 & 79.8 & 81.4 & 5.2 & 5.2 & 82.4 \\
\hline Belize & 1.52 & 25.3 & 22.4 & 30 & 55 & 60 & 500 & 65 & 60 & 30.5 & 74.4 & 77.5 & 79.7 & 7.4 & 7.5 & 94.5 \\
\hline Dominica & 3.15 & 28.3 & 6.8 & 30 & 55 & 70 & 500 & 60 & $\ldots$ & 16.7 & $\ldots$ & $\ldots$ & $\ldots$ & 4.7 & 4.6 & 77 \\
\hline Grenada & 2.07 & 24.5 & 12 & 30 & 50 & 60 & $400^{h}$ & 60 & $\ldots$ & 12.4 & $\ldots$ & $\ldots$ & $\ldots$ & 5 & 4.9 & 92.1 \\
\hline Guyana & 2.1 & 28.5 & 27.3 & $40^{\mathrm{b}}$ & 55 & 60 & 750 & 60 & $\ldots$ & 15.8 & 62.4 & 64.1 & 71.2 & 4.8 & 4.1 & 95.3 \\
\hline $\begin{array}{l}\text { Turks and } \\
\text { Caicos Islands }\end{array}$ & 1.69 & 19 & 14.1 & 30 & 55 & 60 & 500 & 65 & 60 & 21.1 & $\ldots$ & $\cdots$ & $\ldots$ & 1.6 & 0.9 & 87.5 \\
\hline $\begin{array}{l}\text { British Virgin } \\
\text { Islands }\end{array}$ & 1.42 & 21.4 & 7.5 & 30 & 50 & 60 & 500 & 65 & $\ldots$ & 11.9 & $\ldots$ & $\ldots$ & $\ldots$ & 2.2 & 2.8 & 92.8 \\
\hline Jamaica & & & & t & & & & $70^{e}$ & $65^{\mathrm{e}}$ & 13 & 75.7 & 79 & 80.8 & 3.5 & 9.8 & 95.5 \\
\hline Montserrat & 1.26 & 17.1 & 8.4 & 30 & 50 & 60 & $350^{\circ}$ & 60 & $\ldots$ & 48.8 & $\ldots$ & $\ldots$ & $\ldots$ & 2.4 & 2.4 & 96.7 \\
\hline $\begin{array}{l}\text { Saint Kitts and } \\
\text { Nevis }\end{array}$ & 3.07 & 28.4 & 11.8 & 30 & 55 & 60 & 500 & 62 & $\cdots$ & 14.6 & $\ldots$ & $\ldots$ & $\cdots$ & 3.2 & 4 & 94.9 \\
\hline $\begin{array}{l}\text { Saint Lucia } \\
\text { Saint Vincent } \\
\text { and the }\end{array}$ & 3.41 & 39 & 13.7 & & 58 & 60 & $576^{d}$ & 61 & 60 & 13.3 & 73.8 & 77.2 & 79.5 & 3.8 & 4.1 & 96 \\
\hline Grenadines & 3.08 & 29.9 & 19.4 & 30 & 50 & 60 & $325^{c}$ & 60 & $\ldots$ & 16.7 & $\ldots$ & $\ldots$ & $\ldots$ & 4.3 & 5.6 & 91.6 \\
\hline $\begin{array}{l}\text { Trinidad and } \\
\text { Tobago }\end{array}$ & 1.25 & 15.8 & 37 & $g$ & & & 750 & 65 & 60 & 6.9 & 74.8 & 78.6 & 80.5 & 4.7 & 4.7 & 93.4 \\
\hline
\end{tabular}

Source: Oliver Paddison, Social security in the English-Speaking Caribbean (LC/CAR/L.64), Port of Spain, ECLAC subregional headquarters for the Caribbean, December 2005.

Ratio between the maximum insurable wage and the average insurable wage.

After 15 years.

c Increasing to 500 in annual steps of 25 .

144 months, increasing by 12 months every 3 years until 180 is reached on 1 January 2012 .

The retirement age for women is 60 .

Flat-rate pensions plus earnings-related proportion.

9 Pension based on average class in which contributions made over career (non-indexed career earnings approach).

Increasing to 500 in 2008. 
Figure III.4

LATIN AMERICA (SELECTED COUNTRIES): CONTRIBUTION COVERAGE FOR EACH HOUSEHOLD INCOME QUINTILE, AROUND 2003

(Percentages)

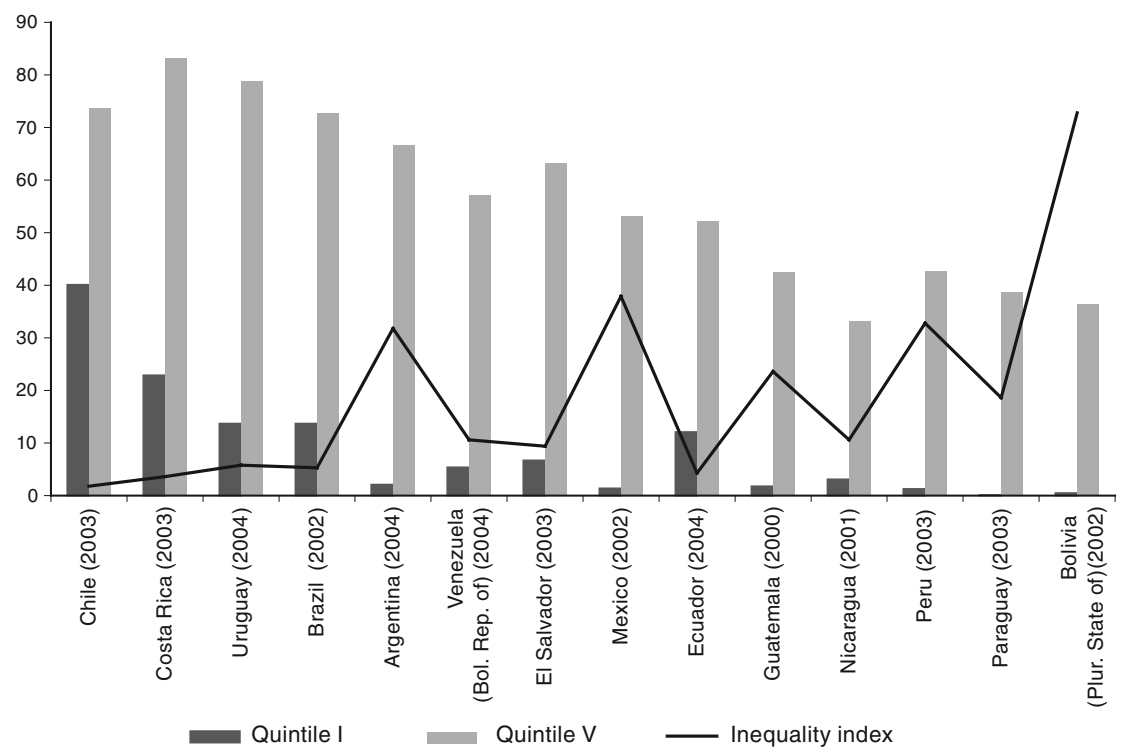

Source: Fabio Bertranou, Envejecimiento, empleo y protección social en América Latina, Santiago, Chile, International Labour Organization (ILO), 2006.

Generally speaking, the disparity between the first and fifth household income quintiles is less in countries with broad employment-based coverage, higher per capita incomes and more solid social security systems. Conversely, the disparities are more notable in those countries where employment-based coverage is low or very low (Mexico, Paraguay, Peru and the Plurinational State of Bolivia).

These discrepancies in coverage also reflect unequal conditions of access to social security benefits (mainly health benefits) during a person's lifetime, in addition to the inequalities and inequities affecting income protection in old age. In equity terms there is a powerful protection paradox at work, as a variety of factors result in the least vulnerable groups gaining access to greater and better protection. One important factor is the labour market, where workers with better quality jobs (employees of large companies or public sector corporations) also have better and more extensive pension coverage. 
The region's employment dynamics in recent years have included greater job instability, more informal and precarious employment, labourmarket deregulation and greater participation of women. These factors are expected to have a negative impact on retirement and pension system coverage in the future. In fact, contribution coverage shrank between 1990 and 2003 and it is doubtful that the labour market dynamic can be reversed in the short to medium term (ECLAC, 2006).

In 2005, a general review of the percentages of informal employment and social security coverage in the various phases of population ageing revealed that the situation is complex in a number of countries in which the process is incipient or moderate (Dominican Republic, Ecuador, El Salvador, Honduras, Paraguay, Peru and the Plurinational State of Bolivia) because their informal employment percentages are currently above the regional average and they have a low level of retirement or other pension coverage (see figure III.5).

Figure III.5

LATIN AMERICA (SELECTED COUNTRIES): INFORMAL EMPLOYMENT

AND PENSION COVERAGE, ${ }^{\text {a AROUND } 2005}$

(Percentages)

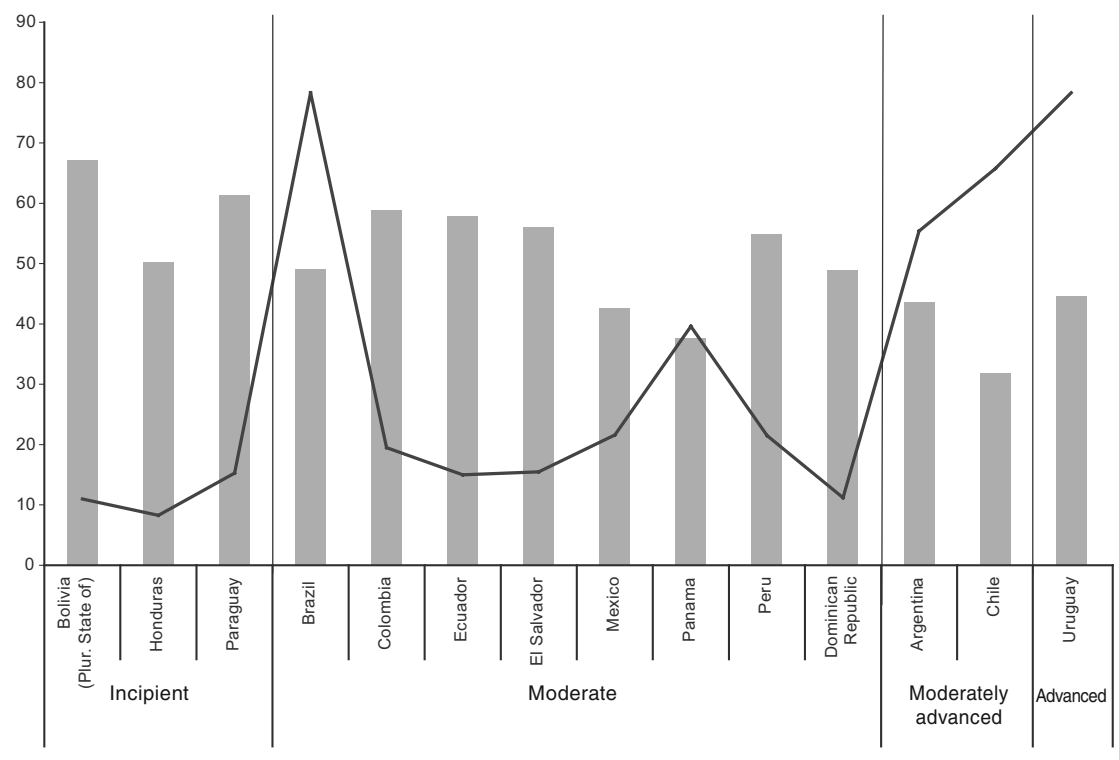

Percentage of informal employment

Percentage with retirement or other pension income

Source: International Labour Organization (ILO) and Economic Commission for Latin America and the Caribbean (ECLAC), on the basis of data from household surveys conducted in the relevant countries. a Pension coverage corresponds to the percentage of people aged 60 or over receiving retirement or other pension income. 
If employment trends in these countries continue, they will lead to major inequalities and inequities. Also, unless there are reforms to strengthen the non-contributory components of pension systems, the most vulnerable groups will be excluded from contribution systems or will receive poor quality pensions due to their irregular contributions, while those in the poorest quintiles will tend to defer their contributions until late in working life.

\section{Limited and unequal protection from retirement and pension systems in old age}

Structural reforms of pension systems have undermined the solidarity inherent in traditional systems. The majority of Latin American and Caribbean countries today have limited capacity to provide older people with means of subsistence. The result is that the inequalities marking people's working lives persist as social protection inequalities in old age (ECLAC, 2000).

A clear measure of the limited capacity of pension systems to provide means of subsistence to older persons is the proportion of this population group receiving retirement or other pension income (ECLAC, 2006). Figure III.6 shows the values for this indicator in 17 Latin American and Caribbean countries around 1997, 2002 and 2005. While there are significant variations, on average the percentage of people receiving retirement or other pension income has remained relatively stable (around 4 in every 10 older persons). This is because, even though countries like Brazil expanded pension coverage for older persons by more than 15 percentage points between 1997 and 2005, in other countries the increases were smaller and, in some cases, coverage decreased.

With regard to retirement and other pension coverage, two countries (Argentina and Brazil) have high levels of coverage in old age despite having only average levels of employment-based pension coverage (between $30 \%$ and 50\%). As can be seen below, this is a direct result of having non-contributory pension programmes. In both Argentina and Brazil, as in other Latin America countries pioneering social security systems (Chile, Costa Rica and Uruguay), gaps in old-age coverage have been lessened by non-contributory pension programmes. Colombia and the Plurinational State of Bolivia have also introduced non-contributory pension schemes in recent years. 
Figure III.6

LATIN AMERICA (SELECTED COUNTRIES): RECEIPT OF RETIREMENT

OR OTHER PENSION INCOME

(Percentages)

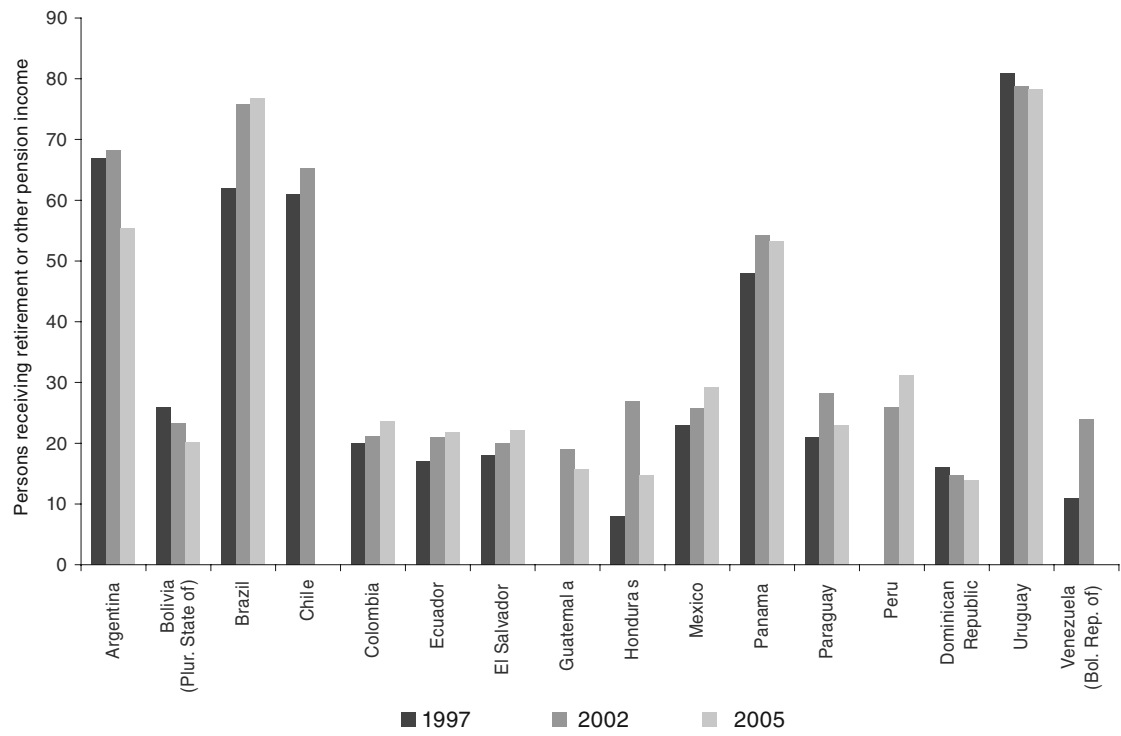

Source: Economic Commission for Latin America and the Caribbean (ECLAC), on the basis of data from household surveys conducted in the relevant countries.

The weak gender perspective in public policies partly explains why old-age social protection in Latin America (calculated on the basis of pensions received) tends to be poorer for women than for men (see figure III.7). Even though female labour force participation increased considerably in the 1960s, it was faster and more extensive in the late 1980s and early 1990s. This means that women became regular participants in the labour market during a period of worsening employment conditions (greater job insecurity and informality) when social security systems were being reformed, which heavily affected women in terms of access and contribution coverage. This made women invisible in reform processes, which entirely failed to address the gender inequalities that had historically marked women's participation in the economy and in social protection systems. On the contrary, inequities continued to worsen (Pautasi and Rodríguez, 2006). As a corollary, women have had, and continue to have, fewer pension savings, as well as limited rights to benefits and State guarantees (Marco, 2004). 
Figure III.7

LATIN AMERICA (SELECTED COUNTRIES): RECEIPT OF RETIREMENT OR OTHER PENSION INCOME IN URBAN AREAS, ACCORDING TO GENDER, AROUND 1997, 2002 AND 2005

(Percentages)

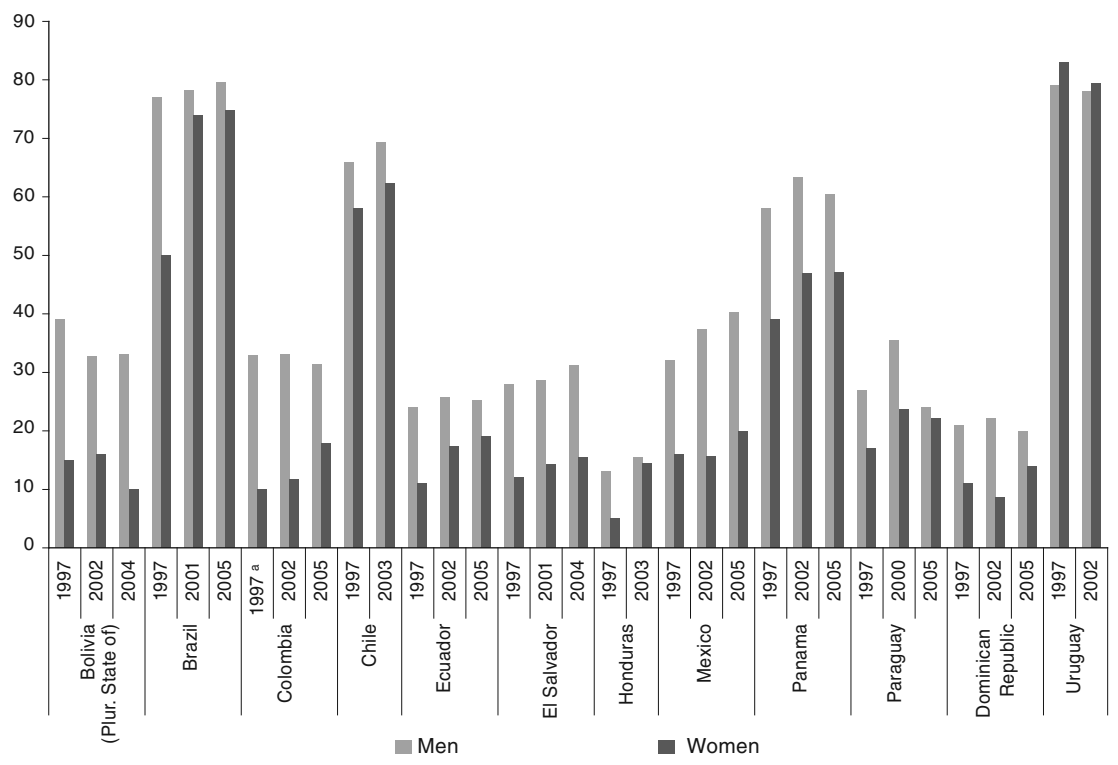

Source: Economic Commission for Latin America and the Caribbean (ECLAC), on the basis of data from household surveys conducted in the relevant countries.

a Income from retirement or other pensions corresponds to total income transfers to people in the variable "active population" category declaring themselves to be "persons receiving retirement or other pensions".

Retirement and other pension coverage in rural areas has traditionally been low (see figure III.8), except in Brazil, whose rural pension system is one of the main examples in the region of the extension of pension coverage through non-contributory mechanisms (ECLAC, 2006). In the first half of 2007, Mexico also introduced a non-contributory programme based on area of residence. This consists of a monthly grant of 500 Mexican pesos (approximately US\$ 46) to all those reaching the age of 70 prior to 1 January 2007 who live in rural communities with fewer than 2,500 inhabitants and receive no similar benefits from other federal programmes (INAPAM, 2007). 
Figure III.8

LATIN AMERICA (SELECTED COUNTRIES): PROPORTION RECEIVING

RETIREMENT OR OTHER PENSION INCOME, ACCORDING TO AREA OF RESIDENCE, AROUND 1997, 2002 AND 2005

(Percentages)

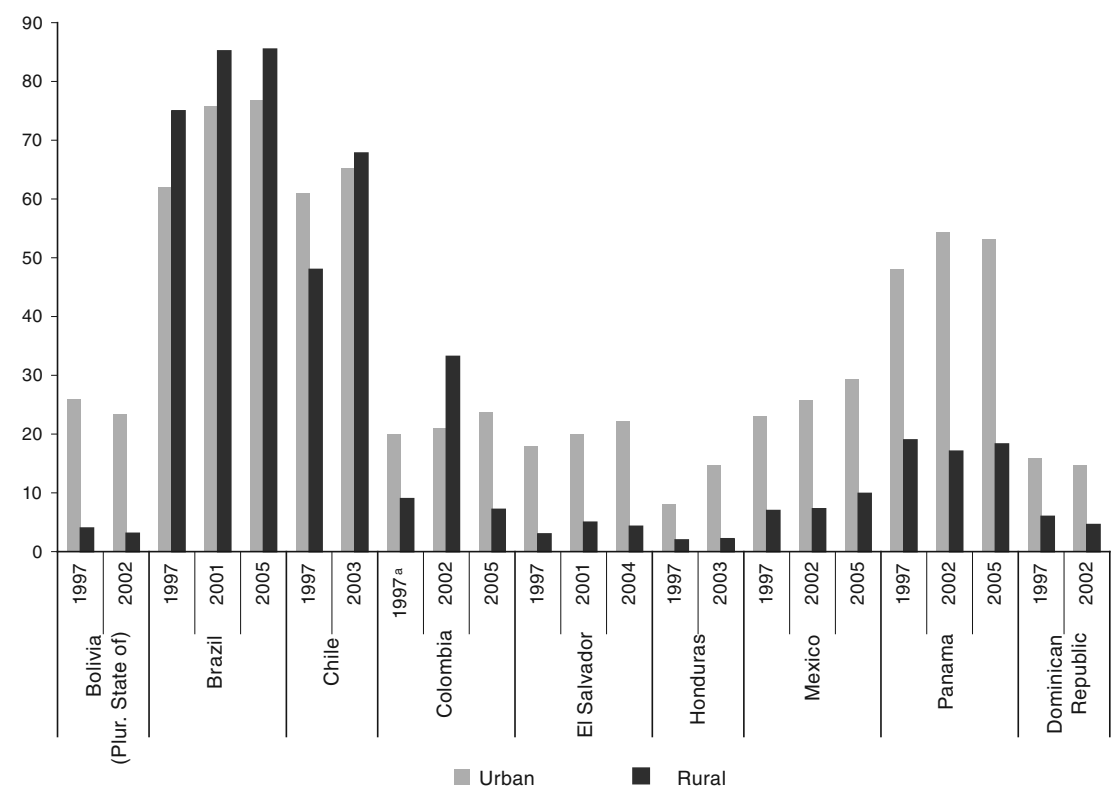

Source: Economic Commission for Latin America and the Caribbean (ECLAC), on the basis of data from household surveys conducted in the relevant countries.

${ }^{a}$ Income from retirement or other pensions corresponds to total income transfers to people in the variable "active population" category declaring themselves to be "persons receiving retirement or other pensions".

In summary, as ECLAC predicted in 2000, the region's pension coverage has not increased significantly in recent years because benefits continue to be heavily dependent on people having worked in the formal sector of the economy for their entire working lives. This compels families to become one of the main sources of protection for older persons, to whom they also provide other services, such as care, when levels of dependency increase. Another consequence of poor pension coverage is to increase the labour force participation of older persons and this, in a context of population ageing, can disrupt the operation of the labour market. 


\section{Employment in old age: trends and forms of economic participation}

Trends in the labour force participation of older persons have focused attention on the developed regions of the world in recent years. In numerous member countries of the Organisation for Economic Co-operation and Development (OECD), the rising trend towards early retirement from the labour market and reduced working hours in old age has slowed to a halt. This, together with the new "active ageing" paradigm, has opened the debate concerning the most appropriate public policies to support the active ageing process (OECD, 1998 and 2000). By contrast, in Latin America, concerns have focused on population ageing and its consequences for pension system financing, with the result that the employment status of older persons has only recently become a subject of public concern and State intervention.

\section{Factors influencing economic participation in old age}

The labour force participation of older persons has undoubtedly been prompted by a number of factors, in particular demographics and health, the size and quality of social protection coverage, the macroeconomic environment and labour market performance.

With respect to demographics, life expectancy has increased in most countries and is expected to continue doing so in the coming years. Furthermore, older people's state of health, which is a critical factor determining their ability to work in old age, has been improving. Advances in medical science give reason to expect disability to decrease in almost every country in the world, suggesting that this age group will livelonger and healthier lives.

The number of years that people are economically active is expected to rise in the region (unlike in most OECD countries) owing to low levels of pension system coverage and increased life expectancy. As a result, the amount of time spent in the labour market, as measured by gross working years, will be on average by eight years higher in 2030 than the 35 years calculated in 1990 for both sexes. These changes are not homogenous and, as evidenced in figure III.9, there are large differences between men and women. From 1990 to 2030, the number of working years will remain 50 for men but will increase from 21 to 37 for women. The main reason for this difference is the growth in the economically active female population since 1990 as a result of lower fertility, growth in the service sector and rural to urban immigration, among other factors (CELADE, 2007). 


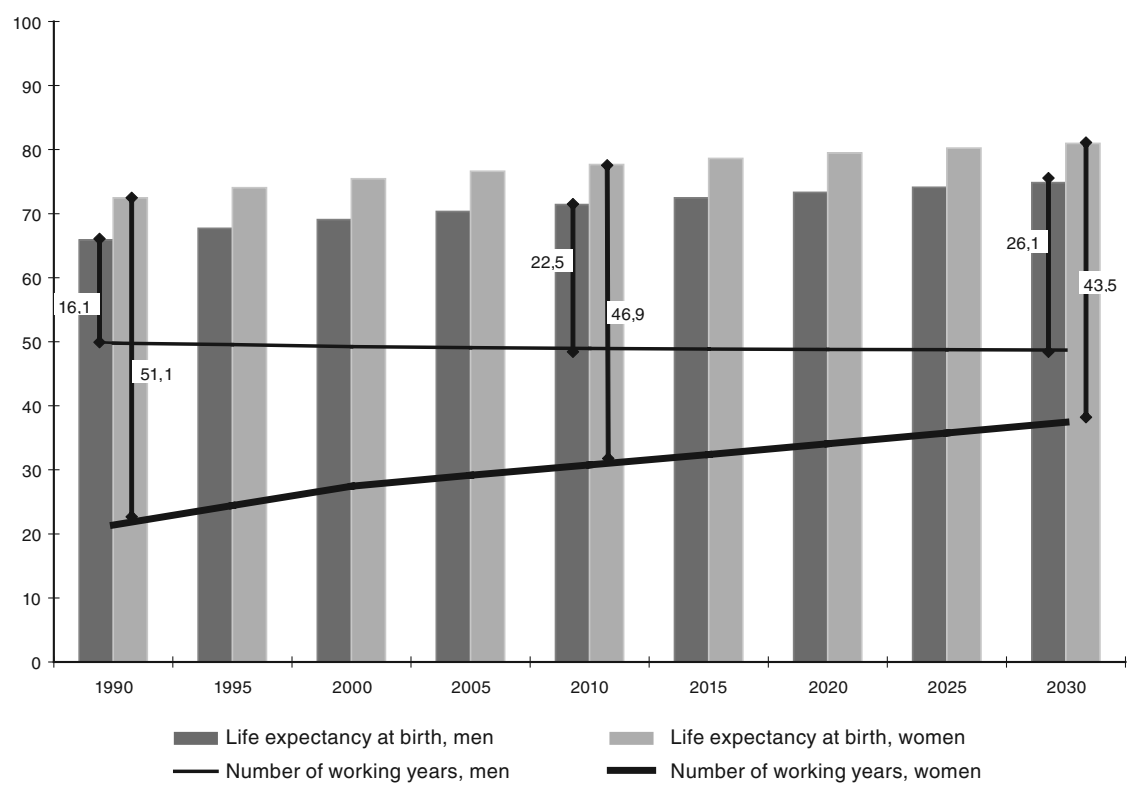

Source: Latin American and Caribbean Demographic Centre (CELADE)-Population Division of ECLAC, Demographic Observatory, No. 2 (LC/G.2337-P), Santiago, Chile.

A comparison between older persons and the rest of the working population confirms that older persons' economic participation rates are growing in Latin America and the Caribbean. This could be a result of the pension system reforms in the 1990s, which introduced tougher conditions of access to benefits (see box III.2). This means that people are not allowed access to benefits until a later age or with a low replacement rate, which encourages retirees and other pension recipients to remain in employment for as long as possible (Bertranou,2006). As a result, older workers in countries with lower social security coverage have higher labour force participation rates (see figure III.10) whereas, in countries with greater coverage, the participation rates of older persons fall, irrespective of whether the system is contributory or non-contributory. The exception is Brazil, where the labour force participation of older persons has different characteristics than in the rest of the region. 
Figure III.10

LATIN AMERICA (SELECTED COUNTRIES): ECONOMIC PARTICIPATION RATE AND PENSION COVERAGE AMONG PEOPLE AGED 60 OR OVER, AROUND 2005

(Percentages)

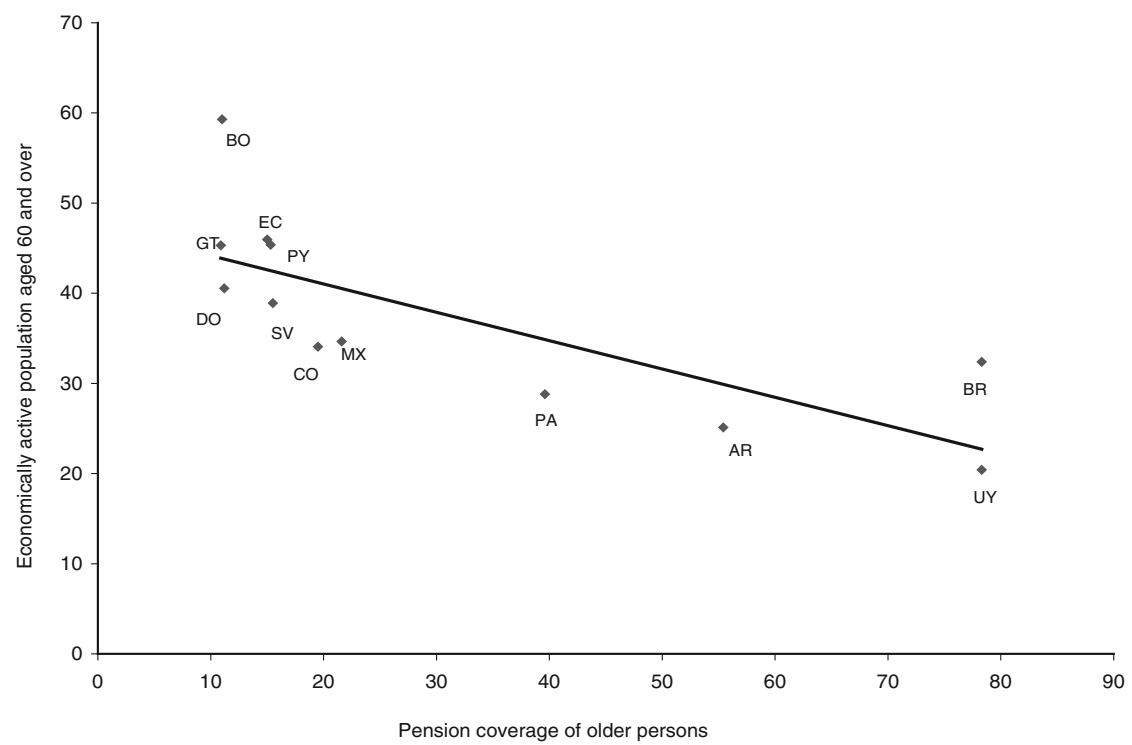

Source: Latin American and Caribbean Demographic Centre (CELADE) - Population Division of ECLAC, Demographic Observatory, No. 2 (LC/G.2337-P), Santiago, Chile, 2007. United Nations publication, Sales No. E/S.07.II.G.28 and Economic Commission for Latin America and the Caribbean (ECLAC), on the basis of data from household surveys conducted in the relevant countries.

a Pension coverage corresponds to the percentage of people aged 60 or over receiving retirement or other pension income.

In terms of the macroeconomic environment, the 1990s was, in general, a time of economic growth in the region and in the last four years the economies of Latin America and the Caribbean have been in a highly favourable cycle (ECLAC, 2007a). The conditions for older persons entering the labour market, however, are not always perfect and their employment tends to be precarious and insecure.

In the poorest countries, economic participation of older persons is higher than in the rest of the region (see figure III.11). In 2005, in Dominican Republic, Ecuador, El Salvador, Guatemala, Paraguay and the Plurinational State of Bolivia (with per capita GDP below the regional average) this segment of the population had a higher rate of economic participation than the regional average projected for 2030 (CELADE, 2007). 
Figure III.11

LATIN AMERICA (SELECTED COUNTRIES): ECONOMIC PARTICIPATION RATE OF OLDER PERSONS AND PER CAPITA GDP IN 2005

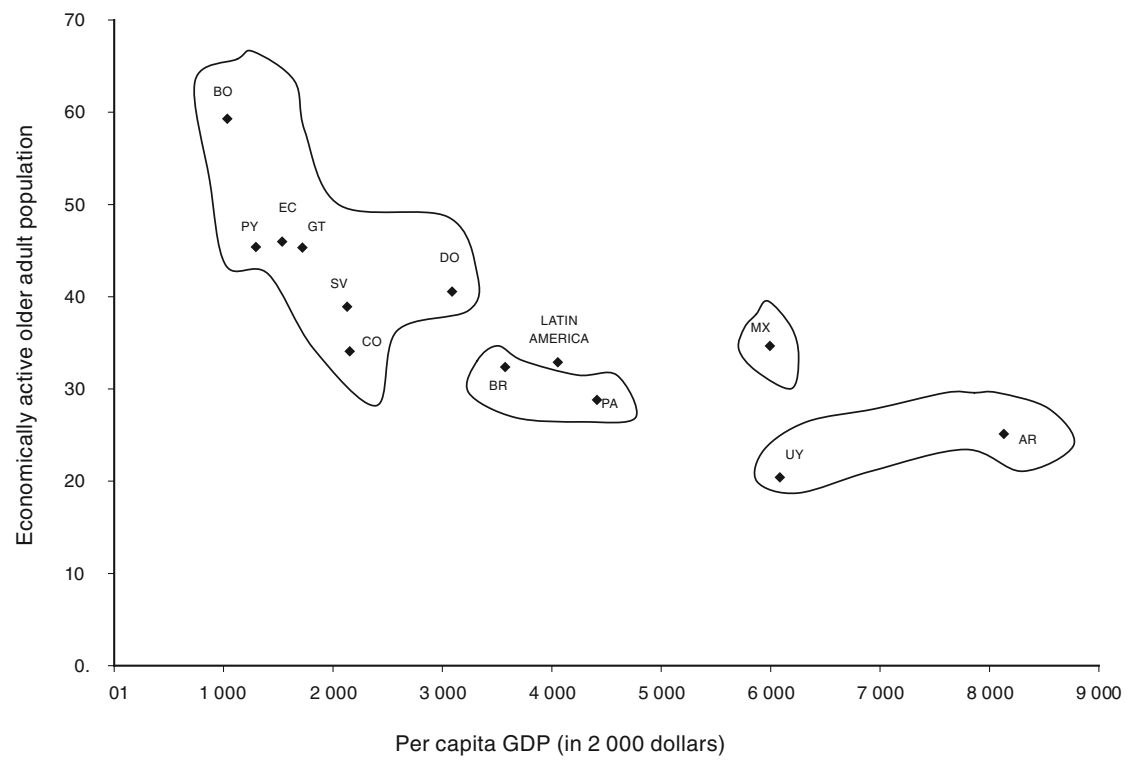

Source: Economic Commission for Latin America and the Caribbean (ECLAC), Social Panorama of Latin America 2006 (LC/G.2326-P), Santiago, Chile, 2007. United Nations publication, Sales No. E.06.II.G.133 and Latin American and Caribbean Demographic Centre (CELADE) - Population Division of ECLAC, Demographic Observatory, No. 2 (LC/G.2337-P), Santiago, Chile, 2007. United Nations publication, Sales No. E/S.07.II.G.28.

The increase in economic participation of older persons in these countries has occurred in a context of deregulation of the labour market and the introduction of new contractual arrangements such as subcontracting of services and fixed-term contracts. These practices have tended to reduce labour costs and have made employment more precarious for the entire population, with high levels of informal employment for workers of all ages (ILO, 2006).

\section{The economic participation of older persons is tending to grow irrespective of the phase of demographic ageing}

In the majority of OECD countries, the decline in the participation rate of older workers is associated with factors such as early retirement, higher per capita income, better education and improved health (OECD, 2000). A different phenomenon can be seen, however, in Latin America and the Caribbean, where since 2005 there has been steady growth in the 
rate of people over 60 participating in the labour market and just over three out of every ten older persons are working or actively seeking work.

Data available for the region shows that in the early years of the twenty-first century, nearly half the older persons in Ecuador, Honduras and Paraguay stated they were working or seeking work (see figure III.12). These countries are in different phases of demographic ageing and it would appear that (regardless of how aged their population is) older persons join the labour force for similar reasons to people in other social groups, such as women. Older persons, like other family members, are a resource that can be drawn upon to boost the household's economic resources in times of crisis, family shortage or if the head of household's conditions of employment deteriorate (whether or not the head of household is an older person).

Figure III.12

\section{LATIN AMERICA (SELECTED COUNTRIES): PARTICIPATION RATE OF PEOPLE AGED 60 OR OVER IN 1995 AND 2005, SHOWING THE CHANGE BETWEEN 1995 AND 2005}

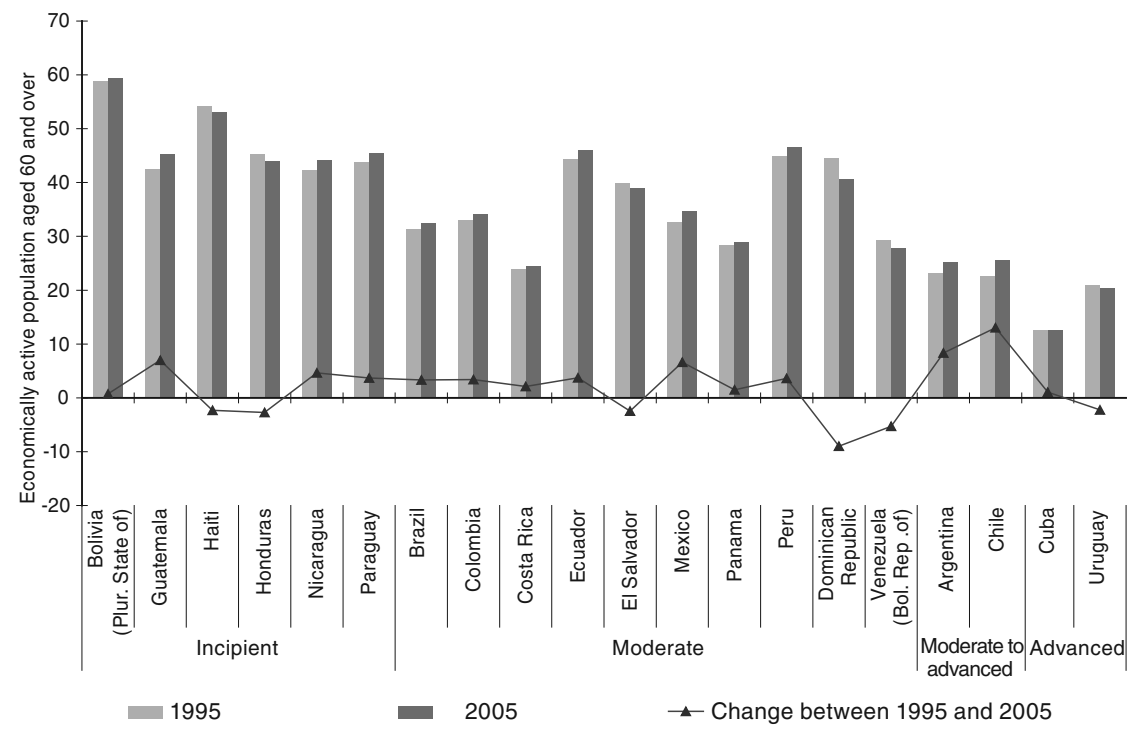

Source: Latin American and Caribbean Demographic Centre (CELADE) - Population Division of ECLAC, Demographic Observatory, No. 2 (LC/G.2337-P), Santiago, Chile, 2007. United Nations publication, Sales No. E/S.07.II.G.28.

Another noteworthy point regarding economic participation in old age is that women account for much of the large increase in the number of people over the age of 60 in the labour force. In Argentina, Brazil and Paraguay, for example, the size of the female labour force over the age 
of 65 doubled during the 1990s. This could stem from the inability of social security systems to provide income protection to older women, who receive less economic income than men despite their widow's pensions.

Costa Rica and Uruguay are the only countries that follow the trend of OECD countries, where participation of those over 60 in the work force decreased by about 10\% in the 1990s. These countries have social security systems with broad coverage and in the case of Uruguay, a demographic history that is similar to those found in developed countries (Varela, 2008).

\section{Informal employment and age and gender differences}

With the exception of Brazil, Chile and Panama, where the proportion of older persons in formal employment grew by 2.7, 8.7, and 2.4 percentage points respectively, in the 1990s, people in other countries tend to move into informal employment when they exceed 60 years of age. Brazil presents a different profile, with nearly $70 \%$ of employed persons in the over- 60 age group working in the formal sector, giving Brazil the highest proportion of older wage and salary earners in the region. (see figure III.13)

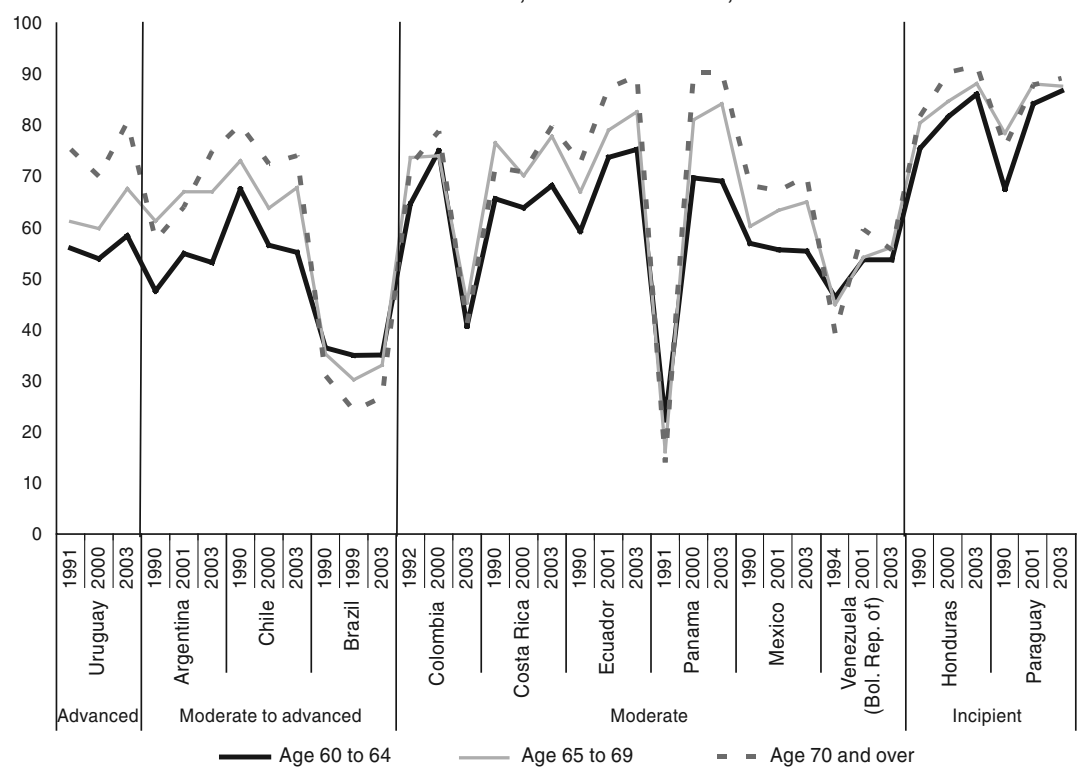

Source: Fabio Bertranou, Envejecimiento, empleo y protección social en América Latina, Santiago, Chile, International Labour Organization (ILO), 2006. 
There are also gender-based differences among countries in terms of informal employment. In Argentina, Paraguay and Uruguay, informality among people aged 65 or over grew between 1990 and 2003, chiefly as a result of a decline in the number of formal jobs for men, whereas in Brazil and Chile, the proportion of informality diminished mainly because the share of women in formal jobs increased.

In spite of this, a comparison of statistics for women's informal employment during the latest period for which figures are available shows that more women aged 60 or over are in informal employment than women of other ages (ILO, 2006). Similarly, in most countries, informality in employment increases as workers age regardless of what phase of demographic ageing the country finds itself in (see figure III.14).

Figure III.14

LATIN AMERICA (SELECTED COUNTRIES): PROPORTION OF OLDER PERSONS IN FORMAL EMPLOYMENT, 1990, 2000 AND 2003

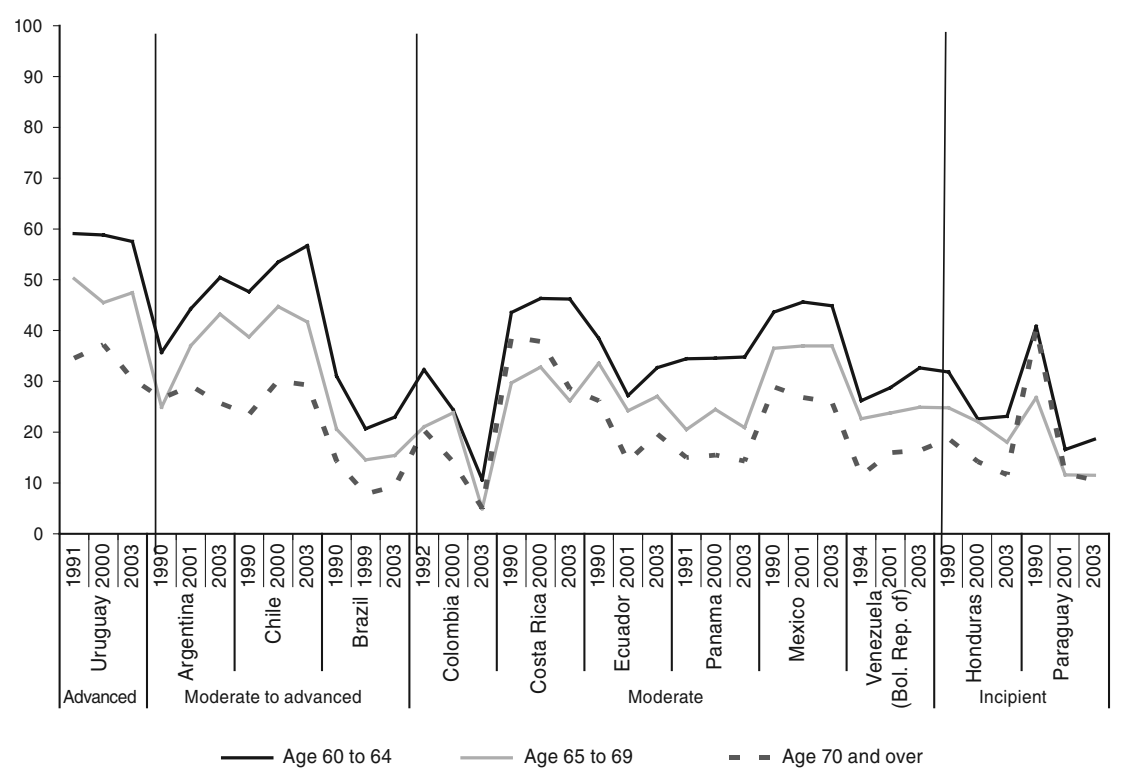

Source: Fabio Bertranou, Envejecimiento, empleo y protección social en América Latina, Santiago, Chile, International Labour Organization (ILO), 2006.

One fundamental difference between the economic participation of older persons in the region as compared to the situation in developed countries is that their numbers are increasing at a time when the size of the economically active population as a whole will continue to grow 
in coming decades. In fact, the economically active population in Latin America reached more than 250 million or $46 \%$ of the population. For the period 2005-2010 the work force is expected to swell by 5.5 million workers per year (almost Nicaragua's total population) and will reach more than 377 million people by 2030. Almost simultaneously, growth rates for the economically active population in Latin America by age groups clearly show the process of future ageing. In the 1990s the group that grew the most was adults 40 to 65 years of age. Since 2000, it has been 65 years and older, while the group that grew the least is, and will continue to be, 15 to 24 year-olds (see figure III.15).

Figure III.15

LATIN AMERICA: GROWTH RATES FOR THE ECONOMICALLY ACTIVE

PARTICIPATION BY GENDER, 1990-2030

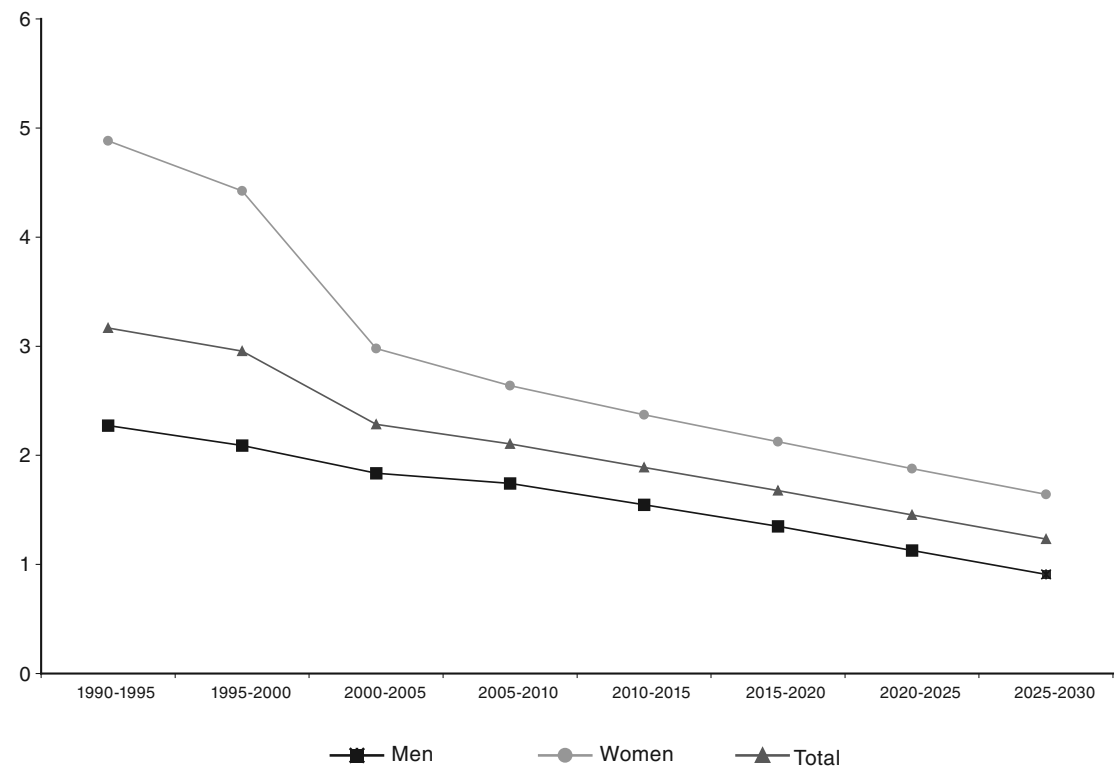

Source: Latin American and Caribbean Demographic Centre (CELADE) - Population Division of ECLAC, Demographic Observatory, No. 2 (LC/G.2337-P), Santiago, Chile, 2007. United Nations publication, Sales No. E/S.07.II.G.28.

Several international organizations have warned about this fact and predict that the ageing of the work force could be accompanied by a decrease in productivity that could effect economic growth and have repercussions in the labour market. Given the scarcity of jobs in the labour market, it has traditionally been expected that older persons make room for young workers and labour policy has been based on this assumption in 
most developing countries, where formal employment is less common and it is difficult for the large numbers of unemployed young workers to find jobs. Hence the fear that the situation could worsen if older workers keep working longer.

For some years now, developed countries have foreseen this problem and have promoted early retirement with the hope that it would improve job prospects for the young unemployed (ILO, 2002b). As a result of this policy, there is now serious concern over the massive exit of experienced workers and the gaps in intergenerational transfer of knowledge-especially in research and development. In Spain, for example, only 15 of every 100 adults 55 or older are currently employed. The decreasing size of this group (around 50\% over the last 30 years) is hard to understand given factors like longer life expectancy and better health.

Consequently, the idea that young and old workers are interchangeable continues to be uncertain. The problem of wage insecurity for older persons should not be solved at the expense of other social groups. In this sense, the 1980 ILO recommendations about older workers establishes the principle whereby strategies and policies should guarantee that employment problems should not be shifted from one age group to another (ILO, 2002a). This directive is particularly important in view of the challenges the region faces in taking advantage of the "favourable demographic situation" in educating and providing adequate employment to a population of young adults (15-24 year-olds) (United Nations, 2007b, ECLAC/CELADE, 2008).

Under this scenario, public policies must evolve and adapt to the demographic realities they seek to address, which means expanding the opportunities for decent jobs for the young and reconciling the demand for income protection with the risks of old age (United Nations, 2007b). In light of this, ECLAC has insisted on the need to continue strengthening the non-contributory subsystem and solidarity mechanisms in social security systems (ECLAC, 2006). 


\section{Non-contributory pensions and protection against the risk of loss of income in old age}

As a matter of overarching principle, all retirement and pension systems should aim at providing, at a minimum, some form of basic income security to all persons in old age. This objective could be achieved by creating, or expanding where it already exists, a basic pillar providing a minimum pension benefit (United Nations, 2007b). Any real expansion of pension coverage in the region necessarily involves, at least in the short and medium terms, the establishment or consolidation of noncontributory schemes that provide basic pensions to people who, regardless of their employment history, reach old age without the income or assets needed for their subsistence (ECLAC, 2006).

Non-contributory pension programmes grant modest and fairly uniform cash benefits to cover the risks of old age, disability and death, that is to say, they are welfare benefits targeted at poor people with little or no ability to pay contributions. Although Argentina, Brazil, Chile, Costa Rica, the Plurinational State of Bolivia and Uruguay have been implementing non-contributory programmes for decades, their coverage is still limited, with the result that they have gone only a little way towards closing the gap left by contributory programmes. Even so, countries like Chile, Brazil and the Plurinational State of Bolivia have made considerable efforts to assist vulnerable older persons.

Based on the various assessments of the effect of non-contributory pensions on poverty and extreme poverty compiled by Bertranou and others (2004), publicly-funded pensions have proven to be a powerful means of both poverty reduction and social reintegration of vulnerable people who have traditionally been excluded from social security and are prey to economic insecurity.

After conducting a simulation to gauge the potential effect on 17 countries in the region of introducing a universal non-contributory pension or a pension targeted at people aged 65 or over, ECLAC concluded that both programmes reduce poverty among older persons by an average of 18 percentage points (see figures III.16 and III.17). The average cost of the targeted pension is $0.93 \%$ of GDP, while the universal pension requires resources averaging around $2.2 \%$ of each country's GDP (ECLAC, 2006). 
Figure III.16

LATIN AMERICA: EFFECT OF NON-CONTRIBUTORY PENSIONS ON POVERTY

(Poverty rate among older persons)

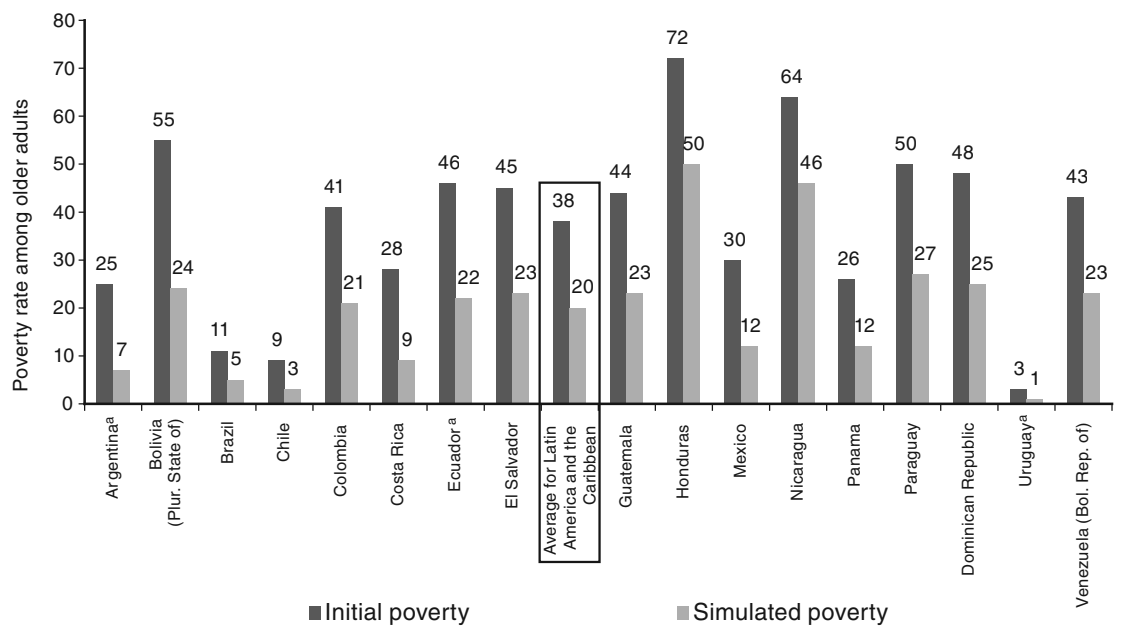

Source: Economic Commission for Latin America and the Caribbean (ECLAC), on the basis of household surveys in 2002, except in the cases of Paraguay (2000), Brazil, Nicaragua and El Salvador (2001) and Chile (2003).

a Urban surveys.

Figure III.17

LATIN AMERICA: COST OF TARGETED AND UNIVERSAL PENSIONS

(Percentages of GDP)

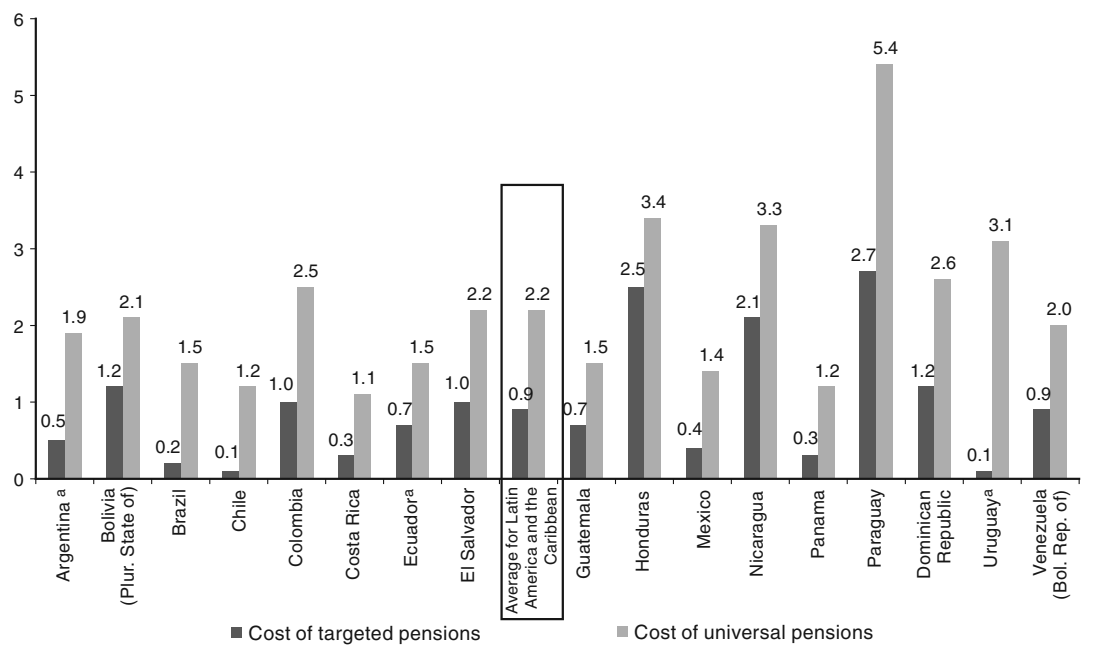

Source: Economic Commission for Latin America and the Caribbean (ECLAC), on the basis of household surveys in 2002, except in the cases of Paraguay (2000), Brazil, Nicaragua and El Salvador (2001) and Chile (2003).

a Urban surveys. 
In a context of population ageing, limited social protection coverage and labour market regulation, non-contributory pensions provide a useful means of reducing inequalities and providing the most vulnerable segments of the population with more economic independence. Although a cash income does not in itself guarantee social integration or the recovery of important solidarity-based relationships (Pisarello and de Cabo, 2006), its development and extension would be a major step towards ensuring greater dignity and security in old age for current and future generations.

\section{E. Progress in implementing the Regional Strategy on Ageing in Latin America and the Caribbean: social security, employment and new business creation}

The International Covenant on Economic, Social and Cultural Rights recognizes work and social security as human rights (articles 6 to 8 , and 9 respectively), placing obligations on the signatory States in terms of compliance, protection and guarantee of rights. The majority of countries in the region have therefore included both work and social security rights as a priority in old-age legislation, policies and action plans.

In spite of widespread support for these rights, in practice, countries' legislative measures and policies have not always led directly to a set of allowances, assets and benefits to which all citizens are entitled. Indeed, in some cases there is a gulf between legislative measures on the one hand, and regulatory, administrative and political, economic and social decisionmaking measures guaranteeing full enjoyment of those rights, on the other. This is what the United Nations Committee on Economic, Social and Cultural Rights (CESCR) pointed out in relation to social security when it expressed its concern at unequal access to and quality of pensions. In cases where credit is due, it has also praised the efforts of the poorest countries to improve the economic conditions of the older adult population. ${ }^{2}$

2 For example, in 2004 the Committee made the following comments about Chile: "The Committee is deeply concerned that the private pension system, based on individual contributions, does not guarantee adequate social security for a large segment of the population that does not work in the formal economy or is unable to contribute sufficiently to the system, such as the large group of seasonal and temporary workers. The Committee notes that women are particularly affected in this regard: 'housewives' and about $40 \%$ of working women do not contribute to the social security scheme and are consequently not entitled to old-age benefits. Moreover, the Committee is concerned at the fact that working women are left with a much lower average pension than men as their retirement age is five years earlier than that of men" (United Nations, 2004). In 2001 it made the following comments about Honduras: "The Committee takes note with appreciation of the family subsidy programmes that are intended to benefit the poorest and most vulnerable groups of the population, in particular children under five years of age, pregnant women and nursing mothers, and elderly persons" (United Nations, 2001). 
In recent years, countries in the region have progressed at differing rates in establishing the right to social security and the right to work in old age. Achievements have been disparate, in terms of target population, areas and type of intervention and amount of funding earmarked. A number of initiatives currently being undertaken by Latin American and Caribbean countries to improve the economic conditions of older persons are described below. The information has been drawn from countries' answers to a survey on Latin American and Caribbean programmes targeted at older persons. Following the Strategy on Ageing recommendations, intervention alternatives have been divided into three categories: (i) social security; (ii) employment and (iii) new business creation (see table III.2).

\section{Social security}

Universal social security coverage is still a pending issue in the region and, faced with demographic change, the challenge is how to increase pension coverage and quality and how to reduce inequalities of access to the pension system for people of working age, extending the noncontributory subsystem of social security.

In the past five years, Latin American and Caribbean countries have made gradual efforts to increase pension coverage and quality, focusing their efforts on improving the quality of pensions and on protecting older persons with no income or no ability to pay contributions. However, there are persistent inequities and inequalities that call for more far-reaching public policy decisions to expand protection to the entire population. Countries that have made efforts to improve pension quality and have increased the value of benefits are: Aruba, Chile, the Dominican Republic, Honduras, Nicaragua, the Netherlands Antilles and Uruguay.

Fewer special protection measures have been implemented for older persons who are unable to pay contributions. Only Argentina has introduced regulations allowing people to cease working at retirement age even though they have not paid enough years of contributions to be entitled to a pension. The law permits them to receive the pension by paying arrears under a payment facilities plan. This initiative will be of direct benefit to women and others with pension coverage gaps. 
Table III.2

PRINCIPAL AREAS OF INTERVENTION OF LATIN AMERICAN AND CARIBBEAN
ECONOMIC SECURITY PROGRAMMES
TARGETED AT OLDER PERSONS

\begin{tabular}{|c|c|c|c|c|c|c|c|}
\hline \multirow[b]{2}{*}{ Countries } & \multicolumn{2}{|c|}{ Social security } & \multicolumn{2}{|c|}{ Employment } & \multicolumn{2}{|c|}{ New business creation } & \multirow[b]{2}{*}{$\begin{array}{l}\text { Other forms of } \\
\text { economic aid } \\
\text { (special bonds, cash } \\
\text { subsidies, family } \\
\text { allowance, other) }\end{array}$} \\
\hline & $\begin{array}{l}\text { Special } \\
\text { protection for } \\
\text { poor people } \\
\text { or those } \\
\text { unable to pay } \\
\text { contributions }\end{array}$ & $\begin{array}{l}\text { Coverage or } \\
\text { adjustment of } \\
\text { pensions under } \\
\text { the contributory } \\
\text { system }\end{array}$ & $\begin{array}{l}\text { Legislation } \\
\text { prohibiting age } \\
\text { discrimination in } \\
\text { employment }\end{array}$ & $\begin{array}{c}\text { Promotion of } \\
\text { employment } \\
\text { for older } \\
\text { workers }\end{array}$ & $\begin{array}{c}\text { Promotion } \\
\text { of loan } \\
\text { opportunities } \\
\text { for productive } \\
\text { activities }\end{array}$ & $\begin{array}{l}\text { Promotion of } \\
\text { productive } \\
\text { initiatives by } \\
\text { older persons }\end{array}$ & \\
\hline Dutch Antilles & & $x$ & & & & & \\
\hline Argentina & $x$ & $x$ & & & & & \\
\hline Aruba $^{\text {a }}$ & $x$ & & & & & & \\
\hline Belize & $x$ & & & & & $x$ & \\
\hline $\begin{array}{l}\text { Bolivia } \\
\text { (Plurinational } \\
\text { State of) }\end{array}$ & $x$ & & & & & & \\
\hline Brazil & $x$ & & $x$ & & $x$ & & \\
\hline Chile & $x$ & $x$ & & $x$ & & $x$ & $x$ \\
\hline Colombia & $x$ & & & & & & \\
\hline Costa Rica & & & $x$ & & $x$ & $x$ & \\
\hline Cuba & & & & $x$ & $x$ & & $x$ \\
\hline El Salvador & & & $x$ & $x$ & $x$ & $x$ & \\
\hline Guatemala & $x$ & & & $x$ & & & \\
\hline Honduras & $x$ & $x$ & & $x$ & $x$ & $x$ & $x$ \\
\hline Mexico $^{b}$ & $x$ & & $x$ & $x$ & & $x$ & \\
\hline Nicaragua & & $x$ & & & & & \\
\hline Panama & & & $x$ & $x$ & & $x$ & $x$ \\
\hline Paraguay & & & $x$ & $x$ & & & $x$ \\
\hline Peru & & & $x$ & $x$ & $x$ & $x$ & \\
\hline $\begin{array}{l}\text { Dominican } \\
\text { Republic }\end{array}$ & $x$ & $x$ & & & & & $x$ \\
\hline Puerto Rico & & & & $x$ & & & $x$ \\
\hline Uruguay & $x$ & $x$ & $x$ & $x$ & & $x$ & \\
\hline
\end{tabular}

Source: Latin American and Caribbean Demographic Centre (CELADE) - Population Division of ECLAC, on the basis of Latin American and Caribbean countries' answers to a survey on programmes targeted at older persons.

${ }^{a}$ Aruba has a non-contributory pension programme with universal coverage.

${ }^{b}$ The Federal District of Mexico has a non-contributory pension programme targeted at all residents over the age of 70 .

Guatemala and the Plurinational State of Bolivia are two of the countries that have devised special protection programmes for all older persons with no income. In the Plurinational State of Bolivia, the solidarity bonus programme, BONOSOL, pays a universal pension to all citizens over the age of 65 , and by 2002 the programme had extended the country's 
pension cover by $40 \%$ (ECLAC, 2006). ${ }^{3}$ In December 2006, Guatemala passed a law on an economic contribution programme for older persons without coverage, following a widespread effort to mobilize social organizations.

In other cases, actions have been targeted at specific segments of the older adult population. They include Brazil's rural pensions programme, Mexico's new rural pensions programme and Belize's programme of non-contributory pensions designed solely for women over the age of 65 . Another selection criterion employed by a number of programmes is age. For instance, in 2003 Argentina extended entitlement to a non-contributory pension to all poor people over the age of 70 with no social security coverage. Another example is the Federal District of Mexico, where the government grants a universal basic pension to all residents over the age of 70, irrespective of the beneficiary's income. Aruba also has a universal programme of non-contributory pensions which covered 13,692 pensioners in 2005, at a cost equivalent to US\$ 83.726 billion for the same year.

This older population segment has also been included in conditional transfer programmes. In Brazil, Chile, Colombia, Panama and Uruguay, poor families with an elderly member receive a grant. Uruguay introduced a novel programme in 2005 - the National Social Emergency Plan (PANES) run by the Ministry of Social Development. One of the Plan's lines of action is to grant a welfare benefit called "citizen income" to anyone in a situation of extreme poverty. Of the total beneficiary population, 7,000 are over the age of 65 . After they cease receiving citizen income, the Social Security Bank (Banco de Previsión Social) pays them a non-contributory old-age pension.

\section{Employment}

The older persons' employment trend analysed earlier in this report arises partly in response to this population's low levels of basic and core skills. The demand for new skills and knowledge places many older workers at a disadvantage, as their training earlier in life is likely to be obsolete (ILO, 2002b). To overcome such problems, countries have implemented a wide range of initiatives, including the provision of job training (Chile, Colombia, El Salvador, Honduras Mexico, Panama, Puerto Rico and Uruguay ) and the development and maintenance of databases and information banks on jobs for older persons (El Salvador, Mexico and Puerto Rico).

Law 3791 an universal old-age income was passed in December 2007, replacing Law 2427 on BONOSOL. The new scheme provides a pension of US\$300 to those aged 60 and over, countrywide. 
Box III.3

PENSION REFORM IN CHILE

Following an intense year of parliamentary debate, Law 20.255, which reformed the Chilean pension system, was unanimously passed by Congress on 16 January 2008 and later enacted on 11 March 2008. The impact of this event, which was huge in Chile on account of its implications for the configuration of the social protection system and its effects on the welfare of present and future generations, reached beyond national borders owing to the influence on other countries of the individual capitalization system implemented in 1981. The pension reform is based on several pillars including: the introduction of a solidary pension system, a new institutional framework, gender equity, greater coverage for selfemployed and young workers, increased competition in the pension industry and fiscal discipline (ILO, 2008).

The reform process began in 2006, at the start of the current administration's term, with the establishment of the Presidential Advisory Council on Pension System Reform. In July of that year the Commission prepared a report that an inter-ministerial committee used as the basis for drafting the bill. On 15 December 2006, the President announced the contents of the bill which was sent to Congress. From there, a group of experts, politicians and stakeholders worked together to reach a consensus so that the bill could be passed (ILO, 2008).

The most important change brought about by the reform was the creation of a system of solidary pensions, which provides for a basic solidary pension for the poor, along with a solidary pension contribution for those who receive low pensions. The basic solidary pension goes to those over 65 who do not receive a pension from any other social security scheme, are members of the low-income population and meet certain criteria established in the Law. The programme started on 1 July 2008. The solidary pension contribution began on the same date and includes a State contribution to older persons who receive low pensions, thus allowing them to increase the value of the pension they receive (www.reformaprevisional.cl).

The reform also includes a series of provisions that directly benefit women aged 60 and over through the implementation of the following measures: (a) a bonus for each living child, consisting of a cash payment made by the State for each living child to all women who meet the eligibility requirements, which increases their pension from the age of 65 onwards; (b) the separation of disability and survivorship benefits for men and women, since currently women pay higher premiums than they should for disability and survivorship insurance. This higher premium will be returned to them via contributions made to their individual accounts, which will increase their final pension benefit; (c) an expansion of coverage for disability and survivorship, making 65 the maximum age for disability and survivorship coverage for both men and women (www.reformaprevisional.cl).

Source: International Labour Organization (ILO), ILO Subregional Office for the Southern Cone of Latin America, "La reforma previsional en Chile y la contribución de la OIT", [online], 2008. 
Other advances have been made to eradicate age-based discrimination in employment, in the form of affirmative action measures or a specific ban on segregating any worker on the grounds of age. In 2002, Brazil, El Salvador, Mexico, Paraguay, Peru and Uruguay adopted such measures, joining a number of countries that had already introduced them (Cuba, Colombia, the Dominican Republic, Ecuador, and Guatemala). Panama has made the most recent progress in this respect. In June 2007, a plenary session of the Panama National Assembly approved a new bill repealing Law 61 of 20 August 1998 (known as the Faúndes Act) that had prevented civil servants over the age of 75 from continuing to work and draw salaries on the government payroll. Panama's new bill came in response to widespread petitions from older people's and civil servants' organizations, especially universities.

Mexico introduced a novel scheme for helping older people to find employment with state support. In March 2007, a decree was signed granting tax incentives to firms hiring older or disabled people. The decree establishes that a tax deduction of up to $25 \%$ of the actual wage shall be granted to improve the welfare of these two groups that are subject to job discrimination.

Uruguay has also implemented an innovative employment support programme to help older perons increase their chances of finding work, supplemented by a number of reception and social support measures - the Social Security Bank's programme for the integrated care of older homeless persons. The Bank has carried out promotion activities at its day centre, which caters for the more basic needs of its target group, provides them with job training and promotes both retraining and the creation of productive microbusinesses. Peru is another country which has also expanded opportunities to enhance the employability of older persons in recent years, with some Ministry of Labour and Employment Promotion programmes also targeting the older adult population.

\section{New business creation}

This is a newer and less common area of government intervention than employment, although the two areas tend to be mutually reinforcing. In general, new business creation concentrates on two spheres of intervention: financial support by means of loans and donations, and technical support or microbusiness promotion.

Loans tend to be targeted at people receiving retirement or other pensions, as in Peru, where the state bank, Banco de la Nación, grants loans to retired civil servants, and in Costa Rica, where there is a loan 
programme for pensioners affiliated to the Teachers' Pension Board (Junta de Pensionados del Magisterio Nacional). ${ }^{4}$ In addition, governments have opened up credit opportunities to groups excluded from the financial market. In El Salvador, for example, a special line of credit was created for older persons in the Mutual Fund for Family Microenterprise (FOSOFAMILIA) and, in Honduras, there are bank microcredit programmes for members of the Central American Chamber of Commerce. In a similar vein, other countries have regulated credit operating conditions. For instance, in Cuba, older persons are given access to long-term loans with payment facilities and, in Brazil, the low-interest loans market has been expanded to include this social group.

There are also varying types of donation to support productive initiatives. Belize has a European Union-funded donations programme for the rural sector that includes older persons. In Chile, older people's organizations can apply for non-reimbursable project financing from a fund subsidized by the Inter-American Development Bank. Mexico runs the 'Tercera Llamada' programme, which funds viable productive initiatives by older persons by means of a joint fund run by a number of public institutions. Honduras runs the Honduran Social Investment Fund (FHIS) for the development of projects to help people to satisfy their own basic needs.

Another path to new business creation is to promote microenterprise. Peru's Ministry of Labour and Employment Promotion runs a programme that fosters the creation of microbusinesses by older persons. El Salvador's Ministry of Labour and Social Security supports older persons' cooperatives by means of the 'Older Entrepreneurs' programme (Adulto Mayor Emprendedor). Costa Rica's Ministry of Labour and Social Security has implemented the National Support Programme for Micro- and Small Enterprises (PRONAMYPE) and the programme 'Entrepreneurs in their Golden Years' (Emprendedores en la Edad de Oro), the latter jointly with the University of Costa Rica.

The measures described in this section reveal that older persons' economic status is beginning to be posted on Latin American and Caribbean public policy agendas. However, this is still at a very early stage. The current momentum stems in part from a favourable international context since the Second World Assembly on Ageing, together with a

4 Since 2006 the National Bank of Costa Rica has been working on an interesting project aimed at older persons and financial products. At the same time its has coordinated its efforts with institutions, associations and businesses that serve older persons with the goal of providing financial services that meet the needs of this segment of the population and of addressing financial illiteracy, awareness raising, education, business creation and intergenerational relations, among others. 
growing awareness of the need to gradually gear public policies to the population's changing age structure.

As with any new public policy issue, before this issue can be included on the agenda, it is first necessary to define the way in which society believes public problems should be addressed. According to the results presented in this section, most countries have opted for an approach centred on employment-promotion and hence centred on new business creation and on addressing poverty among older persons as ways for resolving the problems of economic insecurity in old age.

There has been little experience of rights-based policies in Latin American and the Caribbean. If the State fails to play an active role to ensure that employment really does evolve into systems for distributing income and social recognition (Offe, 1992) and unless the focus on the poorest people is accompanied by a suitable time dimension to gradually extend the benefits to other sectors of the population (OHCHR, 2004), in the future this will infringe two basic principles of rights-based social protection: solidarity and universality.

Other aspects of note in a number of countries are: (i) limited coverage of existing programmes; (ii) poor coordination with other sectoral policies and (iii) non-inclusion of programmes in national budgets. The latter gives cause for concern as, apart from being one of the most important instruments for government management, national budgets are essential to ensure that governments meet their human rights obligations (see box II.3). Progress in this area is crucial to ensure that the programmes currently being implemented really do become government policies and are not conditional upon the priorities of public administrations or international cooperation agencies.

In conclusion, in the past five years the region has come a long way in including economic status as an item on government agendas. Nonetheless, the challenges arising from this policy area are diverse and wide-ranging. In order to meet them it is first necessary to guarantee the sustainability, efficacy and coverage of interventions, focusing on the human rights principles of universality and solidarity. As Latin American and Caribbean countries are well aware of these challenges, they have pinpointed income security as a primary area of concern over the next five-year period and one of the core policies to be addressed without delay. To this end, it is essential not only to improve the economic conditions of today's older population but also to focus attention on the rest of the working-age population because, as mentioned in the introduction to this chapter, social security is still the public policy instrument par excellence that provides the greatest safeguards against the risk of loss of income in old age. 



\section{Chapter IV}

\section{Health protection and ageing in Latin America and the Caribbean}

There is an interrelationship between the epidemiological transition and the demographic transition (Frenk and others, 1991; Galyin and Kates, 1997) that has a direct impact on the demand for health protection. This interrelationship has implications, in other words, as regards the right to access and use a whole range of facilities, goods, services and conditions required to achieve the highest attainable standard of health (United Nations, 2000).

The two transitions interact as population ageing is accompanied by an epidemiological shift from predominantly infectious diseases and high maternal and child mortality to an increase in non-communicable diseases, especially chronic ones (United Nations, 2007b). This has specific consequences for the health systems of the region's countries in terms of the types of disease to be treated and the population groups affected.

The reduction in infectious causes of death benefits mainly children, young people and women, and is largely thanks to, inter alia, mass vaccination programmes, low-cost hygiene and preventive measures and the availability of antibiotics and medicines. Non-communicable illnesses become significant as competitive causes of morbidity and mortality through the incidence of chronic, degenerative and incapacitating diseases. They are progressive, lengthy, and difficult to control and, therefore, more costly to treat.

As infectious diseases become a less prevalent cause of death, the average age of the population rises and the lifespan of those who have survived childhood illnesses continues to expand over time. Eventually, 
the population of older adults - who are more susceptible to chronic diseases than younger people- will grow and the prevalence of noncommunicable diseases will likely increase as well (United Nations, 2007b). Added to this is the higher incidence of other events, such as injuries and falls, which have major implications in terms of maintaining functionality during old age.

The developed countries experienced this transition at a much slower pace than the Latin American and Caribbean region is experiencing it now. In the developed world, the ageing process took place once societies had achieved higher standards of living, less social and economic inequality, and more equal access to health services. In Latin America and the Caribbean, on the other hand, the process is taking place amidst precarious socio-economic conditions, high poverty levels, rising social and economic inequalities and unresolved problems of inequitable access to health services (CELADE, 2003). This essentially means that much of the reduction in mortality in the region is due to exogenous variables (medical discoveries and technology) rather than to higher standards of living (Palloni, DeVos and Peláez, 2002). This goes some way towards explaining why morbidity levels have not fallen and why people remain at risk of spending much of their lives in poor health. ${ }^{1}$

While increased life expectancy is a sign of social and economic development, quality of life during those extra years is even more important. In fact, if medical and technological advances served merely to postpone death, the most direct consequence would be an increase in the lifespan of people suffering disease and debilitating conditions (United Nations, 2007b).

Another hallmark of the region has been the disparity in epidemiological changes, which vary according to the uneven conditions within each country. Thus, demographic and epidemiological processes are further ahead in countries whose populations enjoy higher socio-economic standards and better access to basic services. Conversely, in the most disadvantaged areas, communicable diseases remain the principal causes of morbidity and mortality in all age groups, including older adults (Ham Chande, 2003).

This constitutes a twofold challenge for health protection known as the "epidemiological backlog", whereby the incidence of chronic

Childhood health and health in old age are interrelated. Evidence in recent years has suggested that health in old age (and the prevalence of some chronic diseases) depends on being exposed to and suffering from harmful diseases or conditions during childhood (Barber, 1998; Palloni and others, 2007). For instance, the study by Palloni and others (2007) in Puerto Rico showed that obesity and diabetes (which is on the rise in many of the region's countries) are associated with malnutrition during childhood, while heart disease was also correlated with conditions suffered in childhood. 
and degenerative diseases rises while certain communicable diseases -including respiratory illnesses - and maternal diseases persist. This is a complex dynamic that requires increased investment and resources for treating chronic and degenerative diseases (in terms of both human resources and curative and preventive technologies and instruments), as well as actions to prevent and treat communicable diseases.

Accordingly, the Latin American and Caribbean countries are facing both old and new challenges in the field of health policy. The new challenges relate to changes in demand that require new services and treatments, while the older ones have to do with the region's shortcomings in terms of equal access to timely and quality health services, lack of human and financial resources, and problems of articulation between the various levels of the health-care system and the public and private sectors (ECLAC, 2006).

This chapter reviews and analyses the information available on health and ageing by studying the interactions between the demographic and epidemiological transitions and their consequences for public health, as well as the health requirements arising from epidemiological change in ageing populations and the outlook for health protection in those contexts. The chapter also summarizes the progress that the region's countries have made in terms of the second priority of the Regional Strategy for the Implementation in Latin America and the Caribbean of the Madrid International Plan of Action on Ageing, which relates to health and wellbeing into old age.

\section{A. Epidemiological transition, ageing and the health of the population}

The pace of epidemiological and demographic transitions in the region varies widely. Figure IV.1 shows the obvious increase in the percentage of deaths in the population aged 65 and older for Latin America as a whole and for the four selected countries. Countries that are further along in their demographic transition (Chile and Cuba) have geriatric death rates higher than the regional average. In fact, a comparison between the situations in Haiti and Cuba shows that Haiti will take until 2050 to record the death rates in the population aged 65 and over that Cuba had recorded six decades earlier.

These differences are due, in part, to the different age structures in each country. Cuba has an older age structure than Haiti and therefore its population is more likely to die over age 65 . Similarly, the close link between mortality rate and cause of death by age group explains why Cuba, with its older age structure, also tends to have a higher proportion of 
deaths from chronic degenerative diseases, while a younger population such as Haiti is likely to record a higher proportion of deaths from exogenous illnesses, especially infectious and parasitic diseases, respiratory illnesses and accidents, which occur more frequently in the younger segments of the population.

Figure IV.1

LATIN AMERICA AND THE CARIBBEAN: PERCENTAGE OF DEATHS IN THE POPULATION 65 AND OLDER, 1950-2050

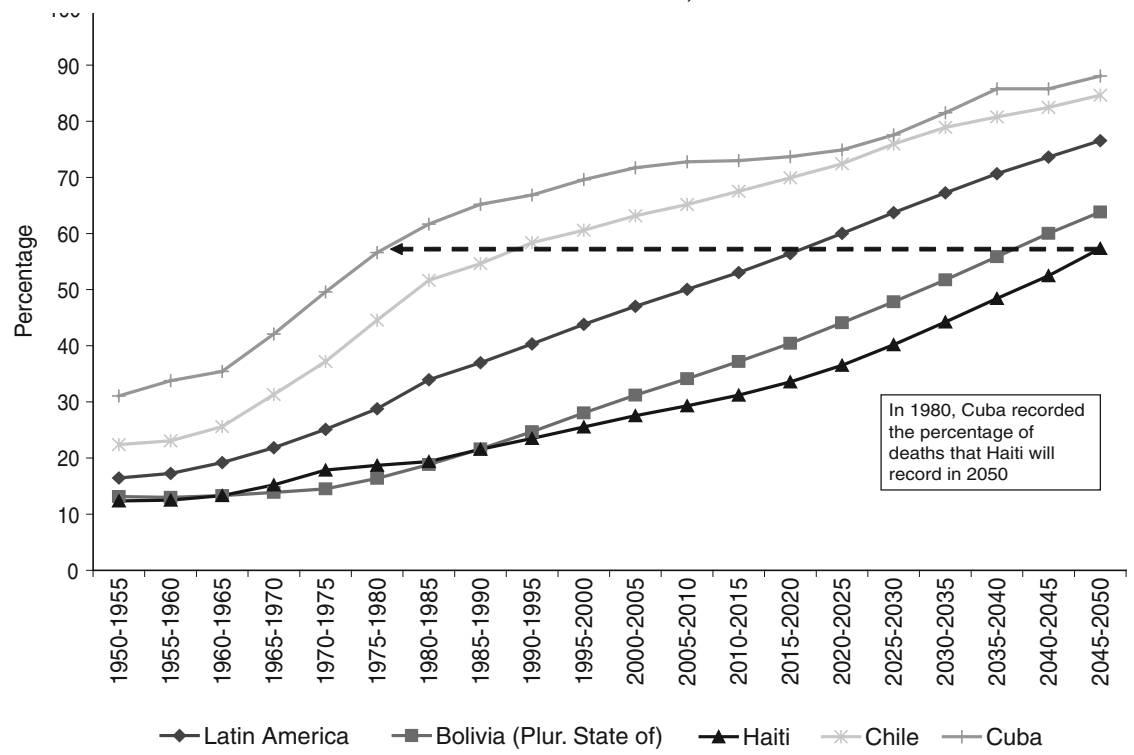

Source: Economic Commission for Latin America and the Caribbean (ECLAC), population estimates and projections for Latin America and the Caribbean as of July 2007 [online] http://www.eclac.cl/celade/ proyecciones/basedatos_BD.htm.

All this supposes a close link between cause of death and the age structure of the population. Figure IV.2, which shows the proportion of deaths from chronic and degenerative diseases as a function of average population age (2002), shows those countries further along in the demographic transition (Argentina, Barbados, Chile, Cuba and Uruguay) at one extreme, with more than $80 \%$ of deaths from those causes and, at the other, those countries about to move into full demographic transition with an ageing process that is still incipient (Guatemala, Haiti, Honduras and Nicaragua, among others). The average age of the population in the latte group of countries is below 20 and the proportion of deaths from chronic and degenerative causes is under $50 \%$, although it is worth noting 
that despite their relatively young population, some countries in this group (Honduras, Nicaragua and the Plurinational State of Bolivia) have proportions of deaths from non-communicable diseases that are similar to countries with moderate levels of ageing.

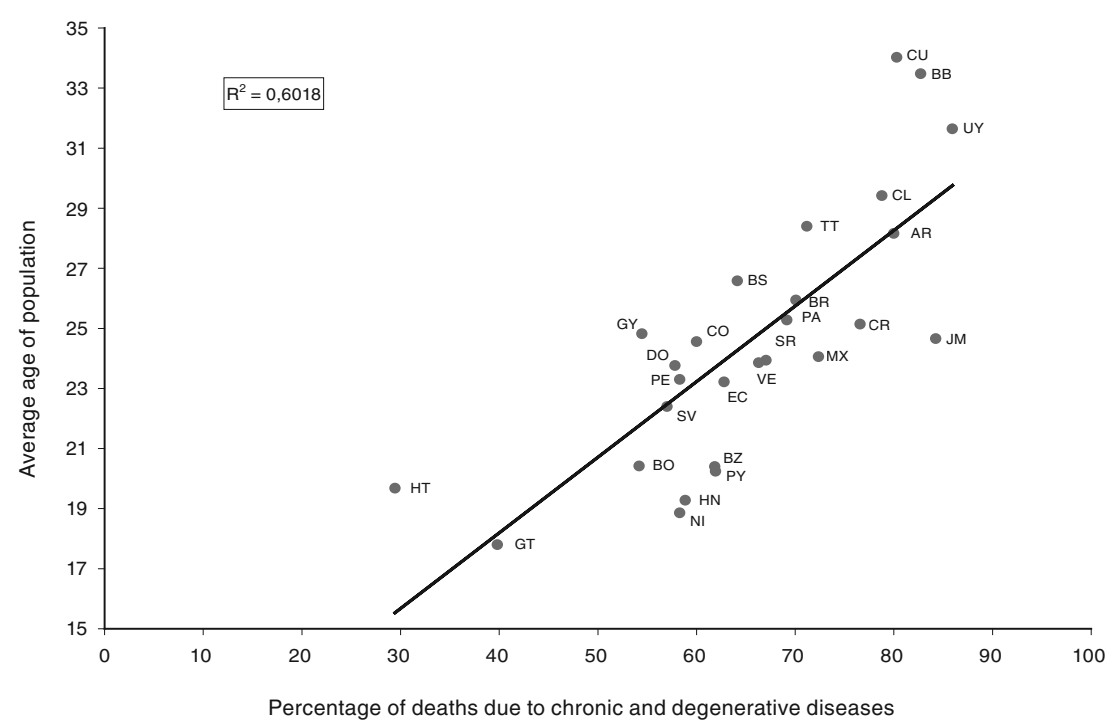

Source: World Health Organization (WHO), "Causes of death" [online] http://www.who.int/research/en/, 2004; and Economic Commission for Latin America and the Caribbean (ECLAC), Social Panorama of Latin America, 2004 (LC/G.2259-P), Santiago, Chile, 2004.

a Average age refers to 2000 and proportion of deaths to 2002.

On average, the Latin American and Caribbean population has a lower life expectancy than that of developed countries, and people also spend much of their lives in poor health conditions. This may be illustrated by comparing life expectancy at birth and health-adjusted life expectancy (HALE) at birth. As shown in figure IV.3, despite the fact that most countries display a considerable increase in life expectancy at birth, each person spends an average of 10 years in poor health (lost health expectancy (LHE)). 
Figure IV.3

LATIN AMERICA AND THE CARIBBEAN: LIFE EXPECTANCY AT BIRTH, BY SEX ${ }^{a}$
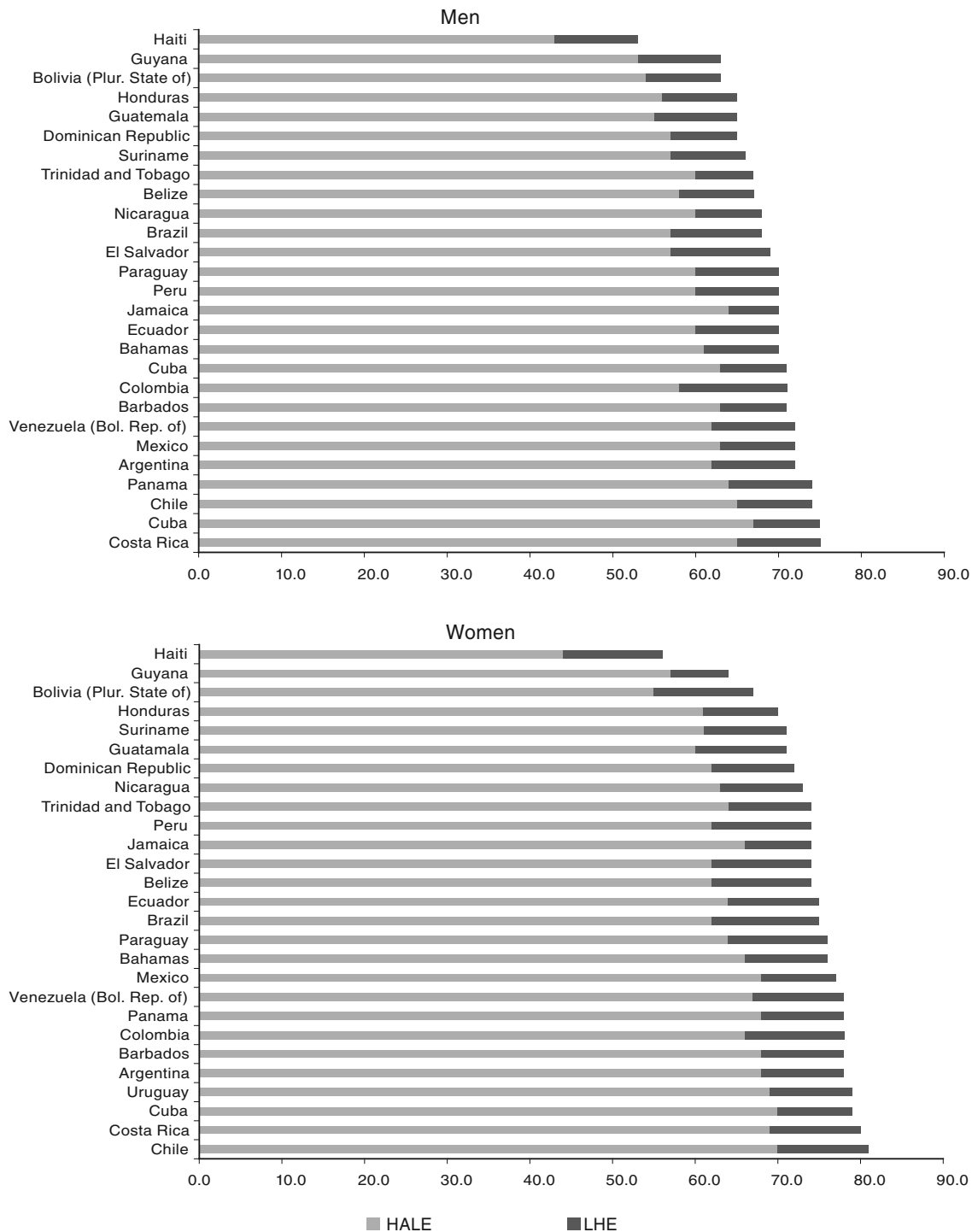

Source: World Health Organization (WHO), World Health Statistics, 2007.

a Expressed in health-adjusted life expectancy (HALE) at birth and lost health expectancy (LHE). Lost health expectancy is the difference between life expectancy and healthy life expectancy at birth and is expressed as a number of years. In this case, health-adjusted life expectancy (HALE) at birth corresponds to 2002 and life expectancy to 2005 . 
The situation varies from country to country. In half of the countries, for instance, men show LHE above the average (9 years), and in Colombia and El Salvador, LHE is 13 years and 12 years, respectively. As for women, 16 countries post rates above average (10.5 years). The country with the worst indicator is Brazil (13 years), followed by Colombia, Paraguay, Belize, El Salvador, Peru, the Plurinational State of Bolivia and Haiti (12 years).

According to several studies (Romero, da Costa Leite and Landmann, 2005; United Nations, 2007b), despite the fact that women have higher life expectancy than men at birth, they tend to spend more years in poor health. In Brazil, for instance, the National Household Survey (PNAD, 2003) found that a higher proportion of women report chronic illness and motor limitations, a proportion that is also closely correlated with income level (Guedes, 2006). In other words, women's physical and social vulnerability is related to both their greater morbidity and the cumulative effect of inequities throughout their lives (PAHO, 1994).

\section{B. Epidemiological profile, health needs and ageing}

Of course, the implementation of health policies and actions requires familiarity with the health needs of the population. One way of summarizing the population's needs is by using disability-adjusted life years (DALYs) per 1,000 people. DALYs offer an indicator of disease burden that enables the classification of a country's main health problems and are expressed as the number of life years lost due to premature death or disability. For the purposes of this analysis, it should be borne in mind that chronic and degenerative diseases have higher associated levels of disability (in the case of neuropsychiatric conditions, for instance) than communicable diseases.

Figure IV.4 shows a breakdown of DALYs by three groups of causes of death: communicable diseases, chronic and degenerative diseases, and accidental and violent causes. The figure shows DALYs per 1,000 inhabitants for each Latin American and Caribbean country, as compared with the averages for the world and for the highest-income OECD countries. The overall level of DALYs in the region is substantially below the world average, but almost $50 \%$ higher than the figure for high-income OECD countries. The largest differences with respect to OECD occur in DALY loss attributable to communicable diseases. 
Figure IV.4

LATIN AMERICA AND THE CARIBBEAN: BURDEN OF

DISEASE INDICATOR, 2002

(Disability-adjusted life years (DALYS) per 1,000 inhabitants)

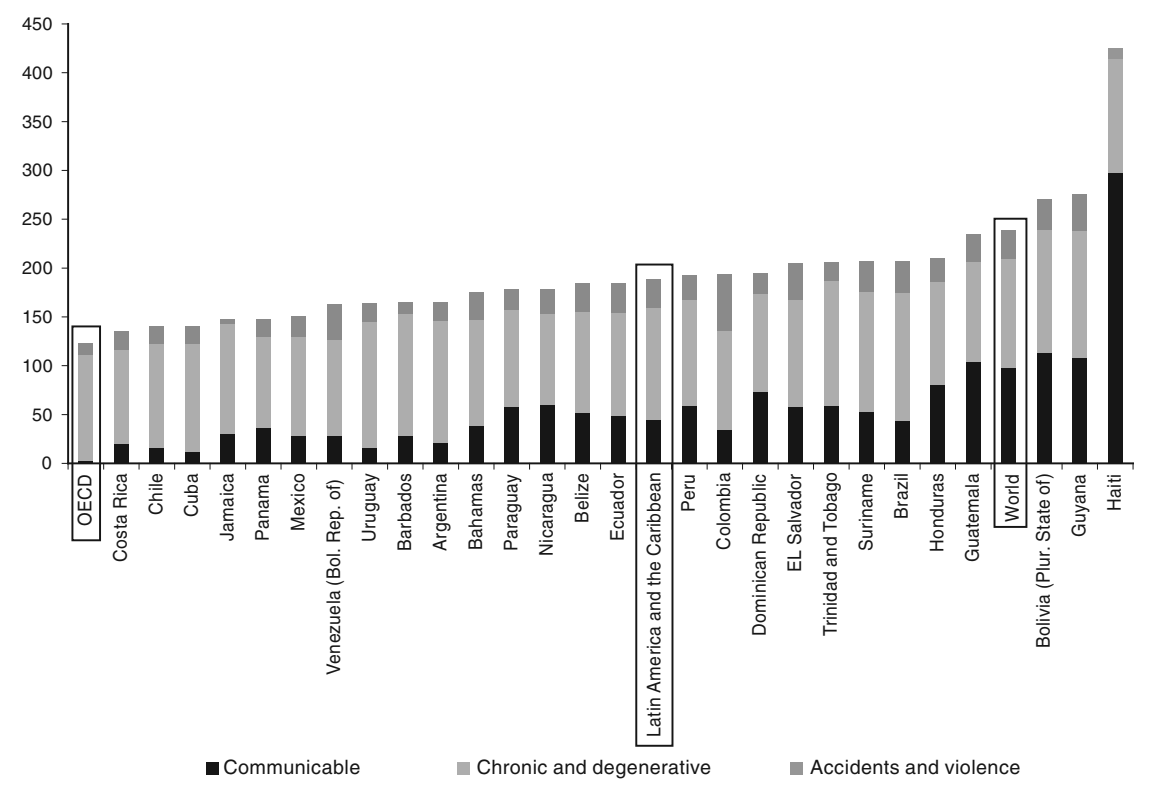

Source: World Health Organization (WHO), 2004. Data relate to divisions by major areas, Economic Commission for Latin America and the Caribbean (ECLAC), Shaping the Future of Social Protection: Access, Financing and Solidarity (LC/G.2294(SES.31/3)), Santiago, Chile, 2006.

Grouping the region's countries by level of income (high, middle and low) shows that, overall, low-income countries have a higher burden of disease (almost equal to the world average). A breakdown by cause of DALYs shows that the poorest countries have a higher incidence of communicable diseases than middle- and high-income countries (ECLAC, 2006). Figures at the country level confirm the overall findings, and show that Haiti is strongly disadvantaged.

Differential analysis of DALYs by age and sex shows where the burden of disease is concentrated. As indicated in table IV.1, the burden of disease tends to be concentrated in old age. However, the breakdown of three major groups of diseases shows that the burden of communicable illness is concentrated in the 0 to 14 age group, while non-communicable causes have the heaviest impact among older adults. These differences apply to men and women alike. Meanwhile, accidental and violent causes are concentrated in male adults (aged 15-59 years). 
Table IV.1 also shows that low-income groups display more DALYs due to communicable diseases than high-income groups at virtually all ages, whereas all socio-economic levels show similar trends for noncommunicable diseases. This suggests that the low-income population group is triply disadvantaged by poverty and high levels of mortality and morbidity due to both communicable and non-communicable causes. This occurs in Panama, where the rate of communicable diseases is higher in disadvantaged areas (including suburbs) and indigenous zones than in the rest of the country (Ministry of Social Development, 2004).

Table IV.1

LATIN AMERICA AND THE CARIBBEAN: BURDEN OF DISEASE INDICATORS BY AGE GROUP, GENDER, CAUSE AND INCOME BRACKET, 2002 a

\begin{tabular}{|c|c|c|c|c|c|c|c|c|c|c|c|c|c|}
\hline & & \multicolumn{4}{|c|}{ High income } & \multicolumn{4}{|c|}{ Middle income } & \multicolumn{4}{|c|}{ Low income } \\
\hline & & \multicolumn{3}{|c|}{ Groups of causes } & \multirow{2}{*}{ All causes } & \multicolumn{3}{|c|}{ Groups of causes } & \multirow{2}{*}{$\begin{array}{c}\text { All } \\
\text { causes }\end{array}$} & \multicolumn{3}{|c|}{ Groups of causes } & \multirow{2}{*}{$\begin{array}{c}\text { All } \\
\text { causes }\end{array}$} \\
\hline & & G1 b & $\mathrm{G} 2^{\circ}$ & $\mathrm{G}^{\mathrm{d}}$ & & $\mathrm{G} 1$ & G2 & G3 & & G1 & G2 & G3 & \\
\hline Total & & 34.8 & 120.0 & 26.6 & 181.4 & 39.3 & 102.8 & 38.5 & 180.5 & 101.3 & 108.0 & 25.8 & 235.1 \\
\hline \multirow{4}{*}{ Men } & $0-14$ & 79.6 & 66.0 & 20.6 & 166.2 & 69.4 & 57.9 & 24.3 & 151 & 170.7 & 65.9 & 22.4 & 259.1 \\
\hline & $15-59$ & 15.9 & 127.0 & 59.3 & 202.2 & 28.1 & 105.4 & 90.5 & 224.0 & 54.3 & 115.4 & 55.2 & 225.0 \\
\hline & $60+$ & 21.9 & 323.9 & 14.3 & 360.1 & 25.1 & 275.9 & 18.7 & 319.7 & 46.0 & 312.2 & 19.5 & 377.7 \\
\hline & Total & 35.8 & 123.7 & 44.0 & 203.5 & 41.2 & 102.5 & 64.0 & 207.7 & 99.2 & 107.5 & 40.4 & 247.1 \\
\hline \multirow{4}{*}{ Women } & $0-14$ & 67.8 & 66.3 & 10.8 & 144.9 & 59.8 & 59.3 & 13.3 & 132.4 & 161.6 & 67.6 & 11.8 & 241.0 \\
\hline & $15-59$ & 20.5 & 113.7 & 10.1 & 144.3 & 28.5 & 103.3 & 13.7 & 145.5 & 71.9 & 113.2 & 11.4 & 196.5 \\
\hline & $60+$ & 18.3 & 282.8 & 5.1 & 306.2 & 19.0 & 262.1 & 6.9 & 288.0 & 42.5 & 295.4 & 6.0 & 343.9 \\
\hline & Total & 33.7 & 116.3 & 9.8 & 159.9 & 37.4 & 103.0 & 13.0 & 153.4 & 103.5 & 108.5 & 11.2 & 223.1 \\
\hline
\end{tabular}

Source: Economic Commission for Latin America and the Caribbean (ECLAC), Shaping the Future of Social Protection: Access, Financing and Solidarity (LC/G.2294(SES.31/3)), Santiago, Chile, 2006.

${ }^{a}$ Disability-adjusted life years (DALYs) for every 1,000 inhabitants, by age, sex, cause and income group.

b Communicable causes.

${ }^{c}$ Non-communicable causes.

${ }^{\mathrm{d}}$ Accidental and violent causes.

One aspect to consider in the light of the above is that the consequences of disability resulting from chronic illness in old age are more severe in society's economically disadvantaged groups, mainly owing to their lack of access to health services (Ham Chande, 2003). Moreover, the projected ageing of the population means that the burden of non-communicable diseases is bound to rise over time, so the demand for more costly health-care services is sure to increase (ECLAC, 2006). This will be in addition to the need to address the epidemiological backlog that disadvantages the most vulnerable in society, regardless of age. 


\section{Burden of disease: the impact of mortality and disability in old age}

The burden of disease provides information on the combined effects of mortality and disability. Death is the event that carries the highest social cost in public health, and disability represents a huge social and individual cost that, in most cases, compromises the quality of life of the individuals and families concerned.

\section{Box IV.1 \\ LATIN AMERICA AND THE CARIBBEAN: SELF-PERCEPTION OF HEALTH IN OLD AGE}

The public opinion survey "Latinobarómetro" (2006) supports analysis of the determinants of subjective health as it includes a question on health over the past 12 months. Within the logistic model, the dichotomous dependent variable "health: (i) good, very good (positive event), and (ii) fair, poor, very poor (negative event)" offers a framework for the determinants of subjective health (age, gender, reported socio-economic status, access to health services, level of education and place of residence).

The model applied to those aged 60 and over helps to define more clearly the health risk factors for older persons, which is considered a key issue. The first finding is the strong effect of the socio-economic component, which persists even after controlling for major variables such as access to health services, age and education. This is the first sign of discriminatory factors in "access" to good health (even if only in terms of self-perception).

The probability of having good or very good health falls with age. However, there is a $U$-shaped relationship between age and self-perception of health after the age of 60 , as those aged $70-79$ are less likely to report good health than those aged 60-69. One probability is slightly higher in the latter group: older men are more likely to report good health than women of the same age. Many explanations have been put forward for these differences (Spizzichino and Egidi, 2007). First, non-fatal chronic diseases are more common among women (Molarius and Janson, 2002; Hoeymans and others., 1999; Idler, Russell and Davis, 2000). Second, women are more attentive to and familiar with their health, and are therefore more likely to report their health problems (Idler, 2003). Another characteristic that affects self-perceived health is level of education: higher schooling increases the probability of reporting good health. The major leap occurs in people with 13 years' schooling or more, who are $200 \%$ more likely than illiterate people to report self-perceived good or very good health (the probability is only $75 \%$ higher among those with 10-12 years' education).

Access to health services is clearly a key factor in enabling older persons to enjoy good health. Those with such access are $195 \%$ more likely to report good health than those with limited access. 
Box IV.1 (concluded)

The model clearly shows that there are considerable differences in the health of older persons according to socio-economic status (echoing the findings of the National Household Survey (PNAD, 2003) in Brazil) and also according to their access to health services (even after controlling for other determining factors). This underscores the importance of one of the key goals related to well-being and health into old age: the ability to access comprehensive health services and the adaptation of services to people's needs and economic conditions.

\section{LOGISTICAL MODEL FOR SELF-PERCEPTION OF GOOD HEALTH (EXP ß) IN POPULATION AGED 60 AND OVER}

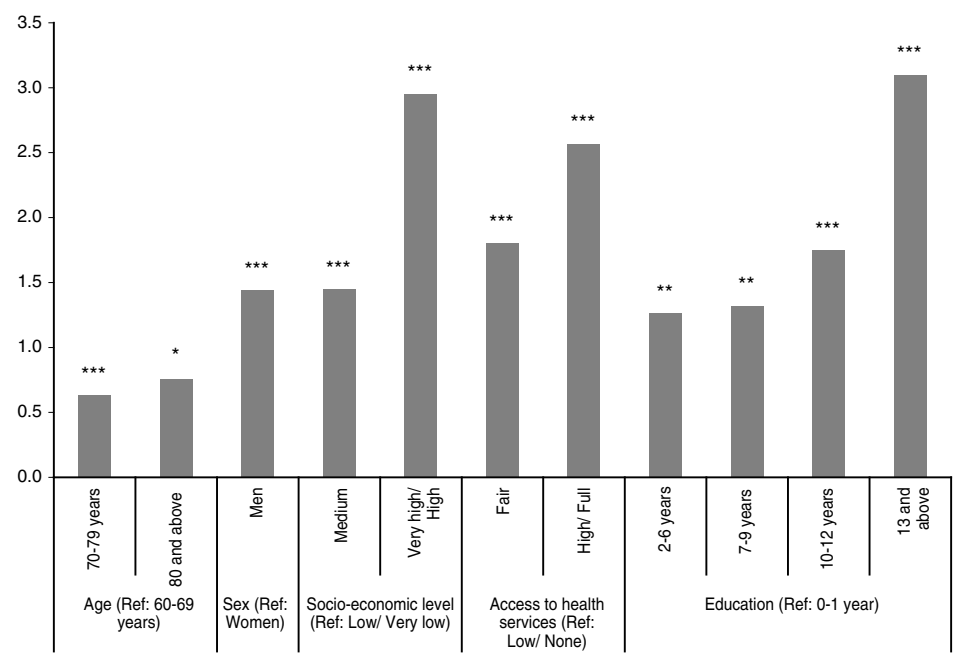

Source: Latin American and Caribbean Demographic Centre (CELADE) - Population Division of ECLAC, on the basis of the Latinobarómetro survey.

Note: ${ }^{* *} p<0.01,{ }^{* *} p<0.05,{ }^{*} p<0.1$. Also included in the model were place of residence and marital status (non significant).

Source: Latin American and Caribbean Demographic Centre (CELADE) - Population Division of ECLAC, on the basis of the 2006 Latinobarómetro survey.

\section{Mortality}

Mortality rates are not only measures of the frequency of death in the population, but are also indicators of the absolute risk of dying of a given cause. Table IV.2 shows estimated mortality rates in men and women aged over 65 by main causes of death in four of the region's countries that are at various stages of the ageing process - Uruguay (advanced), Argentina 
(moderate to advanced), Colombia (moderate), Ecuador (incipient) — in the mid-1990s (1995) and the most recent year of observation available.

Table IV.2

ARGENTINA, COLOMBIA, ECUADOR AND URUGUAY: ESTIMATED MORTALITY RATES FOR MEN AND WOMEN AGED 65 AND ABOVE, 1995 AND 2005

(Per 100,000 inhabitants)

\begin{tabular}{|c|c|c|c|c|c|c|c|c|}
\hline \multirow{2}{*}{ Causes of death/sex } & \multicolumn{2}{|c|}{ Uruguay $^{a}$} & \multicolumn{2}{|c|}{ Argentina } & \multicolumn{2}{|c|}{ Colombia } & \multicolumn{2}{|c|}{ Ecuador } \\
\hline & 1995 & 2001 & 1995 & 2005 & 1995 & 2005 & 1995 & 2005 \\
\hline \multicolumn{9}{|l|}{ Men } \\
\hline $\begin{array}{l}\text { Communicable } \\
\text { diseases }\end{array}$ & 323.7 & 357.5 & 483.6 & 695.1 & 347.0 & 365.8 & 660.5 & 443.1 \\
\hline Circulatory system & 2901.2 & 2400.8 & 3058.4 & 2272.9 & 2680.8 & 2450.5 & 1655.0 & 1458.9 \\
\hline $\begin{array}{l}\text { Ischaemic heart } \\
\text { disease }\end{array}$ & 953.0 & 754.7 & 642.2 & 544.2 & 1133.2 & 1248.2 & 264.8 & 331.6 \\
\hline Malignant neoplasm & 1796.8 & 1818.6 & 1278.4 & 1333.2 & 1011.7 & 1097.3 & 845.3 & 779.6 \\
\hline Diabetes mellitus & 140.0 & 182.0 & 200.9 & 215.3 & 161.9 & 245.7 & 220.9 & 222.3 \\
\hline External causes & 233.3 & 185.3 & 168.5 & 162.7 & 277.4 & 237.1 & 255.1 & 203.9 \\
\hline \multicolumn{9}{|l|}{ Women } \\
\hline $\begin{array}{l}\text { Communicable } \\
\text { diseases }\end{array}$ & 267.1 & 302.9 & 345.6 & 571.9 & 289.1 & 303.7 & 544.2 & 331.9 \\
\hline Circulatory system & 2328.5 & 2017.8 & 2399.4 & 1799.2 & 2374.4 & 2051.3 & 1455.1 & 1338.8 \\
\hline $\begin{array}{l}\text { Ischaemic heart } \\
\text { disease }\end{array}$ & 582.1 & 482.2 & 379.2 & 313.7 & 857.8 & 897.4 & 181.8 & 209.0 \\
\hline Malignant neoplasm & 907.3 & 879.5 & 736.5 & 764.0 & 779.0 & 780.4 & 805.5 & 616.9 \\
\hline Diabetes mellitus & 142.7 & 127.8 & 159.2 & 163.9 & 232.2 & 288.9 & 307.3 & 303.9 \\
\hline External causes & 107.9 & 93.2 & 77.2 & 85.6 & 110.3 & 74.8 & 99.6 & 78.0 \\
\hline
\end{tabular}

Source: Pan American Health Organization (PAHO), special processing, 2007.

a Estimated mortality rates for communicable diseases and diabetes mellitus refer to 2004 .

In the four countries selected, the main causes of death among older persons relate to the circulatory system or malignant neoplasm (in Colombia, the rates are similar for ischaemic heart disease and malignant neoplasm). Predictably, the rates for chronic and degenerative diseases are lower in the youngest country (Ecuador) and higher in countries with more advanced population ageing (such as Uruguay).

Argentina and Uruguay have been able to manage chronic and degenerative illnesses to avoid them resulting in death, whereas Colombia (with moderate population ageing) has not effectively tackled these often fatal illnesses, despite the existence of prevention programmes and technologies capable of palliating their ultimate effect. This may indicate some difficulty in developing and implementing risk-factor monitoring programmes for the primary and secondary prevention of noncommunicable diseases. If this trend continues, it could create long-term 
complications that, if left unchecked, will result in reduced functionality among older persons.

Also noteworthy is the fact that, except in Uruguay, diabetes is having an increasing impact on the health of the older population, particularly women. The rising incidence of diabetes is attributable to a combination of factors that develop over an individual's lifetime (health during childhood, eating habits, and so forth). Diabetes is a disease that responds well to preventive programmes and that, if not treated in time, has serious implications for physical autonomy in old age.

Among the communicable diseases, the main cause of death is acute respiratory illness, which is responsible for the death of around 400 in 100,000 older persons each year. Deaths from this type of cause are typical in low- and middle-income countries, and an increase in the incidence of such diseases is associated with gaps in access to timely health care, among other factors (PAHO, 2002). In the countries studied, the incidence of this type of illness is fairly constant over the different periods. However, the rate is rising among both men and women in Argentina, which could be associated with the timeliness of the influenza vaccination during the period concerned.

\section{Disability}

In terms of this public health issue, countries in the region should visualize what the ageing of their populations will mean in the years to come and evaluate the type of interventions that might be used to extend functional autonomy throughout life. According to the most recent data obtained from special surveys carried out in Argentina, Chile and Uruguay, disability is more prevalent among those aged 65 and above than in the population as a whole (see figure IV.5).

Data by type of impairment for Argentina and Chile show that the largest category of disabilities suffered by older persons is motor limitation (32.0\% and $35.5 \%$, respectively), followed by those related to sensory organs. In many cases, the disability profiles of older persons often involve more than one limitation (36.6\% in Argentina and 15.5\% in Chile).

The prevalence of disability increases in proportion with age. In Nicaragua, for instance, $10.3 \%$ of the nationwide population has a disability, compared with $29.5 \%$ of those aged between 60 and 64 years and $85.3 \%$ of those aged over 80 (INEC, 2003). Changing the measurement criterion to limitations in carrying out activities of daily living (ADL) and restricting the sample to older persons gives a higher disability prevalence rate of $70.9 \%$ among those aged 65 and over $(66.5 \%$ in men and $73.4 \%$ in women) (INEC, 2007). 
Figure IV.5

ARGENTINA, CHILE AND URUGUAY: NATIONWIDE PREVALENCE OF DISABILITY, POPULATION AGED 65 AND OVER, BY SEX

(Percentages)

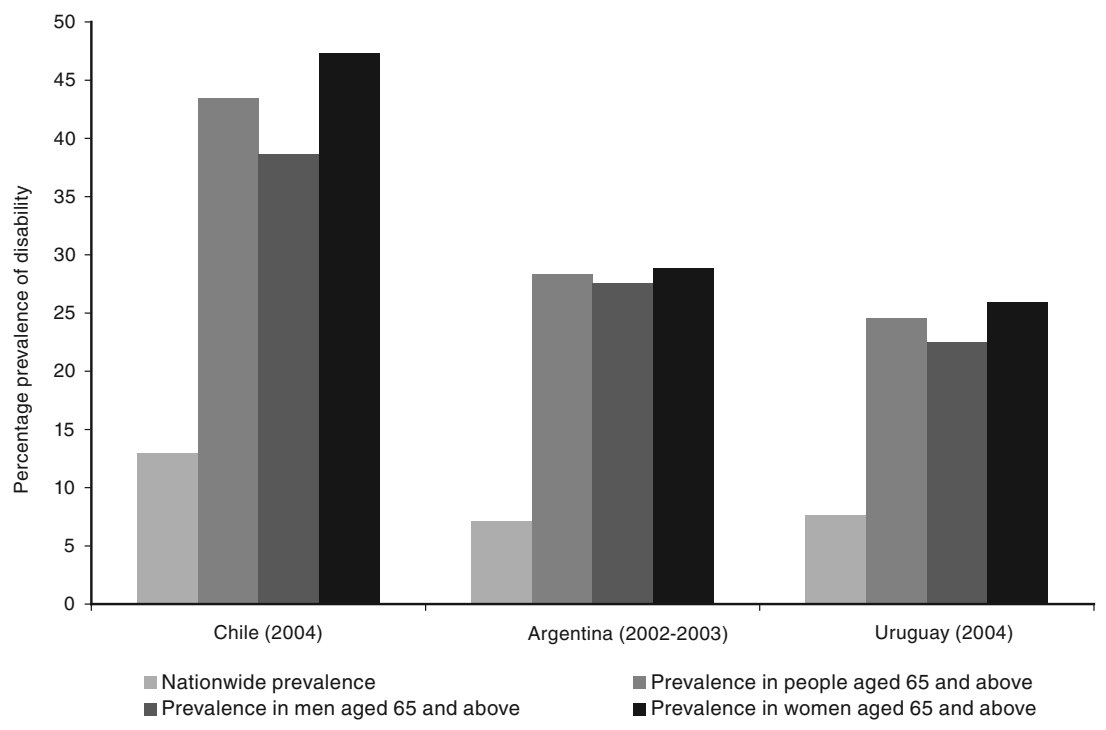

Source: National disability survey, Chile 2004; national disability survey, Argentina 2002-2003; and national disability survey, Uruguay 2004.

Disability is also closely related to poverty. In Brazil, national research showed that older persons at the lowest income levels have the highest levels of disability and have access to fewer medications, prostheses and ortheses (Lima-Costa and others, 2003). Similarly, inequalities in access to formal schooling during childhood increases the risk of dependency in old age. A longitudinal study carried out in Spain showed that people with no primary education (both sexes) were twice as likely to become dependent in old age (Otero and others, 2004). ${ }^{2}$

2 Dependency is understood to mean a lack or loss of personal autonomy for various reasons (principally ageing but also illness, accidents, congenital malformation, and so on) resulting in the individual needing another person's help to carry out the basic activities of daily living (Sempere and Cavas, 2007). 
Box IV.2

INSTITUTIONALIZATION, LONG-TERM CARE AND HUMAN RIGHTS

The findings of various regional and international human rights bodies and specialized agencies of the United Nations show that older persons tend to be in a particularly vulnerable condition, whether in institutions, community homes, long-term care services, psychiatric institutions, health centres or penitentiaries. In long-term care institutions or other services that provide housing or treatment for older persons, it is relatively common to find deplorable living conditions or overcrowding, or treatment that may harm physical or mental health or infringe other basic human rights and fundamental freedoms with frequently irrevocable consequences (Vásquez, 2004).

The rights of residents are fundamental to the functioning of long-term care institutions and all members of staff must actively respect, protect and promote those rights. All residents of institutions have rights and liberties protected in international covenants and national laws, regardless of whether they suffer physical or mental disabilities.

There is little evidence on long-term care institutions in the region and the protection they offer their residents.a However, there is an increasing number of media reports on the terrible living conditions of older persons in this type of institution. Recent research carried out by the Inter-American Development Bank (IDB) and the Pan American Health Organization (PAHO) on the social exclusion of institutionalized older persons with physical and mental disabilities in three Southern Cone countries (Argentina, Chile and Uruguay) shows a heterogeneous situation in terms of these services.

Care requirements are the main reason for entering institutions (49\% in Argentina, $52 \%$ in Uruguay and $63 \%$ in Chile). Argentina has the highest proportion of admittances decided by someone other than the older person him or herself $(12 \%)$, while Chile has the highest percentage of older persons admitted because they have nowhere to live (12\%). Institutionalized older persons in Uruguay have a lower level of functional and mental capacities (45\%), while in Argentina $65 \%$ of residents display no cognitive or physiological degeneration.

The social integration aspects of institution residents analysed in this study were: privacy, visits, outings and mistreatment. Argentina has the highest proportion of older persons sharing a room (almost 90\%), followed Uruguay (nearly $80 \%$ ), with that figure dropping to $55 \%$ in Chile. Most of those who share a room do so with one other person. Between $80 \%$ and $90 \%$ of care home residents receive visits, mainly from family members. As for outings, another critical aspect in such institutions, just under $70 \%$ of residents go out, with poor health being the main cause for not doing so. The proportion of older people who reported being mistreated or witnessing the mistreatment of a fellow resident was $2.4 \%$ in Uruguay, around $8 \%$ in Argentina and $14 \%$ in Chile. These figures are a cause for concern, as the study included a direct question on this issue.

The research findings raised the following suggestions and needs:

- To formulate and apply statutory standards on the establishment and functioning of residential centres and on the oversight of living conditions, human rights and the fundamental freedoms of older persons.

- To strengthen enforcement mechanisms for rules governing establishments in order to protect the rights and freedoms of institutionalized older persons. 
Box IV.2 (concluded)

- To educate service providers and users on optimum care quality, human rights, freedoms and living conditions for well-being and set up effective complaint mechanisms.

With special attention to mental health, to create services and establishments that offer security and treatment while promoting personal dignity to meet the needs of older persons with mental disorders. Similarly, provide mental health services to older persons living in long-term care establishments.

Few countries have introduced legislation to regulate such institutions (Puerto Rico, Peru, the Bolivarian Republic of Venezuela, Costa Rica and Uruguay). In practice, government bodies responsible for overseeing such services usually report problems in assessing compliance with care standards in private institutions; in some cases only institutions that receive State funding are monitored. It is therefore vital to set up effective mechanisms to enable the State to fulfil its obligation to protect the rights to, inter alia, health, freedom, personal integrity, legal protection and informed consent.

Source: Latin American and Caribbean Demographic Centre (CELADE) - Population Division of ECLAC, on the basis of Javier Vásquez, "Discriminación y violencia en la vejez: mecanismos legales e instrumentos internacionales para la protección de los derechos en la edad avanzada", document prepared for the Meeting of Experts on Ageing - Second Central American and Caribbean Forum on Policies for Older Persons, San Salvador, 1012 November 2004; and L. Tellechea, "Derechos humanos en los cuidados a largo plazo", presentation at the Meeting/International Workshop, Havana, 10-12 May 2007.

${ }^{a}$ For more detailed information about this issue in Argentina, see Redondo (2007).

\section{Health spending, ageing and the effect of non-demographic factors}

All issues of health in old age and among the population at large are linked to the coverage and quality of health care in each country. Throughout the region, the health sector has a wide range of institutions and mechanisms for funding, insuring, regulating and providing services (ECLAC, 2006). However, unequal access to health services is a common problem, with tangible consequences for public health. Population ageing poses an additional challenge, as it brings more pressure to bear on available health resources, at a time when countries are still having to contend with many basic health problems affecting other population groups.

Over the last 25 years, health spending has increased considerably. Nonetheless, health spending in the poorest countries has grown slowly, with large inequalities remaining in world health spending (WHO, 2003). Comparing average health expenditure as a proportion of GDP in countries at various stages of population ageing (see table IV.3) shows that, although the region is above the world average, there were no major variations in health spending between the two reference years (2002 and 2004) and no large differences in health spending according to the country's stage of population ageing. 
Table IV.3

LATIN AMERICA AND THE CARIBBEAN: DISTRIBUTION AND LEVEL OF HEALTH SPENDING, 2002 AND 2004

(By stage of population ageing)

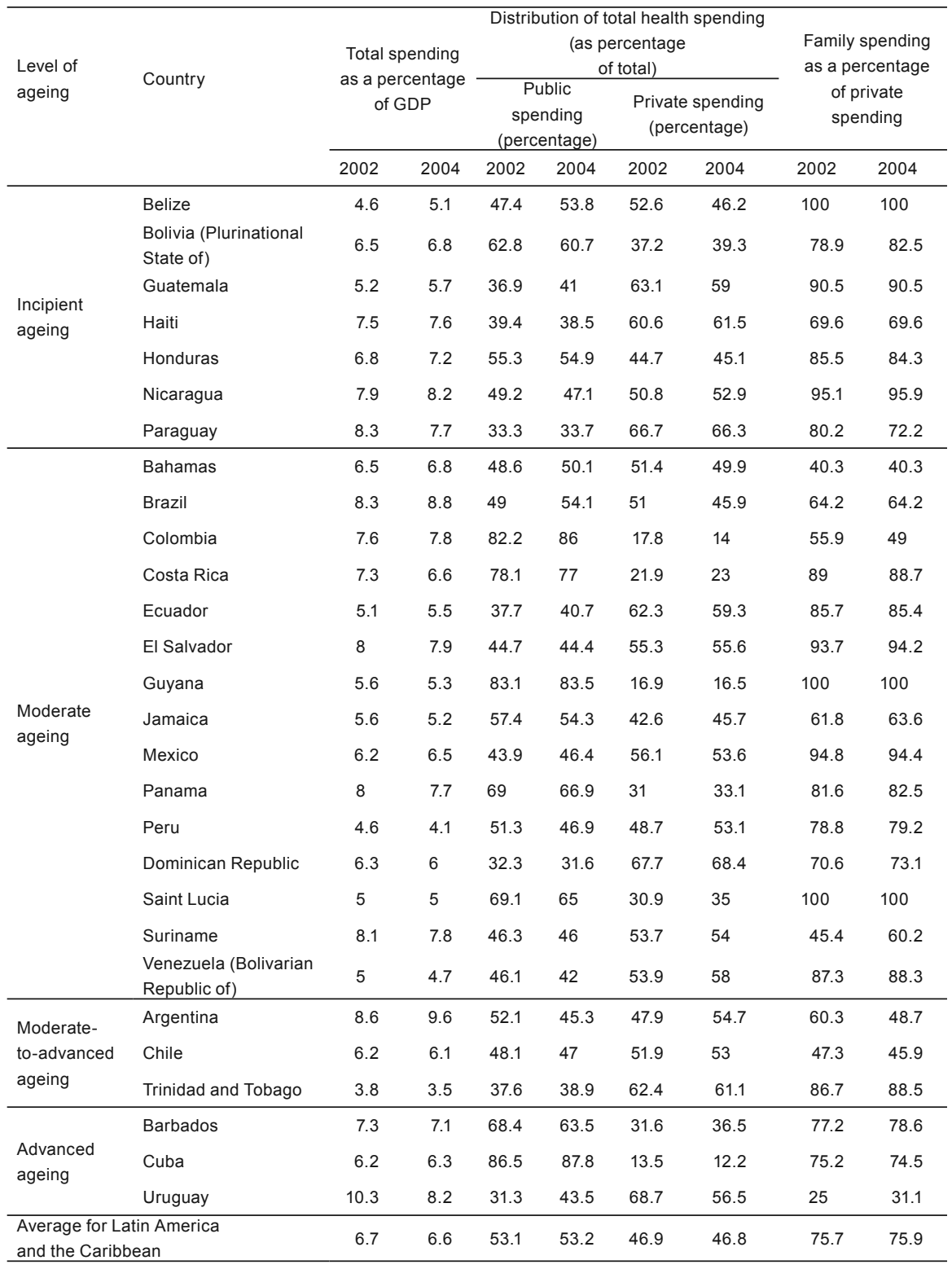

Source: Latin American and Caribbean Demographic Centre (CELADE) - Population Division of ECLAC, on the basis of World Health Organization (WHO), World Health Statistics, 2007. 
In Chile, research by the Superintendency of Health (2006) showed that estimated health spending on older persons was 1\% of GDP in the reference year (2002), rising to $2.1 \%$ in 2020 , given an average annual growth rate of $4 \%$ for the older population. The study found that the increase was less due to demographic factors and more to do with changes in people's health behaviours, inefficient health services, new medical technology and higher prices for medications and health insurance policies.

Although there were no particular patterns in the private-public distribution of health spending based on the stage countries were at in the ageing process (see table IV.3), there was a strong link between that distribution and the country's level of health protection. The higher the level of health protection, the lower private and out-of-pocket spending. Health spending as a proportion of GDP is likely to continue to increase in the future, and it would be problematic if this rise were to be directly absorbed by families funding their access to health services through out-of-pocket spending.

In 16 of the 28 countries analysed there has been an increase in private health spending, with an average of about $75 \%$ out-of-pocket spending. As shown in figure IV.6, the lower public health spending, the higher the level of out-of-pocket spending. This means not only that public spending is limited, but also that families are responsible for the highest percentage of private spending, which results in greater vulnerability to the risks of illness.

This is due to the fact that constraints on the health-care component of social protection translate into serious, morbid events (hypertension, kidney transplants) or minor events (acute respiratory illnesses) which, when recurrent, can lead to major expenditures. Both can have potentially catastrophic impacts on personal and household spending. However, the risk of incurring catastrophic expenses is greater in low-income households, households with older members, uninsured members (or under-insured with high co-payments) or when a member of the household suffers chronic disease or needs frequent hospitalization. Given that some households cannot utilize health services owing to geographical barriers or inability to pay, even greater catastrophes could occur where health protection is insufficient (Perticara, 2008).

The situation of countries in the incipient or moderate stage of population ageing is particularly noteworthy in this context. Ecuador, Haiti, Nicaragua and Paraguay, for instance, have public health spending below $50 \%$, high out-of-pocket spending and a very low proportion of older persons. Given that the pace of population ageing in these countries will be very rapid, and that they must also face the epidemiological backlog amidst widespread poverty, the lack of health protection will definitely worsen unless measures are introduced to strengthen the public system. 
Figure IV.6

LATIN AMERICA AND THE CARIBBEAN: HEALTH SPENDING AS A PERCENTAGE

OF PUBLIC AND FAMILY EXPENDITURE, 2004

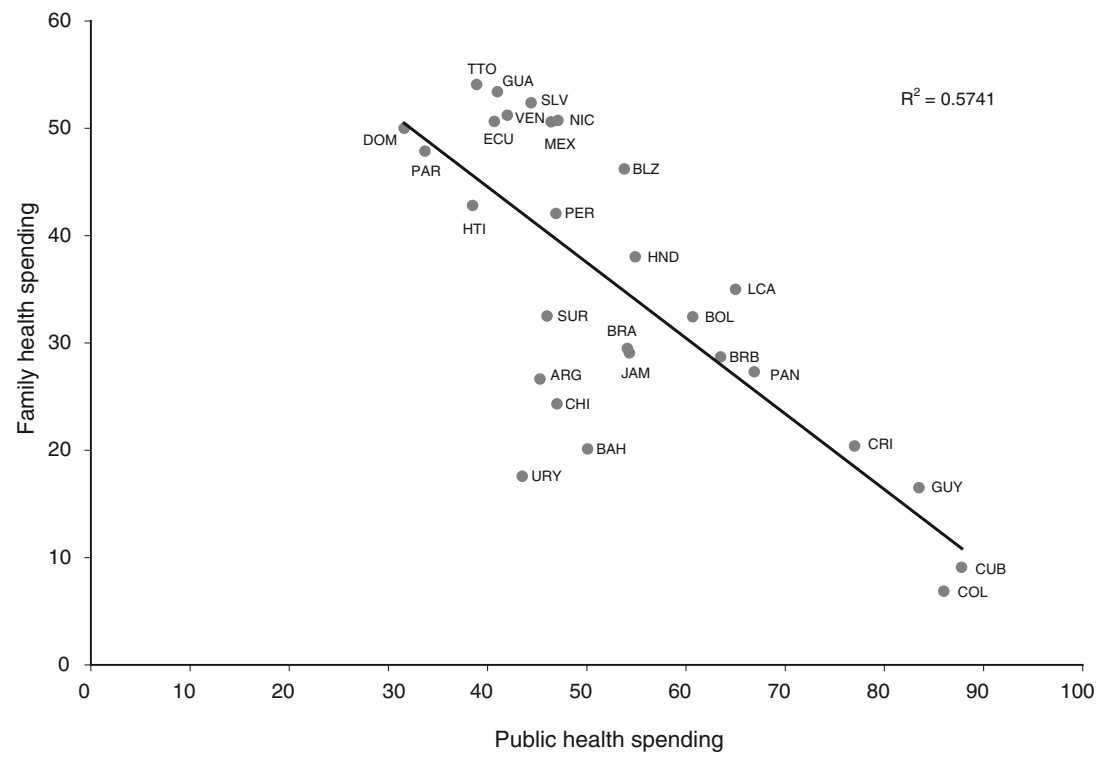

Source: World Health Organization (WHO), World Health Statistics, 2007.

\section{E. Health insurance coverage in old age and inequalities in access to health care}

Where health is concerned, solidarity can be said to exist when access to services is independent of people's contributions to the system or their actual ability to make out-of-pocket payments (ECLAC, 2006). Inequity, on the other hand, stems from having to make out-of-pocket payments to access health services or buy medications (Titelman, 2000). During old age, this is reflected in levels of health insurance coverage and access to health care.

A study on health coverage for older persons in the Southern Cone countries found that, generally speaking, income level was more likely to be a factor of exclusion than age, although this also depends on the type of health system in place within each country.

In Argentina, $76.5 \%$ of older persons are covered by health insurance provided through a workers' association or a group or private health plan. Coverage rates increase in proportion with age $(88.1 \%$ for those aged over 80 and $63.1 \%$ for those aged 60 to 64 ). In Brazil, $70 \%$ of older persons are covered by the public system. In Paraguay, over $83 \%$ of older persons are calculated to have no form of medical insurance and, in the event of illness, either have to foot the bill or go without treatment (OISS, 2007). 
The coverage rates of Argentina and Brazil cannot be extended to the other countries in the region, although even formal coverage levels are no guarantee that insured older persons make consistent and effective use of health services. According to the latest household surveys available in Chile, El Salvador and the Plurinational State of Bolivia, 7 out of 100 older persons with health problems have not visited a health service due to access problems. The proportion of the older population who did not seek treatment for financial reasons ranges from $11 \%$ in Chile and $17 \%$ in El Salvador, to $48 \%$ in the Plurinational State of Bolivia, which has a clear effect on morbidity and disability profiles during old age. Similar results were obtained in the INTRA III study in Peru. In Ecuador, the Demographic and Maternal and Child Health Survey (ENDEMAIN, 2004) found that $68 \%$ of those aged 60 to 74 had this type of difficulties, as did $82 \%$ of those aged over 75 years.

The region-wide panorama confirms this pattern. According to data from Latinobarómetro (see figure IV.7), problems in accessing health care are more acute for older persons with lower socio-economic status. Those of extremely low socio-economic status have no access to health care.

Figure IV.7

LATIN AMERICA AND THE CARIBBEAN: ACCESS TO HEALTH CARE BY OLDER PERSONS, BY SOCIO-ECONOMIC STATUS, 2006

(Percentages)

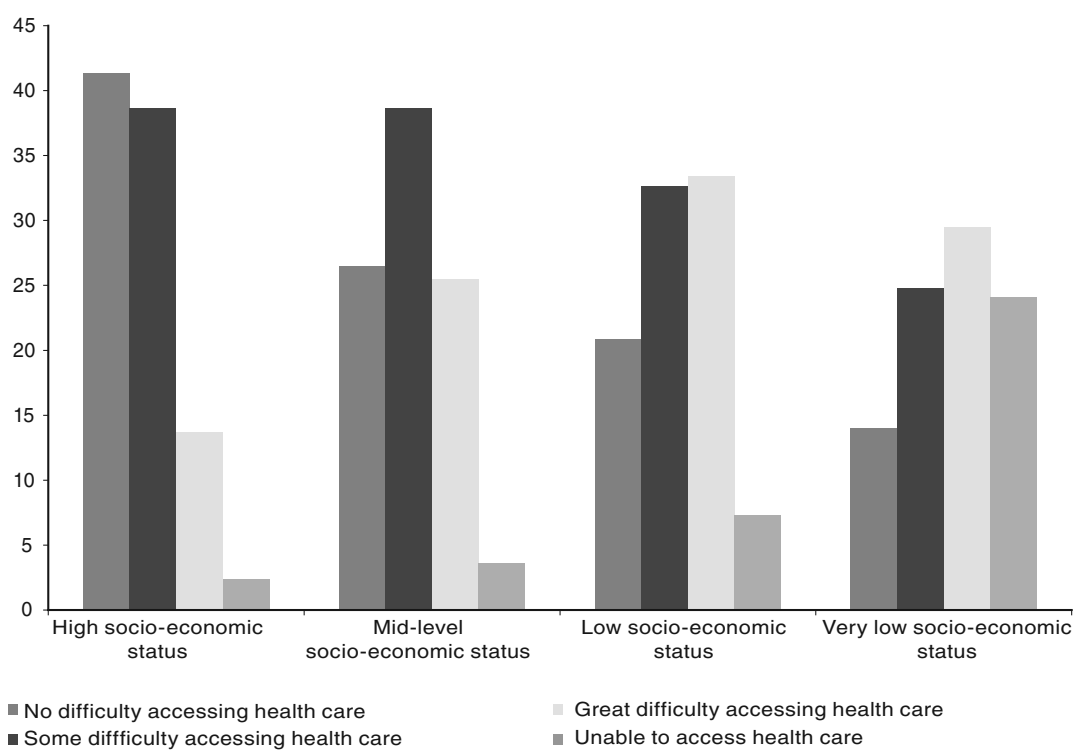

Source: Latin American and Caribbean Demographic Centre (CELADE) - Population Division of ECLAC, on the basis of the 2006 Latinobarómetro survey. 
Although this situation is more common in some countries than in others, it forms enough of a pattern to cause concern. Depending on a country's level of development and how the health system functions, older persons may be faced with two types of situation: (i) widespread deprivation whereby most people find it difficult to access health care and only the most privileged are able to solve their problems, and (ii) persistent inequalities in access, where middle- and high-income groups benefit and those lower down the socio-economic scale find access more difficult, leading to almost permanent exclusion in extreme cases $(\mathrm{WHO}$, cited in Escobar, 2006).

As shown in figure IV.8, in Uruguay older persons of high socioeconomic status report no problems in accessing health care. However, there are no major gaps between this group and the poorest groups who, despite having some difficulties, also report accessing the system when they need to. The situation in Uruguay is less inequitable, although the same cannot be said of the other two countries shown in the figure.

Figure IV.8

EL SALVADOR, HONDURAS AND URUGUAY: ACCESS TO HEALTH CARE AMONG OLDER PERSONS, BY SOCIO-ECONOMIC STATUS, 2006

(Percentages)

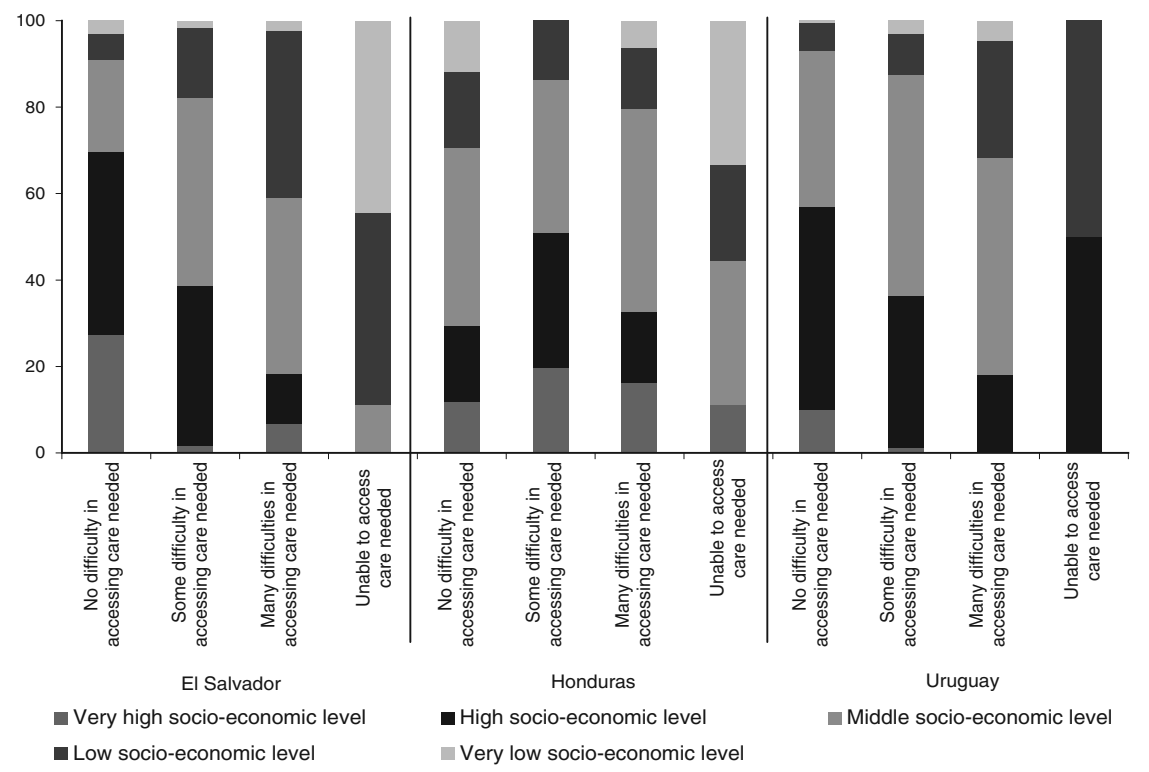

Source: Latin American and Caribbean Demographic Centre (CELADE) - Population Division of ECLAC, on the basis of the 2006 Latinobarómetro survey. 
In El Salvador there are major gaps between older persons of high socio-economic status and the poorest groups, with many of the latter simply unable to access health care. In Honduras, on the other hand, all groups report difficulty in accessing health care; the lowest socioeconomic group show a similar pattern to the rest, in fact with slightly higher levels of trouble-free access (probably thanks to targeted initiatives to combat exclusion). Both countries need to work at extending levels of health protection to the entire population. The strategies recommended by WHO (2003) in this regard aim to combine different forms of targeting (direct, based on characteristics and self-targeting).

\section{F. Explicit guarantees and options for closing health equity gaps in old age}

Improving the health of the older population requires continued investment in curing certain communicable diseases (especially respiratory illnesses), the development of prevention and treatment plans for non-communicable diseases and consideration of how the latter impact levels of functionality among older persons.

To achieve this, countries must make real progress in developing ways to improve coverage for communicable diseases and the pathologies that are the most expensive (in terms of treatment, recovery, morbidity, mortality rates and disability) and the most complex, such as chronic and degenerative diseases. All this must be part of the overall aim to eliminate inequity and solve the problems of social exclusion that dog large swathes of society.

Box IV.3

SYSTEMS INTEGRATED FROM THE START: HEALTH IN THE CARIBBEAN

For historical reasons, such as the colonial heritage in English-speaking countries or scale factors, the public sector in the Caribbean subregion is predominantly vertically integrated, while the private sector insures or provides services to a relatively small proportion of the population (Cuba may be considered an exception, as services are exclusively public).

In all Caribbean countries, except for the Dominican Republic, the bulk of service provision, regulation and funding falls to the public sector, with no explicit separation of procurement, insurance and service provision. The financing of the public system is basically non-contributory and is based on budget allocation and, in some cases, specific taxes. The private sector generally supports service delivery and fundraising. In some countries, the private sector is at the early stages of development, while it has expanded considerably elsewhere (Cercone, 2005). 
Box IV.3 (concluded)

The increasing role played by private insurance and service providers, the high (and rising) level of out-of-pocket health spending and the effects of higher public system costs are pushing the Caribbean region (with the exception of Cuba) towards a model in which the wealthiest seek treatment abroad, middle-income groups use private insurance and services, and the poorest are left with the public system (CCHD, 2006). Reversing this trend and implementing the mechanisms needed to contain the growing system costs are the main challenges facing Caribbean countries in terms of equity and access to health services.

Given that Caribbean countries are expected to see costs rise significantly in the future, mainly due to the growing incidence of cardiovascular disease, obesity and HIV/AIDS (PAHO, 2005b), various reform proposals have been put forward to integrate the system by setting up national health insurance systems as a way of identifying alternative sources of financing and increasing administrative efficiency. Bahamas, Belize, Jamaica, Saint Lucia, Saint Vincent and the Grenadines, and Trinidad and Tobago, among others, are either in the early stages of discussion or are introducing various forms of national health insurance (CCHD, 2006).

The subregion's countries are well placed to implement such reforms, as their historical situation means that they have relatively strong public systems and no financial segmentation between these systems and social security. Such insurance could be funded through general income or the introduction of specific contributions from employers, employees or both, taking care to avoid creating a social insurance system independent of the public sector and thereby segmenting the system.

Source: Economic Commission for Latin America and the Caribbean (ECLAC).

International human rights instruments make reference to universal access to health care. The Committee on Economic, Social and Cultural Rights establishes the progressive realization of the right to health, which involves various States obligations including available, accessible, acceptable and quality health care, as well as moving as expeditiously and effectively as possible towards the full realization of that right (United Nations, 2000).

As a way of advancing in this direction, some of the region's countries have defined packages of explicit guarantees which are offered to the entire population, regardless of economic status or relative risk, or health prioritization mechanisms to organize the investment of resources (Drago, 2007). Despite the fact that explicit guarantees do not always include specific packages for older persons, the mechanism remains an interesting proposition (although it will work only if the population is extremely well informed and the procedure is simple and accessible to all) and could include diseases to which older persons are much more 
vulnerable than the rest of the population, such as cardiovascular disease, muscular-skeletal disease and malignant neoplasm.

As shown in table IV.4, the explicit guarantees that exist in some of the region's countries do not fully include diseases typical of old age or those defined as "catastrophic" that mainly affect those aged 60 and over. This implies that the needs of older persons have not always been fully taken into account in the process of establishing which benefits are to be covered and guaranteed. In some cases, this is because pathologies are prioritized on the basis of prevalence, mortality and morbidity. In other cases, the reason is that guarantees are designed to incorporate segments excluded from health care and to reduce the epidemiological backlog (Sojo, 2006).

Given this context and the recommendation made by ECLAC (2006), the region's basic packages of entitlements should be construed as a means of advancing towards integrated health care systems that provide timely, quality care to the entire population, regardless of risk and income. As countries become more developed, and their population ages, prioritized packages should be progressively extended in accordance with the health needs of the population.

As an alternative strategy, some countries with problematic access to health care or a complex epidemiological profile have defined special packages for older persons that tend to focus on prevention. In the Plurinational State of Bolivia, for instance, free old-age medical insurance guarantees access for those aged 60 and over to public health and social security services such as in-kind assistance for disease insurance, preventive medicine and non-work-related accidents. In Colombia, the Subsidized Compulsory Health Plan (POSS) for older persons enables all those aged 45 and over to undergo a complete medical examination and laboratory tests every five years to detect preventable diseases in good time. Although these packages are not the solution for the major diseases, they are undoubtedly examples that can be replicated and extended to countries that still have a long way to go in upholding the universal right to health.

\section{G. Progress of the Regional Strategy for the Implementation in Latin America and the Caribbean of the Madrid International Plan of Action on Ageing: health services, professional training and long-term care}

The health reforms undertaken in the region in the last few decades have not always resulted in the development of health systems that promote collective and equitable improvements to health. The goal of 
universal access to quality health care faces many stumbling blocks, in particular the lack of financial resources and qualified staff, as well as inequalities in access and quality. According to WHO (2003), it is therefore vital to reinforce health systems and establish priorities for developing health systems if such gaps are to be addressed.

Table IV.4

LATIN AMERICA AND THE CARIBBEAN: PACKAGES OF EXPLICIT UNIVERSAL GUARANTEES AND DISEASES INCLUDED WITH A HIGHER INCIDENCE AMONG OLDER PERSONS

\begin{tabular}{|c|c|c|c|}
\hline Country & $\begin{array}{l}\text { Basic package of } \\
\text { benefits }\end{array}$ & $\begin{array}{l}\text { Coverage for } \\
\text { catastrophic } \\
\text { illness }\end{array}$ & $\begin{array}{l}\text { Coverage for diseases with a higher } \\
\text { incidence among older adults }\end{array}$ \\
\hline Chile & $\begin{array}{l}\text { System of Universal } \\
\text { Access with Explicit } \\
\text { Guarantees (AUGE) }\end{array}$ & Yes & $\begin{array}{l}\text { Visual and cardiovascular health, cancer, } \\
\text { bone and joint disease, mental health, } \\
\text { respiratory health, surgical treatment of } \\
\text { benign prostate hyperplasia, oral health, } \\
\text { polytrauma, neurology, hearing }\end{array}$ \\
\hline Brazil & $\begin{array}{l}\text { Basic Care Plan } \\
\text { (PAB) }\end{array}$ & Yes & $\begin{array}{l}\text { Parkinson's disease, osteoporosis, } \\
\text { Alzheimer's disease, special protocols for } \\
\text { ontological diseases, heart disease and } \\
\text { external causes (such as falls) }\end{array}$ \\
\hline Colombia & $\begin{array}{l}\text { Compulsory Health } \\
\text { Plan (POS) } \\
\text { Subsidized } \\
\text { Compulsory Health } \\
\text { Plan (POSS) }\end{array}$ & Yes & $\begin{array}{l}\text { Hospitalization for observation, low- } \\
\text { complexity surgical interventions, physical } \\
\text { rehabilitation, cancer, prostheses, for hands, } \\
\text { prostheses and ortheses authorized by } \\
\text { law, removal of prostate, uterus, calculus, } \\
\text { cataracts (following } 100 \text { weeks or one year } \\
\text { of contributions), transplant of kidneys, } \\
\text { bone marrow, heart and cornea, dialysis } \\
\text { and haemodialysis, joint replacements } \\
\text { (such as hip), neurosurgery, chemotherapy } \\
\text { and radiotherapy for cancer, major trauma } \\
\text { treatment, cardiovascular surgery }\end{array}$ \\
\hline Mexico & $\begin{array}{l}\text { Industrial health } \\
\text { insurance }\end{array}$ & Partial & $\begin{array}{l}\text { Screening for diabetes mellitus, high blood } \\
\text { pressure, cervical-uterine cancer and } \\
\text { breast cancer, prostatism; diagnosis and } \\
\text { pharmacological treatment of type II diabetes } \\
\text { mellitus, high blood pressure, degenerative } \\
\text { joint disease, closed fracture of long bones } \\
\text { Stabilization of patients (high blood pressure, } \\
\text { diabetes, angina) }\end{array}$ \\
\hline Peru & $\begin{array}{l}\text { Comprehensive } \\
\text { health insurance }\end{array}$ & Partial & $\begin{array}{l}\text { Screening for mental health problems, } \\
\text { early screening for neoplasm, diagnosis } \\
\text { and treatment of distortions, dislocations } \\
\text { and fractures of extremities. Diagnosis } \\
\text { and treatment of medical and surgical } \\
\text { emergencies (max. } 30 \text { days), acute (non- } \\
\text { cancerous) conditions of the digestive } \\
\text { system. Rehabilitation following fractures }\end{array}$ \\
\hline
\end{tabular}

Source: Latin American and Caribbean Demographic Centre (CELADE) - Population Division of ECLAC, on the basis of information from the Ministry of Health of Chile; the Department of Health in Brazil, the Ministry of Social Protection in Colombia, the Health Department in Mexico and the Ministry of Health in Peru. 
Most of the region's countries have set up health programmes for older persons within the relevant ministries or departments. Such institutional arrangements are becoming vital for including matters related to population ageing on the public health agenda. In some cases, these programmes have a steering role on ageing matters such that, in addition to promotion and prevention activities (particularly those to develop personal care and vaccination programmes), they also provide social and health care services. However, there are considerable regional differences in the authority, management capability and resources of these government programmes. There are also broad differences among subregions, with notable particularities in the English-speaking Caribbean specifically. In some cases, the institutions concerned are well-established while others are still being set up.

This section looks at the measures the region's countries have taken in relation to health care for old age, in the light of the recommendations of the Regional Strategy for the Implementation in Latin America and the Caribbean of the Madrid International Plan of Action on Ageing. The information collected is organized under three headings: (a) health services; (b) professional training, and (c) longterm care (see table IV.5).

\section{Health services}

Countries are endeavouring to improve health services for the older population. Strategies include the strengthening of primary health care and the inclusion of specific health care services for older persons; specialized assistance for outpatients, hospital patients and within the home; and pharmaceutical services.

\section{(a) Primary health care}

Primary health care became the central policy of WHO in 1978, with the adoption of the Declaration of Alma-Ata. The basic principles of primary health care are the following: universal access to care and coverage based on needs, health equity, community participation in the formulation and implementation of health agendas and an intersectoral approach to health. Primary health care is usually the first contact older persons have with health services. It is the area in which short-term health problems are resolved and most chronic health problems are managed (PAHO, 2007).

The study "Integrated response of health care systems to rapid population ageing (INTRA)" showed that much remains to be done before primary health care lives up to its guiding principles and the needs of older adults. The difficulties include shortcomings in medical 
Table IV.5

MAIN AREAS OF INTERVENTION OF HEALTH PROGRAMMES TARGETING OLDER PERSONS IN LATIN AMERICA AND THE CARIBBEAN

\begin{tabular}{|c|c|c|c|c|c|c|c|c|}
\hline & \multicolumn{3}{|c|}{ Health services } & \multicolumn{2}{|l|}{ Staff training } & \multicolumn{2}{|c|}{ Long-term care } & \multirow[b]{2}{*}{$\begin{array}{l}\text { Health } \\
\text { promotion } \\
\text { and } \\
\text { prevention } \\
\text { strategies }\end{array}$} \\
\hline & $\begin{array}{l}\text { Inclusion } \\
\text { of ageing } \\
\text { in primary } \\
\text { health } \\
\text { care }\end{array}$ & $\begin{array}{l}\text { Pharmaceutical } \\
\text { services }\end{array}$ & $\begin{array}{l}\text { Specialized } \\
\text { care } \\
\text { (outpatient, } \\
\text { hospital, } \\
\text { home based, } \\
\text { emergency) }\end{array}$ & $\begin{array}{l}\text { University- } \\
\text { level } \\
\text { specialization } \\
\text { in geriatrics or } \\
\text { gerontology }\end{array}$ & $\begin{array}{l}\text { Geriatrics } \\
\text { and } \\
\text { gerontology } \\
\text { training } \\
\text { for health } \\
\text { teams }\end{array}$ & $\begin{array}{l}\text { Development } \\
\text { of } \\
\text { community- } \\
\text { care options }\end{array}$ & $\begin{array}{l}\text { Measures to } \\
\text { regulate the } \\
\text { opening and } \\
\text { operation of } \\
\text { long-term care } \\
\text { institutions }\end{array}$ & \\
\hline Netherlands Antilles & & & $\mathrm{X}$ & & $\mathrm{X}$ & & $\mathrm{X}$ & $\mathrm{X}$ \\
\hline Argentina & & $x$ & $x$ & & $x$ & & & \\
\hline Aruba & & & $x$ & & & & $x$ & $x$ \\
\hline Belize & & $x$ & $x$ & & $x$ & & & $x$ \\
\hline $\begin{array}{l}\text { Bolivia (Plurinational } \\
\text { State of) }\end{array}$ & & & & & & & & $x$ \\
\hline Brazil & $x$ & $x$ & & & & & & $x$ \\
\hline Chile & $x$ & & $x$ & $x$ & $x$ & $x$ & $x$ & $x$ \\
\hline Costa Rica & & & $x$ & $x$ & & $x$ & $x$ & \\
\hline Cuba & $x$ & & $x$ & $x$ & $x$ & $x$ & $x$ & $x$ \\
\hline Dominican Republic & $x$ & $x$ & & $x$ & & & & $x$ \\
\hline El Salvador & & & & & $x$ & & & $x$ \\
\hline Guatemala & & & & & & & $x$ & \\
\hline Honduras & $x$ & & & & $x$ & & $x$ & \\
\hline Mexico & & $x$ & & $x$ & & & & $x$ \\
\hline Nicaragua & & & $x$ & & & & & $x$ \\
\hline Panama & $x$ & & $x$ & & & $\mathrm{X}$ & & $x$ \\
\hline Paraguay & & $x$ & & & & $x$ & & $x$ \\
\hline Peru & & & $x$ & & $x$ & & & \\
\hline Puerto Rico & & $x$ & $x$ & & $x$ & $x$ & $x$ & $x$ \\
\hline Uruguay & & & & & $x$ & $x$ & $x$ & $x$ \\
\hline $\begin{array}{l}\text { Venezuela (Bolivarian } \\
\text { Republic of) }\end{array}$ & & $x$ & $x$ & $x$ & & & $x$ & \\
\hline
\end{tabular}

Source: Latin American and Caribbean Demographic Centre (CELADE) - Population Division of ECLAC, on the basis of replies to the survey on programmes for older persons in Latin America and the Caribbean. 
recommendations, the high turnover of doctors, long waiting times and inadequate infrastructure. Problems of a more structural nature included the fragmentation of primary health care, the lack of specific programmes for older persons and their poor treatment on the part of operators (PAHO, 2007).

The problems identified are common in the countries of the region, with only a handful reporting actions to support primary health care and ageing. In Brazil, the family health programme includes specific services for older persons within primary care. In Cuba, the family doctor and nurse programme includes a regular health check, which serves to refer individuals to a specialized primary structure known as the Multidisciplinary Geriatric Care Team, which assesses, treats and channels patients to secondary institutions where necessary. In Honduras, specific primary care services are included in the basic health package for disadvantaged communities, while Uruguay runs a care and diagnosis protocol for older persons at the primary care level.

\section{(b) Specialized care}

Specialized care for older persons is in the early stages in the region's countries and is being developed in different areas of public health care: within the home, for outpatients and in hospitals.

Home care is a social and health service targeting older persons with some level of dependency. It includes various types of assistance provided in their residences to enable them to remain at home and in their own environment. One of the main advantages of these services is that they reduce institutionalization and hospitalization costs while slowing the functional deterioration associated with old age.

This service is provided in Aruba, Argentina, Belize, Chile, Cuba, the Netherlands Antilles, Peru and Puerto Rico. English-speaking Caribbean countries seem to have more extensive experience in providing social and health services for older persons. One such example is found in Belize City where a comprehensive care programme for older persons is coordinated by civil society. Besides providing health care, the programme offers home-delivered meals and visits from professionals. Aruba has also made progress: in 2007, the Ministry of Health and the Ministry of Social Affairs adopted a strategic plan on continuous care designed to integrate the various levels of health and social assistance. There are currently two pilot projects aimed at identifying patients at risk of suffering cardiovascular accidents and psychiatric patients 
with drug addiction problems. In South America, Chile and Peru are exploring such services, and Argentina has the longest experience and offers the widest coverage, with the national home care programme of the Ministry of Social Development, whose strength lies in combining the needs of the older population, local development and the promotion of employment.

Another type of specialized care is being developed in the outpatient and hospital domains: Costa Rica has an outpatient care service programme (day hospital and medium-term stay); Cuba has geriatric hospital care programmes; Nicaragua has a breast cancer and cervical-uterine cancer care programme that recently extended its coverage to older women receiving widows' or old age pensions; and in the Bolivarian Republic of Venezuela, the National Institute of Social Services is implementing a programme of dental care, multidisciplinary treatment and rehabilitation for older persons. Chile has introduced an emergency treatment system for acute respiratory diseases in health centres, while the Centre for Older Adults in Peru is developing geriatric care programmes for insurance affiliates.

\section{(c) Pharmaceutical services}

According to General Comment No. 14 of the Committee on Economic, Social and Cultural Rights, the basic obligations of States in terms of the right to health include facilitating the provision of essential drugs. Many international agencies have expressed concern over access difficulties and availability of medications for the poorest in society.

Only a few countries have specific measures to facilitate access to medication in old age. One notable experience benefiting older adults and other groups has been under way in Argentina since 2002: the National Medication Policy, which promotes the prescription of generic drugs. This gave rise to the "Remedy" programme, which provides free outpatient medication through primary health care centres, while the Ministry of Health monitors prices to detect any unjustified increases (Escobar, 2007).

Other initiatives to encourage access to medication involve subsidizing pharmaceutical products, as is the case in Belize and the Dominican Republic. Some medicines are supplied free of charge in the Bolivarian Republic of Venezuela and in Paraguay, with the latter supplying free drugs to vulnerable individuals aged over 70 through the Institute for Welfare of the Ministry of Health. In June 2007, 300 people were benefiting from the programme, which aimed to reach 1,000 people by the end of the year. One of the pathologies 
covered by this programme is high blood pressure, and multivitamins and anti-inflammatories are also provided in light of the types of condition suffered by older persons.

\section{Staff training}

One of thorniest problems that health care systems can face is a shortage of staff with which to function. There are two main areas of concern in this regard: a shortage of health workers trained to meet the needs of the older population, and the emigration of health workers (particularly from the English-speaking Caribbean and some Central American countries).

The shortage of health workers has an impact not only on the care provided to older persons but also on that offered to other groups. Although the economic and political landscape is very different to the situation 25 years ago and health requirements have shifted due to demographic and epidemiological changes, medical staff and other health workers (including nurses, technical staff, social workers, psychologists) still have training shortfalls in geriatric care.

The emigration of health workers, both to other countries and within the same country (internal movement towards urban areas), is another emerging issue and one that is also affected by demographic factors. According to WHO (2003), the form of emigration by health professionals that is causing most concern is movement from poor countries to rich countries. The same WHO report points out that "nurses are in high demand in developed countries, partly because of population ageing". This is because baby boomers are now reaching retirement age; this calls for personal and social services geared towards care and health, which in turn fuels migration (Giorguli, Gaspar and Leite, 2006).

Medical specialization in geriatrics is at an early stage in the region, and there tends to be a shortage of medical professionals trained in this area. According to the most recent information available (2007), Puerto Rico has 14 geriatricians; Panama has 20 and Peru 86, while Cuba has 273 doctors specialized in gerontology and geriatrics. Countries that report the availability of geriatrics as a university-level specialization are the Bolivarian Republic of Venezuela, Chile, Costa Rica, the Dominican Republic and Mexico.

One route that is being taken quite frequently and to good effect is to train other health professionals in geriatrics and gerontology, which often provides broader coverage. Cuba has 342 doctors who are not 
geriatricians but who care for older persons following completion of a diploma in gerontology and geriatrics. Chile has trained 347 primary care teams, 350 kinesiologists and 250 other professionals in the adaptation and rehabilitation of non-sighted and partially sighted individuals. El Salvador and Honduras train primary medical workers, nurses and other health workers. Belize has trained nurses and other people to provide longterm care to the older population. The Netherlands Antilles has provided training in psychogeriatrics for health workers. In May 2007, Argentina introduced a gerontology specialization run by the Ministry of Social Development, with 300 students enrolled.

These and other initiatives in the region will broaden the range of professional training opportunities for health teams in the future and will improve countries' capacity to tackle the health needs of their growing populations. As pointed out by WHO (2003), however, progress must be made in developing better incentives to attract and retain medical workers, especially in the most disadvantaged areas (rural communities and poor urban neighbourhoods) and in countries with high levels of health-worker emigration.

\section{Long-term care}

Although countries have made some inroads in policymaking for long-term care, the next few years will bring many challenges. Most of the work is being carried out along two main avenues: developing communitycare options and regulating long-term care institutions.

With regard to community care, Chile has begun setting up integrated community rehabilitation centres, which treat certain pathologies associated with old age. In Cuba, community care initiatives are geared towards preserving and improving the health of older persons through the Grandparents' Circle, Orientation Groups and the 120 Years Club. In Paraguay, rehabilitation workshops on health care for older persons are organized in the community, while Panama recently established a community support system for long-term care. Puerto Rico has various community services to promote the integration of older persons, with the Governor's Office of Elderly Affairs providing funding to over 120 day centres. One of the most important services on offer is meals, both for those who attend the centres and for the housebound. Uruguay and Costa Rica are also promoting day centres as communitybased care options.

The countries that have taken steps to regulate long-term care institutions are Aruba, Chile, Costa Rica, Honduras, the Netherlands 
Antilles and Uruguay. Aruba has restructured its long-term care arrangements and has adapted rest homes to the daily needs of residents. In the Netherlands Antilles, the needs of care institutions are assessed and their operations monitored.

Honduras is implementing measures to improve the capacity of institutions to provide the care needed by its target population. Guatemala and Puerto Rico have mechanisms to oversee long-stay institutions. In Guatemala, long-stay institutions are monitored by the Ombudsman for Older Persons, and in Puerto Rico, the Governor's Office of Elderly Affairs has a Long-Term Care Ombudsman Programme.

\section{Box IV.4 \\ THE INTEGRATED HEALTH-CARE PROGRAMME FOR OLDER PERSONS IN CUBA}

The ageing of the Cuban population will undoubtedly be one of the priorities in the Cuban health-care system between 2006 and 2015. In demographic terms, the country's low fertility levels and low birth rate are expected to fall further and mortality will likely continue to be pushed towards older ages. With the combined effects of fertility, mortality and migration, population growth will be slow and could even stop or go into reverse in coming years. This stationary population pyramid, together with long life expectancy in Cuba, will produce one the fastest and most profound ageing processes in the region (Ministry of Public Health, 2006).

The result in terms of demand for health care is that chronic and noncommunicable diseases and other conditions will be the most prevalent and will have a significant impact on the morbidity and mortality structure. This situation will require preventative and health-promoting approaches, as well as the development of more advanced services and technologies which will inevitably increase health-care costs since the process of population ageing will be accompanied by increasing numbers of people with handicaps or disabilities (Ministry of Public Health, 2006).

Seeking to address the main problems affecting the population, particularly order persons, in 1996 the government created the Integrated Health-Care Programme for Older Persons. Fully State-funded, the scheme has three subprogrammes -community care, institutional care and hospital care- and covers $100 \%$ of the country's older population.

The community care subprogramme has two components. First, primary care, where staff are based in the community and provide outpatient monitoring in order to keep older persons in the community for as long as possible. It includes health evaluations for older persons to check morbidity, functionality, nutrition and oral health among other aspects. The second component is provided through a multidisciplinary gerontology team which ensures comprehensive care for at-risk older persons. It offers specialized medical care through a system of geriatric evaluations, coordinates institutional responses to address the needs of elderly patients, 
Box IV.4 (concluded)

supports family physicians in the primary care health system and helps the community to develop healthy habits. The community care subprogramme is complemented by other services including the Círculos de Abuelos, (Grandparents Circle) attended by $43.7 \%$ of the country's older adult population and the Programa de atención al anciano sólo (Care for elders alone) which covers $71.2 \%$ of the total elderly population living in singleperson households.

The institutional care subprogramme is aimed at raising the quality of life and fulfilment of older persons in institutions and their families through support, prevention, care and rehabilitation, working closely with other levels of care and with the collaboration and participation of the community. There are 144 older persons' homes in the country ( $84 \%$ State-run) with a total of 7,920 residents ( $0.46 \%$ of the country's older adult population). These facilities are staffed by physicians, nurses, physical therapists and psychologists among others. The National Office for Older Persons' Care and Social Services evaluate the management of these homes and offer performance support. The institutions go through a rigorous process of accreditation and since 2000 emphasis has been placed on aligning evaluation, care, treatments and guarantee of rights with international standards. Accordingly, the regulations in place prohibit the use of physical restraints and require proper use of medicines and periodic review of multiple medications used by residents.

The hospital care subprogramme seeks to improve the quality of medical and social care for older adults in hospitals through services for support, prevention and integrated therapy (including rehabilitation). There are 273 geriatric and gerontology specialists and 342 primary care general physicians who have postgraduate training in geriatrics and gerontology and work in health care for older persons. With a view to ensuring the availability of trained professionals in the future, yearly reviews are conducted of the human resources available to tend to the needs of the older population in each province and curricula for undergraduate and postgraduate specialization courses are designed to offer to health professionals.

Source: Ministry of Public Health of Cuba, "Informe de Cuba sobre la aplicación de la Estrategia regional de implementación para América Latina y el Caribe del Plan de Acción Internacional de Madrid sobre el Envejecimiento", 2007.

The countries have clearly been broadening their efforts to improve services and benefits for the older population, although much remains to be done. The main challenges over the next five years include: strengthening health programmes for older persons; ensuring that financial resources from international cooperation do not replace national resources (especially in basic public health items such as vaccinations); and tackling head on the inequalities in older population's access to health care caused by the major differences between the benefits offered to retirees and pensioners by social security institutions, on the one hand, and those offered to the rest of the older population by Ministries or Departments of Health, on the other. 
All this, combined with the particularities of the demographic and epidemiological transitions in the region, suggests that national protection in the countries should move towards strengthening the solidarity mechanisms needed to provide equitable access to health services for the whole population (ECLAC, 2006). Such measures are essential for older persons and other vulnerable groups in society, such as children and adolescents, the disabled and those living in poverty.

Health is a fundamental human right that should be enjoyed throughout a lifetime, irrespective of income and illness risk. The information set forth in this chapter draws attention to the deep-seated inequalities driven by socio-economic status, as well as gaps in access to health care for those living in rural areas or poor urban suburbs. Against this backdrop, in the short term it will be a tough proposition to manage the region's double morbidity burden, achieve the Millennium Development Goals and improve autonomy in old age unless health systems are strengthened. 


\section{Chapter V \\ Enabling environments and ageing in Latin America and the Caribbean}

\section{A. Living arrangements and ageing}

The demographic picture in the countries of Latin America and the Caribbean has altered profoundly in recent decades because of rapidly declining fertility and rising life expectancy. These changes have been a critical factor in shaping new living arrangements, with the result that there are now a host of new types of households and family arrangements (Arriagada, 2007). ${ }^{1}$ Families extending over three or even four generations have become common and although there are also older persons who live alone, this is less likely to be the case in Latin America and the Caribbean than in other regions of the world.

The composition and structure of households are associated with demographic, economic and cultural factors that are the driving forces in their formation, alteration and dissolution. The fact that many generations live together under one roof may be the result of three factors: (a) inadequate resources; (b) progressively declining health, which prevents a large proportion of older persons from living independently; and (c)

1 The author indicates that these transformations increased particularly from 1990 to 2005. Among the most notable changes were the decrease in the number of nuclear families, a drop in two-parent nuclear families with children, an increase in single-parent households headed by women and an increase in non-family households, especially single-member households. 
the difficulties that people have attaining financial independence, which forces them to remain a part of their parents' household (ECLAC, 2000).

From the cost-benefit standpoint, co-residence with others can benefit both older persons themselves and other household members by providing them with companionship and physical and financial support, although it can also contribute to the loss of privacy, a reduced social status for the older person, and excessive physical and emotional demands on the families of older persons with physical or mental impairments (Martin, 1990 en Saad, 2004).

Whether or not older persons live independently is very largely a matter of physical and financial viability. Older persons who are in good health or can pay for support services, and who can defray the costs of running a home, are more likely to choose to live independently. Once these prerequisites are in place, however, there are a number of other factors that may be evaluated. These include the location of the dwelling (close to services, low-cost transport facilities, opportunities for keeping up networks of friendships, etc.) and its design (number of rooms, temperature and noise control, indoor safety, etc.). Owing to the difficulties of representing the diversity of living arrangements through statistics, households were divided into two categories for the purpose of assessing older persons' living arrangements: multigenerational households and single-person households. In addition, a typology was constructed to measure the relative importance of the resources contributed by older persons to multigenerational households with a view to determining their degree of financial independence from other household members.

\section{Households containing older persons: multigenerational arrangements and independent living in old age}

Despite the changes on the horizon, the proportion of older persons is still below $10 \%$ in a large number of countries in the region. An analysis of the proportion of households containing one or more older person shows, however, that at least two in every ten households in the region include an older person.

A more detailed analysis of this indicator reveals a significant relationship between the percentage of households containing older persons and the relative size of the older population (see figure V.1). Thus, multigenerational households represent about $20 \%$ of total households in countries where ageing is incipient and almost $30 \%$ in countries where it is moderate to advanced. Some exceptions are Ecuador and Brazil, where 
ageing is moderate but multigenerational households make up $27.3 \%$ and $19.8 \%$, respectively, of the total.

Figure V.1

LATIN AMERICA (SELECTED COUNTRIES): RELATIONSHIP BETWEEN THE PERCENTAGE OF OLDER PERSONS AND THE PERCENTAGE OF HOUSEHOLDS CONTAINING OLDER PERSONS, 1990 AND 2000 CENSUSES

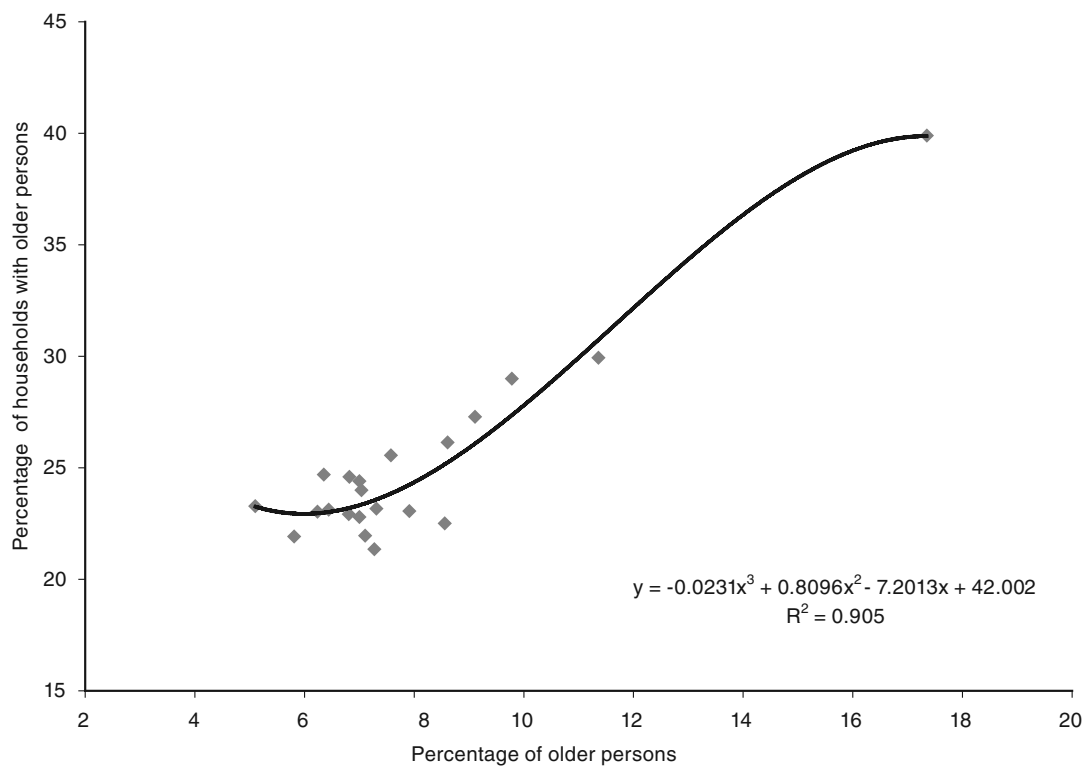

Source: Latin American and Caribbean Demographic Centre (CELADE) - Population Division of ECLAC, on the basis of processing of national population censuses and microdata.

Ageing becomes more evident at the household level, where older persons play an important role either as heads of household or secondary members. In countries like Chile, Ecuador and Panama the percentage of rural households with older members exceeds $30 \%$ (see figure V.2). Conversely, the highest percentage of households with older members (around 25\%) can be found in urban areas of Argentina, Costa Rica, Guatemala and Nicaragua. 
Figure V.2

LATIN AMERICA AND THE CARIBBEAN: HOUSEHOLDS CONTAINING

OLDER PERSONS, 1990 AND 2000

(Percentages)

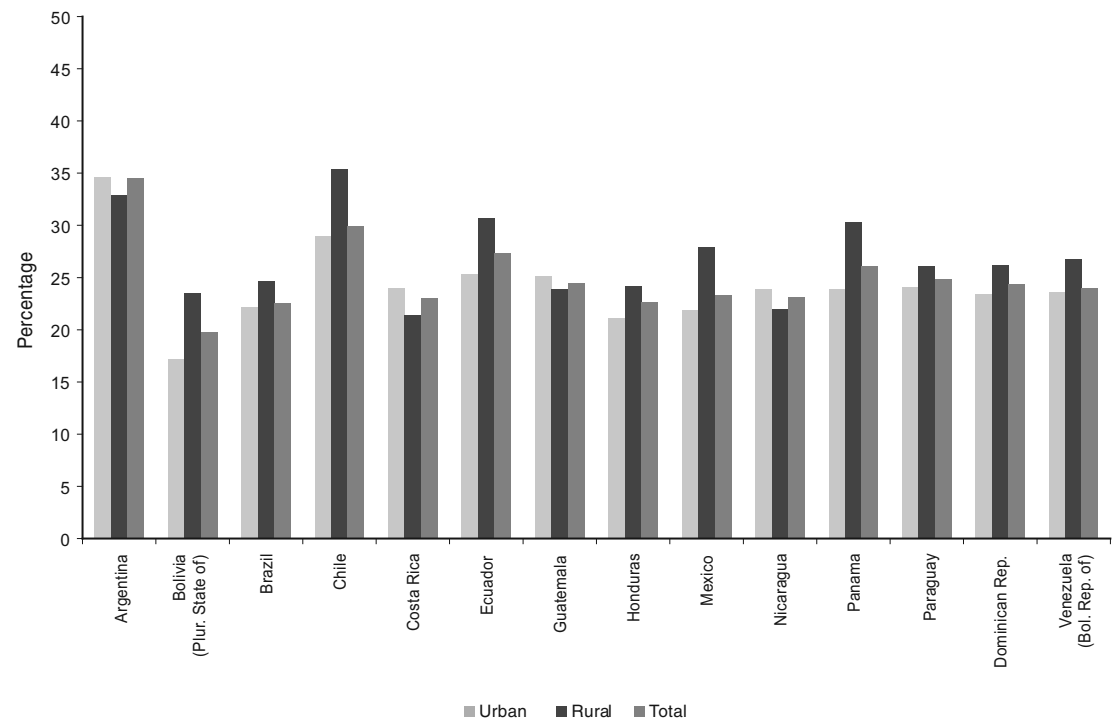

Source: Latin American and Caribbean Demographic Centre (CELADE) - Population Division of ECLAC, on the basis of processing of national population censuses and microdata.

In Latin America and the Caribbean as whole, the proportion of older persons who live alone is not as high as in other regions of the world, and in most countries does not exceed $17 \%$. A comparison of trends observed during the 1990 and 2000 censuses, however, shows a possible increase in the probability that older persons might live alone. The countries with the highest figures on independent living in 2000 were Argentina (16.6\%) and the Plurinational State of Bolivia (15.6\%) (see figure V.3).

According to the available information,except in the case of Brazil, older persons are more likely to live alone in rural than in urban areas (see figure V.4). One study indicates that rural-urban migration is the main factor breaking the bonds of co-residence and proximity. Migration does not, however, necessarily entail the rupture of emotional ties or the absence of monetary transfers. Nevertheless, the distance separating older persons in rural areas from offspring living in towns rules out the kind of instrumental support that the former might require for carryingout the activities of daily life (Iwakami, Camarano and Leitão e Mello, 2004). 
Figure V.3

LATIN AMERICA (SELECTED COUNTRIES): PERSONS AGED 60 AND

OVER LIVING ALONE, 1980, 1990 AND 2000

(Percentages)

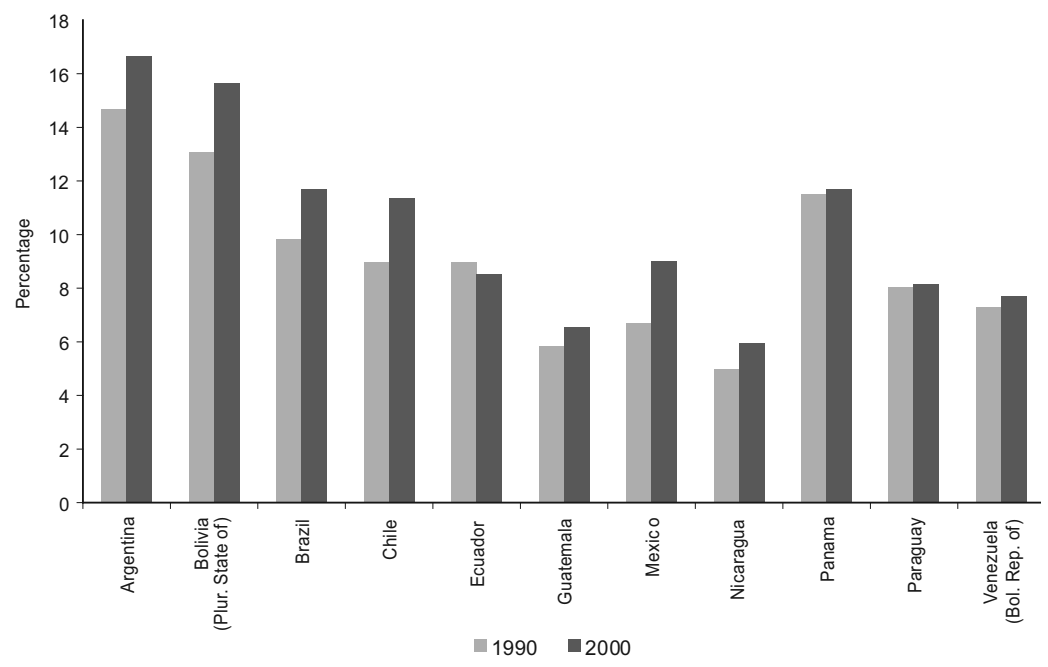

Source: Latin American and Caribbean Demographic Centre (CELADE) - Population Division of ECLAC, on the basis of processing of national population censuses and microdata.

Figure V.4

LATIN AMERICA (SELECTED COUNTRIES): PERSONS AGED 60 AND

OVER LIVING ALONE, URBAN AND RURAL AREAS, 2000

(Percentages)

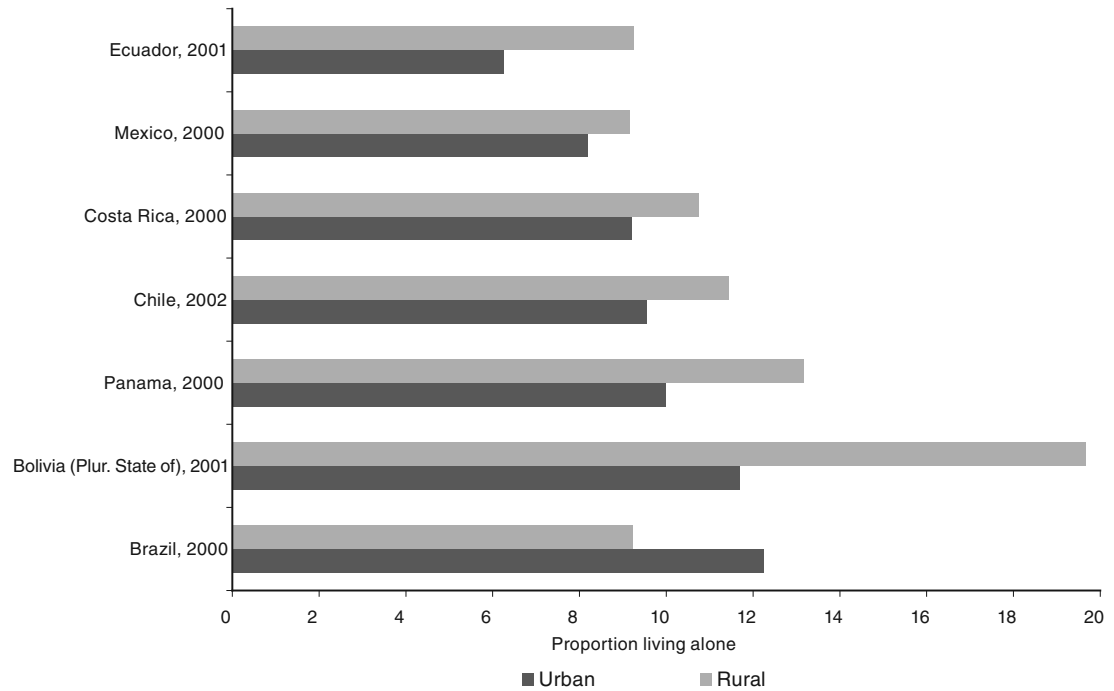

Source: Latin American and Caribbean Demographic Centre (CELADE) - Population Division of ECLAC, on the basis of special processing of national population censuses and microdata. 
There are subregional differences in the percentages of older persons living alone. Independent living is more prevalent in the Caribbean than in South and Central America, where the figures are considerably lower (United Nations, 2006b). In any event, in the region as a whole, there are fewer older persons living alone than in other parts of the world. According to data from the United Nations Population Division (United Nations, 2006b), this type of household represents $9 \%$ of all households containing older persons, a percentage very close to that seen in Africa $(8 \%)$ and Asia $(7 \%)$, whereas the figure in Europe and North America is $26 \%$.

Looking beyond the figures, the main difference between older persons living alone in the region and in the developed countries is that in the latter they are more likely to live alone as a matter of choice and conditions are favourable to this type of arrangement. In Latin America and the Caribbean, on the other hand, living alone may represent a risk for older persons lacking a better choice (Saad, 2004).

\section{Co-residence and opportunities for mutual support between generations}

Multigenerational households remain a good option for older persons and their families in the region as they facilitate support for older persons with a high level of vulnerability (Saad, 2004) and can benefit from older persons' income contributions to family resources (ECLAC, 2000).

There is a clear relationship between the contribution made to the family budget by older persons in multigenerational households and the incidence of poverty. In poor households where the older person's contribution is small (less than 25\%), co-residence is often associated with financial dependency or care needs of the older members. In poor households where the financial contribution of older persons is substantial (over 50\%), on the other hand, it seems that the opposite relationship holds, in other words, members of younger generations are the ones who benefit the most from co-residence (ECLAC, 2000).

According to the latest information available, in 15 countries of the region older persons provide more than $50 \%$ of family income in about four out of every 10 multigenerational households, while in a very similar proportion, older persons contribute less than $25 \%$ of family income. ${ }^{2}$ The data presented in figure V.5 show that the countries where older persons contribute most to household income are Argentina, Brazil, Chile, the

If Brazil is excluded, the proportion of households where older people contribute over $50 \%$ falls to three in 10 and the proportion where older people contribute less than $25 \%$ rises to about four in 10 . 
Plurinational State of Bolivia and Uruguay. In these countries, social security coverage (whether contributory or non-contributory) seems to have a direct impact on the ability of older persons to make significant contributions to household income and, accordingly, on the likelihood of the families of younger generations attaching themselves to the households formed by older persons.

Figure V.5

LATIN AMERICA (15 COUNTRIES): MULTIGENERATIONAL HOUSEHOLDS AND THE CONTRIBUTION OF OLDER PERSONS TO HOUSEHOLD INCOME, AROUND 2005

(Percentages)

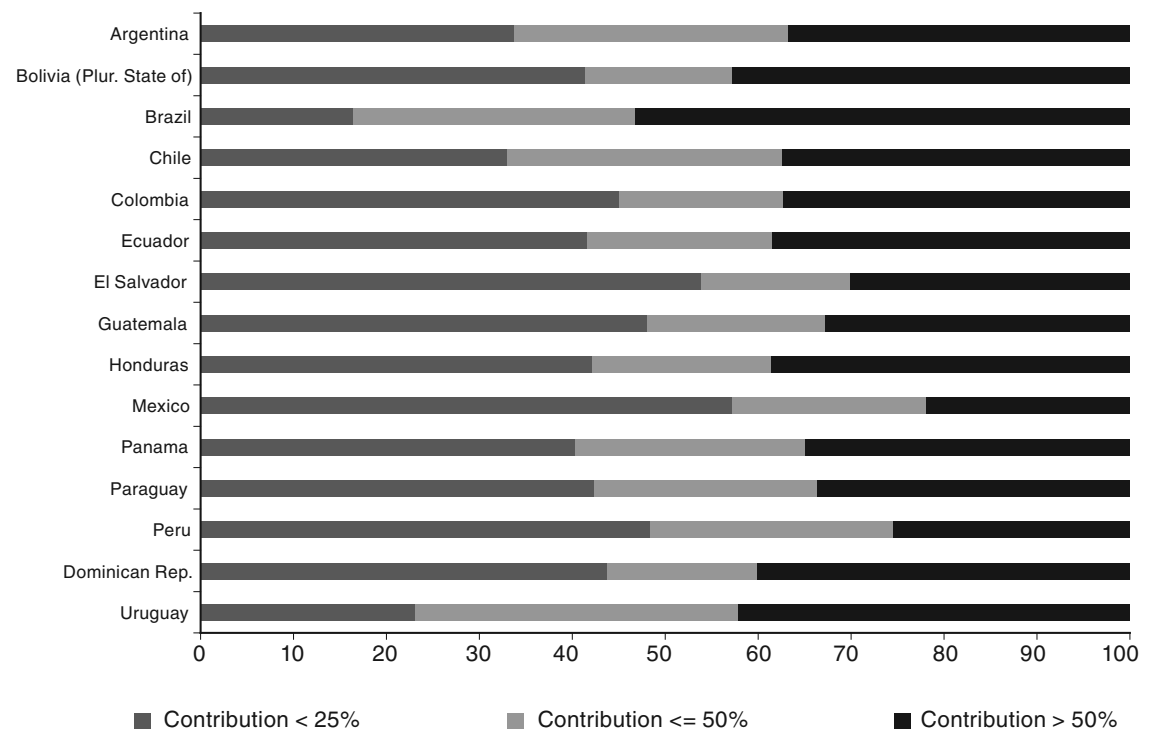

Source: Latin American and Caribbean Demographic Centre (CELADE) - Population Division of ECLAC, on the basis of Household surveys conducted in the countries concerned.

To sum up, family arrangements involving the presence of older persons have a number of similar features among the countries of the region. From the perspective of the implications for well-being, the most significant is the effect of social protection benefits received by older members, which often spread to the whole family (see chapter III). When older persons have financial and other resources, they invariably share them with their children and younger family members, thus strengthening the family resource base and contributing to the well-being of different generations (United Nations, 2005a). 


\section{B. Ageing and care systems}

The increase in the older population and the gradual rise in life expectancy have aroused interest in the workings of care systems. The emphasis on this issue is due primarily to three factors. First, ageing increases the demand for assistance services because older persons often experience some deterioration in their health (physical or mental, or both) and a weakening of social networks owing to the loss of partners, friends or relatives. Second, care has traditionally devolved upon women who, owing to economic or social pressures or as a matter of personal choice, have gradually been turning away from this kind of work. At the same time, the participation of women in the labour market outside the home is not always matched by a greater role for men in care responsibilities, whether because of gender socialization or because those requiring care set a lower value on men's capabilities in this area. Third, social services to support the social reproduction of the older population have not gained full public support, so that the family (and to a lesser extent the market) is acting as the main absorption mechanism for risks associated with the loss of functionality in old age.

The region's countries are particularly sensitive in this regard, since the ageing process has been faster than in the developed countries, demand for care at preschool ages is still high and socioeconomic conditions have not always made it possible to introduce public measures sufficient to cover assistance needs; at best, other spheres of social protection have been given precedence (Huenchuan and Guzmán, 2007).

\section{The effect of ageing on care systems}

The rise in the older population ought not to be a problem for care systems; the problem arises from the fact that societies have not created the proper mechanisms for coping with this development and its implications. Care is the social activity carried out to ensure the social and physical survival of dependent persons, i.e., those who lack personal autonomy and need help from others to carry out essential activities of daily living.

The need for care at more advanced ages is nothing new. In all societies there have always been people who have needed others' help to carry out day-to-day activities. Since the mid-twentieth century, 
however, the response to care needs has changed substantially (Casado and López, 2001). Thus, because of the peculiarities of the present situation, care has been turning into a problem of modern times.

On the one hand, there are people who cannot look after themselves, as there always have been; and on the other, traditional methods of meeting their needs are in jeopardy, just at a time when increasing numbers of people are requiring help due to population ageing, the use of artificial methods to increase lifespans, higher accident survival rates, etc. (Sempere and Cavas, 2007). This is why numerous studies have identified the need for care as a new social risk, one that is characteristic of transition or post-transition societies and that demands a whole range of specific public protection services.

The main difference between the region's countries and the developed countries is that in the latter, the need for care began to be considered a social risk in the 1970s. At that time, a report by OECD (1973) stated that "growth is not an end in itself, but a means to raise the overall wellbeing of societies", and the opportunity to enjoy lifelong good health was placed at the top of a list of social concerns. In the countries of the region, on the other hand, this process has been taking place only recently, partly because traditional care systems continued to operate in a fairly stable way well into the 1980s.

As figure V.6 shows, the population requiring care is expected to increase greatly over the coming years. Even as the population under 5 remains a major source of demand for protection and care, the population aged over 75 will gradually increase. Although people often enjoy good health and a high degree of independence at this age, the fact remains that they are far more likely to become frail or disabled as they grow older.

The effect of these changes will be felt more strongly over the coming years as the trend becomes socially and demographically entrenched, requiring changes to the social and health-care provision currently available to the older adult population, children and the disabled.

\section{The role of the family and women as caregivers}

In the sociology of old age, care systems are treated for academic purposes as part of the wider field of social support. In the economics of ageing, however, care is part of the field of economic security: if older persons had to pay for the assistance services they received from relatives, the likelihood of their being poor would certainly be much greater. 
Figure V.6

LATIN AMERICA: NUMBER OF PERSONS AGED OVER 75 AND

CHILDREN UNDER 5, 1950-2050

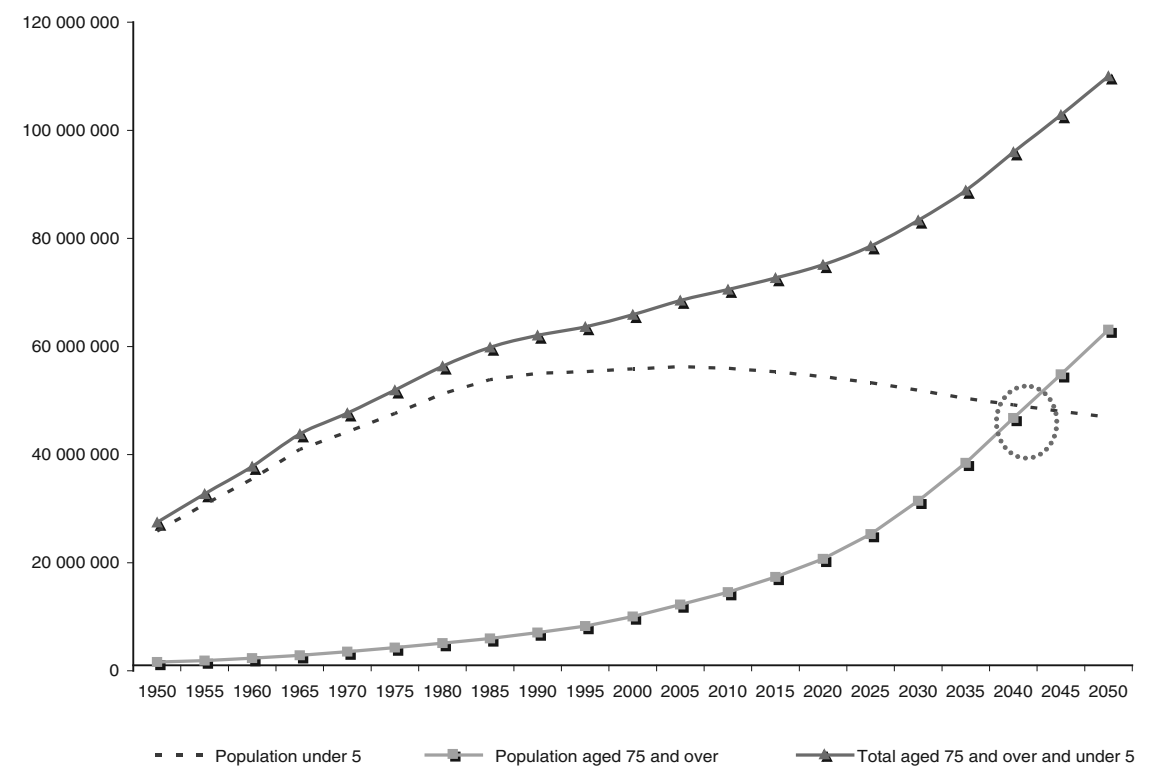

Source: Latin American and Caribbean Demographic Centre (CELADE) - Population Division of ECLAC, on the basis of special processing of census microdata.

There are three sources of care in old age: the family, the State and the market. None of these institutions has exclusive competence in the provision of care, and as a result there is not always a clear dividing line between the assistance supplied by each of these three agents, although there are differences as regards the main responsibility attributed to each one. Data from the 2006 Latinobarómetro opinion survey show that, in most of the countries, the people interviewed thought the responsibility for ensuring that older persons enjoyed decent living conditions fell upon the family, then to a lesser extent upon the State and, to a much lesser degree upon, the individual concerned (see figure V.7).

Although this view is a constant in most of the countries, opinions vary in some of them according to the sex of the respondent. Thus, while a larger proportion of women than men on average think that the family has prime responsibility, a larger proportion of men than women think that the main responsibility is the State's. The only country where more than $50 \%$ of men and a similar proportion of women think that the State has the main responsibility for the welfare of older persons is Argentina. In Panama, on the other hand, more than $65 \%$ of the men and women interviewed thought the family had the main responsibility. 
Figure V.7

LATIN AMERICA AND THE CARIBBEAN: INSTITUTIONS CONCERNED WITH OLDER PERSONS' WELFARE

(Percentages)

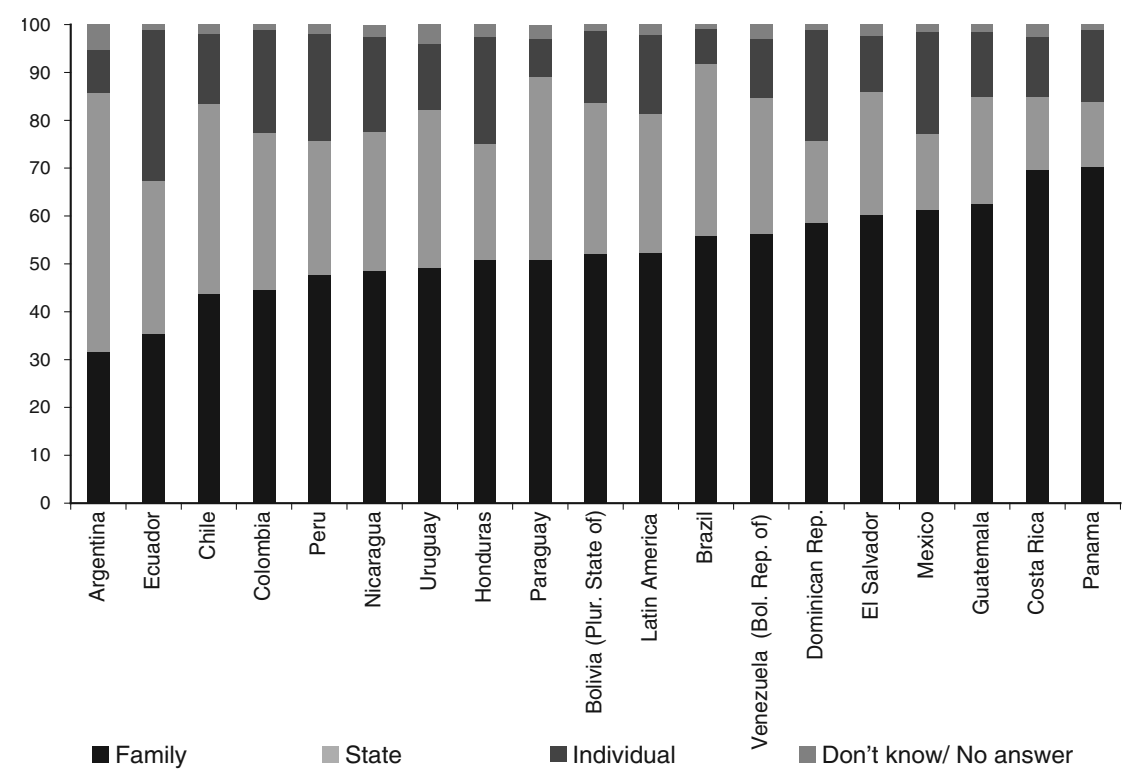

Source: Latin American and Caribbean Demographic Centre (CELADE) - Population Division of ECLAC, on the basis of special processing of data from the 2006 Latinobarómetro opinion survey.

It is interesting to note that when the State plays only a weak role as a unifying factor in political life and as a provider of social protection, hopes are placed on the family as a likely force for social cohesion, and it is subjected to excessive expectations as the institution with ultimate responsibility for filling the gaps in protection. This is part of the reason why, in countries with low levels of social protection, Latinobarómetro respondents tend to see the family as bearing the main responsibility for the well-being of older persons.

In fact, the family is still one of the most important sources of care in old age. For example, data from the SABE survey show that around 2000 a large proportion of older persons in seven cities of Latin America and the Caribbean received support from their families to carry out functional and instrumental activities of daily living (see table V.1). 
Table V.1

PROPORTION OF OLDER PERSONS HAVING DIFFICULTY AND RECEIVING HELP WITH ACTIVITIES OF DAILY LIVING ${ }^{a}$

\begin{tabular}{|c|c|c|c|c|}
\hline \multirow{2}{*}{ Characteristics } & \multicolumn{2}{|c|}{$\begin{array}{l}\text { Functional activities of daily living } \\
\text { (FADL) }\end{array}$} & \multicolumn{2}{|c|}{$\begin{array}{c}\text { Instrumental activities of daily } \\
\text { living (IADL) }\end{array}$} \\
\hline & Having difficulty & $\begin{array}{l}\text { Receiving } \\
\text { help }^{\mathrm{b}}\end{array}$ & $\begin{array}{l}\text { Having } \\
\text { difficulty }\end{array}$ & $\begin{array}{l}\text { Receiving } \\
\text { help }^{\mathrm{b}}\end{array}$ \\
\hline \multicolumn{5}{|l|}{ Age } \\
\hline $60-64$ & 13 & 26 & 15 & 75 \\
\hline $65-74$ & 15 & 33 & 21 & 79 \\
\hline $75+$ & 31 & 51 & 47 & 88 \\
\hline \multicolumn{5}{|l|}{ Sex } \\
\hline Men & 15 & 43 & 20 & 83 \\
\hline Women & 23 & 42 & 35 & 84 \\
\hline \multicolumn{5}{|l|}{ Marital status } \\
\hline Unmarried & 23 & 43 & 35 & 85 \\
\hline Married & 16 & 40 & 21 & 82 \\
\hline
\end{tabular}

Source: Paulo Saad, "Transferencias informales de apoyo de los adultos mayores en América Latina y el Caribe: estudio comparativo de encuestas SABE", Notas de población, No. 77 (LC/G.2213-P), Santiago, Chile, Economic Commission for Latin America and the Caribbean (ECLAC), 2003.

a In seven selected cities, and by demographic characteristics.

b As a proportion of those having difficulty.

In the Chilean sample, for example, the proportion receiving help with functional activities of daily living (about 52\%) is twice as high as in Uruguay (about 26\%). In general, the proportion receiving help with instrumental activities of daily living is significantly higher than the proportion receiving help with functional activities of daily living, ranging from just under 70\% in Argentina to almost 92\% in Brazil. Another aspect documented by this survey is that the greatest support comes from family members living in the same household, followed by children living outside it (Saad, 2003).

These data reveal the scale of the family contribution to the social reproduction of the older population. This is partly a consequence of the relatively young population structure and the slow and inadequate development of social security systems which, in most of the region's 
countries, have yet to establish solid systems of institutional protection specifically designed for dependent older persons. The result is that families have instead had to solve the problem by means of intergenerational solidarity strategies that often involve extending and reconfiguring households. Thus, financial assistance and the care of older persons has become a responsibility for families themselves, the State having assumed only a secondary role (ECLAC, 2000).

Accordingly, as different authors have pointed out, some further distinctions have to be drawn, since in speaking of the family it is necessary to identify the role of women as carers (Sánchez, 1996). ${ }^{3}$ The fact is that tradition, socialization and economic relationships make women the key carers for older persons (and indeed for other social groups), irrespective in most cases of whether the woman works in paid employment or in the home.

The conclusion from all this is that unless there are explicit interventions to provide this type of service, the ability to provide care to older persons can vary from family to family depending on the type of living arrangement. Setting out from the fact that women are the main carers for older persons when they live with them in the same household, a major difference can be identified between families where the woman has a job outside the home and families where she is employed on domestic work. In the first case, opportunities for providing assistance to an older person are more limited (although it is becoming increasingly common for women carrying out productive work outside the home to combine this with care tasks), and use is likely to be made of external services where affordable.

In short, the likelihood of older persons receiving help from their offspring with functional and instrumental activities of daily living is conditioned by the demographic and social circumstances of earlier decades, which have been changing substantially.

Care giving is usually associated only with children, so that other types of care are overlooked. In addition, it is generally assumed that most care giving is done in youth, when women are responsible for their children. The evidence shows, however, that they can also be carers at other stages of life and that they end up providing care more than once over their life cycle, first for their children, then for their parents, and finally for their infirm spouse. These three episodes generally occur at three distinct times in women's lives: youth, adulthood, and maturity (Kahan and others, 1994 in Robles, 2003). 
The main changes include:

- The sharp drop in fertility, which will reduce the potential size of the family support network available to older persons in future. The generations that are currently providing help to older members of their families are not as likely to receive such support from their own children or grandchildren (Huenchuan and Guzmán, 2007a and 2007b).

- Full incorporation of women into non-domestic work is reducing their availability for care functions, with which they have traditionally been overburdened because of their gender status. This change is resulting in a reduction in the capacity to provide a range of assistance services to household members with some degree of dependency, making it necessary to use external services to replace female relatives in this task (Maldonado and Hernán, 1998).

- Rising life expectancy means that old age is being prolonged. Families are having to look after their older members for longer and women are ageing even as they care for the younger and older generations. A women who has children at 25 can be a mother for 45 or 55 years. Despite the traditional notion that women's time is dedicated to their children only for the first 10 years, experience shows that providing help is a lifelong responsibility. Longer female lifespans will prolong this role, which will coexist with the role of daughter as parents too live longer (Calasanti, 1996 in Sánchez, 1996).

Protecting people who are in need of care in old age will be an unavoidable responsibility for public policies over the coming decades. The challenge is to meet the needs of people who are in a situation of particular vulnerability and thus require support to carry out essential activities of daily living, attain greater personal autonomy and be able to exercise their rights as citizens to the fullest extent (Sempere and Cavas, 2007). 
Box V.1

\section{PERCEPTIONS OF ILL-TREATMENT AND VIOLENCE AGAINST OLDER} PERSONS IN LATIN AMERICA AND THE CARIBBEAN

Ill-treatment of older persons was recognized as a social problem in the 1980s, since when there has been an ongoing debate about its definition and typology and the best ways of preventing it. It is now defined as any single or repeated act or omission that causes harm or suffering and occurs in any relationship where there is an expectation of trust. Physical, psychological, sexual and financial ill-treatment and the abuse of property are among the types recognized (CELADE, 2003).

No reliable, representative statistics are available in the region to give a full picture of the true scale of this problem. Often isolated cases are brought to light in the press or reported by family members or people close to the older individuals concerned, or monographs are published on the causes and consequences of the problem.

To ascertain how older persons were treated, a question on the subject was included in the Latinobarómetro survey applied in 18 countries of Latin America and the Caribbean, and over half of all those interviewed replied that older persons were treated badly or very badly. This regional perception differs by country. In six of them the proportion giving this answer was higher than the regional average, Guatemala being the country where the largest percentage of people $(70 \%)$ answered that older persons were treated badly or very badly. At the other extreme are three countries (Mexico, Dominican Republic and Bolivarian Republic of Venezuela) where over $60 \%$ of respondents thought older persons were treated well or very well (figure 1).

While there are virtually no differences at the regional level between men and women in their perception of how older persons are treated, in five countries (Chile, Mexico, Paraguay and Uruguay) women took a worse view of this treatment than men (gap of five points); only in El Salvador and the Bolivarian Republic of Venezuela did men have a worse perception than women. Perceptions do not differ much by the age of respondents: $52 \%$ of those aged between 15 and 29 thought that older persons were treated badly or very badly, a figure that rises to $55 \%$ among those aged 30 to 59 and over 60 (figure 2).

The same survey asked respondents whether they themselves knew of any cases of domestic violence against older persons, and in the region as a whole $22 \%$ said they did. The highest proportions answering affirmatively were in Nicaragua and El Salvador, with 33\% and 31\%, respectively, while Brazil and Chile recorded the lowest level of awareness of cases of this type (figure 3). While in the region as a whole there is no clear divide between men and women as regards their awareness of domestic violence against older persons, in seven countries (Brazil, Ecuador, Colombia, Peru, Dominican Republic, Costa Rica and Paraguay) women claimed to know of more such cases than men (figure 4). 
Box V.1 (continued)

Figure 1

LATIN AMERICA AND THE CARIBBEAN: PEOPLE BELIEVING THAT

OLDER PERSONS ARE TREATED BADLY OR VERY BADLY, 2006

(Percentages)

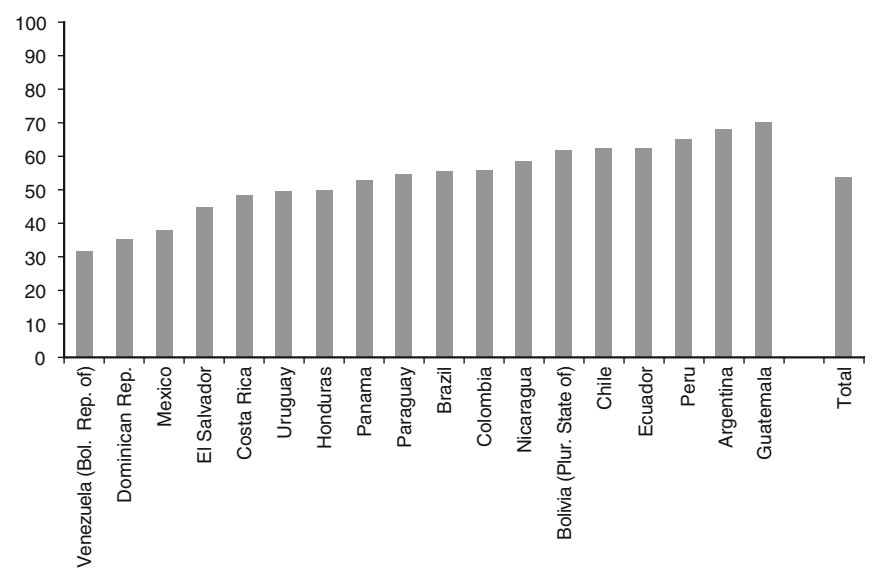

Figure 2

LATIN AMERICA AND THE CARIBBEAN: PEOPLE BELIEVING THAT OLDER

PERSONS ARE TREATED BADLY OR VERY BADLY, BY SEX, 2006

(Percentages)

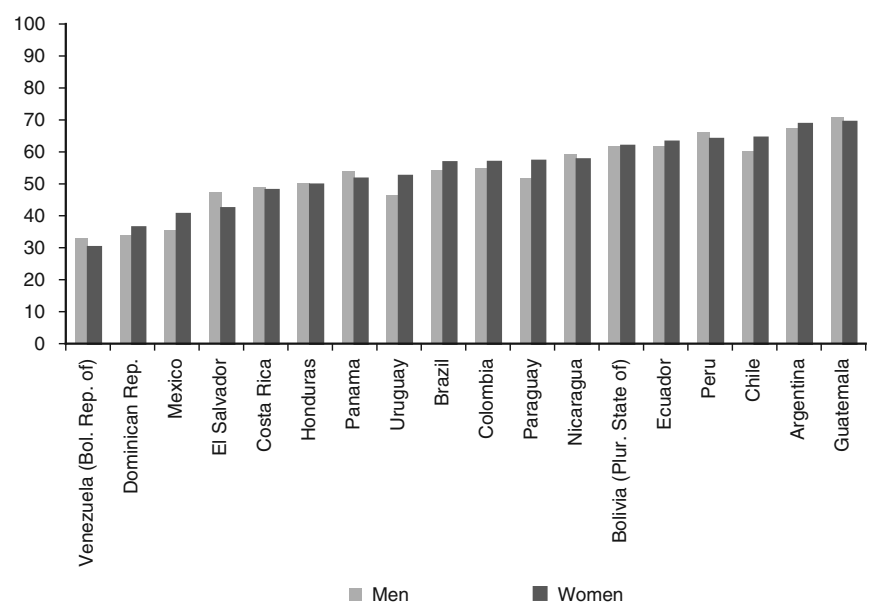

Source: Latin American and Caribbean Demographic Centre (CELADE) - Population Division of ECLAC, on the basis of processed data from the 2006 Latinobarómetro opinion survey. 
Box V.1 (continued)

Figure 3

LATIN AMERICA AND THE CARIBBEAN: PEOPLE CLAIMING TO KNOW OF

A CASE OF DOMESTIC VIOLENCE AGAINST OLDER PERSONS, 2006

(Percentages)

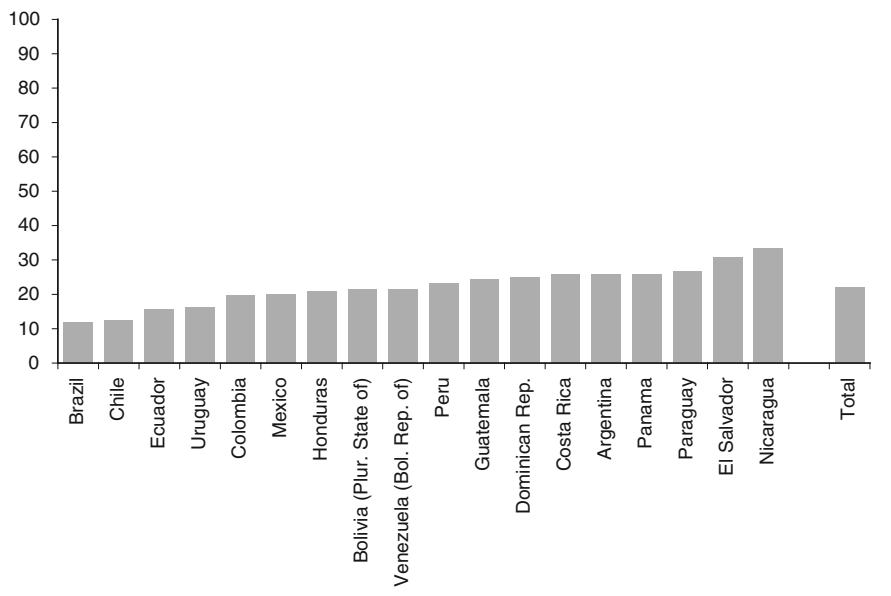

Figure 4

LATIN AMERICA AND THE CARIBBEAN: PEOPLE CLAIMING TO KNOW OF A CASE OF DOMESTIC VIOLENCE AGAINST OLDER PERSONS,

BY SEX, 2006

(Percentages)

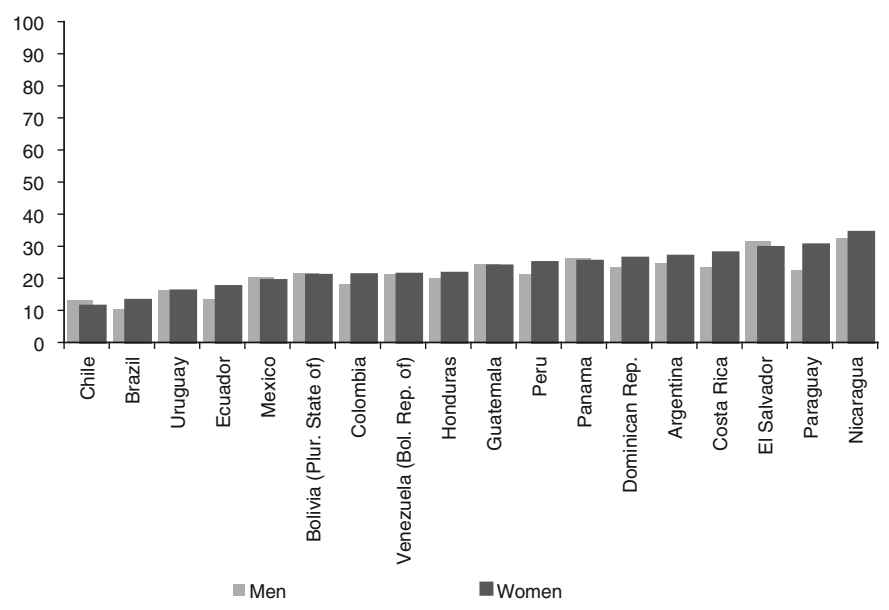

Source: Latin American and Caribbean Demographic Centre (CELADE) - Population Division of ECLAC, on the basis of processed data from the 2006 Latinobarómetro opinion survey. 
Box V.1 (concluded)

There is now general acceptance that it is not enough merely to identify cases of ill-treatment involving older persons. In addition to this, all the countries ought to develop systems of service provision (health, social, legal protection, police, etc.) to respond effectively to the problem and, if possible, prevent it (WHO, 2002). Given that the causes leading to ill-treatment are numerous and complex and that there are certain conditions that favour it (including stress among carers, lack of resources to meet victims' needs, the provision of care by unqualified individuals and situations of economic crisis and unemployment), prevention work is essential if this problem is not to spread further.

Source: Latin America and Caribbean Demographic Centre (CELADE) - Population Division of ECLAC.

\section{Housing, local environments and ageing}

The major changes that have been occurring in the demographic profile of Latin America and the Caribbean over recent decades have had consequences for the planning and management of social services. Housing has been no exception, with the main issues deriving in this case from acute social inequity and a large backlog of unmet accommodation needs (Arriagada, 2003b). Thus, the ageing process is taking place in a context of housing shortages and problems with basic services access and social harmony in cities.

Access to housing is a human right which must be satisfied, and this entails changes in land use and environmental conditions. Decent housing is essential to survival and to a secure, independent and autonomous way of life. Precisely because it is so important to people's lives, consuming a large part of their income and strongly influencing their own and their families' self-esteem and the welfare of the community in which they live, there is a consensus that access to housing should be treated as an enforceable right vis-à-vis the public authorities and the rest of society. In fact, the right to adequate housing is a composite one; when it is infringed, so are other essential rights and interests (Pisarello and De Cabo, 2003).

The right to housing can also be seen as extending to the environment and urban design in general. In this case, housing issues encompass of at least three levels of analysis: (i) the individual dwelling, (ii) its immediate environment and (iii) the urban or rural setting as an existential framework and way of life. Consequently, the question of whether housing is decent and appropriate should be answered with reference not just to the individual dwelling but also to its immediate environment and, most particularly, the urban or rural setting in which it is located (Bassols Coma, 1983).

Housing and its environment strongly influence older persons' quality of life, both in the objective sphere of living conditions and 
assets and in the sphere of subjective or perceived well-being. Ensuring that housing is appropriate means recognizing the diversity of older persons' needs and preferences, from the option of "growing old at home" to situations of frailty requiring care and special types of living arrangements (CELADE, 2003).

Housing should both satisfy the need for autonomy and independence and provide security across a broad spectrum of living situations, while creating the potential for well-being among older persons and the other generations living with them. Viewed in this light, housing can be understood as an instrument for safeguarding older persons' health and quality of life, with dwellings varying in the degree to which they match the needs of a heterogeneous older adult population. As for local environments, these should facilitate the integration of all citizens affected by some vulnerability, irrespective of its origin, and neutralize the risks of discrimination.

In short, housing and local environment policies should be designed on the basis of a renewed vision of social inclusion for all, and housing and urban programmes can play a significant part in helping older persons to develop a fuller range of activities and social contacts, and thus to enjoy a healthy old age while participating in their residential environment on decent terms.

\section{Security of housing tenure in old age}

Among the attributes that adequate housing must possess, stability of occupation is very important as it provides security of access over time and allows people to connect with their social and geographical environment.

Assessing this means considering both the period of residence and the legal situation with tenure or occupation, and determining the occupant's degree of security in relation to the time horizon over which he or she wishes to inhabit the home. Thus, ownership can be taken as a reflection of stability in an older person's housing situation, as it is a measure of residential security and indicates greater protection against eviction.

In the countries with information available on this subject for the year 2000 , over $80 \%$ of older persons state that they are living in a home of their own (see figure V.8). There is no common pattern as regards differences between urban and rural areas. In some cases the percentages living in their own homes are higher in rural areas (Costa Rica, Dominican Republic, Ecuador, Guatemala, Mexico, Nicaragua, Panama, Paraguay and the Plurinational State of Bolivia), whereas in Argentina, Brazil, Chile and the Bolivarian Republic of Venezuela this rate is higher among older persons in urban areas (see figure V.9). 
Figure V.8

LATIN AMERICA AND THE CARIBBEAN (SELECTED COUNTRIES): OLDER PERSONS

LIVING IN THEIR OWN HOMES, 2000 CENSUSES

(Percentages)

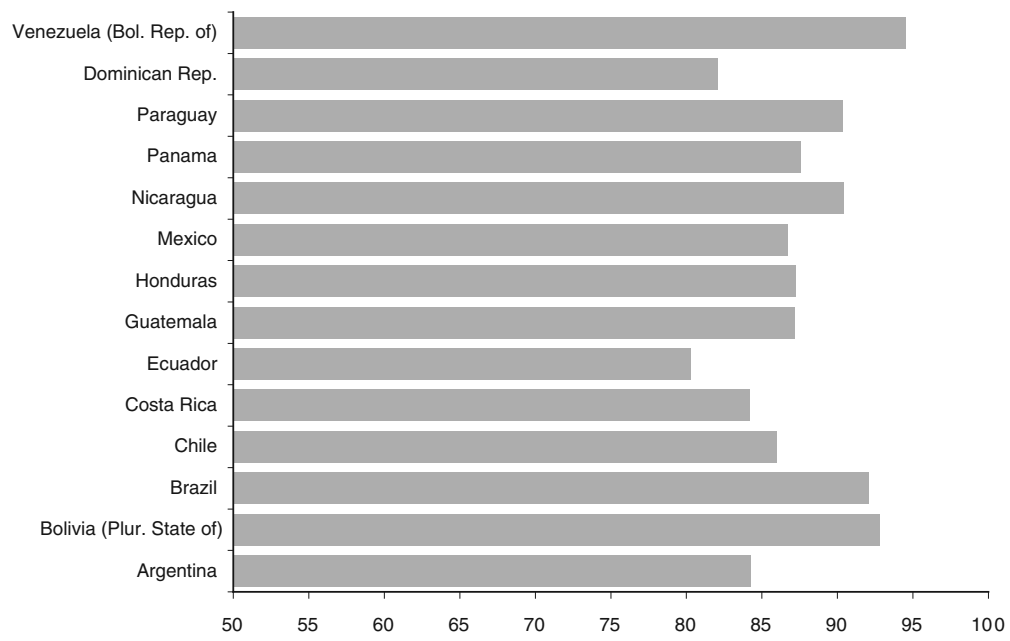

Source: Latin American and Caribbean Demographic Centre (CELADE) - Population Division of ECLAC, on the basis of special processing of census microdata.

Figure V.9

LATIN AMERICA AND THE CARIBBEAN (SELECTED COUNTRIES): OLDER PERSONS

LIVING IN THEIR OWN HOMES, URBAN AND RURAL AREAS, 2000 CENSUSES

(Percentages)

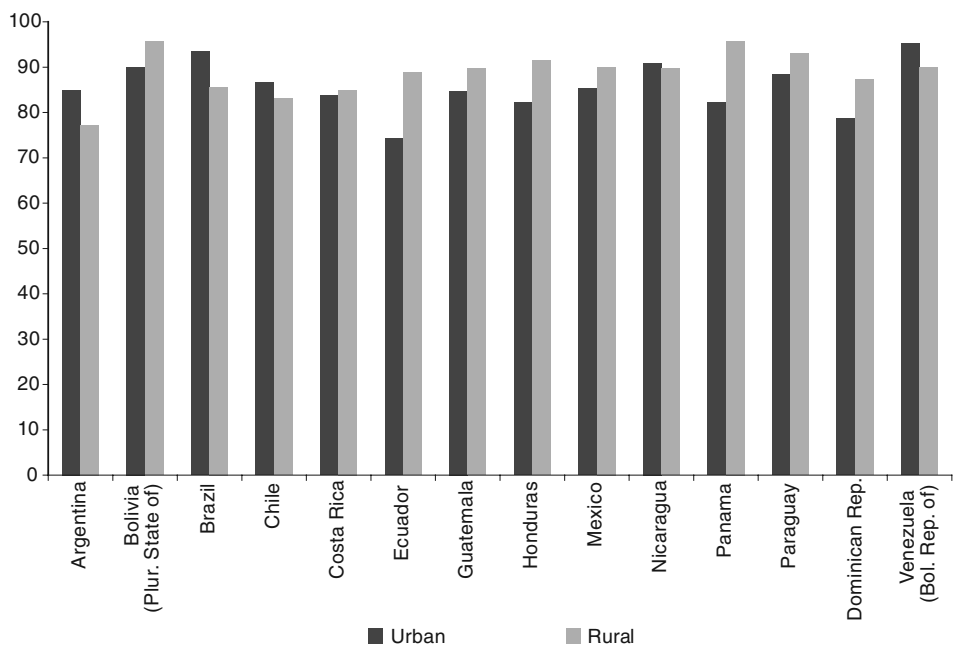

Source: Latin American and Caribbean Demographic Centre (CELADE) - Population Division of ECLAC, on the basis of special processing of census microdata. 
Homes containing older persons are more likely to be owneroccupied than others and the rate of owner-occupation is higher in countries that are further advanced in the demographic transition. One reason for the higher percentage of older persons declaring that they own their homes is the progress made in awarding title to land. ${ }^{4}$ It should be noted, though, that there are methodological biases in the perception of ownership (members of a household will often claim they own their home even though they do not own the site or land it stands on).

A home of their own can be an asset for older persons and their families, as it represents property that can be bequeathed to future generations. To perform its function properly, however, a home needs to have a number of characteristics and facilities (in respect of health, mobility, equipment, fittings, etc.) that younger segments of the population might consider non-essential (Bosch, 2006).

Given all this, housing policy is an essential component of measures aimed at older persons, since other social interventions can lose all their effectiveness if this right is not guaranteed. Other things being equal, furthermore, the best option is for people to grow old in their own homes, both from the point of view of their own dignity, wishes and independence and also financially, if the public expenditure associated with institutionalization is taken into account (Bosch, 2006).

\section{The housing situation: deficiencies, housing quality and ageing}

Changes in the age structure of the population have generated new housing needs owing to faster growth in the number of families containing older persons, which are consumers of housing.

There are new housing requirements and major backlogs in all the region's countries. If each country's stage in the ageing process is compared with the quality of its housing stock, it transpires that countries which are less advanced in the ageing process have farreaching problems with their housing stock and a large proportion of substandard housing lacking in basic amenities. In countries that are further advanced in the ageing process, on the other hand, the proportion of inadequate housing is smaller but more households and

\footnotetext{
4 There has been a need in the region to consolidate procedures for awarding land title and improve the workings of land markets (FAO, 2002). Systematic land registration has reduced costs considerably and facilitated people's access to the land title process (Jaramillo, 1998). In the case of informal settlements in Latin America, government programmes have been limited to the creation of policies to provide credit or regularize land holdings and protect them with legal title (Marques, 2006).
} 
families are affected by quantitative deficiencies or the need for new housing (Arriagada, 2003b and González, 2006).

To obtain an overview of the region's housing situation, 12 countries at different stages in the ageing process were selected and the housing deficiency index was calculated for households containing older persons. To calculate this indicator, use was made of a simple average that combines the percentage of households in which members are not living in homes of their own with a material conditions index (average percentage lacking floors and walls), the percentage without water inside the home and the percentage living in overcrowded dwellings. The figures in table V.2 reveal the following housing situation in some of the region's countries:

Table V.2

LATIN AMERICA AND THE CARIBBEAN (SELECTED COUNTRIES):

HOUSING DEFICIENCY INDEX FOR HOUSEHOLDS CONTAINING OLDER PERSONS

\begin{tabular}{|c|c|c|c|}
\hline \multirow[b]{2}{*}{ Ageing } & \multicolumn{3}{|c|}{ Housing deficiency index } \\
\hline & $\begin{array}{c}\text { Low } \\
\text { (index below 15) }\end{array}$ & $\begin{array}{c}\text { Medium } \\
(15 \text { to } 30)\end{array}$ & $\begin{array}{c}\text { High } \\
\text { (over 30) }\end{array}$ \\
\hline Incipient & & & $\begin{array}{l}\text { Paraguay - Plurinational } \\
\text { State of Bolivia } \\
\text { Guatemala - Nicaragua }\end{array}$ \\
\hline Moderate & $\begin{array}{l}\text { Costa Rica } \\
\text { Venezuela (Bolivarian } \\
\text { Republic of) }\end{array}$ & $\begin{array}{l}\text { Mexico - Ecuador } \\
\text { Brazil a - Panama }\end{array}$ & \\
\hline $\begin{array}{l}\text { Moderate- } \\
\text { advanced }\end{array}$ & Chile & & \\
\hline Advanced & Uruguay & & \\
\hline
\end{tabular}

Source: Camilo Arriagada, "El déficit habitacional en Brasil y México y sus dos megaciudades globales: estudio con los censos de 1990 y 2000", Población y desarrollo series, No. 62 (LC/L.2433-P), Santiago, Chile, Economic Commission for Latin America and the Caribbean (ECLAC), 2005. United Nations publication, Sales No. S.05.II.G.179.

a The floor information was not available for Brazil.

- Incipient ageing countries. Households containing older persons score worst for housing deficiencies (Paraguay, the Plurinational State of Bolivia, Guatemala and Nicaragua). The housing situation is quite critical because a substantial proportion of households containing older persons are lacking in floors or walls, have no access to drinking water or suffer from overcrowding, which would justify a substantial number of initiatives to meet the needs of this social group. 
- Moderate ageing countries. Mexico, Ecuador, Brazil and Panama have intermediate housing deficiency scores. In the first two, this is mainly because of inadequate access to drinking water. In Costa Rica and the Bolivarian Republic of Venezuela, conversely, there is a low index of housing deficiencies in households containing older persons.

- Moderate to advanced ageing countries. Housing indicators in Chile are positive, providing an opportunity to consolidate the housing situation of older persons. This means focusing housing programmes on the country's housing backlog.

- Advanced ageing countries. In Uruguay, the housing deficiency index is low, meaning there is an opportunity to consolidate the housing situation of older persons by means of targeted measures to deal with a housing backlog of moderate proportions.

\section{Access to basic services in old age and inequalities by area of residence}

All persons have the right to sufficient supplies of drinking water to meet their essential needs and to have access to acceptable sanitation facilities that take account of the requirements of hygiene, human dignity, public health and environmental protection (United Nations, 2005b). Accordingly, the States drawing up the Millennium Development Goals included target 10, which is a commitment to "halve, by 2015, the proportion of people without sustainable access to safe drinking water and basic sanitation".

The situation in the region as regards access to these services for older persons is mixed and not well understood. Countries' situations differ by their development level, and access also varies within countries by area of residence. In the 14 countries considered, 5.8 million older persons, or $17 \%$ of the older adult population covered by the analysis, lack access to drinking water in the home.

There is a wide urban-rural divide: whereas $8 \%$ of older persons (2.2 million) lack access to drinking water inside the home in urban areas, 3.6 million older persons lack this service in rural areas. Thus, virtually half $(48 \%)$ of all older persons in rural areas suffer from this deficiency (see figure V.10). This is because drinking water and sanitation coverage in the region's countries is substantially higher in urban areas than in rural ones. 
Figure V.10

LATIN AMERICA AND THE CARIBBEAN (SELECTED COUNTRIES):

OLDER PERSONS LIVING IN HOUSEHOLDS WITH NO

DRINKING WATER SUPPLY INSIDE THE HOME,

2000 CENSUSES

(Percentages)

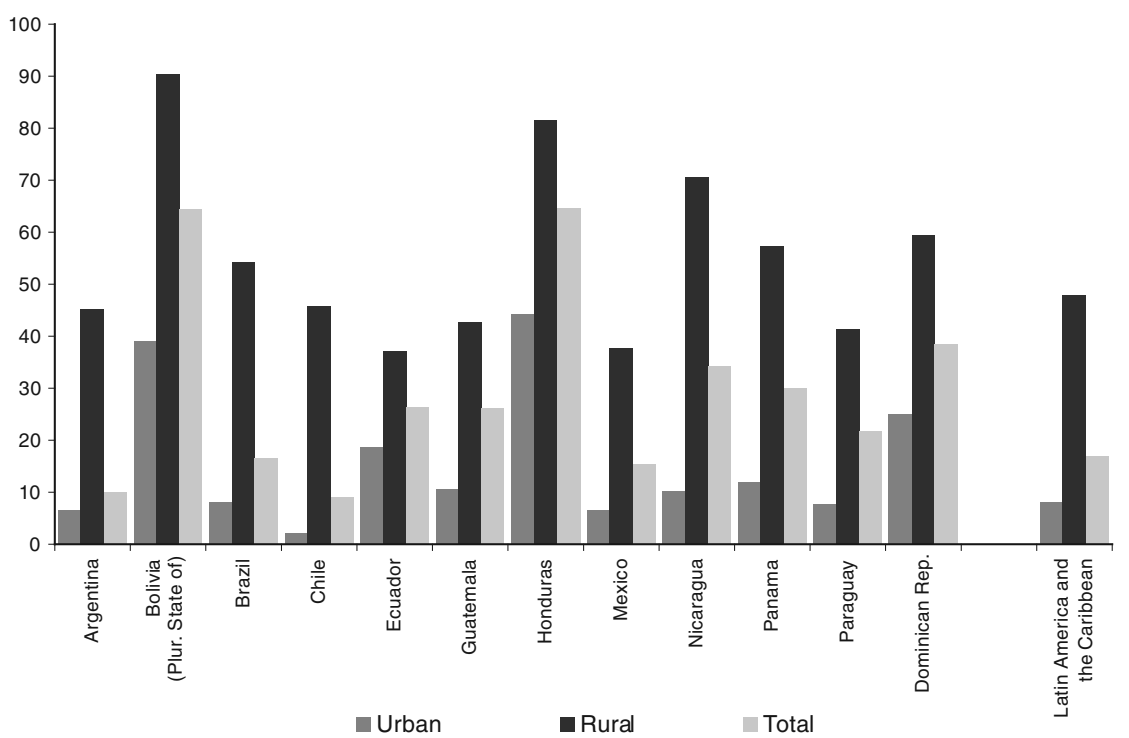

Source: Latin American and Caribbean Demographic Centre (CELADE) - Population Division of ECLAC, on the basis of special processing of census microdata.

As a result of this situation, many of the solutions (such as tanker trucks) to which older persons have to resort are similar to those used by poor people in the majority of areas lacking these basic services. They are extremely expensive, so that these people end up spending more on water (as a proportion of their income) than the better-off. In addition, these solutions pose great risks to health, since the quality of the water obtained cannot be assured (Jouravlev, 2004).

The number of older persons living in households without sanitation is 2.5 million $(7.3 \%)$, and the situation is worst in rural areas. There are 1.6 million older persons lacking acceptable sanitary facilities in the countryside $(22 \%)$, while in urban areas just $3.1 \%$ of the population over 60 live in homes without sanitation (see figure V.11). Frequently, too, the technological solutions adopted in rural areas (septic tanks and latrines) do not have a level of quality or functionality comparable to that found in cities, especially when it comes to home connections (Jouravlev, 2004). 
Figure V.11

LATIN AMERICA AND THE CARIBBEAN (SELECTED COUNTRIES): OLDER PERSONS LIVING IN HOUSEHOLDS WITH NO SANITATION, 2000 CENSUSES

(Percentages)

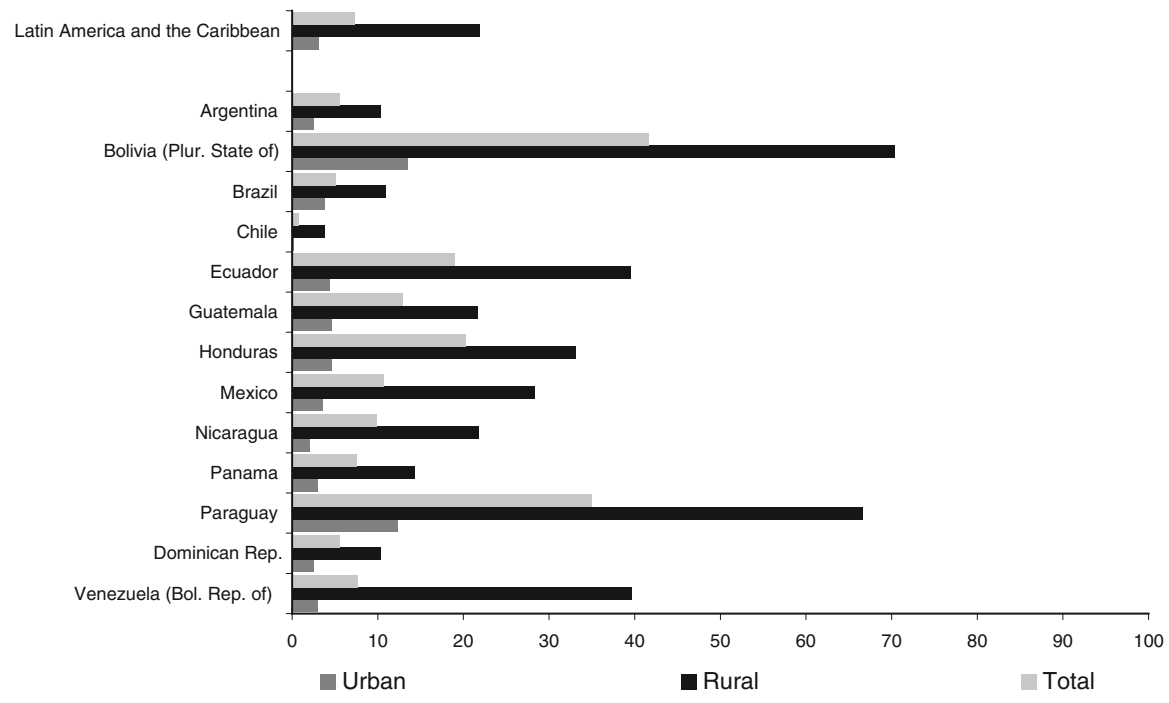

Source: Latin American and Caribbean Demographic Centre (CELADE) - Population Division of ECLAC, on the basis of specially processed census microdata.

In the English-speaking Caribbean, the coverage of basic services is over $95 \%$ in a number of countries (Bahamas, Barbados, Saint Kitts and Nevis and Saint Lucia). Because of their size, the English-speaking Caribbean countries ought to find it easier to match growing demand to the resources available given the greater scope for communicating options and costs so that communities are predisposed to pay for services. Furthermore, local governments are closer to direct consumers, which means that programmes can be better targeted, more responsive and cheaper (Jouravlev, 2004).

Older persons lacking basic services are extremely vulnerable to a variety of related risks, since the lack of appropriate sanitation facilities and an adequate, safe and physically accessible supply of water restricts their access to a range of other rights, such as the right to a healthy environment, health and adequate nutrition, that are directly or indirectly linked to water and sanitation (Hopenhayn and Espíndola, 2007). Lack of access to high-quality basic services and a good environment that safeguards people's health and is conducive 
to full development of their capabilities does not only affect the elderly, but puts the entire family at a social disadvantage. If there are children in the household, for example, there are also increased risks of premature mortality and a higher incidence of communicable or diarrhoeic diseases.

\section{Equipping housing and local environments for social inclusion at all ages}

When older persons live with other family members, it is important for the home to be designed so that different generations can coexist harmoniously. This is not easy to achieve, but it does facilitate the integration of older persons into their families (United Nations, 2006a).

The problems of housing for older persons take a variety of forms, such as difficulties of access and mobility, inappropriate housing design and isolation. These different aspects of the problem tend to arise in combination, so that two or three of these difficulties are usually present at the same time.

In the Health, Well-Being, and Aging Survey (SABE), older persons identified the main risks they were exposed to in the home. The leading risk comes from the lack of special fixtures in bathrooms, such as supports on sanitary installations and handles or rails to provide greater security when these are used. In second place they cite the risk that unsecured carpets create by causing older persons to stumble or slip, with the danger of falls and injuries that this entails. Other risks identified by older persons include split levels or steps, inadequate lighting and objects that impede movement (see figure V.12).

It should be noted that these are some of the risks facing older persons who live in the capital cities of the countries where the survey was conducted. In smaller towns and cities and scattered rural areas, risks in the home are probably greater because housing infrastructure tends to be less well adapted to the needs of an ageing population.

The idea of having housing that is suitable for all the generations living in it is to allow all household members to carry out their activities independently. The environment in which the housing is located is also vital for the prospects of maintaining good health and creating or strengthening formal and informal relationships between individuals and social groups and enhancing social cohesion (PAHO, 1996). 
Figure V.12

LATIN AMERICA AND THE CARIBBEAN (SELECTED COUNTRIES): HAZARDS AFFECTING OLDER PERSONS IN THE HOME

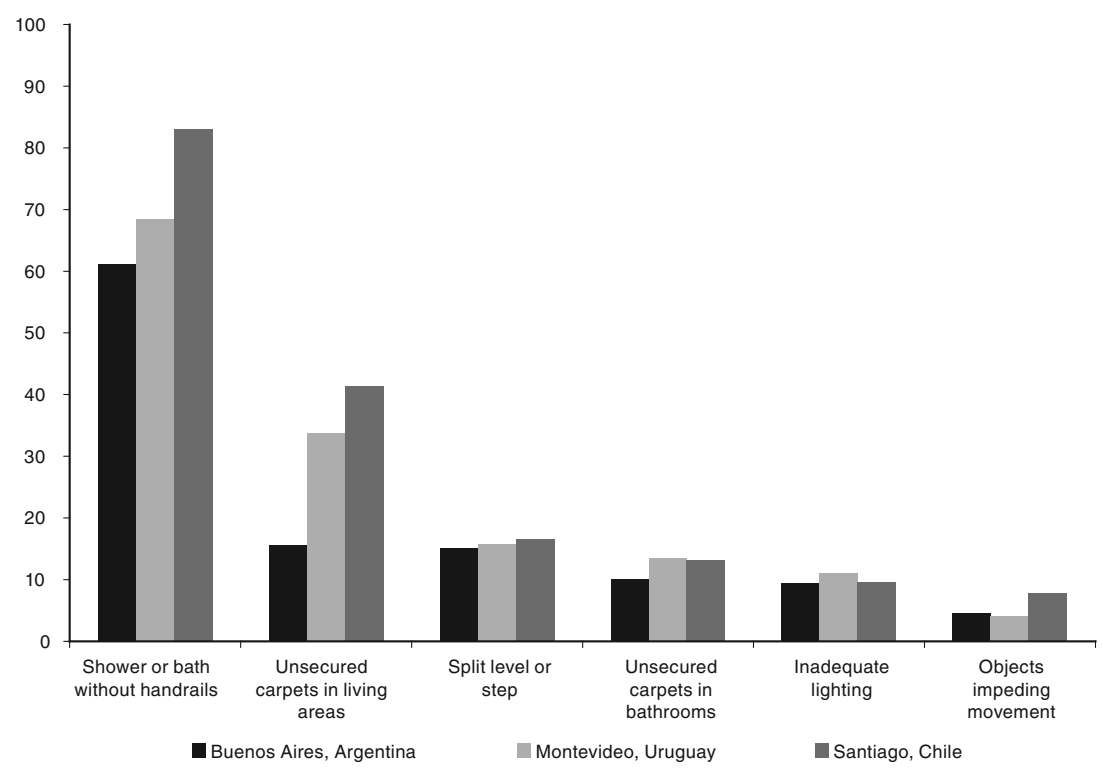

Source: Pan-American Health Organization (PAHO), Health, Well-Being, and Aging Survey (SABE), 2000.

Although old age might constrain people's ability to remain integrated in the community, experience shows that the risk of increasing frailty is greater even than the individual difficulties involved in community participation. If conditions were as good as possible and appropriate to the needs of older persons (and indeed of other social groups), there would surely be less potential for generational segregation. As the United Nations (2006a) has pointed out, "if older persons cannot be mobile, they will never feel truly independent... Addressing the needs of older persons requires the creation of enabling and supportive environments to give older persons the option of ageing in place if they do not need and do not wish to leave their homes."

Local neighbourhoods and cities need to have a plan to ensure social and physical accessibility for all, so that older persons can play an active role in everyday life. This means adapting the urban environment of cities (handrails, ramps, anti-slip pavement surfaces, removal of 
obstacles to movement), but also designing them so that shapes, textures, colours, sounds and light allow people to visualize their journeys clearly, easily recognizing the environment and its components. This would be useful not only for older persons but also for the disabled, children and pregnant women and indeed for everyone moving about the city, creating environments that were hospitable to all.

If it is accepted that people are entitled to housing and a safe, appropriate and stimulating environment so that they can have a decent life and a better old age, the policies implemented to this end will mean a fuller life for the whole of society.

\section{Box V.2 \\ THE QUALITY OF LOCAL ENVIRONMENTS IN OLD AGE: PERCEPTIONS OF LOCAL INFRASTRUCTURE AND EQUIPMENT IN CHILE}

The second quality of life and health survey conducted in Chile in 2006 includes aspects relating to people's satisfaction in different areas of life, one example being their perception of their local environment. The information collected in that section brings to light some of the infrastructure and equipment problems affecting older persons in their local areas.

At the national level, the greatest problem perceived by older persons in relation to infrastructure and equipment is the lack of parks and green areas $(43 \%)$, followed by the lack of sports infrastructure $(40.5 \%)$, inadequate surfacing of streets and pavements (38.6\%) and inadequate lighting of these (35\%). The lack of community centres and of shops and businesses represents a problem for $33.5 \%$ and $28.3 \%$ of older persons, respectively (figure 1).

Satisfaction levels are higher in urban areas than in rural ones. Taking all eight variables together, $43 \%$ of older persons in urban areas say they are dissatisfied with local infrastructure and equipment, while in rural areas just over half $(53 \%)$ of the older adult population expresses dissatisfaction with local infrastructure and equipment. Older persons in the countryside express higher levels of dissatisfaction over the lack of paved roads $(52.5 \%)$, the lack of shops and businesses (50\%) and inadequate road lighting (46.4\%). Another difference between urban and rural areas concerns perceptions of access to communications media: while $40 \%$ of older persons in rural areas express dissatisfaction about this, just $12 \%$ of older persons in urban areas do (figure 1).

There are also differences in satisfaction levels between older men and older women, with men expressing lower levels of satisfaction and differing over some of the main problems they identify. While there is general agreement that the lack of green areas locally is the main problem, this is a source of dissatisfaction to $47 \%$ of men but only $39 \%$ of women. 
Box V.2 (continue)

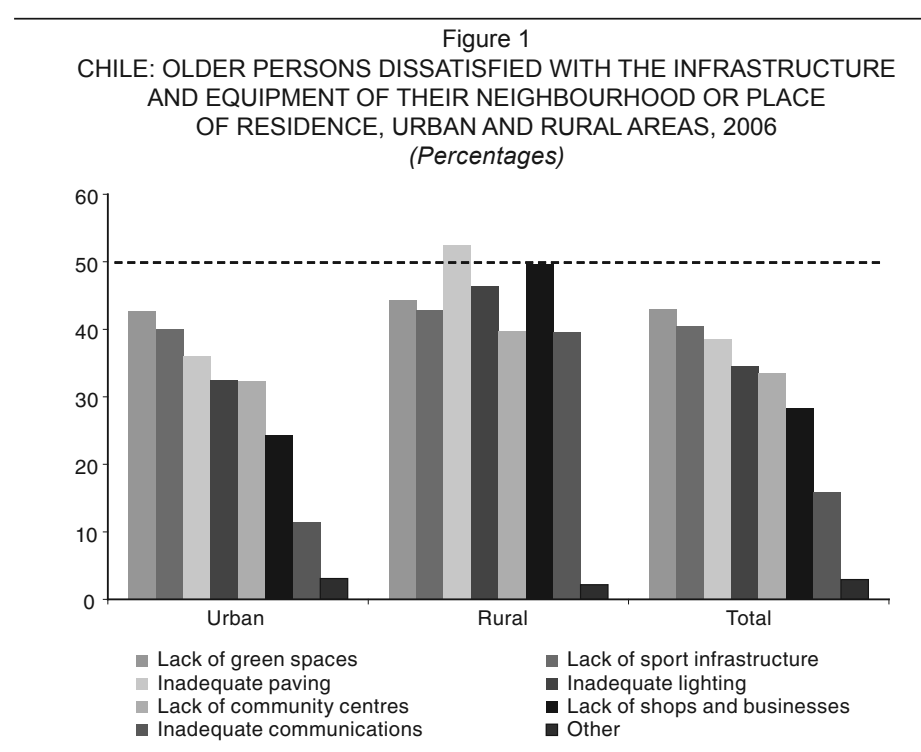

Figure 2

CHILE: OLDER PERSONS DISSATISFIED WITH THE INFRASTRUCTURE AND EQUIPMENT OF THEIR NEIGHBOURHOOD OR PLACE OF RESIDENCE, BY SEX, 2006

(Percentages)

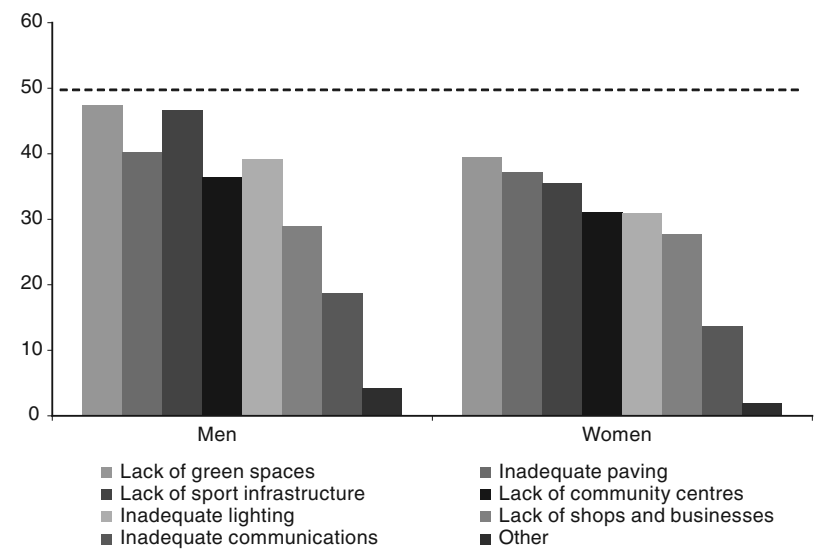

Source: Latin American and Caribbean Demographic Centre (CELADE) - Population Division of ECLAC, on the basis of processed data from the second quality of life and health survey carried out by the Ministry of Health, Santiago, Chile, 2006. 
The second most important problem for men is the lack of sports infrastructure $(46.7 \%)$, while for women it is inadequate paving of streets $(37.2 \%)$. Women place the lack of community centres and inadequate street lighting virtually on a par, whereas men regard inadequate lighting as a more important problem than the lack of community centres. The differences in satisfaction levels between older men and women and the different weight they give to infrastructure and equipment problems show that older persons have different needs and priorities depending on sex, age and whether they live in an urban or rural area.

This information on older persons' levels of satisfaction with local infrastructure and equipment provides an insight into this population group's perception of well-being in relation to its living conditions. It also offers information that it is very important to consider when developing and implementing interventions to improve the quality of local environments.

Source: Latin American and Caribbean Demographic Centre (CELADE) - Population Division of ECLAC, on the basis of data from the second quality of life and health survey, Ministry of Health, Santiago, Chile, 2006.

\section{Progress in implementing the Regional Strategy on Ageing in Latin America and the Caribbean: enabling social and physical environments}

The environment in which people age is changing rapidly. As has already been discussed, people are having fewer children, women are increasingly entering the labour market, and roles are being prolonged and renewed with advancing age. Again, young people are still finding it difficult to strike out on their own once they have started families, there are no institutional arrangements to help dependent older persons grow old in their own homes, and there are persistent backlogs in the provision of basic services for the whole population.

The section on ensuring enabling and supportive environments in the Regional Strategy on Ageing lays it down as a goal that "older persons shall be afforded physical, social and cultural environments conducive to their social development and to the exercise of rights and duties in old age". The Strategy recommendations include issues relating to housing, transport and public spaces in the physical environments category, while social environment issues include social support networks, image and illtreatment. While issues relating to participation and education form part of the Regional Strategy's first priority area, which deals with the older persons and development, they are included in the present section for the purposes of this analysis because of their close connection with the other matters dealt with in this subject area. 
The progress made by the region's countries will now be described, taking into consideration the recommendations of the Regional Strategy for the issues referred to in the previous paragraph. The information given in this section was supplied by the countries in their responses to the survey on programmes for older persons in Latin America and the Caribbean conducted by CELADE - Population Division of ECLAC (see table V.3).

Table V.3

MAIN AREAS OF INTERVENTION OF PHYSICAL AND SOCIAL ENVIRONMENT PROGRAMMES DESIGNED FOR OLDER PEOPLE IN LATIN AMERICA AND THE CARIBBEAN

\begin{tabular}{|c|c|c|c|c|c|c|c|}
\hline & \multicolumn{3}{|c|}{ Physical environments } & \multicolumn{4}{|c|}{ Social environments } \\
\hline & Housing & Transport & Accessibility & $\begin{array}{c}\text { Social } \\
\text { networks and } \\
\text { family support }\end{array}$ & $\begin{array}{c}\text { Social } \\
\text { participation }\end{array}$ & III-treatment & Education \\
\hline Aruba & $x$ & $x$ & $x$ & $x$ & & & \\
\hline $\begin{array}{l}\text { Netherlands } \\
\text { Antilles }\end{array}$ & & & & $x$ & & & $x$ \\
\hline Argentina & & $x$ & $x$ & $x$ & $x$ & $x$ & \\
\hline Belize & $x$ & & & $x$ & $x$ & $x$ & $x$ \\
\hline $\begin{array}{l}\text { Bolivia } \\
\text { (Plurinational } \\
\text { State of) }\end{array}$ & & & & & & $x$ & \\
\hline Brazil & & $x$ & & $x$ & $x$ & $x$ & \\
\hline Chile & $x$ & $x$ & & $x$ & $x$ & $x$ & \\
\hline Colombia & & & $x$ & & & $x$ & \\
\hline Costa Rica & $x$ & $x$ & & $\mathrm{x}$ & $\mathrm{X}$ & $\mathrm{x}$ & $x$ \\
\hline Cuba & $x$ & $x$ & & $x$ & $x$ & $x$ & \\
\hline El Salvador & $x$ & & & & & $x$ & \\
\hline Guatemala & & $x$ & & $\mathrm{x}$ & & & \\
\hline Honduras & & & $x$ & & & $x$ & \\
\hline Mexico & $x$ & & $x$ & & & $x$ & \\
\hline Nicaragua & & & $x$ & $\mathrm{x}$ & & $x$ & \\
\hline Panama & $x$ & & & $x$ & & $x$ & \\
\hline Paraguay & & & $x$ & & $x$ & & \\
\hline Peru & $x$ & & & & & $x$ & \\
\hline Puerto Rico & $x$ & $x$ & $\mathrm{x}$ & $x$ & & $x$ & \\
\hline $\begin{array}{l}\text { Dominican } \\
\text { Republic }\end{array}$ & $\mathrm{X}$ & & $x$ & $x$ & & $\mathrm{x}$ & $x$ \\
\hline Uruguay & $\mathrm{x}$ & & & $x$ & $x$ & $x$ & \\
\hline $\begin{array}{l}\text { Venezuela } \\
\text { (Bolivarian } \\
\text { Republic of) }\end{array}$ & & $x$ & & & & $\mathrm{X}$ & \\
\hline
\end{tabular}

Source: Latin American and Caribbean Demographic Centre (CELADE) - Population Division of ECLAC, on the basis of the countries' responses to the survey on programmes for older people in Latin America and the Caribbean. 


\section{Social environments: social support, ill-treatment, participation and education}

One area of work that is beginning to come to prominence in interventions aimed at older persons is the strengthening of social support networks; that is, the creation, promotion or consolidation of informal protection mechanisms developed by families and communities so that people can grow old in their homes and feel integrated into the community.

In some countries this issue is being addressed by encouraging volunteers to provide specific help to older persons (Argentina, Costa Rica, Puerto Rico and Uruguay), while in some cases it is older persons themselves who provide support to other people of their own generation. Another working method involves the provision of meal services. In Guatemala, for example, 12 community canteens have been set up for older persons in rural and urban areas, while in Belize assistance, meals and health care are being provided to the poorest sections of the elderly population with the support of a non-governmental organization.

Measures have also been taken to strengthen the social fabric that provides older persons with another type of support. In Costa Rica, for example, the Assistance Programme for Institutionalized Older People supplies financial resources to non-profit social welfare institutions providing care to the older adult population. In Nicaragua, support is being given to local organizations run by older persons themselves in rural areas. And in Cuba, government agencies are working under the leadership of local governments to coordinate and strengthen the family and community support given to the older adult population.

In Argentina, the Netherlands Antilles, Aruba, Panama and Puerto Rico, different community-based care options are being implemented. In the Dominican Republic, the Solidarity Programme is providing financial support to families that maintain an older person. In Chile, the Ministry of Planning's Comprehensive Programme for Older Adults is designed to improve the quality of life of older persons living in conditions of poverty and social isolation by bringing them into contact with the institutional resources available and helping them to integrate into the community; and in Brazil, the Social Assistance Reference Centres (CRAS) programme is being implemented to assist low-income families. The actions being undertaken include some designed to improve intergenerational relations in the family and the community. 
Ill-treatment of older persons is a violation of human rights and a major cause of injuries, sickness, lost productivity, isolation and despair (WHO, 2002), and it is a subject to which international agencies have paid special attention. Concern about it is expressed in all the countries, although intervention methods differ considerably in terms of scope and resources. This is partly because of the lack of statistical information on the extent of the problem and partly because violence against older persons generally takes place in private, with neither the victim nor the aggressor being willing to acknowledge the situation. To deal with this issue, governments have launched campaigns for good treatment and taken specific preventive measures. In some cases public prosecutors have become directly involved, while in others the issue has now begun to be seen as a public policy matter for which the State has particular responsibility.

Thus, most of the countries report that campaigns have been held to raise awareness of the issue (Belize, Chile, Colombia, El Salvador, Mexico, Nicaragua, Panama, Puerto Rico and the Bolivarian Republic of Venezuela). Some countries describe more consolidated national working programmes, among them Brazil, which has its plan of action to deal with violence against older persons (2007-2010), encompassing prevention, reporting, treatment and rehabilitation measures, supplemented by specialist social assistance referral centres, whose main focus is on helping the victims of violence.

Argentina has also been developing a programme to prevent discrimination, abuse and ill-treatment of older persons, while Costa Rica is implementing a programme called "Creating ties of solidarity" to finance care, rehabilitation and treatment projects for people who are indigent or have been ill-treated or abandoned. Puerto Rico is another country that has built up considerable experience of the issue through its Governor's Office of Older Persons Affairs, while in Peru the National Programme to Combat Family and Sexual Violence operated by the Ministry of Women and Social Development has included older persons in its target population.

Another area of work is socio-legal guidance for victims of violence. In Peru, local government social services are taking measures to prevent ill-treatment of older persons and safeguard their rights. In the Dominican Republic, a special agency has been created within the public prosecutor's service to act on complaints in coordination with the National Council for the Elderly. In the Bolivarian Republic of Venezuela, the free legal support and assistance service of the National Institute of Social Services (INASS) assists the victims of ill-treatment, while in Honduras the remit of the public prosecution service for consumers and the elderly includes the rights of older persons. 
In the Plurinational State of Bolivia, the domestic violence law treats assaults on older persons as an aggravating circumstance, while in Belize the subject was recently included in the relevant legislation (March 2007). In Uruguay, an Inter-institutional Commission for Ill-Treatment of the Elderly was created in 2005, and the Police-Older Adult Programme is tasked with detecting cases of violence and providing victims with guidance and advice. In El Salvador, situations of ill-treatment are monitored; in Chile, the National Service for Older Adults has a telephone assistance hotline for older persons who have been subjected to violence; and in Cuba, as a preventive strategy, the subject has been introduced in carers' training institutions for those dealing with physically or mentally dependent patients to foster a positive relationship between them.

Lastly, support for social participation by the elderly and access to continuing education are also areas that are beginning to be addressed by the countries. Argentina, Brazil, Cuba, Guatemala, Paraguay, Costa Rica, Chile, Honduras, Puerto Rico and Uruguay reported on specific activities to promote social networking, either by supporting older persons' organizations or through training. A smaller number of countries are taking measures in the sphere of education, examples being Belize, Costa Rica, the Dominican Republic and the Netherlands Antilles. Here it is important to highlight the efforts of Argentina and Brazil to provide the older population with opportunities for participation so that their opinions can be listened to and taken into account when policies and programmes affecting them are designed. In both countries, older persons' organizations have been seen as a first point of contact for participation in policy dialogue.

The issue of social environments is commonly dealt with by the main institutions responsible for ageing-related matters in the region's countries. This gives it a high profile nationally, unlike health or social security, which are usually construed as individual rather than collective matters. However, the brief synopsis provided in this section shows that, other than in a few countries, the measures taken do not always have public policy status and that, according to the information available, in several countries the work being done is in the nature of pilot projects that need to be consolidated and provided with guaranteed financing so that they can become sustainable. 
Box V.3

INTEGRATED CENTRES FOR THE CARE OF OLDER PERSONS IN BRAZIL AND THE PREVENTION OF VIOLENCE AGAINST THEM

Violence against older persons is a phenomenon that has been gaining attention recently in Brazil and around the world. Abuse against older persons was described in British scientific journals for the first time in 1975, while in Brazil the issue began to emerge as of 1990 . It is hoped that with the creation, in 2003, of the Statute of Older Persons' Rights, which makes reporting abuse mandatory, the true magnitude of the problem will be known.

To address the issue through systemic strategic action, the Government of Brazil designed the National Plan for Tackling Violence against Older Persons (2007-2010). Such an initiative was unheard of in the region, inasmuch as it was the result of a combined effort among the Federal Government, the National Council on Older Persons' Rights and social groups and was the first example of concrete action aimed at preventing, treating and criminalizing violence in old age.

The Plan serves as an instrument to further the implementation of a policy to promote and defend the rights of the older adult population in Brazil, within a framework of respect, tolerance and harmonious intergenerational coexistence. In addition, it seeks to improve institutional mechanisms and instruments at all levels to improve the understanding and application of the policy of guaranteed rights promoted by the Government of Brazil.

Part of the Plan was the creation of the integrated centres for the care of older persons and the prevention of violence against them. The centres make up the National Network in Defence of the Rights and Protection of Older Persons, which grew out of an initiative of the Special Secretariat on Human Rights in the Office of the President of the Republic of Brazil through the Office of the Undersecretary for the Defence and Promotion of Human Rights.

The centres are linked to governmental and non-governmental institutions, under the supervision and evaluation of the Latin American Research Centre on Violence and Health in Brazil. They focus on providing humane care to older persons who are in violent situations or whose rights have been violated. The centres' activities are aimed at raising awareness among older persons themselves, their families, professionals and the community about rights, citizenship and non-violence in old age.

The centres' principal objectives are to:

- Provide guidance to older persons who have been victims of violence regarding their human rights and legal protection, and refer them to the appropriate specialized networks such as the Ombudsman, Ministries, health services, delegations, long-term care facilities and social services;

- Engage the legal, psychological and social fields in the development of actions for care, prevention and promotion through the establishment of a multi-disciplinary team of social workers, psychologists and attorneys; Mediate in conflicts to improve the quality of life of the rpesons involved; 
Box V.3 (concluded)

- Conduct campaigns to educate and train those who work with older persons, including family members, counsellors and agents to become multipliers of a culture of respect for older persons.

- Most of these services are currently available in 18 States in Brazil. They are funded by the Special Secretariat on Human Rights and include the development of networks and the participation of older persons.

Source: Special Secretariat for Human Rights, "Informe de Brasil sobre la aplicación de la Estrategia regional de implementación para América Latina y el Caribe del Plan de Acción Internacional de Madrid sobre el Envejecimiento", 2007.

\section{Physical environments: housing, transport and accessibility}

On the whole, physical environments are an area of intervention that has been left largely untouched by the region's countries, although there are some notable exceptions. Most housing-related initiatives are aimed at those living in poverty, or at those with the financial capacity to apply for credits. In the field of transport, only a few countries provide free travel while the rest offer fare reductions, which may be unenforced or involve bureaucratic procedures that older persons are not always willing to undertake. As regards the accessibility of public spaces, the most promising interventions involve urban inclusion strategies, but they are largely confined to just a few countries. Other countries have taken steps to remove architectural barriers to access, focusing mainly on the mobility of the disabled but benefiting older persons in the process.

The countries reporting on initiatives in the housing sector include Aruba, Belize, Chile, Costa Rica, Cuba, El Salvador, Mexico, Panama, Peru and Uruguay. In Aruba, the Ministry of Education, Social Affairs and Infrastructure reserves a number of housing units for people with special needs, including older persons. Chile is implementing a similar scheme whereby the Ministry of Housing and Urban Affairs operates a special housing programme for older persons.

In Peru, the Ministry of Housing, Construction and Sanitation is implementing the "Techo propio" (home ownership) and "Techo propio deuda cero" (debt-free home ownership) programmes, which promote access to housing and better living conditions for people on low incomes; while the programme is not exclusive to older adults, they have been included among its beneficiaries. Similar schemes exist in Panama and El Salvador, providing assistance and material support to improve the quality of housing for the poorest older persons. Puerto Rico is implementing a programme of rental subsidies and home improvements for older persons. 
Cuba also has a house building and repair plan to help with refurbishment of homes occupied by elderly people, while Belize is implementing an initiative with the same objective, providing small-scale assistance to repair the homes of the poorest older persons with financial support from a charity.

In Costa Rica, the Banco Hipotecario has a housing programme for older persons living alone. In Mexico, the Security and Social Service Institute for State Workers has a lending programme to enable retirees to buy a new or used home or improve an existing one. In Uruguay, the "Programme for Other Housing Solutions" of the Social Security Bank includes a rental subsidy for insurance holders.

Interventions relating to transport are even fewer. Although a number of countries have legislated for fare reductions for older persons, these are not always implemented. The most advisable option, according to the reports from the countries, would seem to be the provision of subsidies to transport firms so that older persons can simply take up the benefit without charge. This avoids the need for bureaucratic procedures that actually make access to transport harder for older persons, even when reduced fares are on offer. The countries with free transport are Aruba, Argentina, Brazil, Guatemala, Puerto Rico and the Bolivarian Republic of Venezuela, while the countries reporting specific discounts on transport fares are Belize and Chile.

In Aruba, older persons have been exempt from paying fares on public transport since before 2001, and to this end the State provides a subsidy to transport firms, worth US\$ 611,000 in the 2007 fiscal year. In Argentina, the railway operating company in the suburban area of the city of Buenos Aires is given a subsidy so that retirees can use the service for free. In Brazil, older persons can use public and semi-urban transport for free. In Puerto Rico, the "Golden Programme" of the Metropolitan Transport Authority allows free travel on metropolitan transport for people aged over 75, in addition to the SENDA programme designed to make it easier for older persons and the disabled to reach different destinations (health services, supermarkets, banks and government offices). In Guatemala, an agreement was recently struck with private firms to allow older persons to travel for free on public transport.

In the Bolivarian Republic of Venezuela, the elderly travel for free on ground transport in urban areas and receive discounts on air tickets and intercity services, and special seats are set aside for them. In Belize, some cities have reduced fares on public transport for older persons, while Chile is implementing a preferential fare on the underground transport system in the capital. 
The countries that have reported on interventions in the public space are Argentina, Aruba, Colombia, Honduras, Mexico, Nicaragua, Paraguay and Peru. The experience of Brazil is worth highlighting here: since 1990, the country has been pursuing an innovative public policy to democratize cities. This is the City Statute, whose aim is greater social and geographical inclusiveness in urban areas. Among other things, this instrument is designed to promote the full exercise of citizenship and the visible participation, action or organization of the city's inhabitants, particularly the most vulnerable, who include older persons, the disabled and children.

Argentina is also making progress in this direction. The national accessibility plan, which covers the whole population but is particularly aimed at people with reduced mobility and communication difficulties, is designed to amend provincial and municipal zoning, planning and building laws to reduce barriers to inclusion for all and to facilitate community living. A similar initiative is planned in Aruba, where a 2006 evaluation of the accessibility of public buildings and services for people with sensory and motor difficulties led to the formulation of a plan that was recently submitted to the Ministry of Education, Social Affairs and Infrastructure for implementation in the near future.

In Peru, the "Mi Barrio" (My Neighbourhood) programme is meant to improve the living environment and conditions of people in deprived urban neighbourhoods, while in Paraguay courses on accessibility in the physical environment are being held for engineers and architects. Nicaragua has developed a strategy to publicize the country's compulsory technical standards for user access. Mexico and Honduras are also making progress with accessibility in public buildings, while Colombia is implementing programmes to facilitate access to physical spaces under its national plan for the disabled.

In summary, physical environments are an area in which more determined efforts will be required in the near future. Population ageing is placing new demands on housing, transport and public spaces. It is striking that no country reported on measures to extend the coverage of basic services or develop initiatives for the creation of specific housing solutions to facilitate intergenerational living, among a variety of other aspects.

As already mentioned, all these issues have vital implications for autonomy and independence in old age, and the fact that older persons are benefiting from measures taken under disabled access plans shows that interventions in physical environments which benefit one vulnerable group are bound to have a positive effect on other social sectors with specific needs, and indeed on the population as a whole. 


\section{Chapter VI \\ Implementing the Regional Strategy on Ageing in Latin America and the Caribbean: challenges and perspectives}

The age structure of the Latin American and Caribbean population has been changing at varying rates depending on the stage that the demographic transition has reached in each country. These changes in the size of generations relative to each other have come about as life expectancy has increased and fewer children are born, giving rise to a new scenario that has profound implications for family organization, levels of well-being and social cohesion, and the economic, political and cultural spheres (Guzmán, 2002b). Population ageing poses some major challenges for the countries of the region, since the older adult population is growing faster than it is in developed countries. This poses major challenges for Latin America and the Caribbean and places the region at an immediate and significant disadvantage.

\section{A. The main challenges}

The majority of older persons lack access to old-age pensions that would protect them against the risks of income loss when they reach an advanced age. Moreover, the social security coverage provided through employment is highly uneven, making it more likely that future generations will be financially vulnerable.

One of the ways to avert such vulnerability in old age is to generate income through participation in the labour market. This solution tends 
to be financially disadvantageous, however, and offers little security. As a result, the family acts as one of the main mechanisms of economic risk absorption in old age. This takes the form not only of informal money transfers, but also of service provision, since the market cost of those services is unaffordable for most older persons in the region.

Health-care systems are adapting slowly to the changes in demand arising from demographic, epidemiological and technical dynamics. This translates into higher costs and expenditures on health care and makes it more difficult to ensure timely access to good quality services for all the population. Health-care coverage is unequal and, even when older persons have health insurance, it often falls short of covering attendance at a health centre whenever necessary. When it comes to matters of health, the current generation of older persons is concerned about whether they will be able to obtain medications at accessible prices and receive effective health services that are appropriate to their needs, as well as properly regulated long-term care that respects their fundamental rights and freedoms as they become more dependent.

Environments, too, are slow to adapt to empower older persons to exercise their rights. There is still a culture in which older persons suffer age-based discrimination and in which violence against the most vulnerable members of society is thought best resolved at home. In addition, as well as lagging behind - more severely in some places than others - in terms of access to basic services and housing, the region is now showing a deficit in the quality of housing for older persons, which undermines their autonomy and the coexistence of the generations. In turn, there are large failings as regards access to public spaces, whose current state is far from conducive to the creation of community-based social capital in many of the region's countries.

In Latin America and the Caribbean, the demographic transition has wrought changes in the family structure and, as the population grows older, a higher percentage of households count older persons among their members. Until now, the family has provided emotional, economic, social and health-care support for its older members and has thus become established as the entity responsible for their care and social integration (Villa, 2003). But with families shrinking in size and -in recent decadesbecoming structurally much more diversified, as well as facing an excessive task load as they are forced to meet new demands in the context of an ever weaker State, the fact is that excessive demands are now placed on them. As an institution, the family can hardly discharge all the functions assigned to it without the necessary support. 


\section{B. How states are responding}

Faced with these challenges, the countries of the region have gradually formed responses to a demographic situation for which many of them were unprepared. One such response is to pass legislation to protect the rights of older persons exclusively and regulate basic aspects of human coexistence, such as the right to association, non-discrimination and personal safety, as well as providing social protection for rights such as education, work, social security, housing, the protection of the family, and so on.

This type of legislation is based on international human rights instruments, which necessarily constitute the normative framework for any rights-based action in support of older persons. In theory, these laws should lead to legally recognized rights being put into practice in the form of sectoral efforts on ageing and development. However, except for a few notable cases, legal standards do not always result in real rights coverage in old age and protection remains as flawed as ever.

The gap between de jure and de facto rights in old age is due, in part, to the lack of mechanisms to make them enforceable. Additionally, there are shortcomings in access to information. States have an obligation to produce and deliver relevant information on older persons' rights that are recognized in their national legislation. Although efforts have been made in this direction, in most of the countries older persons are unaware of their rights, thus making them ineffective.

Enforceability also depends on the public budget. Most of the existing legislation makes no reference to sources of funding to protect recognized rights. And in cases where the body of legislation does cover financing, the provisions are often disregarded. This limits the ability of governing bodies and of the public institutional structure as a whole to take action that could broaden the protection of older persons' rights.

Another issue that is becoming more prominent in the public policies of the Latin American and Caribbean countries is income protection. Although this is still an emerging area, there have been some noteworthy experiences in this direction. A number of countries have solid social security systems, which include broad coverage and extensive services and benefits for the retired and pensioned population.

Other countries are making efforts to make older persons more employable and to offer different alternatives for helping them achieve better positions in the labour market. This is an area into which a number of countries are venturing and interventions of this type, although still weak, are attracting governments' attention, especially where social security systems are severely flawed. 
Income protection through non-contributory pensions - where the capacity of the contributory system is insufficient- is still limited in the region. In States where such programmes are run, they have been found to have a significant impact on levels of poverty in old age and to represent an important investment in development which benefits families and communities, as well as the economy at large (United Nations, 2005b).

The countries have broadened their efforts to improve services and benefits for the older adult population regarding health protection, too. They have invested resources in improving certain benefits and in training staff and regulating long-term care. Progress has also been made on developing an institutional structure specifically for health care in old age. Practically all of the region's health ministries or departments have a specific unit or programme that is responsible for organizing and coordinating action in this regard.

A number of countries have undertaken work on preventive care and the promotion of healthy habits. Although the impact of such initiatives is not yet known, systematic resources and efforts have been invested in this area in the last five years.

There are, however, some complex issues regarding health protection that have yet to be comprehensively tackled. One of these is access to medication, which currently requires a large proportion of out-of-pocket spending. The system has also been slow to adapt to the new epidemiological profile and, worst of all, access to health care is extremely uneven and highly associated with income level and level of social security coverage.

The physical and social environment is also beginning, albeit only just, to be viewed as a matter for public concern. Generally speaking, the institutions governing such matters in the countries of the region have concentrated on the social environment and much of their efforts have focused on the prevention of mistreatment, the promotion of association and the creation of opportunities for lifelong learning. As for the physical environment, what progress there is largely concerns broader action to improve access for people with disabilities, which also benefits the elderly population and other social groups. This achievement has had little impact on the ubiquitous matters of housing and transport, however, which have been less extensively addressed and need to be dealt with more comprehensively in the near future.

\section{Ageing and a society for all}

Although older persons are at the heart of the areas of effort mentioned, it is nonetheless true that the problems affecting the older adult population and those affecting the rest of society are closely linked. Hence, in view 
of the scarcity of resources in most of the region's countries, the visibility of ageing issues and their budgetary and technical allocations also affect other social groups.

From this perspective, the problems of older persons - and the solutions found in terms of social protection - must be set within the broader framework of the construction of a society for all. As well as progressing towards broader coverage, social interventions must pursue such basic objectives as solidarity and social cohesion as key factors in obtaining certain levels of well-being, as well as the exercise of rights for the entire population.

Consensus is lacking as to whether it is economically feasible to provide social protection for older persons. Indeed, the policy options considered tend to address to questions of social cohesion rather than economic issues. Some contend that the growing emphasis on promoting individual and family responsibility for the well-being of older persons will lead to a general weakening of overall social cohesion (United Nations, $2005 b)$. By contrast, an active State role in providing protection for the entire population, especially the most vulnerable, will benefit not only the recipients of those funds, but their families as well, and will create social capital and economic assets for future generations.

The idea of social integration is not limited in time or space. On the contrary, it means that present and future generations have the right to equality and social justice. The decisions that are taken today affect the structure of social integration now and in the future, as well as the opportunities it creates. The idea of intergenerational equity supposes that each generation will address its own needs in such a way as not to prejudice or disadvantage the next. As societies and their demographic composition change, there is a need to refocus on the different generations' responsibilities to each other and to adjust to the new realities (United Nations, 2005b).

Rapid population ageing brings multiple challenges and requires responses that ensure a fair distribution of resources, in order to provide adequately for the needs of all society's age groups. It also requires shifts in attitudes, policies and practices so as to enhance quality of life for older persons. Older persons cannot be excluded, therefore, from whatever route the Latin American and Caribbean countries find towards progress and justice. The key question here is how to help this group to participate fully in the possibilities created by progress and the demands imposed by justice (CELADE, 1997).

The effective social integration of older persons depends on equity of access to different and economic services and on guaranteed rights. In countries where basic pensions are lacking and poverty widespread, policies to improve income security in old age must include poverty 
reduction as part of their strategy. The possibilities of future generations breaking the intergenerational transmission of poverty are likely to increase where non-contributory pensions are included in the range of solutions to poverty and the other aspects involved are also addressed. Countries that already have such programmes must continue to work towards increasing the coverage of benefits, taking into account such principles as the universality and solidarity.

Countries that bear a double epidemiological burden need health policies to deal more explicitly with this situation. Some will still be addressing the problem of meeting the Millennium Development Goals to reduce child mortality and improve maternal health, even as they are adjusting their health-care systems to deal with the needs of a growing older population (United Nations, 2007b). In the more advanced countries, by contrast, the emphasis should be on promoting a healthy lifestyle at all stages of life in order to reduce chronic disease to a minimum. It is also extremely important to improve solidarity in health-care systems, by broadening access opportunities on a basis of equality for the entire population.

Countries that are still lagging in terms of housing availability and access to basic services need to progress towards meeting the target of increasing sustainable access to drinking water and basic sanitation as set out in the Millennium Development Goals at the same time as they devise new solutions for living arrangements to facilitate the coexistence of several generations. It is also essential to create the conditions to promote ageing at home and support families in the caregiving tasks carried out by household members.

A recent report compiled by the United Nations (2007b) noted that developing countries must avoid repeating the mistakes of some of the richer nations, which built numerous institutions for older persons. Often, community-based care can be a more effective and inclusive solution and, where there is no alternative to long-term care facilities, the process should be adapted to the local culture and not limited to following previously established patterns.

The opportunity to make progress in all these areas is closely associated with the ability to take advantage of the demographic dividend. As foreseen by CELADE (2008), in Latin America and the Caribbean, changes in the age structure are occurring in such a way that the workingage population will increase proportionally during the next few decades of the twenty-first century. In other words, dependency ratios will tend to decrease, at least for a time, so most of the region's countries will have the opportunity to heighten their productive potential and prepare for the final stage of the demographic transition, when the older population will increase proportionally. 
Given this scenario, the main challenge for Latin America and the Caribbean lies in the region's ability to take advantage of the positive potential created by the demographic transition to prepare itself opportunely and adequately to face the new requirements emerging from these changes, in order to foster sustainable development with social equity for the region (Machinea, 2007).

In short, and as is emphasized in the recent report by the SecretaryGeneral of the United Nations, Governments are making efforts to address the challenge of population ageing (United Nations, 2006a). The information available suggests that such measures are essential and need to be further complemented with new interventions. In this regard, and building on the earlier discussion, it is extremely important to enhance the capacities and resources of the institutional structure available in the countries of the region, to strengthen the technical capacity of national teams responsible for ageing issues and to plan ahead and properly graduate the measures to be taken, for which up-to-date and accessible information on the older adult population and its needs is essential.

In more advanced countries, it is essential to gauge the effectiveness of the legislation, policies and programmes in place. A careful analysis should be undertaken to establish which public policy measures are most important and investment prioritized accordingly. Increasingly, participatory processes are acknowledged to be particularly important in improving public administration. A participatory normative and programmatic process makes interventions more effective and helps to include older persons in the decisions that affect them.

In order to move in this direction, each society must be aware of the value and significance of the intergenerational contract. It is important to appreciate what this pact contributes to society in terms of social cohesion and to value the willingness of societies to fulfill their social commitments (United Nations, 2005a). Governments need to reformulate policies in order to underpin and maintain a society that includes everyone, instead of treating action on older persons as a matter separate from the future of society as a whole. 



\section{Bibliography}

Abramovich, Víctor (2004), “Una aproximación al enfoque de derechos en las estrategias y políticas de desarrollo de América Latina", document prepared for the meeting Rights and development in Latin America: a working seminar, Santiago, Chile, 9 - 10 December.

Abramovich, Víctor and Christian Courtis (2006), El umbral de la ciudadanía: el significado de los derechos sociales en el Estado social constitucional, Buenos Aires, Editores del Puerto.

Arriagada, Camilo (2005), "El déficit habitacional en Brasil y México y sus dos megaciudades globales: estudio con los censos de 1990 y 2000", Población y desarrollo series, No. 62 (LC/L.2433-P), Santiago, Chile, Economic Commission for Latin America and the Caribbean (ECLAC). United Nations publication, Sales, No. S.05.II.G.179.

(2003a), "Acceso a la vivienda de las personas mayores en América Latina: diagnóstico y desafíos regionales después del Plan Mundial de Madrid", Santiago, Chile, Latin American and Caribbean Demographic Centre (CELADE) - Population Division of ECLAC, unpublished.

(2003b), "La dinámica demográfica y el sector habitacional en América Latina", Población y desarrollo series, No. 33 (LC/L.1843-P), Santiago, Chile, Economic Commission for Latin America and the Caribbean (ECLAC). United Nations publication, Sales No. S.03.II.G.8.

Arriagada, Irma (comp.) (2007), “Familias y políticas públicas en América Latina: una historia de desencuentros", Libros de la CEPAL series, No. 96 (LC/G.2345-P), Santiago, Chile, Economic Commission for Latin America and the Caribbean (ECLAC). United Nations publication, Sales No. S.07.II.G.97.

Barker, David (1998), Mothers, Babies and Health in Later Life, London, Churchill Livingstone, March.

Bassols Coma, Martín (1983), “Consideraciones sobre el acceso a la vivienda en la Constitución española de 1978", Revista de derecho urbanístico, No. 85, Madrid, Editorial Montecorvo. 
Bertranou, Fabio (2006), Envejecimiento, empleo y protección social en América Latina, Santiago, Chile, International Labour Organization (ILO).

Bertranou, Fabio, Woulter Van Ginneken and Carmen Solorio (2004), "The impact of tax-financed pensions on poverty reduction in Latin America: evidence from Argentina, Brazil, Chile, Costa Rica and Uruguay", International Social Security Review, vol. 57, No. 4, Oxford, Blackwell Publishing.

Bosch Meda, Jordi (2006), "El problema de la vivienda en la vejez en Cataluña", Revista $A C E$, vol. 1, No. 1, Barcelona, Centro de Política de Suelo y Valoraciones.

Bravo, Jorge and Mauricio Holz (2007), "Interage transfers in Chile, 1997: economic significance", document presented at the seminar Ageing in Developing Countries: Building Bridges for Integrated Research Agendas, Santiago, Chile, 23-24 April.

Bucheli, Marisa, Rodrigo Ceni and Cecilia González (2007), The Public Transfers Flows Between Generations: Uruguay (1994), Montevideo, Departament of Economics, University of the Republic.

Casado, David and G. López (2001), Vejez, dependencia y cuidados de larga duración. Situación actual y perspectivas de futuro, Colección Estudios Sociales, No. 6, Barcelona, Fundación "La Caixa".

CCHD (Caribbean Commission on Health and Development) (2006), Report of the Caribbean Commission on Health and Development, Washington, D.C., Pan American Health Organization (PAHO)/Caribbean Community (CARICOM).

CELADE (Latin American and Caribbean Demographic Centre-Population Division of ECLAC) (2008), Demographic change and its influence on development in Latin America and the Caribbean (LC/G.2378(SES.32/14)), Santiago, Chile, Economic Commission for Latin America and the Caribbean (ECLAC).

(2007), Demographic Observatory: Economically Active Population, No. 2 (LC/G.2337-P), Santiago, Chile, Economic Commission for Latin America and the Caribbean (ECLAC). United Nations publication, Sales No. E/S.07.II.G.28. (2006a), "Envejecimiento. América Latina y el Caribe: desafíos y oportunidades de una sociedad que envejece", Temas de población y desarrollo, No. 5, Santiago, Chile.

(2006b), "Los derechos en la vejez", Envejecimiento y desarrollo, No. 4, Santiago, Chile.

(2004), "América Latina y el Caribe: estimaciones y proyecciones de población 1950-2050", Demographic Bulletin, No.73 (LC/G.2225-P), Santiago, Chile, Economic Commission for Latin America and the Caribbean (ECLAC), January.

(2003), "La situación de las personas mayores", document presented at the Regional Intergovernmental Conference on Ageing, Santiago, Chile, 19-21 November. (1997), Ageing: Four Dimensions of a Society for All Ages, series A, No. 309 (LC/DEM/G.174), Santiago, Chile.

Cercone, J. (2005), "Análisis de la situación y sistemas de salud de países del Caribe", working paper, Santiago, Chile, Economic Commission for Latin America and the Caribbean (ECLAC).

Chackiel, Juan (2004), "La dinámica demográfica en América Latina”, Población y desarrollo series, No. 52 (LC/L.2127-P), Santiago, Chile, Economic Commission for Latin America and the Caribbean (ECLAC). United Nations publication, Sales No. S.04.II.G.55. 
Chesnais, Jean Claude (1990), El proceso de envejecimiento de la población, series E, No. 35 (LC/DEM/G.87), Santiago, Chile, Economic Commission for Latin America and the Caribbean (ECLAC).

Descola, Phillippe (1986), La selva culta: simbolismo y praxis en la ecología de los achuar, Quito, Abya Yala-MLAL.

Drago, Marcelo (2007), “El modelo de garantías explícitas en las políticas públicas chilenas", document presented at the Workshop on explicit guarantees in the implementation of the economic, social and cultural rights in Latin America and the Caribbean, Santiago, Chile, 2-4 April.

ECLAC (Economic Commission for Latin America and the Caribbean) (2007a), Economic Survey of Latin America and the Caribbean, 2006-2007 (LC/G.2338-P), Santiago, Chile. United Nations publication, Sales No. E.07.II.G.2. (2007b), Social Panorama of Latin America 2006 (LC/G.2326-P), Santiago, Chile. United Nations publication, Sales No. E.06.II.G.133.

(2007c), Social Cohesion: Inclusion and a Sense of Belonging in Latin America and the Caribbean ((LC/G.2335), Santiago, Chile.

(2006), Shaping the Future of Social Protection: Access, Financing and Solidarity (LC/G.2294 (SES.31/3)), Santiago, Chile.

(2005), Social Panorama of Latin America 2005 (LC/G.2288-P), Santiago, Chile. United Nations publication, Sales No. E.05.II.G.161.

(2004), Social Panorama of Latin Amrica 2004 (LC/L.2259-P), Santiago, Chile. United Nations publication, Sales No. E.04.II.G.148.

(2000), Social Panorama of Latin America 1999-2000 (LC/G.2068-P), Santiago, Chile. United Nations publication, Sales No. E.00.II.G.18.

Escobar, Guillermo (2006), Federación Iberoamericana del Ombudsman, Madrid, Trama Editorial.

FAO (Food and Agriculture Organization of the United Nations) (2002), "Balance between food security and the sustainable management of natural resources in Latin America and the Caribbean", document presented at the twentysenventh Regional Conference for Latin America and the Caribbean, Havana, Cuba, 22-26 April.

Frenk, J. and others (1991), "The epidemiological transition in Latin America", Bulletin of the Pan American Health Organization, vol. 111, No. 6, Washington, D.C., Pan American Health Organization.

Gaylin, D.S. and J. Kates (1997), "Refocusing the lens: epidemiological transition theory, mortality differentials, and the AIDS pandemic", Social Science and Medicine, vol. 44, No. 5, Amsterdam, Elsevier.

Gill, Indermit, Truman Packard and Juan Yermo (2004), Keeping the Promise of Old Age Income Security in Latin America: A Regional Study of Social Security Reforms, Washington, D.C., World Bank.

Giorguli, Silvia, Selene Gaspar and Paula Leite (2006), La migración mexicana y el mercado de trabajo estadounidense: tendencias, perspectivas y ioportunidades?, Mexico City, National Population Council (CONAPO).

Goldani, Ana María (2006), “Famílias e envelhecimento: complexidades do 'cuidado'", document presented at the Reunión sobre indicadores para el seguimiento del Plan de Acción Internacional de Madrid sobre el Envejecimiento, Rio de Janeiro, 24-26 July. 
González, Daniela (2006), “Vivienda, uso del espacio urbano y envejecimiento en América Latina", presentation prepared for the course "Indicadores de calidad de vida en la vejez", Santiago, Chile, 4-8 December.

Guedes, Gilvan Ramalho (2006), “Os diferenciais de gênero na influência do status sócio-econômico e da estrutura domiciliar nos resultados de saúde do idoso brasileiro", document presented at the XV Encuentro Nacional de Estudios Poblacionales, Caxambú, Brazil, 18-22 September.

Guendel, Ludwig (2000), La política pública y la ciudadanía desde el enfoque de los derechos humanos: la búsqueda de una nueva utopía, San José, Latin American Faculty of Social Sciences (FLACSO)/United Nations Children's Fund (UNICEF)/ University of Costa Rica.

Guzmán, José Miguel (2002a), “Envejecimiento y desarrollo en América Latina y el Caribe", Población y desarrollo series, No. 28 (LC/L.1737-P), Santiago, Chile, Economic Commission for Latin America and the Caribbean (ECLAC). United Nations publication, Sales No. S.02.II.G.49. (2002b), “¿Podremos construir una sociedad para todas las edades?” [online] http:/ / www.un.org/spanish/envejecimiento/guzman.htm

Guzmán, José Miguel and others (2006), "La démographie de l'Amérique latine et de la Caraibe depuis 1950", Revue Population 2006, No. 5/6, Paris, Institut national d'études démographiques.

Guzmán, José Miguel and Sandra Huenchuan (2004), "Políticas hacia las familias con adultos mayores: notas preliminares", Cambio de las familias en el marco de las transformaciones globales: necesidad de políticas públicas eficaces, Irma Arriagada and Verónica Aranda (eds.), Seminarios y conferencias series, No. 42 (LC/L.2230-P), Santiago, Chile, Economic Commission for Latin America and the Caribbean (ECLAC). United Nations publication, Sales No. S.04.II.G.150.

Ham Chande, Roberto (2003), El envejecimiento en México: el siguiente reto de la transición demográfica, Mexico City, El Colegio de la Frontera Norte.

Hill, Kenneth, José Morelos and Rebeca Wong (coords.) (1999), Las consecuencias de las transiciones demográficas y epidemiológicas en América Latina, Mexico City, El Colegio de México.

Hoeymans, N., E.J. Feskensand others (1999), "The contribution of chronic conditions and disabilities to poor self-rated health in elderly men", Journals of Gerontology Series A: Biological Sciences and Medical Sciences, vol. 54, No. 10, Washington, D.C., Gerontological Society of America.

Hopenhayn, Martín and Ernesto Espíndola (2007), "The right of children and adolescents to a healthy environment. A diagnosis from Latin America and the Caribbean", Challenges, No. 5, Santiago, Chile, Economic Commission for Latin America and the Caribbean (ECLAC)/United Nations Children's Fund (UNICEF).

Hoskins, Dalmer (2002), "Prioridades del desarrollo en un mundo que está envejeciendo", Informe del seminario realizado el 31 de octubre de 2002 en el National Press Club, Washington, D.C., HelpAge International/National Academy of Social Insurance/Initiative for Policy Dialogue.

Huenchuan, Sandra (2006), “El envejecimiento de la población indígena en América Latina: aproximación conceptual y sociodemográfica", Pueblos indígenas y afrodescendientes de América Latina y el Caribe: información sociodemográfica para politicas y programas, Project documents, No. 72 (LC/W.72), Santiago, Chile, Economic Commission for Latin America and the Caribbean (ECLAC). 
Huenchuan, Sandra and Alejandro Morlachetti (2007), "Derechos sociales y envejecimiento: modalidades y perspectivas de respeto y garantía en América Latina", Notas de población, No. 85 (LC/G.2346-P),, Santiago, Chile, Economic Commission for Latin America and the Caribbean (ECLAC).

Huenchuan, Sandra and José Miguel Guzmán (2007a), "Seguridad económica y pobreza en la vejez: tensiones, expresiones y desafíos para el diseño de política", Notas de población, No. 83 (LC/G.2340-P), Santiago, Chile, Economic Commission for Latin America and the Caribbean (ECLAC). (2007b), "Políticas hacia las familias con personas mayores: el desafío del cuidado en la edad avanzada", Familias y politicas públicas en América Latina: una historia de desencuentros, Irma Arriagada (comp.), Libros de la CEPAL series, No. 96 (LC/G.2345-P), Santiago, Chile, Economic Commission for Latin America and the Caribbean (ECLAC). United Nations publication, Sales No.S.07.II.G.97.

Idler, E.L. (2003), "Discussion: gender differences in self-rated health, in mortality, and in the relationship between the two", The Gerontologist, vol. 43, No. 3, Washington, D.C., The Gerontological Society of America.

Idler, E.L., L.B. Russell and D. Davis (2000), "Survival, functional limitations, and selfrated health in the NHANES 1 epidemiologic follow-up study, 1992", American Journal of Epidemiology, vol. 152, No. 9, Oxford, Oxford University Press.

ILO (International Labour Organization) (2008), La reforma previsional en Chile y la contribución de la OIT, Santiago, Chile, ILO Subregional Office for the Southern Cone of Latin America.

(2006), "Anexo estadístico", Panorama laboral 2006: América Latina y el Caribe, Lima, Regional Office for Latin America and the Caribbean [online] http:// www.oit.org.pe/portal/documentos/pl_2006_esp_final_corregido.pdf (2002a), Social Security: A New Consensus, Geneva.

(2002b), "An inclusive society for an ageing population: The employment and social protection challenge", document presented at the Second World Assembly on Ageing, Madrid, 8-12 April.

INAPAM (National Institute for Older Adults) (2007), "Programas de adultos mayores en zonas rurales y programa 70+" [CD-ROM] [August 2007].

INEC (National Institute of Statistics and Censuses) (2007), "Prevalencia de la discapacidad en personas de 65 años y más" [electronic mail, 30 August 2007]. (2003), Encuesta Nicaragüense para Personas con Discapacidad 2003, Managua.

Iwakami Beltrão, K., A. Camarano, A. and J. Leitão e Mello (2004), “Mudanças nas condições de vida dos idosos rurais brasileiros: resultados não-esperados dos avanços da Seguridade Rural", document presented at the First Congress of the Latin American Population Association (ALAP), Caxambú, Brazil, September.

Jaramillo, Carlos Felipe (1998), “El mercado rural de tierras en América Latina: hacia una nueva estrategia", Perspectivas sobre mercados de tierras rurales en América Latina, Technical report, No. ENV-124, Washington, D.C., Inter-American Development Bank.

Jaspers, Dirk (2007), "A new look at the population pyramid", ECLAC Notes, No. 53, July, Santiago, Chile, Economic Commission for Latin America and the Caribbean (ECLAC).

Jouravlev, Andrei (2004), “Los servicios de agua potable y saneamiento en el umbral del siglo XXI", Recursos naturales e infraestructura series, No. 74 (LC/L.2169-P), Santiago, Chile, Economic Commission for Latin America and the Caribbean (ECLAC). United Nations publication, Sales No. S.04.II.G.98. 
Kirk, Dudley (1996), "Demographic transition theory", Population Studies, vol. 50, No. 3, London, Population Investigation Committee.

Lima-Costa, María Fernanda and others (2003), "Socioeconomic position and health in a population of Brazilian elderly: the Bambui Health and Aging Study (BHAS)", Pan American Journal of Public Health, vol. 13, No. 6, Washington, D.C., Pan American Health Organization (PAHO), June.

Livi-Bacci, Máximo (1994), "Population policies: a comparative perspective", International Social Science Journal, No. 141, Paris, United Nations Educational, Scientific and Cultural Organization (UNESCO).

Machinea, José Luis (2007), "The Latin American and Caribbean population challenge", ECLAC Notes, No. 53, Santiago, Chile, Economic Commission for Latin America and the Caribbean (ECLAC), July.

(2006), Statement of José Luis Machinea, Executive Secretary of the Economic Commission for Latin America and the Caribbean at the Opening meeting of the ECLAC Sessional Ad-Hoc Committee on Population and Development (DIS2-ES), 20 March.

Maldonado, Jesús and María José Hernán (1998), “Los retos de la solidaridad ante el cambio familiar", Cuadernos técnicos de servicios sociales, Madrid, Consejería de Sanidad y Asuntos Sociales.

Marín, Pedro Paulo and others (2007), "Exclusión social de discapacitados físicos y mentales dependientes institucionalizados en América Latina y el Caribe", Washington, D.C., Inter-American Development Bank (IDB)/Pan American Health Organization (PAHO).

Marques, Leticia (2006), “El derecho humano a la vivienda adecuada en América Latina: de la teoría a la práctica" [online] http:/ / www.idrc.ca/openebooks/323-2/.

Mesa-Lago, Carmelo (2004), "Las reformas de pensiones en América Latina y su impacto en los principios de la seguridad social", Financiamiento del desarrollo series, No. 144 (LC/L.2090-P), Santiago, Chile, Economic Commission for Latin America and the Caribbean (ECLAC). United Nations publication, Sales No. S.04.II.G.29. (1978), Social Security in Latin America, Pennsylvania, University of Pittsburgh Press.

MIDES (Ministry of Social Development) (2004), “Diagnóstico nacional de la situación de las personas mayores en Panamá: edificar una sociedad para todos las edades" [online] http:/ / www.portaldoenvelhecimento.net/download/panama.pdf.

Ministry of Public Health, Cuba (2006), Proyecciones de la salud pública en Cuba para el 2015, Havana, February.

Molarius, Anu and Staffan Janson (2002), "Self-rated health, chronic diseases, and symptoms among middle-aged and elderly men and women", Journal of Clinical Epidemiology, vol. 55, No. 4, Amsterdam, Elsevier.

OHCHR (Office of the United Nations High Commissioner for Human Rights) (2004), Human Rights and Poverty Reduction. A Conceptual Framework (HR/ PUB/04/1), New York, United Nations.

OECD (Organisation for Economic Co-operation and Development) (2000), Reforms for an Ageing Society, Paris.

(1998), Maintaining Prosperity in an Ageing Society, Paris.

(1973), Liste des préoccupations sociales communes à la plupart des pays de l'OCDE, Paris. 
Offe, Claus (1992), La sociedad del trabajo: problemas estructurales y perspectivas de futuro, Madrid, Alianza.

OISS (Ibero-American Social Security Organization) (2007), "Situación y demandas de las personas mayores en los países delConoSur.Apuntes para un diagnóstico", Proyecto sobre personas mayores, dependencia y servicios sociales en los países del Cono Sur, Madrid.

Otero, Ángeland others (2004), "Volumen y tendencias de la dependencia asociada al envejecimiento en la población española", Revista española de salud pública, vol. 78, Madrid, Ministerio de Sanidad y Consumo.

Paddison, Oliver (2005), Social Security in the English-Speaking Caribbean (LC/CAR/ L.64), Port of Spain, ECLAC subregional headquarters for the Caribbean.

Palloni, Alberto, Susan De Vos and Martha Peláez (2002), "Aging in Latin America and the Caribbean", Working Paper, No. 99-02, Madison, Wisconsin, Center for Demography and Ecology, University of Wisconsin.

Palloni, Alberto and others (2007), "The influence of early conditions on health status among elderly Puerto Ricans", Social Biology, vol. 52, No. 3-4, Washington, D.C., Society for the Study of Social Biology.

PAHO (Pan American Health Organization) (2007), "La renovación de la APS y la atención a los adultos mayores", July, unpublished. (2005), World Health Report 2005, Washington, D.C. (2002), Health in the Americas, Washington, D.C. (1996), "Healthy people in healthy spaces", Annual Report of the Director, 1996, Washington, D.C.

(1994), La salud y las mujeres en América Latina y el Caribe: viejos problemas y nuevos enfoques, Washington, D.C.

Pautasi, Laura and Corina Rodríguez (2006), "Ingreso ciudadano y equidad de género: ¿modelo para armar? Una aproximación al caso latinoamericano", La renta básica como nuevo derecho ciudadano, Gerardo Pisarello and Antonio De Cabo, Madrid, Editorial Trotta.

Perticara, Marcela (2008), "Incidencia de los gastos de bolsillo en salud en siete países latinoamericanos", Políticas sociales series, No. 141 (LC/L.2879-P), Santiago, Chile, Economic Commission for Latin America and the Caribbean (ECLAC).

Pisarello, Gerardo (2003), Vivienda para todos: un derecho en (de)construcción: el derecho a una vivienda digna y adecuada como un derecho exigible, Madrid, Editorial Icaria.

Pisarello, Gerardo and Antonio De Cabo (2006), La renta básica como nuevo derecho ciudadano, Madrid, Editorial Trotta.

Redondo, Nélida (2007), “Exclusión social de los discapacitados físicos y mentales dependientes de institucionalizados en América Latina y el Caribe. Informe Argentino", Buenos Aires, ISALUD, Foundation, Pan American Health Organization (PAHO), Inter-American Development Bank (IDB).

Reyes Gómez, Laureano (2002), Envejecer en Chiapas. Etnogerontología Zoque, Mexico City, National Autonomous University of Mexico.

Robles, Leticia (2003), "Una vida cuidando a los demás: una carrera de vida en ancianas cuidadoras", exposition presented at the 51st International Congress of Americanists, Santiago, Chile, 14-18 July.

Rodríguez, Jorge (2004), “Migración interna en América Latina y el Caribe: estudio regional del período 1980-2000", Población y desarrollo series, No. 50 (LC/L.2059-P), Santiago, Chile, Economic Commission for Latin America and the Caribbean (ECLAC). United Nations publication, Sales No. S.04.II.G.3 
(2003), "La fecundidad alta en América Latina y el Caribe: un riesgo en transición", Población y desarrollo series, No. 46 (LC/L.1996-P), Santiago, Chile, Economic Commission for Latin America and the Caribbean (ECLAC). United Nations publication, Sales No. S.03.II.G.158.

Rodríguez, Jorge (2001), Vulnerabilidad y grupos vulnerables: un marco de referencia conceptual mirando a los jóvenes, Población y desarrollo series, No. 17 (LC/L.1588-P), Santiago, Chile, Economic Commission for Latin America and the Caribbean (ECLAC). United Nations publication, Sales No. S.01.II.G.131.

Romero, Dalia, Iúri da Costa Leite and Célia Landmann Szwarcwald (2005), "Expectativa de vida saudável no Brasil: uma aplicação do método de Sullivan", Cadernos de saúde pública, vol. 21, No. 1, Rio de Janeiro, Escola Nacional de Saúde Pública Sergio Arouca.

Rosero-Bixby, Luis and Arodys Robles (2006), "Los dividendos demográficos en Costa Rica a partir del mapeo de la economía del ciclo vital del individuo", presentation at the II Congress of the Latin American Population Association, Guadalajara, Mexico, 3-5 September.

Saad, Paulo (2004), "Transferencias de apoio intergeneracional no Brasil e na América Latina", Os novos idosos brasileiros. Muito além dos 60?, A.A. Camarano (org.), Rio de Janeiro, Institute of Applied Economic Research (IPEA).

(2003), "Transferencias informales de apoyo de los adultos mayores en América Latina y el Caribe: estudio comparativo de encuestas SABE", Notas de población, No. 77 (LC/G.2213-P), Santiago, Chile, Latin American and Caribbean Demographic Centre (CELADE) - Population Division of ECLAC.

Sánchez, Carmen Delia (1996), Sistema de apoyo y familiares de pacientes de Alzheimer, San Juan, Puerto Rico, Oficina del Gobernador para Asuntos de la Vejez.

Schkolnik, Susana (2007), Estudio sobre la protección social de la tercera edad en Ecuador, Quito, Latin American and Caribbean Demographic Centre (CELADE) -Population Division of ECLAC/Ministry of Social Welfare.

(2004), "La fecundidad en América Latina: ¿transición o revolución?", Seminarios y conferencias series, No. 36 (LC/L.1588-P), Santiago, Chile, Economic Commission for Latin America and the Caribbean (ECLAC). United Nations publication, Sales No. S.01.II.G.131.

Schkolnik, Susana and Juan Chackiel (2004), "Less advanced sectors in the Latin American fertility transition", CEPAL Review, No. 83 (LC/G.2231-P), Santiago, Chile, August.

Schwarz, A. (2002), "La relación entre desarrollo y protección social", Informe del seminario realizado el 31 de octubre de 2002 en el National Press Club, Washington, D.C., HelpAge International/National Academy of Social Insurance/Initiative for Policy Dialogue.

Sempere, Antonio and Faustino Cavas (2007), Ley de dependencia. Estudio de la Ley 39/2006, sobre promoción de la autonomía personal y atención a las personas en situación de dependencia, Pamplona, Editorial Aranzadi.

Sojo, Ana María (2006), “La garantía de prestaciones en salud en América Latina: equidad y reorganización de los cuasimercados a inicios del milenio", Estudios y perspectivas series, No. 44 (LC/MEX/L.708), Mexico City, ECLAC subregional headquarters in Mexico. United Nations publication, Sales No. S.06.II.G.9. 
Spizzichino, Daliele and Viviana Egidi (2007), “Objective and subjective dimensions of gender differences health. An analysis of the Italian health interview survey", document presented at the Workshop of the EAPS Working Group on Health, Morbidity and Mortality: Individual, Area and Group Variation in Morbidity and Mortality, Rome, 17-19 September.

Superintendencia de Salud (2006), "Impacto del envejecimiento en el gasto en salud: Chile 2002-2020", working paper, Santiago, Chile, July.

Tabor, Steven (2002), "Assisting the poor with cash: design and implementation of social transfer programs", Social Protection Discussion Paper, No. 223, Washington, D.C., World Bank.

Tellechea, Lourdes (2007), "Derechos humanos en los cuidados a largo plazo", presentation at the Meeting/International Workshop, Havana, 10-12 May.

Titelman, Daniel (2000), "Reformas al sistema de salud en Chile: desafíos pendientes", Financiamiento del desarrollo series, No. 104 (LC/L.1425-P), Santiago, Chile, Economic Commission for Latin America and the Caribbean (ECLAC). United Nations publication, Sales No. S.00.II.G.99.

United Nations (2007a), Convention on the Rights of Persons with Disabilities (A/RES/61/106), New York, January.

(2007b), World Economic and Social Survey 2007: Development in an Ageing World, New York, Department of Economic and Social Affairs. (2007c), World Population Ageing, 2007, New York, Department of Economic and Social Affairs.

(2006a), Monitoring of Population Programmes, Focusing on the Changing Age Structures of Population and their Implications for Develpment. Report of the Secretary-General (E/CN.9/2007/4), New York, Economic and Social Council, December.

(2006b), Living Arrangements of Older Person around the World (ST/ESA/ SER.A/240), New York, Population Division, Department of Economic and Social Affairs.

(2005a), Social development, including questions relating to the world social situation and to youth, ageing, disabled persons and the family (A/60/501), New York, General Assembly.

(2005b), Report on the World Social Situation (A/60/117), New York, July.

(2004), Consideration of Reports Submitted by States Parties under Articles 16 and 17 of the Covenant: Concluding Observations of the Comittee on Economic, Social and Cultural Rights. Chile (E/C.12/1/Add.105), New York.

(2001), Consideration of Reports Submitted by States Parties Under Articles 16 and 17 of the Covenant: Concluding Observations of the Committee on Economic, Social and Cultural Rights. Honduras (E/C.12/1/Add.57), New York.

(2000), The Right to the Highest Attainable Standard of Health, General Comment, No. 14 (E/C.12/2000/4), New York, Economic and Social Council (ECOSOC). (1999), "International Year of Older Persons 1999" [online] http:/ / www.un.org/ esa/socdev/iyop/

(1995a), The economic, social and cultural rights of older persons, General Comment, No. 6 (E/C.12/1995/16/Rev.1), Geneva, Committee on Economic, Social and Cultural Rights. 
(1995b), Report of the World Summit for Social Development (A./CONF.166/9), Copenhaguen.

Vallin, Jacques (1994), La demografía, Santiago, Chile, Latin American and Caribbean Demographic Centre (CELADE)-Population Division of ECLAC.

Vásquez, Javier (2004), “Discriminación y violencia en la vejez: mecanismos legales e instrumentos internacionales para la protección de los derechos en la edad avanzada", document prepared for the Meeting of Experts on Ageing - Second Central American and Caribbean Forum on Policies for Older Persons, San Salvador, 10-12 November.

Villa, Miguel (2004), “La transición demográfica y algunos retos sobre población y desarrollo en América Latina", Población y desarrollo en México y el mundo, Mexico City, National Population Council (CONAPO).

(2003), "Discurso del oficial a cargo del Centro Latinoamericano y Caribeño de Demografía (CELADE), Population Division of ECLAC, señor Miguel Villa", Redes de apoyo social de las personas mayores en América Latina y el Caribe (Santiago, Chile, 9-12 December 2002) (LC/L.1995), Santiago, Chile. United Nations publication, Sales No. S.03.II.G.157.

Villa, Miguel and Daniela González (2004), "Dinámica demográfica de Chile y América Latina: una visión a vuelo de pájaro", Revista de sociología, No. 18, Santiago, Chile, Faculty of Social Sciences, University of Chile.

Villa, Miguel and Jorge Rodríguez (2002), Vulnerabilidad sociodemográfica: viejos y nuevos riesgos para comunidades, hogares y personas (LC/R.2086), Santiago, Chile, Latin American and Caribbean Demographic Centre (CELADE)Population Division of ECLAC.

Villa, Miguel and Luis Rivadeneira (2000), “El proceso de envejecimiento de la población de América Latina y el Caribe: una expresión de la transición demográfica", Encuentro latinoamericano y caribeño sobre las personas de edad: ponencias presentadas al seminario técnico, Seminarios y conferencias series, No. 2 (LC/L.1399-P), Santiago, Chile, Economic Commission for Latin America and the Caribbean (ECLAC). United Nations publication, Sales No. S.00.II.G.88.

WHO (World Health Organization) (2007), World Health Statistics 2007, France. (2004), “Causes of death"[online] http:/ / www.who.int/research/en/.

(2003), World Health Report 2003: Shaping the Future, Geneva [online] http:// www.who.int/whr/2003/en.

(2002), "Abuse of the elderly", World Report on Violence and Health, Geneva.

World Bank /Inter-American Development Bank (2004), "Informe del gasto público para lograr sostenibilidad fiscal y servicios públicos eficientes y equitativos" [online] www.bancomundial.org.bo. 
Annex 
Table A.1

LATIN AMERICA AND THE CARIBBEAN: TOTAL, PROPORTION AND GROWTH RATE OF THE POPULATION AGED 60 AND OVER, 1950-2050

\begin{tabular}{|c|c|c|c|c|c|c|c|c|c|c|c|c|c|c|c|}
\hline \multirow{2}{*}{ Stage of ageing } & \multirow{2}{*}{$\begin{array}{l}\text { Country or } \\
\text { territory }\end{array}$} & \multicolumn{5}{|c|}{ Population aged 60 and over } & \multicolumn{5}{|c|}{$\begin{array}{l}\text { Percentage of the population aged } \\
60 \text { and over }\end{array}$} & \multicolumn{4}{|c|}{$\begin{array}{l}\text { Growth rate of the population } \\
\text { aged } 60 \text { and over }\end{array}$} \\
\hline & & 1950 & 1975 & 2000 & 2025 & 2050 & 1950 & 1975 & 2000 & 2025 & 2050 & $\begin{array}{c}1950- \\
1975\end{array}$ & $\begin{array}{l}1975- \\
2000\end{array}$ & $\begin{array}{l}2000- \\
2025\end{array}$ & $\begin{array}{r}2025- \\
2050\end{array}$ \\
\hline $\begin{array}{l}\text { Latin America and } \\
\text { the Caribbean }\end{array}$ & & 9305994 & 20986036 & 42920967 & 100452132 & 183688194 & 5.6 & 6.5 & 9.0 & 14.8 & 24.3 & 3.3 & 2.9 & 3.4 & 2.4 \\
\hline Latin America & & 8927994 & 20264036 & 41626967 & 98010132 & 180278194 & 5.5 & 6.4 & 8.1 & 14.5 & 23.6 & 3.3 & 2.9 & 3.4 & 2.4 \\
\hline The Caribbean & & 378000 & 722000 & 1294000 & 2442000 & 3410000 & 6.4 & 8.4 & 11.7 & 19.6 & 27.8 & 2.6 & 2.3 & 2.5 & 1.3 \\
\hline \multirow{9}{*}{ Incipient ageing } & Subtotal & 683409 & 1301713 & 2702504 & 6117689 & 14632168 & 5.1 & 5.3 & 6.0 & 8.6 & 15.9 & 2.6 & 2.9 & 3.3 & 3.5 \\
\hline & Belize & 4000 & 9000 & 14000 & 37000 & 93000 & 5.8 & 6.7 & 5.8 & 9.5 & 19.1 & 3.2 & 1.8 & 3.9 & 3.7 \\
\hline & $\begin{array}{l}\text { Bolivia } \\
\text { (Plurinational } \\
\text { State of) }\end{array}$ & 152272 & 264090 & 537452 & 1191151 & 2786304 & 5.6 & 5.5 & 6.4 & 9.0 & 16.7 & 2.2 & 2.8 & 3.2 & 3.4 \\
\hline & French Guiana & 2000 & 4000 & 9000 & 37000 & 71000 & 7.8 & 7.1 & 5.5 & 12.6 & 17.5 & 2.8 & 3.2 & 5.7 & 2.6 \\
\hline & Guatemala & 132998 & 280006 & 660749 & 1429230 & 3625044 & 4.2 & 4.5 & 5.9 & 7.2 & 13.0 & 3.0 & 3.4 & 3.1 & 3.7 \\
\hline & Haiti & 179625 & 321103 & 527062 & 1039305 & 2542712 & 5.5 & 6.5 & 6.3 & 8.3 & 15.7 & 2.3 & 2.0 & 2.7 & 3.6 \\
\hline & Honduras & 92424 & 152257 & 345833 & 842440 & 2129510 & 6.7 & 5.0 & 5.3 & 8.6 & 17.2 & 2.0 & 3.3 & 3.6 & 3.7 \\
\hline & Nicaragua & 53612 & 114638 & 263681 & 672506 & 1569275 & 4.5 & 4.4 & 5.3 & 9.8 & 19.6 & 3.0 & 3.3 & 3.7 & 3.4 \\
\hline & Paraguay & 66478 & 156619 & 344727 & 869057 & 1815323 & 4.5 & 5.9 & 6.3 & 10.8 & 18.0 & 3.4 & 3.2 & 3.7 & 2.9 \\
\hline \multirow{10}{*}{ Moderate ageing } & Subtotal & 6088688 & 14114818 & 30618474 & 77426570 & 143952331 & 5.1 & 5.8 & 7.6 & 14.6 & 24.3 & 3.4 & 3.1 & 3.7 & 2.5 \\
\hline & Bahamas & 5000 & 11000 & 25000 & 67000 & 118000 & 6.3 & 5.8 & 8.2 & 16.9 & 26.3 & 3.2 & 3.3 & 3.9 & 2.3 \\
\hline & Brazil & 2627168 & 6541030 & 14031549 & 35076146 & 63117213 & 4.9 & 6.0 & 8.0 & 15.2 & 24.6 & 3.6 & 3.1 & 3.7 & 2.3 \\
\hline & Colombia & 625956 & 1425447 & 2854086 & 8125841 & 14918105 & 5.0 & 5.6 & 6.7 & 14.6 & 23.9 & 3.3 & 2.8 & 4.2 & 2.4 \\
\hline & Costa Rica & 73731 & 141318 & 297281 & 878067 & 1654843 & 7.6 & 6.9 & 7.6 & 15.8 & 26.6 & 2.6 & 3.0 & 4.3 & 2.5 \\
\hline & $\begin{array}{l}\text { Dominican } \\
\text { Republic }\end{array}$ & 105758 & 233602 & 638708 & 1509370 & 2729130 & 4.5 & 4.6 & 7.7 & 12.5 & 19.5 & 3.2 & 4.0 & 3.4 & 2.4 \\
\hline & Ecuador & 275680 & 422401 & 902716 & 2255926 & 4423165 & 8.1 & 6.1 & 7.3 & 13.2 & 21.9 & 1.7 & 3.0 & 3.7 & 2.7 \\
\hline & El Salvador & 93072 & 194906 & 451705 & 953718 & 2249054 & 4.8 & 4.7 & 7.2 & 10.4 & 20.1 & 3.0 & 3.4 & 3.0 & 3.4 \\
\hline & Guyana & 28000 & 40000 & 52000 & 130000 & 127000 & 6.6 & 5.5 & 6.9 & 19.0 & 26.6 & 1.4 & 1.0 & 3.7 & -0.1 \\
\hline & Jamaica & 83000 & 173000 & 258000 & 420000 & 620000 & 5.9 & 8.6 & 10.0 & 14.4 & 22.4 & 2.9 & 1.6 & 1.9 & 1.6 \\
\hline
\end{tabular}


Table A.1 (concluded)

\begin{tabular}{|c|c|c|c|c|c|c|c|c|c|c|c|c|c|c|c|}
\hline \multirow[t]{2}{*}{ Stage of ageing } & \multirow{2}{*}{$\begin{array}{l}\text { Country or } \\
\text { territory }\end{array}$} & \multicolumn{5}{|c|}{ Population aged 60 and over } & \multicolumn{5}{|c|}{$\begin{array}{l}\text { Percentage of the population aged } \\
60 \text { and over }\end{array}$} & \multicolumn{4}{|c|}{ Growth rate of the population aged 60 and over } \\
\hline & & 1950 & 1975 & 2000 & 2025 & 2050 & 1950 & 1975 & 2000 & 2025 & 2050 & $1950-1975$ & $1975-2000$ & $2000-2025$ & $2025-2050$ \\
\hline \multirow{6}{*}{ Moderate ageing } & Mexico & 1486500 & 3320844 & 7342634 & 18444919 & 35262511 & 5.4 & 5.6 & 7.3 & 14.9 & 26.8 & 3.2 & 3.2 & 3.7 & 2.6 \\
\hline & Panama & 55834 & 112037 & 233629 & 597233 & 1114440 & 6.5 & 6.5 & 7.9 & 14.2 & 22.5 & 2.8 & 2.9 & 3.8 & 2.5 \\
\hline & Peru & 433205 & 843213 & 1854445 & 4238416 & 8495511 & 5.7 & 5.6 & 7.1 & 12.6 & 21.8 & 2.7 & 3.2 & 3.3 & 2.8 \\
\hline & Saint Lucia & 4000 & 8000 & 14000 & 27000 & 52000 & 5.1 & 7.6 & 9.6 & 13.8 & 24.1 & 2.8 & 2.2 & 2.6 & 2.6 \\
\hline & Suriname & 18000 & 21000 & 37000 & 77000 & 122000 & 8.4 & 5.8 & 8.7 & 16.0 & 28.6 & 0.6 & 2.3 & 2.9 & 1.8 \\
\hline & $\begin{array}{l}\text { Venezuela } \\
\text { (Bolivarian } \\
\text { Republic of) }\end{array}$ & 173784 & 627020 & 1625721 & 4625934 & 8949359 & 3.4 & 4.9 & 6.7 & 13.2 & 21.8 & 5.1 & 3.8 & 4.2 & 2.6 \\
\hline \multirow{6}{*}{$\begin{array}{l}\text { Moderate to advanced } \\
\text { ageing }\end{array}$} & Subtotal & 1686950 & 3905182 & 6702127 & 12020128 & 18813891 & 7.0 & 10.3 & 12.4 & 18.0 & 25.8 & 3.4 & 2.2 & 2.3 & 1.8 \\
\hline & Argentina & 1207209 & 2971006 & 4941660 & 7749566 & 12476798 & 7.0 & 11.4 & 13.4 & 16.9 & 24.7 & 3.6 & 2.0 & 1.8 & 1.9 \\
\hline & Chile & 416741 & 814176 & 1568467 & 3846562 & 5698093 & 6.9 & 7.8 & 10.2 & 20.1 & 28.2 & 2.7 & 2.6 & 3.6 & 1.6 \\
\hline & Guadeloupe & 14000 & 29000 & 55000 & 119000 & 154000 & 6.7 & 8.8 & 12.8 & 24.7 & 32.9 & 2.9 & 2.6 & 3.1 & 1.0 \\
\hline & $\begin{array}{l}\text { Netherlands } \\
\text { Antilles }\end{array}$ & 10000 & 14000 & 23000 & 53000 & 74000 & 9.0 & 8.4 & 10.7 & 25.6 & 39.8 & 1.3 & 2.0 & 3.3 & 1.3 \\
\hline & $\begin{array}{l}\text { Trinidad and } \\
\text { Tobago }\end{array}$ & 39000 & 77000 & 114000 & 252000 & 411000 & 6.1 & 7.6 & 8.8 & 18.0 & 31.0 & 2.7 & 1.6 & 3.2 & 2.0 \\
\hline \multirow{6}{*}{ Advanced ageing } & Subtotal & 846947 & 1664323 & 2897862 & 4887745 & 6289804 & 7.9 & 10.7 & 15.3 & 24.7 & 33.6 & 2.7 & 2.2 & 2.1 & 1.0 \\
\hline & Barbados & 18000 & 33000 & 35000 & 81000 & 99000 & 8.5 & 13.4 & 13.1 & 26.7 & 36.4 & 2.4 & 0.2 & 3.4 & 0.8 \\
\hline & Cuba & 411955 & 928847 & 1635230 & 2918713 & 3733718 & 7.0 & 10.0 & 14.7 & 26.1 & 37.5 & 3.3 & 2.3 & 2.3 & 1.0 \\
\hline & Martinique & 17000 & 31000 & 61000 & 117000 & 142000 & 7.7 & 9.4 & 15.8 & 29.0 & 40.6 & 2.4 & 2.7 & 2.6 & 0.8 \\
\hline & Puerto Rico & 136000 & 272000 & 597000 & 1025000 & 1327000 & 6.1 & 9.3 & 15.6 & 23.7 & 30.0 & 2.8 & 3.1 & 2.2 & 1.0 \\
\hline & Uruguay & 263992 & 399476 & 569632 & 746032 & 988086 & 11.8 & 14.1 & 17.1 & 21.0 & 26.5 & 1.7 & 1.4 & 1.1 & 1.1 \\
\hline
\end{tabular}

Source: Population projections and estimates by the Latin American and Caribbean Demographic Centre (CELADE) - Population Division of ECLAC [online] http://www.eclac.cl/ celade/proyecciones/basedatos_BD.htm. 
Table A. 2

LATIN AMERICA AND THE CARIBBEAN: RANKING OF COUNTRIES

AND TERRITORIES BY STAGES OF AGEING, 2000

\begin{tabular}{|c|c|c|c|}
\hline Stage & Country or territory & Ageing index & $\begin{array}{l}\text { Global fertility } \\
\text { rate }\end{array}$ \\
\hline \multirow{8}{*}{ Incipient ageing } & Belize & 16.1 & 2.9 \\
\hline & $\begin{array}{l}\text { Bolivia (Plurinational } \\
\text { State of) }\end{array}$ & 17.9 & 3.5 \\
\hline & Guatemala & 14.5 & 4.2 \\
\hline & French Guiana & 19.5 & 3.3 \\
\hline & Haiti & 17.0 & 3.5 \\
\hline & Honduras & 15.2 & 3.3 \\
\hline & Nicaragua & 15.9 & 2.8 \\
\hline & Paraguay & 20.4 & 3.1 \\
\hline \multirow{20}{*}{ Moderate ageing } & Bahamas & 36.9 & 2.0 \\
\hline & Brazil & 33.2 & 2.2 \\
\hline & Colombia & 26.9 & 2.2 \\
\hline & Costa Ricaz & 31.3 & 2.1 \\
\hline & Dominican Republic & 24.8 & 2.8 \\
\hline & Ecuador & 26.8 & 2.6 \\
\hline & El Salvador & 23.2 & 2.7 \\
\hline & Guyana & 29.0 & 2.3 \\
\hline & Jamaica & 32.9 & 2.4 \\
\hline & Mexico & 29.3 & 2.2 \\
\hline & Panama & 30.2 & 2.6 \\
\hline & Peru & 27.0 & 2.5 \\
\hline & Saint Lucia & 36.0 & 2.2 \\
\hline & Suriname & 31.4 & 2.4 \\
\hline & $\begin{array}{l}\text { Venezuela (Bolivarian } \\
\text { Republic of) }\end{array}$ & 25.7 & 2.5 \\
\hline & Argentina & 54.1 & 2.3 \\
\hline & Chile & 57.7 & 1.9 \\
\hline & Guadeloupe & 62.1 & 2.1 \\
\hline & Netherlands Antilles & 67.8 & 1.9 \\
\hline & Trinidad and Tobago & 46.5 & 1.6 \\
\hline \multirow{5}{*}{ Advanced ageing } & Barbados & 72.7 & 1.5 \\
\hline & Cuba & 87.8 & 1.5 \\
\hline & Martinique & 84.6 & 1.9 \\
\hline & Puerto Rico & 85.1 & 1.8 \\
\hline & Uruguay & 76.5 & 2.1 \\
\hline
\end{tabular}

Source: Population projections and estimates by the Latin American and Caribbean Demographic Centre (CELADE) - Population Division of ECLAC [online] http://www.eclac.cl/celade/proyecciones/basedatos_BD.htm., Estimaciones y proyecciones de población [en línea] www.eclac.cl/celade/proyecciones/basedatos_BD.htm. 
Table A. 3

EUROPEAN COMMUNITY (SELECTED COUNTRIES): POPULATION AGED 65 AND

OVER, NATIONAL TOTAL AND THREE MAJOR CITIES, 1999-2003 (Percentages)

\begin{tabular}{|c|c|c|c|c|}
\hline Country & National total & & City & \\
\hline United Kingdom & 15.59 & $\begin{array}{c}\text { Londres } \\
12.44\end{array}$ & $\begin{array}{c}\text { Birmingham } \\
14.53\end{array}$ & $\begin{array}{c}\text { Liverpool } \\
15.28\end{array}$ \\
\hline France & 16.12 & $\begin{array}{c}\text { Paris } \\
15.4\end{array}$ & $\begin{array}{l}\text { Lyon } \\
14.67\end{array}$ & $\begin{array}{c}\text { Lille } \\
12.78\end{array}$ \\
\hline Germany & 16.64 & $\begin{array}{l}\text { Berlin } \\
15.02\end{array}$ & $\begin{array}{c}\text { Hamburgo } \\
17.08\end{array}$ & $\begin{array}{c}\text { Munich } \\
16.05\end{array}$ \\
\hline Netherlands & 13.6 & $\begin{array}{c}\text { Ámsterdam } \\
11.99\end{array}$ & $\begin{array}{c}\text { Rotterdam } \\
15\end{array}$ & $\begin{array}{l}\text { Utrecht } \\
11.85\end{array}$ \\
\hline Spain & 16.63 & $\begin{array}{c}\text { Madrid } \\
19.54\end{array}$ & $\begin{array}{c}\text { Barcelona } \\
22.03\end{array}$ & $\begin{array}{c}\text { Valencia } \\
17.61\end{array}$ \\
\hline Italy & 18.25 & $\begin{array}{l}\text { Roma } \\
19.04\end{array}$ & $\begin{array}{l}\text { Milan } \\
22.78\end{array}$ & $\begin{array}{c}\text { Nápoles } \\
15.59\end{array}$ \\
\hline
\end{tabular}

Source: Statistical Office of the European Communities (EUROSTAT) [online] http://epp.eurostat.ec.europa.eu/. 
Table A.4

LATIN AMERICA AND THE CARIBBEAN (SELECTED COUNTRIES): POPULATION AGED 60 AND OVER, NATIONAL TOTAL, MAJOR CITIES, OTHER URBAN AND RURAL, 2000 ROUND OF CENSUSES (Percentages)

\begin{tabular}{|c|c|c|c|c|}
\hline $\begin{array}{l}\text { Country and } \\
\text { census year }\end{array}$ & Geographical entity & $\begin{array}{c}\text { Population } \\
\text { aged } 60 \text { and } \\
\text { over }\end{array}$ & $\begin{array}{l}\text { Women aged } \\
60 \text { and over }\end{array}$ & $\begin{array}{c}\text { Population aged } 60 \\
\text { and over } \\
\text { with fewer than four years } \\
\text { of schooling }\end{array}$ \\
\hline \multirow{4}{*}{ Argentina, 2001} & National total & 13.4 & 57.8 & 24.6 \\
\hline & $\begin{array}{l}\text { Greater Buenos } \\
\text { Aires }\end{array}$ & 15.2 & 59.9 & 16.9 \\
\hline & Other urban & 12.6 & 58.2 & 26.1 \\
\hline & Rural & 11.8 & 47.1 & 48.3 \\
\hline \multirow{4}{*}{$\begin{array}{l}\text { Bolivia } \\
\text { (Plurinational } \\
\text { State of), } 2001\end{array}$} & National total & 7.0 & 53.7 & 67.4 \\
\hline & La Paz & 5.9 & 55.2 & 46.5 \\
\hline & Other urban & 5.5 & 56.0 & 49.2 \\
\hline & Rural & 9.2 & 51.7 & 86.8 \\
\hline \multirow{5}{*}{ Brazil, 2000} & National total & 8.6 & 55.1 & 49.3 \\
\hline & Rio de Janeiro & 11.0 & 59.7 & 25.1 \\
\hline & Sao Paulo & 8.3 & 58.5 & 30.3 \\
\hline & Other urban & 8.4 & 56.3 & 48.9 \\
\hline & Rural & 8.4 & 47.1 & 72.1 \\
\hline \multirow{4}{*}{ Chile, 2002} & National total & 11.4 & 55.9 & 30.9 \\
\hline & Santiago & 11.2 & 59.1 & 20.5 \\
\hline & Other urban & 10.9 & 56.4 & 29.5 \\
\hline & Rural & 13.4 & 46.9 & 58.7 \\
\hline \multirow{4}{*}{ Costa Rica, 2000} & National total & 7.9 & 52.3 & 49.7 \\
\hline & San Jose & 8.8 & 57.1 & 33.3 \\
\hline & Other urban & 8.2 & 54.5 & 43.3 \\
\hline & Rural & 7.0 & 46.0 & 70.1 \\
\hline \multirow{4}{*}{ Ecuador, 2001} & National total & 9.1 & 51.9 & 47.7 \\
\hline & Quito & 8.4 & 55.9 & 26.0 \\
\hline & Other urban & 8.8 & 53.1 & 38.1 \\
\hline & Rural & 9.8 & 49.5 & 64.3 \\
\hline \multirow{4}{*}{ Guatemala, 2002} & National total & 6.4 & 50.3 & 77.6 \\
\hline & Guatemala City & 7.3 & 56.3 & 41.9 \\
\hline & Other urban & 6.9 & 51.5 & 75.8 \\
\hline & Rural & 5.8 & 47.1 & 93.6 \\
\hline \multirow{4}{*}{ Honduras, 2001} & National total & 5.8 & 51.1 & 50.3 \\
\hline & Tegucigalpa & 5.3 & 59.3 & 28.5 \\
\hline & Other urban & 5.9 & 54.5 & 42.5 \\
\hline & Rural & 5.9 & 47.4 & 69.8 \\
\hline \multirow{4}{*}{ Mexico, 2000} & National total & 7.3 & 53.2 & 49.5 \\
\hline & Mexico City & 7.0 & 57.1 & 29.2 \\
\hline & Other urban & 7.0 & 54.4 & 44.3 \\
\hline & Rural & 8.3 & 48.7 & 72.6 \\
\hline \multirow{4}{*}{ Panama, 2000} & National total & 8.6 & 50.6 & 41.3 \\
\hline & Panama City & 8.0 & 55.9 & 21.0 \\
\hline & Other urban & 9.0 & 53.5 & 31.1 \\
\hline & Rural & 9.1 & 43.8 & 66.5 \\
\hline \multirow{4}{*}{ Paraguay, 2002} & National total & 7.1 & 53.2 & 39.2 \\
\hline & Asuncion & 7.5 & 58.3 & 24.6 \\
\hline & Other urban & 6.7 & 54.9 & 37.6 \\
\hline & Rural & 7.2 & 48.2 & 51.5 \\
\hline
\end{tabular}

Source: Latin American and Caribbean Demographic Centre (CELADE) - Population Division of ECLAC, based on processing of census microdata using the System for the Retrieval of Census Data for Small Areas by Microcomputer (REDATAM), 2000 round of censuses 
Table A.5

LATIN AMERICA AND THE CARIBBEAN: INDICES OF TOTAL DEPENDENCY AND DEPENDENCY IN OLD AGE, BY FIVE-YEAR PERIODS, 1950-2050

\begin{tabular}{|c|c|c|c|c|c|c|c|c|c|c|c|}
\hline \multirow{2}{*}{ Stages } & \multirow{2}{*}{$\begin{array}{l}\text { Country or } \\
\text { territory }\end{array}$} & \multicolumn{4}{|c|}{ Dependency index } & \multicolumn{6}{|c|}{ Index of dependency in old age } \\
\hline & & 1950 & 1975 & 2000 & 2025 & 2050 & 1950 & 1975 & 2000 & 2025 & 2050 \\
\hline \multicolumn{2}{|c|}{ Latin America and the Caribbean } & 84.5 & 91.3 & 66.7 & 60.5 & 71.7 & 10.26 & 12.38 & 13.7 & 23.4 & 40.7 \\
\hline Latin America & & 84.4 & 91.3 & 66.8 & 60.4 & 71.6 & 10.21 & 12.28 & 13.6 & 23.2 & 40.6 \\
\hline The Caribbean & & 85.9 & 91.3 & 65.2 & 68.1 & 81.0 & 11.77 & 15.92 & 19.3 & 32.9 & 50.3 \\
\hline \multirow{8}{*}{ Incipient ageing } & Belize & 81.6 & 116.1 & 84.8 & 57.7 & 62.2 & 10.5 & 14.5 & 10.6 & 14.2 & 31.1 \\
\hline & $\begin{array}{l}\text { Bolivia } \\
\text { (Plurinational } \\
\text { State of) }\end{array}$ & 88.7 & 94.5 & 84.8 & 61.2 & 58.6 & 10.6 & 10.8 & 11.8 & 14.5 & 26.4 \\
\hline & French Guiana & 66.7 & 80.6 & 70.1 & 65.9 & 63.7 & 13.3 & 9.7 & 9.3 & 20.5 & 28.6 \\
\hline & Guatemala & 95.4 & 97.4 & 99.8 & 71.3 & 55.2 & 8.3 & 8.9 & 11.8 & 12.3 & 20.1 \\
\hline & Haiti & 82.5 & 90.5 & 86.8 & 62.7 & 61.4 & 10.2 & 11.9 & 11.5 & 13.5 & 25.4 \\
\hline & Honduras & 94.0 & 110.2 & 92.2 & 61.9 & 59.0 & 12.1 & 10.3 & 10.7 & 14.0 & 27.3 \\
\hline & Nicaragua & 93.7 & 106.2 & 85.7 & 61.1 & 64.9 & 8.0 & 8.4 & 9.6 & 15.8 & 32.3 \\
\hline & Paraguay & 106.3 & 98.8 & 80.7 & 61.7 & 62.9 & 9.3 & 11.1 & 11.6 & 17.4 & 29.4 \\
\hline \multirow{15}{*}{ Moderate ageing } & Bahamas & 83.7 & 89.0 & 59.8 & 61.1 & 76.7 & 11.6 & 11.0 & 12.7 & 27.5 & 45.8 \\
\hline & Brazil & 86.7 & 86.4 & 60.4 & 59.8 & 73.6 & 9.1 & 11.3 & 12.9 & 24.3 & 42.8 \\
\hline & Colombia & 90.9 & 96.8 & 64.9 & 58.5 & 71.3 & 9.5 & 11.1 & 11.3 & 23.1 & 40.9 \\
\hline & Costa Rica & 85.5 & 93.3 & 64.9 & 57.9 & 76.7 & 14.2 & 13.3 & 12.5 & 24.9 & 47.0 \\
\hline & $\begin{array}{l}\text { Dominican } \\
\text { Republic }\end{array}$ & 104.2 & 100.2 & 72.3 & 66.3 & 65.9 & 8.9 & 8.9 & 12.6 & 20.8 & 32.3 \\
\hline & Ecuador & 91.0 & 99.7 & 71.9 & 60.5 & 67.9 & 15.5 & 12.2 & 12.6 & 21.2 & 36.8 \\
\hline & El Salvador & 91.7 & 101.4 & 74.8 & 57.7 & 65.6 & 9.1 & 9.5 & 12.6 & 16.5 & 33.3 \\
\hline & Guyana & 91.4 & 98.6 & 60.4 & 66.3 & 68.3 & 12.7 & 10.8 & 11.2 & 31.5 & 44.7 \\
\hline & Jamaica & 71.8 & 115.8 & 75.2 & 65.4 & 70.6 & 9.9 & 18.2 & 17.4 & 24.0 & 38.3 \\
\hline & Mexico & 91.6 & 106.9 & 68.1 & 57.2 & 77.0 & 10.3 & 11.3 & 12.4 & 23.4 & 47.4 \\
\hline & Panama & 87.8 & 97.5 & 66.1 & 62.0 & 69.8 & 12.2 & 12.8 & 13.2 & 22.9 & 38.2 \\
\hline & Peru & 89.5 & 95.3 & 71.7 & 59.1 & 67.5 & 10.8 & 10.9 & 12.4 & 20.0 & 36.5 \\
\hline & Saint Lucia & 82.6 & 118.0 & 69.7 & 58.2 & 73.4 & 10.9 & 16.0 & 16.9 & 22.1 & 41.9 \\
\hline & Suriname & 93.7 & 113.5 & 67.4 & 63.4 & 76.2 & 16.2 & 11.8 & 13.8 & 26.1 & 46.8 \\
\hline & $\begin{array}{l}\text { Venezuela } \\
\text { (Bolivarian } \\
\text { Republic of) }\end{array}$ & 88.2 & 93.1 & 68.0 & 61.1 & 68.0 & 6.4 & 9.5 & 11.2 & 21.4 & 36.6 \\
\hline \multirow{5}{*}{$\begin{array}{l}\text { Moderate-to-advanced } \\
\text { ageing }\end{array}$} & Argentina & 60.2 & 68.4 & 70.8 & 63.8 & 73.8 & 11.3 & 19.2 & 22.9 & 27.8 & 42.8 \\
\hline & Chile & 77.2 & 81.2 & 61.2 & 65.6 & 81.1 & 12.1 & 14.2 & 16.4 & 33.3 & 51.1 \\
\hline & Guadeloupe & 85.8 & 102.5 & 60.7 & 77.1 & 96.2 & 12.4 & 17.3 & 20.2 & 44.3 & 64.4 \\
\hline & $\begin{array}{l}\text { Netherlands } \\
\text { Antilles }\end{array}$ & 76.2 & 72.2 & 60.2 & 70.5 & 116.1 & 14.3 & 15.5 & 20.4 & 43.4 & 86.2 \\
\hline & $\begin{array}{l}\text { Trinidad and } \\
\text { Tobago }\end{array}$ & 87.1 & 84.0 & 54.2 & 60.7 & 91.8 & 11.5 & 13.8 & 13.4 & 28.9 & 59.4 \\
\hline \multirow{5}{*}{ Advanced ageing } & Barbados & 71.5 & 83.6 & 50.5 & 70.2 & 103.8 & 14.6 & 25.4 & 18.9 & 45.5 & 74.4 \\
\hline & Cuba & 76.4 & 89.8 & 54.4 & 67.5 & 100.2 & 12.3 & 18.7 & 22.7 & 43.8 & 75.1 \\
\hline & Martinique & 81.1 & 98.8 & 63.6 & 80.7 & 112.1 & 13.1 & 19.3 & 25.4 & 52.0 & 85.5 \\
\hline & Puerto Rico & 97.2 & 74.8 & 64.6 & 73.3 & 85.7 & 12.0 & 16.1 & 25.6 & 41.0 & 55.8 \\
\hline & Uruguay & 65.8 & 71.9 & 71.8 & 68.8 & 77.0 & 19.5 & 24.3 & 29.5 & 35.4 & 46.9 \\
\hline
\end{tabular}

Source: Population projections and estimates by the Latin American and Caribbean Demographic Centre (CELADE) Population Division of ECLAC [online] http://www.eclac.cl/celade/proyecciones/basedatos_BD.htm. 